\title{
Lipid accumulation in skeletal muscle; big deal?! : mechanisms underlying the development of insuline resistance
}

Citation for published version (APA):

Meex, R. C. R. (2011). Lipid accumulation in skeletal muscle; big deal?! : mechanisms underlying the development of insuline resistance. [Doctoral Thesis, Maastricht University]. Maastricht University. https://doi.org/10.26481/dis.20110908rm

Document status and date:

Published: 01/01/2011

DOI:

10.26481/dis.20110908rm

Document Version:

Publisher's PDF, also known as Version of record

Please check the document version of this publication:

- A submitted manuscript is the version of the article upon submission and before peer-review. There can be important differences between the submitted version and the official published version of record.

People interested in the research are advised to contact the author for the final version of the publication, or visit the DOI to the publisher's website.

- The final author version and the galley proof are versions of the publication after peer review.

- The final published version features the final layout of the paper including the volume, issue and page numbers.

Link to publication

\footnotetext{
General rights rights.

- You may freely distribute the URL identifying the publication in the public portal. please follow below link for the End User Agreement:

www.umlib.nl/taverne-license

Take down policy

If you believe that this document breaches copyright please contact us at:

repository@maastrichtuniversity.nl

providing details and we will investigate your claim.
}

Copyright and moral rights for the publications made accessible in the public portal are retained by the authors and/or other copyright owners and it is a condition of accessing publications that users recognise and abide by the legal requirements associated with these

- Users may download and print one copy of any publication from the public portal for the purpose of private study or research.

- You may not further distribute the material or use it for any profit-making activity or commercial gain

If the publication is distributed under the terms of Article 25fa of the Dutch Copyright Act, indicated by the "Taverne" license above, 


\section{Lipid accumulation in skeletal}

muscle; big deal?!

Mechanisms underlying the development of insulin resistance 


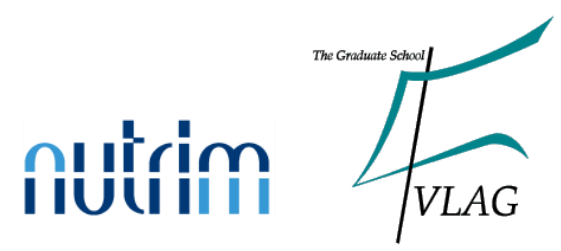

The study presented in this thesis was performed within NUTRIM, School for Nutrition, Toxicology and Metabolism, which participates in the Graduate School VLAG (Food Technology, Agrobiotechnology, Nutrition and Health Sciences), accredited by the Royal Netherlands, Academy of Arts and Sciences.

Cover Design: Niki Schneemann, Ruth Meex

Layout: Ruth Meex

978-94-91211-55-3

() copyright Ruth Meex, Maastricht 2011

Printing: Ipskamp Drukkers Enschede 


\title{
Lipid accumulation in skeletal muscle;
}

\section{big deal?!}

Mechanisms underlying the development of insulin resistance

\author{
Proefschrift
}

Ter verkrijging van de graad van doctor aan de universiteit Maastricht, op gezag van de Rector Magnificus, Prof. Mr G.P.M.F Mols volgens het besluit van het College van Decanen, in het openbaar te verdedigen op

Donderdag, 8 september 2011 om 14.00

door

Ruth Carla Raf Meex

Geboren op 21 december 1981 te Genk 


\section{Promotores}

Prof. dr. M. K. C. Hesselink

Prof. dr. P. Schrauwen

\section{Beoordelingscommissie / Assessment Committee}

Prof. dr. C. D. A. Stehouwer (voorzitter)

Prof. dr. M. A. van Baak

Prof. dr. J. F. C. Glatz

Dr. S. Kersten, Wageningen Universiteit

Prof. dr. R. Zechner, University Graz

The research described in this thesis was supported by a grant of the Dutch Diabetes Research Foundation (grant 2004.00.059), and by a VIDI (grant 917.66.359) for innovative research from the Netherlands Organization for Scientific Research (NWO).

Financial support by the Dutch Diabetes Research Foundation; Pfizer; Boehringer Ingelheim; Nutricia Advanced Medical Nutrition, Danone Reseach, Centre for Specialised Nutrition; and Novo Nordisk is gratefully acknowledged. 


\section{CONTENTS}

$\begin{array}{lll}\text { Chapter } 1 \text { Introduction } & \text { p. } 7\end{array}$

Chapter 2 The modulation of myocellular fat stores; lipid droplet dy- p. 23 namics in health and disease.

Chapter 3 Restoration of muscle mitochondrial function and metabolic flexibility in type 2 diabetes by exercise training is paralleled by increased myocellular fat storage and improved insulin sensitivity.

Chapter 4 Increased expression of myocellular PAT proteins and improved control of basal lipolysis and metabolic flexibility after a 12 week insulin-sensitizing exercise program in type 2 diabetic subjects.

Chapter 5 The use of statins potentiates the insulin sensitizing effects of exercise training in obese males with and without type 2 diabetes.

Chapter 6 High oxidative capacity protects against lipid-induced insulin resistance

p. 55

p. 75

p. 93

p. 111

Chapter 7 Stimulation of human whole-body energy expenditure by salsalate is fuelled by higher lipid oxidation under fasting conditions and by higher oxidative glucose disposal under insulin stimulated conditions.

Chapter 8 General Discussion

Summary

p. 170

Samenvatting

p. 176

Dankwoord

p. 182

Curriculum vitae

p. 188

Publications

p. 190 



\title{
CHAPTER 1
}

\section{Introduction}

\begin{abstract}
Global prevalence and incidence rates of type 2 diabetes are very high and increase rapidly. It has been estimated that in 2000 approximately 171 million individuals were diagnosed with type 2 diabetes and this number is likely to double by 2030 . Type 2 diabetes is characterized by high plasma glucose levels and results from a reduction in insulin secretion from the pancreas, and from a blunted sensitivity of tissues for insulin. The underlying mechanism of insulin resistance is not yet known. Accumulation of intramyocellular lipids (IMCL) has been associated with the severity of insulin resistance. However, endurance trained athletes also have elevated IMCL levels while being highly insulin sensitive, making IMCL accumulation per se less plausible as a cause for the development of insulin resistance. It is therefore suggested that other parameters, such impaired mitochondrial function, a decreased ability to switch between glucose oxidation and fat oxidation (metabolic inflexibility) and a decreased ability to store glucose, are also important in development of insulin resistance. This PhDthesis focuses on theses parameters and on their role in relation to the development of the insulin resistant state
\end{abstract}

Ruth C. R. Meex 


\section{Diabetes; state of affairs.}

Diabetes mellitus is a chronic disease, characterized by high plasma glucose levels (hyperglycaemia). Diabetes requires long-term medical attention as hyperglycaemia may lead to the progressive development of retinopathy, nephropathy, and/or neuropathy, and can result in blindness, amputations or cardiovascular diseases. Cardiovascular diseases for example, occur two to three times as much in diabetic individuals as in age- and gender-matched non-diabetic persons (1), making diabetes the fifth leading cause of death worldwide (2).

Diabetes can be divided in two subgroups; type 1 and type 2 diabetes. Type 1 diabetes, also called insulin-dependent diabetes, is typically seen in children and young adults. It is not exactly known how type 1 diabetes develops, but it is likely to be caused by an auto-immune disorder. Type 2 diabetes, or non-insulin-dependent diabetes, is the most common form of diabetes, affecting $90-95 \%$ of all diabetes patients. Type 2 diabetes occurs mostly in adults and elderly, although in recent years it has also been increasingly reported in children and adolescents. Type 2 diabetes results from the interaction between a genetic predisposition, behavioural factors, and environmental factors such as ethnicity, alcohol, smoking, physical fitness, diet, obesity and fat distribution (3-5) But while multiple factors contribute to the development of type 2 diabetes, there is no doubt that lifestyle is a key player; $80 \%$ of all type 2 diabetic subjects are overweight (6).

Global prevalence and incidence rates of type 2 diabetes are very high and increase rapidly in both developed and developing countries. It has been estimated that in 2000 approximately 171 million individuals were diagnosed with type 2 diabetes and that this number is likely to double by 2030 (7). Calculations estimate there is one undiagnosed case of type 2 diabetes for each two individuals that are diagnosed, also in countries with a high level of medical care. Health care costs associated with type 2 diabetes and its clinical complications are substantial $(1 ; 8 ; 9)$; people with type 2 diabetes (T2D) are three times more likely to be hospitalized each year, and other 
expenses are accounted for medicine use, home nursing visits, physician visits, transportation, sick-leave days and loss of income (8). In total, direct medical and indirect expenditures in the USA in 2007, attributable to type 2 diabetes, were estimated at $\$ 218$ billion. Currently, this represents a cost of approximately $\$ 700$ annually for each American (9) and the growing number of diabetic individuals will enlarge the future economic impact even more. Considering these facts and numbers, it is obvious that type 2 diabetes is a major problem in today's society.

\section{From normal glucose tolerance towards overt diabetes.}

The development of type 2 diabetes mellitus is characterized by a progressive deterioration of glucose tolerance over several years ( $\sim 5$ years) $(10)$. The transition from the normal glucose tolerance (NGT) state towards impaired glucose tolerance (IGT) to diabetes is accompanied by a reduction in insulin secretion from the pancreas and by a decreased insulin action (i.e. insulin resistance), and both effects are already detectable in the transition from NGT to IGT (10). During this phase, insulin secretion decreased by $27 \%$, whereas in the second phase towards diabetes, there was an additional decline of $57 \%$. In the transition of NGT to diabetes, total body insulin action decreased with $31 \%$ and $14 \%$ after administering a high $(400 \mathrm{mU} / \mathrm{m} 2)$ and a low dose $(40 \mathrm{mU} / \mathrm{m} 2)$ of insulin respectively (10). The disruption of the normal relationship between insulin sensitivity and $\beta$-cell function is central to the pathogenesis of hyperglycaemia in type 2 diabetes; when $\beta$-cells function is normal, individuals can compensate for insulin resistance and increased glucose levels by increasing insulin secretion. However, when $\beta$-cell function deteriorates, the insulin secretion eventually declines and leads to an even more pronounced hyperglycaemia. Thus, insulin resistance turns into type 2 diabetes, when $\beta$-cells are unable to compensate for insulin resistance with hyperinsulinemia. Numerous of people are insulin resistant, but not all of them progress to type 2 diabetes $(10 ; 11)$.

Type 2 diabetes is diagnosed by measuring venous plasma glucose levels before and 2 hours after ingestion of a $75 \mathrm{~g}$ oral glucose load. According to the World Health 
Organization (12), diabetes is diagnosed when fasting glucose levels are 7.0mmol/1 or higher, or if $2 \mathrm{~h}$ glucose levels equals or exceed $11.1 \mathrm{mmol} / \mathrm{l}$. In addition to these two stages, also pre-diabetic stages are defined. Impaired fasting glucose (IFG) state is established with fasting glucose levels between 6.1 and $6.9 \mathrm{mmol} / \mathrm{l}$ and $2 \mathrm{~h}$ values below $7.8 \mathrm{mmol} / \mathrm{l}$, and impaired glucose tolerance (IGT) is assessed when fasting glucose levels are below 7.0 and $2 \mathrm{~h}$ values $\geq 7.8$ and $<11.1 \mathrm{mmol} / \mathrm{l}$. Both the IGT and IFG are considered highly important risk factors for developing diabetes (13).

\section{Insulin resistance: a problem on whole body level.}

In skeletal muscle, glucose and fatty acids are the main substrates used for oxidation and subsequent generation of ATP. In the fasted state, ATP generation mainly relies on fatty acid oxidation, whereas in the postabsorptive state substrate use shifts towards glucose oxidation. The ability to switch between both substrates is called metabolic flexibility (14) and appears to depend on insulin sensitivity. In this regard, insulin has shown to be crucial for the uptake of glucose into the cell as well as for storage of glucose in the form of glycogen. In addition insulin also inhibits glycogen breakdown in the liver and thus reduces hepatic glucose output. In adipose tissue, insulin promotes lipogenesis and inhibits adipose tissue lipolysis, thereby preventing the release of free fatty acids (FFA) into the circulation.

Given the important role of insulin in multiple tissues in the body, insulin resistance in muscle, liver and adipose tissue results in multiple disturbances, such as a decreased glucose uptake from the blood stream and an increased output of glucose and free fatty acids into the circulation (15). Although it is obvious that for a complete understanding of maintaining proper blood glucose homeostasis inter organ crosstalk is important, the focus of the research outlined in the present thesis will be on skeletal muscle only. It has been shown that more than $80 \%$ of blood glucose is taken up in the muscle, indicating that muscle insulin resistance greatly contributes to the increased plasma glucose levels in type 2 diabetes patients (16). 


\section{Pathophysiology of insulin resistance}

Obesity is strongly associated with whole-body insulin resistance. Obesity results in spill-over of fatty acids from the expanded adipose tissue into the blood stream, which may lead to an enhanced uptake and storage of fatty acids in non-adipose tissues (e.g. liver, pancreas and in cardiac and skeletal muscle) and consequently to insulin resistance.

While especially lipid storage in skeletal muscle (in this thesis referred to as IntraMyocellular Lipids, IMCL) has been associated with the severity of insulin resistance $(17 ; 18)$, the exact mechanism on how IMCL accumulation may lead to the development of insulin resistance is not yet completely known. In the previous 2 decades, three main hypotheses have been postulated, from which a disturbed insulin signalling pathway is probably the most well known. According to this hypothesis, high levels of IMCL increase the presence of fatty acid intermediates like diacylglycerol (DAG), long-chain fatty acyl CoA (LCFACoA) and ceramides. These fatty acid intermediates are suggested to negatively affect the insulin receptor through activation of PKC and inhibition of PKB, resulting in an impaired insulin signalling cascade, a decreased GLUT 4 translocation to the membrane of the muscle cell and in a reduced glucose uptake from the blood into the muscle cell (19). Another hypothesis states that intracellular fatty acid metabolites can lead to insulin resistance through activation of the inflammatory $\mathrm{I} \kappa \mathrm{B} / \mathrm{NF} \kappa \mathrm{B}$ pathway $(20 ; 21)$. Under resting conditions

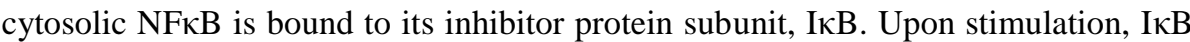
kinase (IKK) gets activated, leading to the phosphorylation and degradation of I $\kappa \mathrm{B}$. As a result, $\mathrm{NF \kappa B}$ translocates to the nucleus where it can bind to target genes and increases the expression of chemokines, pro-inflammatory cytokines and inflammatory enzymes (22). These can also activate $\mathrm{NF \kappa B}$, in a feed forward loop, leading to a progressive inflammatory response, and a deterioration of insulin sensitivity. A third pathway by which fatty acids may lead to insulin resistance is through lipid peroxidation. According to this theory, an increased residence time of lipids may be targeted by reactive oxygen species, leading to lipid peroxidation. These lipid peroxides are suggested to affect mitochondria of the cells, resulting in mitochondrial dysfunction, 
a decreased oxidative capacity and in insulin resistance. Although these 3 theories are here postulated separately, they are interrelated share common mechanisms and are not mutually exclusive.

\section{Athlete paradox; a role for lipid mobilisation, lipid oxidation or substrate switching?}

Although a tight correlation between IMCL accumulation and the severity of insulin resistance has been shown $(17 ; 23)$, this is only true for sedentary, untrained individuals. Endurance trained athletes are also characterized by elevated fat content in the muscle, but in contrast to their sedentary counterparts, they are highly insulin sensitive (24-27). The precise mechanism by which trained persons are protected from the insulin desensitizing effects of IMCL is incompletely understood, but it is likely that well orchestrated regulation of lipid droplet degradation and synthesis in close interplay with and (the ability to switch between glucose oxidation and fat oxidation), contribute to this phenomenon.

\section{Lipid droplet degradation and synthesis}

Recently, the process of lipid droplet dynamics gained a considerable amount of interest. For the past 40 years, hormone sensitive lipase (HSL) was considered the only lipase involved in TAG breakdown $(28 ; 29)$. However, in a landmark series of papers published in 2004, adipose triglyceride lipase (ATGL) was demonstrated to be the catalyst for the initial step of lipolysis and is thereby critical for complete lipolysis (30-32). ATGL and HSL are tightly regulated (33-35) and are responsible for $95 \%$ of total lipolytic activity (29), suggesting only a quantitatively minor role for other lipases including monoacylglycerol lipase (MGL). Lipid droplets in skeletal muscle are surrounded by a variety of proteins such as ADRP, TIP-47, S3-12 and CGI-58, which regulate the balance between lipid droplet synthesis and breakdown.. The regulation of lipid droplet dynamics is a complex process and dysregulation may play a role in the development of insulin resistance (36). Therefore, it will be discussed in detail in chapter 2 . 


\section{Mitochondrial function}

Mitochondrial dysfunction may also play a role in the development of insulin resistance. In recent years, this has been topic of intense research. Endurance trained athletes are characterized by a high mitochondrial content and a high oxidative capacity. Kelley et al. were the first to show that mitochondria of obese and diabetic subjects were affected in number, size and morphology (37). Subsequent studies indeed confirmed reduced mitochondrial content, and established a reduced intrinsic mitochondrial function (i.e. respiratory capacity per mitochondria) $(38 ; 39)$ and a reduced in vivo ATP synthesis and $\mathrm{PCr}$ resynthesis rate in type 2 diabetic patients and first-degree relatives of type 2 diabetic patients $(38 ; 40)$. However, there is no consensus yet on whether mitochondrial dysfunction and insulin resistance are causally related. In fact, recent studies revealed that a decreased mitochondrial function is not always present in the insulin resistant state (41) and likewise, it has been shown that improvements in insulin sensitivity are not always paralleled by improved mitochondrial function (42).

\section{Metabolic flexibility}

Metabolic flexibility is also different between trained and diabetic persons. Whereas trained subjects are very well able to switch in substrate oxidation upon insulin activation, insulin resistant persons are characterized by metabolic inflexibility. On one hand, this metabolic inflexibility may originate from decreased insulin stimulated uptake of glucose into the cell, i.e. insulin resistance, reflecting a reduced availability of glucose for oxidation. (43) On the other hand, it could also reflect the inability of mitochondria to shift fuel selection. At his point, the relationship between mitochondrial function, metabolic flexibility and insulin resistance is not completely clear. It seems valid to state that oxidative capacity and metabolic flexibility are not always defect in the diabetic state, but this however does not rule out that in the presence of elevated IMCL levels, well regulated mitochondrial function and metabolic flexibility are both needed to prevent a deterioration in insulin sensitivity. 


\section{Treatment of diabetes}

Early treatment of diabetes is important to control blood glucose values and to prevent diabetes-related complications. Treatment can be achieved through lifestyle interventions, i.e. exercise and diet, or through blood glucose lowering drugs.

Based on a large number of clinical trials, exercise is considered fundamental in the treatment of diabetes (44). Exercise can delay and reduce the incidence of diabetes in persons at high risk by 58 percent (45) and can improve (or even restore) abnormalities in oxidative capacity, substrate selection (i.e metabolic flexibility), mitochondrial function and density, capillary density and lipid profile (46). Interesting from a therapeutic point of view is the evidence that exercise is at least as effective in older participants as it is in younger participants (45) and that also long-standing insulin treated patients can benefit from exercise training (47). Also nutritional intervention programs have been shown to be successful in preventing or delaying the onset diabetes. Especially weight reduction leads to improved insulin sensitivity $(48 ; 49)$, suggesting that nutritional treatment should primarily focus on this target. The underlying mechanism may differ from exercise though; while exercise training leads to an improved mitochondrial function but not to a decreased IMCL content, the opposite observation has been made after weight loss (42). With respect to weight loss, it has been reported however, that lengthening of the treatment does not always prevent relapse (50), and that a combination with exercise should be applied to obtain long term benefits (50-52).

Apart from diet and exercise, diabetes can also be treated with blood glucose lowering drugs. Blood glucose lowering drugs can be divided in several subclasses; drugs aimed to improve insulin sensitivity in liver, adipose tissue and skeletal muscle (f.e.Thiazolidinedionen (TZD's) and Metformin), drugs aimed to increase insulin secretion of the pancreas (f.e. Sulfonylurea derivates (SU-derivates)), and drug aimed to extend the duration of activity of the so-called satiety hormones GIP and GLP-1 (Dipeptidyl-peptidase-4 (DPP-4) inhibitors). The majority of type 2 diabetes patients are treated with one or more types of blood glucose lowering drugs. Although there is 
no doubt that they are an important cornerstone in the treatment of diabetes, the beneficial effects of medication (53) do not exclude the importance of lifestyle changes as part of the medical treatment. In fact, some studies have shown that lifestyle interventions may be even more effective in obtaining glycemic control compared to drugs $(54 ; 55)$ and should, if possible, be the preferred method of treatment.

Next to blood glucose lowering drugs, many T2D patients are also prescribed statins, as diabetes and hyperlipidemia often present concurrently. Statins are shown to be effective in lowering high lipid circulating lipid levels. However, statins have also been associated with myotoxicity, mitochondrial dysfunction (56-60), muscular damage $(58 ; 61)$, and a blunted response to exercise training $(62 ; 63)$. Given the importance of exercise in the treatment of T2D and given the key role of muscle and mitochondria in patients, the effect and underlying working mechanism of statins should therefore be addressed. Apart from statins, also aspirin is widely used medication in T2D patients. Aspirin is predominantly used as a anti-coagulance, although early reports of professor Ebstein in 1876 showed that aspirin and aspirin alike compounds (i.e. salsalate, (sodium) salicylate and salicylic acid) are also able to decrease urine volume and urine sugar content in diabetic patients (64). These positive effects were confirmed in following studies and extended with observations of decreased plasma glucose levels (65-69), decreased glycosuria $(65 ; 69)$ and increased insulin secretion $(67 ; 70 ; 71)$. The underlying mechanism however, is controversial. Some studies suggest that the anti-diabetic effects are caused by an improved insulin sensitivity with a possible role for the $\mathrm{I} \kappa \mathrm{B} / \mathrm{NF} \kappa \mathrm{B}$ pathway $(72 ; 73)$, but this is not supported by all studies. In fact, some investigations even report a deterioration $(74 ; 75)$ in insulin sensitivity or observe mitotoxic effects upon aspirin treatment salicylate $(76 ; 77)$.

\section{Outline of the thesis}

Type 2 diabetes is a complex disease in which muscle insulin resistance plays a prominent role. This $\mathrm{PhD}$ project focused on the insulin resistant state and used interventions (i.e. exercise training, lipid infusion and salsalate administration) as a tool to modulate insulin sensitivity in order to investigate the underlying mechanisms. 
As described previously, lipid accumulation in skeletal muscle, is strongly associated with the severity of insulin resistance. The field of lipid droplet dynamics in skeletal muscle however, is relatively unexplored. Chapter 2 starts with an overview of current knowledge with respect to lipase activity, lipid droplets and lipid droplet coating proteins, and their roles in relation to muscular insulin sensitivity.

Exercise training is an insulin sensitizing intervention. However, exercise has been shown to increase IMCL levels in obese subjects and diabetes patients rather than decrease. Furthermore, the interaction of exercise-mediated effects on IMCL accumulation, mitochondrial content, in vivo mitochondrial function, metabolic flexibility and substrate oxidation remained unclear and it was also not known whether the response in diabetes patients is different from the response in BMI matched normoglycemic control subjects. In this $\mathrm{PhD}$ project, a 12-week combined progressive exercise program has been applied and above-mentioned research questions have been addressed in both groups. Findings are presented in chapter 3.

Chapter 4 proceeds on the exercise-induced effects described in chapter 3 (i.e. changes in metabolic flexibility, oxidative capacity and insulin sensitivity) and aims to explain them in the light of observed changes in lipases, lipase activity and lipid droplet coating proteins.

Exercise-induced improvements are suggested to be blunted in persons on statin intake (ST). To test this hypothesis, the entire group of diabetes patients and healthy control subjects were restratified according to statin use. Strikingly, the insulin sensitizing effects of training were more prominent in ST than in the control group without statin (C). These results are discussed in more detail in chapter 5.

Lipid infusion is a model to induce acutely and transiently insulin resistance in healthy subjects within 3-4 hours after the onset of the infusion. Chapter 6 describes a study in which healthy, young untrained males and healthy, young endurancetrained males underwent 2 hyperinsulinemic euglycemic clamps with either glycerol 
or lipid infusion. As anticipated, insulin resistance was less pronounced in endurance trained subjects compared to untrained subjects. In analogy to the study presented to chapter 3, this chapter will evaluate their change in insulin sensitivity in relation to their changes in IMCL accumulation, mitochondrial content, in vivo mitochondrial function, metabolic flexibility and substrate oxidation.

Finally, chapter 7 extends on the study described in chapter 6 and considers the effect of salsalate on lipid-induced insulin resistance in young healthy untrained male subjects. Salsalate has been suggested to improve insulin sensitivity and glucose homeostasis and to ameliorate lipid-induced insulin resistance. Therefore, the untrained subjects were submitted to a $2^{\text {nd }}$ hyperinsulinemic euglycemic clamp with simultaneous lipid infusion, preceded by 4 days of a high dosage of salsalate. The aim of the study was to ameliorate lipid-induced insulin resistance and explore underlying mechanisms.

This thesis will end with a general discussion in chapter 8 , in which all findings will be discussed in the light of current knowledge and literature. 


\section{References}

1. Hogan P, Dall T, Nikolov P: Economic costs of diabetes in the US in 2002. Diabetes Care 26:917-932, 2003

2. Roglic G, Unwin N, Bennett PH, Mathers C, Tuomilehto J, Nag S, Connolly V, King H: The burden of mortality attributable to diabetes: realistic estimates for the year 2000 . Diabetes Care 28:2130-2135, 2005

3. Brito EC, Lyssenko V, Renstrom F, Berglund G, Nilsson PM, Groop L, Franks PW: Previously associated type 2 diabetes variants may interact with physical activity to modify the risk of impaired glucose regulation and type 2 diabetes: a study of 16,003 Swedish adults. Diabetes 58:1411-1418, 2009

4. McIntyre EA, Walker M: Genetics of type 2 diabetes and insulin resistance: knowledge from human studies. Clin Endocrinol (Oxf) 57:303-311, 2002

5. Schulze MB, Hu FB: Primary prevention of diabetes: what can be done and how much can be prevented? Annu Rev Public Health 26:445-467, 2005

6. Bloomgarden ZT: American Diabetes Association Annual Meeting, 1999: diabetes and obesity. Diabetes Care 23:118-124, 2000

7. Wild S, Roglic G, Green A, Sicree R, King H: Global prevalence of diabetes: estimates for the year 2000 and projections for 2030. Diabetes Care 27:1047-1053, 2004

8. Economic costs of diabetes in the U.S. In 2007. Diabetes Care 31:596-615, 2008

9. Dall TM, Zhang Y, Chen YJ, Quick WW, Yang WG, Fogli J: The Economic Burden Of Diabetes. Health Aff (Millwood)

10. Weyer C, Bogardus C, Mott DM, Pratley RE: The natural history of insulin secretory dysfunction and insulin resistance in the pathogenesis of type 2 diabetes mellitus. J Clin Invest 104:787-794, 1999

11. Kahn SE, Hull RL, Utzschneider KM: Mechanisms linking obesity to insulin resistance and type 2 diabetes. Nature 444:840-846, 2006

12. Organisation WH: Definition and diagnosis of diabetes mellitus and intermediate hyperglycemia: report of a WHO/IDF consultation., 2006

13. de Vegt F, Dekker JM, Jager A, Hienkens E, Kostense PJ, Stehouwer CD, Nijpels G, Bouter LM, Heine RJ: Relation of impaired fasting and postload glucose with incident type 2 diabetes in a Dutch population: The Hoorn Study. JAMA 285:2109-2113, 2001

14. Kelley DE, Mandarino LJ: Fuel selection in human skeletal muscle in insulin resistance: a reexamination. Diabetes 49:677-683, 2000

15. Groop LC, Saloranta C, Shank M, Bonadonna RC, Ferrannini E, DeFronzo RA: The role of free fatty acid metabolism in the pathogenesis of insulin resistance in obesity and noninsulin-dependent diabetes mellitus. J Clin Endocrinol Metab 72:96-107, 1991

16. DeFronzo RA, Gunnarsson R, Bjorkman O, Olsson M, Wahren J: Effects of insulin on peripheral and splanchnic glucose metabolism in noninsulin-dependent (type II) diabetes mellitus. J Clin Invest 76:149-155, 1985

17. Krssak M, Falk Petersen K, Dresner A, DiPietro L, Vogel SM, Rothman DL, Roden M, Shulman GI: Intramyocellular lipid concentrations are correlated with insulin sensitivity in humans: a 1H NMR spectroscopy study. Diabetologia 42:113-116, 1999

18. Pan DA, Lillioja S, Kriketos AD, Milner MR, Baur LA, Bogardus C, Jenkins AB, Storlien LH: Skeletal muscle triglyceride levels are inversely related to insulin action. Diabetes 46:983-988, 1997

19. Shulman GI: Cellular mechanisms of insulin resistance. J Clin Invest 106:171-176, 2000

20. Sriwijitkamol A, Christ-Roberts C, Berria R, Eagan P, Pratipanawatr T, Defronzo RA, Mandarino LJ, Musi N: Reduced Skeletal Muscle Inhibitor of $\{$ kappa $\}$ B beta $\}$ Content Is 
Associated With Insulin Resistance in Subjects With Type 2 Diabetes: Reversal by Exercise Training. Diabetes 55:760-767, 2006

21. Itani SI, Ruderman NB, Schmieder F, Boden G: Lipid-induced insulin resistance in human muscle is associated with changes in diacylglycerol, protein kinase $\mathrm{C}$, and IkappaB-alpha. Diabetes 51:2005-2011, 2002

22. Cai D, Yuan M, Frantz DF, Melendez PA, Hansen L, Lee J, Shoelson SE: Local and systemic insulin resistance resulting from hepatic activation of IKK-beta and NF-kappaB. Nat Med 11:183-190, 2005

23. Perseghin G, Scifo P, De Cobelli F, Pagliato E, Battezzati A, Arcelloni C, Vanzulli A, Testolin G, Pozza G, Del Maschio A, Luzi L: Intramyocellular triglyceride content is a determinant of in vivo insulin resistance in humans: a $1 \mathrm{H}-13 \mathrm{C}$ nuclear magnetic resonance spectroscopy assessment in offspring of type 2 diabetic parents. Diabetes 48:1600-1606, 1999

24. Goodpaster BH, He J, Watkins S, Kelley DE: Skeletal muscle lipid content and insulin resistance: evidence for a paradox in endurance-trained athletes. J Clin Endocrinol Metab $86: 5755-5761,2001$

25. Schrauwen-Hinderling VB, Schrauwen P, Hesselink MK, van Engelshoven JM, Nicolay K, Saris WH, Kessels AG, Kooi ME: The increase in intramyocellular lipid content is a very early response to training. J Clin Endocrinol Metab 88:1610-1616, 2003

26. Tarnopolsky MA, Rennie CD, Robertshaw HA, Fedak-Tarnopolsky SN, Devries MC, Hamadeh MJ: Influence of endurance exercise training and sex on intramyocellular lipid and mitochondrial ultrastructure, substrate use, and mitochondrial enzyme activity. Am J Physiol Regul Integr Comp Physiol 292:R1271-1278, 2007

27. van Loon LJ, Koopman R, Manders R, van der Weegen W, van Kranenburg GP, Keizer HA: Intramyocellular lipid content in type 2 diabetes patients compared with overweight sedentary men and highly trained endurance athletes. Am J Physiol Endocrinol Metab 287:E558-565, 2004

28. Fredrikson G, Stralfors P, Nilsson NO, Belfrage P: Hormone-sensitive lipase of rat adipose tissue. Purification and some properties. J Biol Chem 256:6311-6320, 1981

29. Schweiger M, Schreiber R, Haemmerle G, Lass A, Fledelius C, Jacobsen P, Tornqvist H, Zechner R, Zimmermann R: Adipose triglyceride lipase and hormone-sensitive lipase are the major enzymes in adipose tissue triacylglycerol catabolism. J Biol Chem 281:4023640241, 2006

30. Zimmermann R, Strauss JG, Haemmerle G, Schoiswohl G, Birner-Gruenberger R, Riederer M, Lass A, Neuberger G, Eisenhaber F, Hermetter A, Zechner R: Fat mobilization in adipose tissue is promoted by adipose triglyceride lipase. Science 306:1383-1386, 2004

31. Villena JA, Roy S, Sarkadi-Nagy E, Kim KH, Sul HS: Desnutrin, an adipocyte gene encoding a novel patatin domain-containing protein, is induced by fasting and glucocorticoids: ectopic expression of desnutrin increases triglyceride hydrolysis. J Biol Chem 279:47066-47075, 2004

32. Jenkins CM, Mancuso DJ, Yan W, Sims HF, Gibson B, Gross RW: Identification, cloning, expression, and purification of three novel human calcium-independent phospholipase A2 family members possessing triacylglycerol lipase and acylglycerol transacylase activities. J Biol Chem 279:48968-48975, 2004

33. Langin D, Dicker A, Tavernier G, Hoffstedt J, Mairal A, Ryden M, Arner E, Sicard A, Jenkins CM, Viguerie N, van Harmelen V, Gross RW, Holm C, Arner P: Adipocyte lipases and defect of lipolysis in human obesity. Diabetes 54:3190-3197, 2005

34. Mairal A, Langin D, Arner P, Hoffstedt J: Human adipose triglyceride lipase (PNPLA2) is not regulated by obesity and exhibits low in vitro triglyceride hydrolase activity. Diabetologia, 2006 
35. Jocken JW, Langin D, Smit E, Saris WH, Valle C, Hul GB, Holm C, Arner P, Blaak EE: Adipose TriGlyceride Lipase (ATGL) and Hormone-Sensitive Lipase (HSL) protein expression is decreased in the obese insulin resistant state. J Clin Endocrinol Metab, 2007

36. Blaak EE, Schiffelers SL, Saris WH, Mensink M, Kooi ME: Impaired beta-adrenergically mediated lipolysis in skeletal muscle of obese subjects. Diabetologia 47:1462-1468, 2004

37. Kelley DE, He J, Menshikova EV, Ritov VB: Dysfunction of mitochondria in human skeletal muscle in type 2 diabetes. Diabetes 51:2944-2950, 2002

38. Phielix E, Schrauwen-Hinderling VB, Mensink M, Lenaers E, Meex R, Hoeks J, Kooi ME, Moonen-Kornips E, Sels JP, Hesselink MK, Schrauwen P: Lower intrinsic ADPstimulated mitochondrial respiration underlies in vivo mitochondrial dysfunction in muscle of male type 2 diabetic patients. Diabetes 57:2943-2949, 2008

39. Mogensen M, Sahlin K, Fernstrom M, Glintborg D, Vind BF, Beck-Nielsen H, Hojlund K: Mitochondrial respiration is decreased in skeletal muscle of patients with type 2 diabetes. Diabetes 56:1592-1599, 2007

40. Schrauwen-Hinderling VB, Kooi ME, Hesselink MK, Jeneson JA, Backes WH, van Echteld CJ, van Engelshoven JM, Mensink M, Schrauwen P: Impaired in vivo mitochondrial function but similar intramyocellular lipid content in patients with type 2 diabetes mellitus and BMI-matched control subjects. Diabetologia 50:113-120, 2007

41. De Feyter HM, Lenaers E, Houten SM, Schrauwen P, Hesselink MK, Wanders RJ, Nicolay $\mathrm{K}$, Prompers JJ: Increased intramyocellular lipid content but normal skeletal muscle mitochondrial oxidative capacity throughout the pathogenesis of type 2 diabetes. FASEB J 22:3947-3955, 2008

42. Toledo FG, Menshikova EV, Azuma K, Radikova Z, Kelley CA, Ritov VB, Kelley DE: Mitochondrial capacity in skeletal muscle is not stimulated by weight loss despite increases in insulin action and decreases in intramyocellular lipid content. Diabetes 57:987-994, 2008

43. Galgani JE, Heilbronn LK, Azuma K, Kelley DE, Albu JB, Pi-Sunyer X, Smith SR, Ravussin E: Metabolic flexibility in response to glucose is not impaired in people with type 2 diabetes after controlling for glucose disposal rate. Diabetes 57:841-845, 2008

44. Albright A, Franz M, Hornsby G, Kriska A, Marrero D, Ullrich I, Verity LS: American College of Sports Medicine position stand. Exercise and type 2 diabetes. Med Sci Sports Exerc 32:1345-1360, 2000

45. Knowler WC, Barrett-Connor E, Fowler SE, Hamman RF, Lachin JM, Walker EA, Nathan DM: Reduction in the incidence of type 2 diabetes with lifestyle intervention or metformin. N Engl J Med 346:393-403, 2002

46. Sigal RJ, Kenny GP, Boule NG, Wells GA, Prud'homme D, Fortier M, Reid RD, Tulloch H, Coyle D, Phillips P, Jennings A, Jaffey J: Effects of aerobic training, resistance training, or both on glycemic control in type 2 diabetes: a randomized trial. Ann Intern Med 147:357-369, 2007

47. Praet SF, Jonkers RA, Schep G, Stehouwer CD, Kuipers H, Keizer HA, van Loon LJ: Long-standing, insulin-treated type 2 diabetes patients with complications respond well to short-term resistance and interval exercise training. Eur J Endocrinol 158:163-172, 2008

48. Weyer C, Hanson K, Bogardus C, Pratley RE: Long-term changes in insulin action and insulin secretion associated with gain, loss, regain and maintenance of body weight. Diabetologia 43:36-46, 2000

49. Schenk S, Harber MP, Shrivastava CR, Burant CF, Horowitz JF: Improved insulin sensitivity after weight loss and exercise training is mediated by a reduction in plasma fatty acid mobilization, not enhanced oxidative capacity. J Physiol 587:4949-4961, 2009

50. Weiss EC, Galuska DA, Kettel Khan L, Gillespie C, Serdula MK: Weight regain in U.S. adults who experienced substantial weight loss, 1999-2002. Am J Prev Med 33:34-40, 2007 
51. MacLean PS, Higgins JA, Wyatt HR, Melanson EL, Johnson GC, Jackman MR, Giles ED, Brown IE, Hill JO: Regular exercise attenuates the metabolic drive to regain weight after long-term weight loss. Am J Physiol Regul Integr Comp Physiol 297:R793-802, 2009

52. Jakicic JM, Winters C, Lang W, Wing RR: Effects of intermittent exercise and use of home exercise equipment on adherence, weight loss, and fitness in overweight women: a randomized trial. JAMA 282:1554-1560, 1999

53. Zinman B, Harris SB, Neuman J, Gerstein HC, Retnakaran RR, Raboud J, Qi Y, Hanley AJ: Low-dose combination therapy with rosiglitazone and metformin to prevent type 2 diabetes mellitus (CANOE trial): a double-blind randomised controlled study. Lancet 376:103-111, 2010

54. Goldberg RB, Temprosa M, Haffner S, Orchard TJ, Ratner RE, Fowler SE, Mather K, Marcovina S, Saudek C, Matulik MJ, Price D: Effect of progression from impaired glucose tolerance to diabetes on cardiovascular risk factors and its amelioration by lifestyle and metformin intervention: the Diabetes Prevention Program randomized trial by the Diabetes Prevention Program Research Group. Diabetes Care 32:726-732, 2009

55. Kitabchi AE, Temprosa M, Knowler WC, Kahn SE, Fowler SE, Haffner SM, Andres R, Saudek C, Edelstein SL, Arakaki R, Murphy MB, Shamoon H: Role of insulin secretion and sensitivity in the evolution of type 2 diabetes in the diabetes prevention program: effects of lifestyle intervention and metformin. Diabetes 54:2404-2414, 2005

56. Ghirlanda G, Oradei A, Manto A, Lippa S, Uccioli L, Caputo S, Greco AV, Littarru GP: Evidence of plasma CoQ10-lowering effect by HMG-CoA reductase inhibitors: a doubleblind, placebo-controlled study. J Clin Pharmacol 33:226-229, 1993

57. Paiva H, Thelen KM, Van Coster R, Smet J, De Paepe B, Mattila KM, Laakso J, Lehtimaki T, von Bergmann K, Lutjohann D, Laaksonen R: High-dose statins and skeletal muscle metabolism in humans: a randomized, controlled trial. Clin Pharmacol Ther 78:60-68, 2005

58. Phillips PS, Haas RH, Bannykh S, Hathaway S, Gray NL, Kimura BJ, Vladutiu GD, England JD: Statin-associated myopathy with normal creatine kinase levels. Ann Intern Med 137:581-585, 2002

59. Schick BA, Laaksonen R, Frohlich JJ, Paiva H, Lehtimaki T, Humphries KH, Cote HC: Decreased skeletal muscle mitochondrial DNA in patients treated with high-dose simvastatin. Clin Pharmacol Ther 81:650-653, 2007

60. Sirvent P, Mercier J, Lacampagne A: New insights into mechanisms of statin-associated myotoxicity. Curr Opin Pharmacol 8:333-338, 2008

61. Draeger A, Monastyrskaya K, Mohaupt M, Hoppeler H, Savolainen H, Allemann C, Babiychuk EB: Statin therapy induces ultrastructural damage in skeletal muscle in patients without myalgia. J Pathol 210:94-102, 2006

62. Urso ML, Clarkson PM, Hittel D, Hoffman EP, Thompson PD: Changes in ubiquitin proteasome pathway gene expression in skeletal muscle with exercise and statins. Arterioscler Thromb Vasc Biol 25:2560-2566, 2005

63. Thompson PD, Zmuda JM, Domalik LJ, Zimet RJ, Staggers J, Guyton JR: Lovastatin increases exercise-induced skeletal muscle injury. Metabolism 46:1206-1210, 1997

64. Ebstein W: Invited comment on W. Ebstein: On the therapy of diabetes mellitus, in particular on the application of sodium salicylate. J Mol Med 80:618; discussion 619, 2002

65. Reid J, Macdougall AI, Andrews MM: Aspirin and diabetes mellitus. Br Med J:1071-1074, 1957

66. Gilgore SG, Rupp JJ: Response of blood glucose to intravenous salicylate. Metabolism 10:419-421, 1961

67. Field JB, Boyle C, Remer A: Effect of salicylate infusion on plasma-insulin and glucose tolerance in healthy persons and mild diabetics. Lancet 1:1191-1194, 1967

68. Hecht A, Goldner MG: Reappraisal of the hypoglycemic action of acetylsalicylate. Metabolism 8:418-428, 1959 
69. Anderson WF, Thompson J: Aspirin in the Treatment of Diabetes Mellitus in the Elderly. Gerontol Clin (Basel) 22:234-243, 1963

70. Robertson RP, Chen M: Modulation of insulin secretion in normal and diabetic humans by prostaglandin E and sodium salicylate. Trans Assoc Am Physicians 90:353-365, 1977

71. Chen M, Robertson RP: Restoration of the acute insulin response by sodium salicylate. A glucose dose-related phenomenon. Diabetes 27:750-756, 1978

72. Kim JK, Kim YJ, Fillmore JJ, Chen Y, Moore I, Lee J, Yuan M, Li ZW, Karin M, Perret P, Shoelson SE, Shulman GI: Prevention of fat-induced insulin resistance by salicylate. J Clin Invest 108:437-446, 2001

73. Yuan M, Konstantopoulos N, Lee J, Hansen L, Li ZW, Karin M, Shoelson SE: Reversal of obesity- and diet-induced insulin resistance with salicylates or targeted disruption of Ikkbeta. Science 293:1673-1677, 2001

74. Newman WP, Brodows RG: Aspirin causes tissue insensitivity to insulin in normal man. J Clin Endocrinol Metab 57:1102-1106, 1983

75. Bratusch-Marrain PR, Vierhapper H, Komjati M, Waldhausl WK: Acetyl-salicylic acid impairs insulin-mediated glucose utilization and reduces insulin clearance in healthy and non-insulin-dependent diabetic man. Diabetologia 28:671-676, 1985

76. Charnock JS, Opit LJ: The effect of salicylate on adenosine-triphosphatase activity of ratliver mitochondria. Biochem J 83:596-602, 1962

77. Haas R, Parker WD, Jr., Stumpf D, Eguren LA: Salicylate-induced loose coupling: protonmotive force measurements. Biochem Pharmacol 34:900-902, 1985 


\title{
CHAPTER 2
}

\section{The modulation of myocellular fat stores; lipid droplet dynamics in health and disease}

\begin{abstract}
Storage of fatty acids as triacylglycerol (TAG) occurs in almost all mammalian tissues. Whereas adipose tissue is by far the largest storage site of fatty acids as TAG, subcellular TAG-containing structures -referred to as lipid droplets (LD)- are also present in other tissues. Until recently, LD were considered inert storage sites of energy dense fats. Nowadays, however, LD are increasingly considered dynamic functional organelles involved in many intracellular processes like lipid metabolism, vesicle trafficking and cell signaling. Next to TAG, LD also contain other neutral lipids such as diacylglycerol. Furthermore, LD are coated by a monolayer of phospholipids decorated with a variety of proteins regulating the delicate balance between LD synthesis, growth and degradation. Disturbances in LD coating proteins may result in disequilibrium of TAG synthesis and degradation giving rise to insulin desensitizing lipid intermediates, especially in insulin responsive tissues like skeletal muscle. For a proper and detailed understanding, more information on processes and players involved in LD synthesis and degradation is necessary. This, however, is hampered by the fact that research on LD dynamics in (human) muscle is still in its infancy. A rapidly expanding body of knowledge on LD dynamics originates from studies in other tissues and other species. Here, we aim to review the involvement of LD coating proteins in LD formation and degradation (LD dynamics) and to extrapolate this knowledge to human skeletal muscle and to explore the role of LD dynamics in myocellular insulin sensitivity.
\end{abstract}

Ruth C. R. Meex

Patrick Schrauwen Matthijs Hesselink

American Journal of Physiology Regul Integr Comp Physiol 297: R913-924, 2010 


\section{Introduction}

Storage of fat in white adipose tissue (WAT) is the most widely studied form of triacylglycerol (TAG) storage. In periods of caloric excess, adipose tissue mass expands by increasing TAG content. During starvation, hydrolysis of TAG results in mobilization of fatty acids to meet the organism's energy requirement and TAG content in adipocytes declines. Stored TAG hence represents a dynamic pool of fatty acids.

Whereas adipose tissue is by far the largest storage site of fatty acids as TAG, almost all mammalian cell types have the ability to store fatty acids as TAG in lipid droplets (LD), so-called ectopic fat storage. The LD coating phospholipid monolayer is covered with phospholipids, cholesterol and proteins. Next to TAG, LD also contain other neutral lipids like diacylglycerols (DAG), cholesteryl esters, retinyl esters and free cholesterol. Lipid droplets may range in size from $200 \mu \mathrm{m}$ in diameter to micro lipid bodies of only $50 \mathrm{~nm}$ in diameter, depending on the cellular lipid load and cell type (92).

Nowadays, LD are considered dynamic functional organelles. Next to lipid metabolism, LD are also involved in vesicle trafficking and cell signaling $(16,92)$. The physiological role of lipid droplets varies with the subcellular localization, the morphology and the (sub)proteome of the droplet. In adipocytes, the cytoplasm is almost entirely occupied by the LD, whereas in tissues with a high lipolytic rate like cardiac and skeletal muscle, numerous small LD are present. Size, and possibly function, is sensitive to diet, disease, nutritional status, and training status (92) and on the balance between LD synthesis and LD degradation.

Abundant storage of TAG in LD in metabolically dynamic tissues like cardiac and skeletal muscle, liver and pancreas may interfere with subcellular processes like insulin signaling. Thus, a strong positive correlation between ectopic TAG storage measured by ${ }^{1} \mathrm{H}$ NMR spectroscopy as intramyocellular lipid content (IMCL) and insulin resistance $(57,69,101)$ has been reported in insulin resistant subjects. Interestingly, endurance training, an insulin sensitizing intervention, also coincides with increased IMCL content (40). In fact we have shown that an increase in IMCL is a 24 
very early response to training (119). In addition, it has been shown that a 4-month insulin sensitizing intervention of combined weight loss and physical activity significantly decreased LD size, without a decline in total myocellular triacylglycerol content (49). It is therefore unlikely that the presence of LD per se impedes insulin signaling. Rather, it has been hypothesized that intermediates in LD synthesis and degradation like DAG, ceramides and fatty acyl CoA esters might be responsible (56, $104,112,122)$. The balance between LD synthesis and degradation, here referred to as LD dynamics partly determines the fraction of lipid-derived intermediates.

In adipocytes the phospholipid monolayer coating the LD is decorated with several proteins involved in lipid droplet dynamics referred to as PAT proteins. PAT proteins (Perilipin, ADRP (for adipocyte differentiation-related protein), and TIP47 (for tailinteracting protein of $47 \mathrm{kDa})$ ). are characterized by a common $\mathrm{N}$-terminal motif (PAT domain). Other recently discovered proteins like S3-12 and OXPAT possess a high sequence homology with the PAT domain and are also considered PAT proteins. Throughout this review, we will use the term PAT proteins not only for Perilipin, ADRP and TIP-47, but also for S3-12 and OXPAT.

To better understand the origin of insulin desensitizing lipid moieties in skeletal muscle, a detailed understanding of the processes involved in LD formation and degradation is hence warranted. To date, however, data on LD dynamics in (human) muscle is still scarce. A rapidly expanding body of knowledge on LD dynamics comes from studies in other tissues and other species. Therefore, we aim to review the current prevailing knowledge on the process of LD synthesis and degradation and to extrapolate this knowledge to human skeletal muscle and where data allow, explore the putative involvement in muscular insulin sensitivity.

\section{Lipid droplet hydrolysis}

Hydrolysis of TAG stored in LD, requires a tight interplay between multiple lipases. Tight (co)regulation of two major lipases hormone sensitive lipase (HSL) and Adipose Triglyceride Lipase (ATGL) has been demonstrated in human adipose tissue $(61,73,81)$. It can be hypothesized that an imbalance between HSL en ATGL activi- 
ty affects the level of insulin-desensitizing intermediates like DAG, not only in adipose tissue but also in peripheral tissues like skeletal muscle.

\section{HSL}

Hormone sensitive lipase (HSL) is a cytosolic protein with three isoforms of which one (the $84 \mathrm{kDa}$ isoform) is abundantly present in adipose tissue (141) and in lesser amounts in cardiac and skeletal muscle $(51,67,72,123)$ Phosphorylation of specific serine residues of HSL results in activation of HSL and subsequent translocation from the cytosol to the phospholipid monolayer covering the LD to exert lipolytic activity $(14,23,33)$. HSL has affinity to multiple lipid related substrates (reviewed in (52)). Here, we will focus on its affinity to TAG, DAG and monoacylglcerol (MAG).

Activation of HSL can occur via a hormonal route and - in case of muscle - a contraction-mediated route. In the hormonal route, binding of catecholamines increases cAMP levels thereby activating PKA. Subsequently, phosphorylation of HSL activation sites (Ser-563, Ser-659 and Ser-660) occurs (2, 5, 72, 146). Adrenergic activation of HSL can be blunted by insulin via activation of AKT/PKB and PDE3B resulting in degradation of cAMP, thereby interfering with adrenergic activation of lipolysis $(28,78,94,149)$. Although hormonal regulation of lipolysis in muscle is similar to adipose tissue lipolysis, the contractile nature of muscle and the resultant rapid fluctuations in energy requirement need additional routes to control muscle lipolysis. Physical exercise enhances circulatory adrenalin levels and increases muscle AMPK activity. Stimulation of muscle lipolysis by exercise-induced increases in adrenalin can partly be blunted by AMPK dependent phosphorylation of HSL at inactivating serine residues Ser-565 in skeletal muscle (possibly to adjust lipolytic rate to exercise intensity), this AMP-dependent inactivation is not reported in adipose tissue (145147). Increases in $\mathrm{Ca}^{2+}$ in the sarcolemma, which initiates muscle contraction, also results in activation of PKC and its downstream target ERK and subsequent HSL activation $(30,45)$. These effects jointly regulate fine-tuning of exercise-induced activation of muscle lipolysis to fuel muscle contraction during graded exercise as well as during prolonged exercise. 
$A T G L$

For the past 30 years, HSL was considered the only lipase involved in TAG degradation. Interestingly, in HSL knock-out mice total adipose tissue mass did not change $(100,143)$ while hydrolysis of TAG was still possible but DAG levels were increased (48). This suggests that a lipase other than HSL must be involved in TAG hydrolysis. This protein has been identified and was named adipose triglyceride lipase (ATGL) (162). Independent studies identified the same protein at about the same time and called it iPLA2 (58) and desnutrin (142). ATGL is well preserved across species, and homologues have been reported in yeast (Tgl4 (7)), in plants (SUGARDEPENDENT1 lipase (31)), and in Drosophila (Brummer lipase (46)). Here we will use the term ATGL for this lipase.

ATGL mRNA is predominantly expressed in WAT and BAT, and to a lesser extent in cardiac and skeletal muscle $(47,60,63,65,142,162)$. Cell studies revealed PPAR $\gamma$-mediated control of ATGL gene expression $(65,142)$. Both thiazolidinedione-based PPAR $\gamma$ agonists and non thiazolidinedione-based PPAR $\gamma$ agonists increased ATGL mRNA and ATGL protein in 3T3-L1 adipocytes (64). Knock down of PPAR $\gamma$ reduced ATGL mRNA and protein expression in adipocytes (64). Treating mice with rosiglitazone increased ATGL mRNA and protein content $(64,77,121)$.

During fasting, a state in which PPAR $\gamma$ is activated through elevated free fatty acid levels, ATGL mRNA and ATGL protein expression is upregulated $(63,142)$. Refeeding results in a decreased transcription of ATGL in mice $(63,65)$. Decreases in transcription of the ATGL gene after refeeding can be a direct effect of reduced PPAR $\gamma$ activity in adipose tissue; it can also be mediated via insulin, transient hyperglycemia or reduced FFA levels by insulin-mediated suppression of adipose tissue lipolysis. Later studies revealed that transcriptional control of the ATGL gene in adipose tissue is under control of insulin rather than glucose $(63,65,68)$. Thus, ATGL appears to be under control of PPAR $\gamma$ as well as insulin.

In 3T3-L1 adipocytes and under basal conditions, the majority of ATGL protein was present in the cytoplasm, whereas a distinct fraction of ATGL was tightly associated with LD (162). ATGL hydrolyses the first ester bond of TAG and is likely to limit lipolysis in smooth muscle, cardiac muscle and possibly skeletal muscle (47, 48, 
120). Although knock-down of ATGL (or its homologue Brummer lipase in case of Drosophila) resulted in a decreased lipolysis and an increase in LD size in Drosophila, 3T3-L1 cells and in HeLa cells $(35,46,63,124)$, adipose tissue mass in mice lacking ATGL was increased, but not massively. Rather, fat storage in non-adipose tissue increased to supraphysiological levels in skeletal and cardiac muscle $(47,120)$. At 12 weeks of age, a striking 20-fold rise in cardiac TAG content was observed. As a result of the increase in TAG accumulation, cardiac function was severely hampered and the knock-out of ATGL resulted in cardiac failure and premature death (47). In humans, carriers of a ATGL polymorphism resulting in lower ATGL activity, possess excessive ectopic TAG accumulation along with myopathy (35).

Reduced TAG lipolysis in muscle of ATGL knock-out mice was paralleled by a decrease in fat oxidation and a concomitant increase in glucose oxidation during fasting and an unanticipated increased glucose uptake (47, 54). Increased glucose uptake by the muscle, despite excessive TAG storage, may reflect substrate availability; in the absence of ATGL activity, fatty acids cannot be released from the LD and can hence not be used as an energy source. Thus glucose uptake and oxidation must increase to meet the energy demand.

The relatively modest ( 2 fold) increase in adipose tissue mass and liver fat in ATGL knock-out mice (47), suggests that in these tissues ATGL may not be the major TAG lipase. In cardiac muscle and to a lesser extent in skeletal muscle, however, TAG storage in ATGL knock-out mice is more pronounced, suggesting an important role for ATGL-based lipolysis of TAG in muscle. Overexpression of ATGL in 3T3-L1 cells, COS-7 cells and HeLa cells $(46,63,124,142)$ and overexpression of the Brummer lipase (homologue of human ATGL) in Drosophila (46, 63, 124 , 142), resulted in increased TAG lipolysis and a concomitant decrease in LD size. Unilateral overexpression of ATGL in skeletal muscle increased oxidation of LD-derived fatty acids and increased insulin desensitizing lipid intermediates like DAG and ceramide (148), suggesting that increased ATGL activity was not matched with increased HSL activity. Thus, disequilibrium between ATGL and HSL activity may increase DAG content and impede insulin signaling. 
In diet-induced obese C57BL/6J mice and ob/ob mice low ATGL protein levels have been reported in muscle along with high muscle TAG storage $(65,142,148)$. In contrast to ATGL protein levels, however, ATGL mRNA expression was higher in skeletal muscle of C57BL/6J high-fat mice and ob/ob mice compared to non-obese controls (148). Similar observations have been made in subcutaneous adipose tissue of obese subjects where low ATGL protein content was observed along with high levels of ATGL mRNA (127), suggesting that post-transcriptional processes profoundly affect ATGL protein content. Despite the dissociation between mRNA expression and protein content, the above mentioned studies indicate an association between myocellular ATGL and obesity. In adipose tissue however, diet-induced obesity in mice did not affect ATGL protein content $(64,121)$, and ATGL mRNA levels in ob/ob mice were comparable to lean littermates (71). Similarly, in adipose tissue of obese humans, ATGL gene expression (81) or protein content (114) was comparable to non-obese subjects. Furthermore, in insulin resistant subjects, adipose tissue ATGL mRNA levels were lower compared to obese subjects with preserved insulin sensitivity irrespective of body fat mass or fat distribution (9).

In insulin resistant subjects, weight loss resulted in a decrease in ATGL and HSL mRNA- and protein level (61), but in non-insulin resistant subjects this decrease was not detected (81). However, the insulin resistant subjects were studied in negative energy balance, whereas the non-insulin resistant subjects were studied after energy balance was restored (81). In normoglycemic young man, exercise training resulted in increased ATGL protein in muscle without changes in HSL protein level but with a decline in muscle TAG content (4). Strikingly, exercise training in general improves insulin sensitivity, whereas the changes observed here could imply increased DAG levels which is supposed to impede insulin sensitivity. Unfortunately data on DAG or insulin sensitivity have not been reported in this study.

ATGL activity requires (co)activation by comparative gene identification-58 (CGI58), also known as $\alpha / \beta$-hydrolase domain containing 5 (ABHD5) $(74,120,160)$. CGI-58 stimulates TAG hydrolysis in wild-type and HSL deficient adipose tissue but fails to activate lipolysis in the absence of ATGL, suggesting that CGI-58 is not a lipase as such but rather facilitates lipolysis by ATGL but not HSL (120). ATGL 
activity was enhanced 20-fold in the presence of CGI-58 (74). Furthermore, a mutation in CGI-58 is associated with Chanarin-Dorfman Syndrome, a rare genetic disease resulting in excessive ectopic TAG accumulation. Re-introduction of functional CGI-58 normalizes the TAG content in peripheral tissues of these patients (74). These results indicate that CGI-58 is required to maximize the rate of TAG hydrolysis. Regulation of ATGL activity by CGI-58 requires interaction with lipid droplet coating proteins of the PAT family, which will be discussed in section 3.6.

Several studies have provided evidence that ATGL and HSL act coordinately in hydrolyzing triglycerides (73). The current hypothesis states that ATGL hydrolyzes the first ester bond of the TAG molecule whereas HSL preferentially degrades DAG $(36,120)$. Data indicate that this is the case for TAG stored in adipose tissue as well as for TAG stored ectopically. A disequilibrium in ATGL and HSL activation in insulin-responsive tissues like muscle may increase the content of the insulin desensitizing lipid intermediate DAG. So far, however, this putative disequilibrium has not been reported in muscle of type 2 diabetic subjects.

\section{MGL and other lipases}

Information on the role and regulation of monoacylglycerol lipase (MGL) is limited, especially for ectopically stored fat. Based on the specific affinity of ATGL for TAG and of HSL for DAG, also a lipase with a high specificity for MAG hydrolysis could be of importance in adipose tissue and skeletal muscle. In adipose tissue it has indeed been shown that MGL is of importance for complete hydrolysis of MAG (37). Experiments in murine white adipose tissue in vitro to examine the relative contribution of ATGL and HSL to total lipolysis revealed that joint action of ATGL and HSL is responsible for $95 \%$ of total hydrolytic activity (120), suggesting a quantitatively minor role for other lipases including MGL.

Triacylglycerol hydrolase (TGH) and triacylglycerol hydrolase homologue (TGH-2) are TAG specific lipolytic enzymes highly expressed in liver and adipose tissue (98). In contrast to ATGL and HSL, TGH and TGH-2 efficiently hydrolyse triacylglycerol comprised of short-chain fatty acids. Due to hepatic conversion of short-chain fatty acids into long-chain fatty acids by elongases, and the absence in muscle of a short 
chain fatty-acid specific synthase, the vast majority of the TAG stored in the human body comprises long-chain fatty acids. Whereas, the quantitative role of TGH and TGH-2 in hydrolysis of hepatic TAG may be highly relevant, its role in hydrolysis of myocellular TAG may be less prominent.

Jointly, ATGL and HSL can hydrolyse the vast majority of the TAG in adipose tissue and skeletal muscle, at present there is little reason suggesting that defects in hydrolysis of MAG in skeletal muscle can play a major role in modulating lipid desensitizing intermediates in skeletal muscle.

\section{Lipid droplet coating proteins}

The lipid droplet (LD) is coated by a phospholipid monolayer decorated with a family of proteins, referred to as PAT proteins characterized by a common N-terminal motif. PAT refers to perilipin, ADRP and TIP47, but the PAT family also comprises S3-12 and OXPAT, two proteins with sequence homology and/or similar function as the originally identified PAT proteins. Each of these PAT proteins has a unique tissue distribution and lipid binding properties. In addition, all PAT proteins identified so-far can localize to LD, whereas TIP47 are also present in other subcellular compartments. It is thus likely that the different PAT proteins may have (at least partly) distinct roles in TAG management.

\section{Perilipin}

In adipose tissue, activation of perilipin by phosphorylation is required for full activation of HSL related hydrolysis. Perilipin is the predominant PAT protein in adipose tissue involved in control of storage and degradation of lipid stored in the LD $(1,39$, 125, 126). Expression of perilipin is under control of the transcription factor PPAR $\gamma$ $(1,6,26)$ and perilipin is predominantly found on the LD of adipose tissue $(10,43$, 103). In the fed state and in the presence of insulin, perilipin is not phosphorylated on PKA site serines and coats the LD in adipose tissue $(32,89)$, thereby limiting lipolytic activity of HSL to lipid stored in the LD $(15,88)$. In contrast, under lipolytic conditions, perilipin gets phosphorylated by PKA $(15,43,44)$ allowing HSL to access 
the $\operatorname{LD}(88,91,126,132,133)$. In line with this, TAG levels in adipose tissue of perilipin knock-out mice $(83,133)$ and in cells lacking perilipin is reduced $(15,83$, 88), suggesting a pivotal role for perilipin in regulating HSL activity. Despite higher lean body mass and an increased metabolic rate, perilipin null mice tend to develop glucose intolerance and peripheral insulin resistance (115). Interestingly, perilipin levels in adipose tissue from obese zucker rats and obese humans appears lower than in lean controls if matched for fat cell mass $(26,91,144)$. It is important to note that most of the data on regulation of lipolyis of lipid stored in LD and of interaction of perilipin with HSL has been published in the pre-ATGL era and it can hence not be excluded that part of these observations have been biased by lipase activity of ATGL, which by then, was not yet discovered.

Although hydrolysis of TAG in myocellular LD involves HSL activity, skeletal muscle is devoid of perilipin. Rather, adrenaline and contractile activity-associated increases in TAG hydrolysis in myocellular LD goes along with recruitment of HSL to ADRP and TIP-47 coated LD (105) suggesting that these PAT proteins may be myocellular analogues of perilipin that operate in muscle to control basal and stimulated lipolysis.

\section{$A D R P$}

Shortly after the discovery of perilipin, adipose differentiation-related protein (ADRP) was identified $(34,59)$. ADRP is expressed in a wider range of tissues than perilipin $(13,50)$, including rodent and human skeletal muscle $(103,105)$. ADRP is involved in the uptake of long-chain fatty acids from the cytoplasm and incorporation of fatty acids in $\operatorname{LD}(20,38,76,80,85)$. In livers from ob/ob mice (116), and etomoxir (i.e. CPT-1 inhibitor) treated rats (128) and in specific diseases states involving ectopic fat accumulation $(50,90)$ ADRP expression is increased.

Like perilipin, ADRP decorates the LD membrane, thus affecting lipolytic activity of ATGL and recruitment of another PAT protein, TIP47, to the lipid droplet $(76,97)$. In ADRP expressing tissues, hydrolysis of TAG in LD might indeed be under control of ADRP $(105,150)$. Tissue specific and whole body knock-out studies of ADRP resulted in resistance to diet-induced hepatic steatosis while adipocyte differentiation 
and lipolysis were unaffected (20). The absence of changes in adipogenesis may originate from a compensatory induction of TIP47. In ADRP knock-out cells with concomitant siRNA mediated downregulation of TIP47, LD formation was attenuated and fatty acids added to the system incorporated into phospholipids in cellular membranes other than LD (131). Downregulation of hepatic ADRP using anti-sense oligonucleotides reduced hepatic steatosis, hypertriglyceridemia, and insulin resistance in obese mice (55) and rescued diet-induced obese mice from developing insulin resistance. These favorable effects were attributed to lower levels of the insulin desensitizing lipid intermediate DAG in the livers of the treated animals (140).

ADRP may also be involved in regulating subcellular localization of the LD. In preadipocytes ADRP associates with the intermediate filament protein vimentin $(10,43$, 103) suggesting that intracellular trafficking of the lipid droplets may occur. This notion was substantiated by the observation that the microtubular motor protein dynein -allowing the droplet to move within the cell along the microtubular systemco-precipitated with ADRP (12). Extending these observations to skeletal muscle is intriguing; in mature skeletal muscle, LD can be found in a highly organized manner along myofibrils and adjacent to Z-discs (figure 1) in direct vicinity of the Z-disc interconnecting intermediate filament desmin (102). The highly organized subcellular structure of skeletal muscle is initiated during differentiation when vimentin expression decreases and desmin expression increases, allowing alignment of myofibrils in a regular array of Z-discs interconnected by desmin (139). In this respect, it is interesting to note that in fully differentiated skeletal muscle the motor protein dynein and a microtubular network machinery both are present to traffic nascent LD from the ER towards a location in vicinity of the Z-disc and in association with mitochondria. 

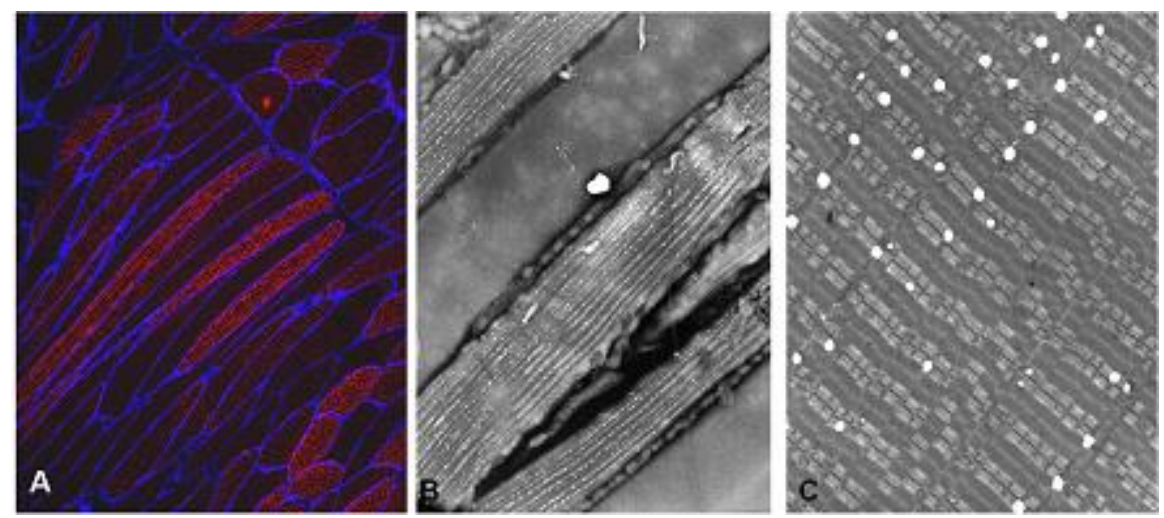

Figure 1. Lipid droplets in skeletal muscle are deposited in a highly organized manner, revealing a string of punctate red lipid droplets if examined in OilredO stained sections imaged by fluorescence microscopy (panel a). If examined using WETSEM technology imaged by low-power electron microscopy (137), lipid droplets appear in strings of punctate white lipid droplets (panel b). In glutaraldehyde fixed, osmiumtetroxide post-fixed and uranylacetate stained ultra-thin sections examined in transmission electron microscopy, lipid droplets can be observed adjacent to Z-discs and mitochondria in skeletal muscle (panel c).

In 3T3-L1 preadipocytes and in early stages of differentiating 3T3-L1 adipocytes, the gene encoding for ADRP is induced and ADRP protein content increases $(13,59)$. In fully differentiated adipocytes, however, ADRP protein levels drop, despite the persistence of high levels of ADRP mRNA. At the protein level it has been shown that maintenance of ADRP content highly depends on the amount of neutral lipids present in the cell. ADRP which is not bound to neutral lipids is post-translationally targeted for proteasomal degradation $(84,157)$.

Like perilipin, the ADRP promoter contains a PPAR-responsive element. Likewise, ADRP gene expression can be stimulated by PPAR $\alpha-(25,27,134)$ and PPAR $\beta / \delta$ ligands $(21,118)$. It remains uncertain whether PPAR $\gamma$ is also involved, since several investigations present conflicting results (reviewed in (27)).

TIP47

Another member of the PAT protein family is the $47 \mathrm{kDa}$ protein TIP47 (also known as pp17 (136)). TIP47 is ubiquitously expressed (26) and shares $43 \%$ homology with ADRP (8). TIP47 gene expression is not regulated by PPAR $\gamma(26,27)$. Originally, TIP47 was described to be a mannose-6-phosphate receptor sorting device $(8,29)$. However, knock down of TIP47 had no effect on mannose-6-phosphate receptors, 
but did affect LD biogenesis, lipid incorporation and lipid liberation (17). Knockingout ADRP in human hepatocytes (Huh7) cells or in immortalized fibroblasts derived from ADRP ablated embryonic cells, resulted in a compensatory increase in TIP47 $(97,131)$.

In contrast to ADRP, cytosolic TIP47 that is not associated with neutral lipids is not degraded but may translocate to nascent LD allowing LD growth $(87,97,153)$. Studies using freeze fracture followed by immunogold labeling revealed that TIP47 and ADRP both are indeed extensively found in association with the LD membrane, but may also invade the LD (109-111). Thus, TIP47 may have a role in the packaging of neutral lipids into droplets as well $(17,153)$. Exactly how TIP47 exerts its role, especially in skeletal muscle lipid droplet packaging, however, remains to be established.

\section{S3-12}

The PAT member family with the lowest sequence homology to the other PAT proteins is S3-12 (117). S3-12 shares a 33 amino acid motif with ADRP and has a protein sequence identity of 50\% with both TIP47 and ADRP (79) but does not have a PAT domain. S3-12 mRNA is induced in early stages of adipocyte differentiation (117), and coats nascent lipid droplets during TAG synthesis in 3T3-L1 adipocytes $(151,154)$. S3-12 is highly expressed in WAT and to a lesser, but detectable, extent in BAT, cardiac and skeletal muscle (117). Transcriptional regulation of S3-12 has been shown to be PPAR $\gamma$ dependent (26). So far, little data is available on the exact role of S3-12 in muscle lipid metabolism.

\section{OXPAT/MLDP/LSDP5}

Three independent labs recently identified a new PAT domain containing LD coating protein expressed mainly in tissues with a high capacity for fat oxidation, like (type 1) muscle fibers, cardiac muscle, brown adipose tissue and liver. This tissue expression profile resulted in the protein being named OXPAT (152). The same protein has also been identified in the myocardium and was named Myocardial Lipid Droplet Protein (MLDP) (158) while a $3^{\text {rd }}$ research group named the protein Lipid Storage Droplet Protein (LSDP5) (25). Throughout this review we will use the name OX- 
PAT. The primary structure of OXPAT shares a high degree of homology to ADRP and TIP47 (25). Importantly, OXPAT has the same PAT domain as the other PAT proteins, but has its own unique tissue expression pattern. Via mechanism(s) not yet identified, OXPAT promotes both long chain fatty acids esterification into TAG as well as long chain fatty acid oxidation (152). Since there is a significant overlap in tissues expressing OXPAT en S3-12 it has been suggested that OXPAT and S3-12 are coordinately and reciprocally regulated (152). However, detailed information on the concordant regulation of S3-12 and OXPAT is currently lacking.

Twelve hours of fasting increased OXPAT mRNA and 24 hours of fasting increased OXPAT protein expression in liver and to a lesser extent in other tissues like the heart. After 12 hours of refeeding OXPAT mRNA levels had returned to baseline levels (25). Interestingly, in the highly oxidative soleus muscle, the already abundant levels of OXPAT did not respond to fasting or refeeding. Activation of PPAR $\alpha$ induced OXPAT expression in wild type mice, but not in PPAR $\alpha$ knock out mice, suggesting that the presence of PPAR $\alpha$ is required for induction of the OXPAT gene. Fasting increased OXPAT mRNA levels in wild type mice, but for reasons not yet understood, also in the PPAR $\alpha$ knock out animals. It should be noted, though, that due to a considerably lower baseline expression of OXPAT in the PPAR $\alpha$ knock-out mice, OXPAT mRNA content upon fasting did not reach the levels observed in fed wild type mice. Thus, it can be concluded that fasting-induced increases in OXPAT expression does not require a functional PPAR $\alpha$ gene whereas functional PPAR $\alpha$ is important for basal expression of OXPAT in liver and heart $(25,152,158)$ Interestingly, mice and humans treated with Pioglitazone (a PPAR $\gamma$ agonist with PPAR $\alpha$ affinity) increased gene expression of OXPAT in adipose tissue but not in skeletal muscle (152). Recently, we showed that in skeletal muscle from humans that OXPAT protein content in obese control subject was comparable to levels found in BMI matched type 2 diabetic patients. Interestingly, we also showed that upon Rosiglitazone-induced insulin sensitization OXPAT levels declined significantly without changes in myocellular LD content (86) 


\subsection{Lipid droplet binding proteins not related to the PAT family}

Full activation of ATGL requires interaction of a co-activator known as CGI-58 which in turn interacts with perilipin and ADRP on the surface of LD in 3T3-L1 cells $(41,130,159-161)$. It has been hypothesized that physical association of ATGL with CGI-58 requires release of CGI-58 from the (adipocyte) droplet to exert full lipolytic activity of ATGL $(130,160)$. Experimental data in 3T3-L1 adipocytes indicate that in the basal condition CGI-58 strongly interacts with perilipin. Upon phosphorylation of perilipin, CGI-58 detaches from perilipin and is released from the droplet to translocate and interact with ATGL at the surface of small LD at sites devoid of perilipin (41).

Given the ubiquitous expression of CGI-58 and the multiple tissues expressing ATGL, it is likely that activation of TG hydrolysis by ATGL and its co-activation by CGI-58 is not restricted to adipose tissue, but is also operational in e.g. cardiac and skeletal muscle. The notion that CGI-58 might also be operational in skeletal muscle is substantiated by the observations that patients suffering from mutations in either the CGI-58 gene or in the ATGL gene present with severe muscle weakness and myopathies $(3,66))$. As perilipin is not present in muscle tissue, co-regulation of ATGL by CGI-58 in skeletal muscle most likely involves other (PAT) protein(s). Indeed it has recently been shown in mouse cardiac myocytes that in virtually all OXPAT containing LD also CGI-58 was detected. In LD mainly coated by ADRP no such interaction was observed. Loading cardiac myocytes with oleate promoted interaction of OXPAT with CGI-58 and appeared critical in regulating ATGL lipolytic acivity in OXPAT containing LD (42).

By detailed examination of multiple proteins undergoing major changes in expression during adipogenesis, two members of the Cide domain-coating proteins, CideA and CideC (also known as Fat-specific Protein 27, FSP27) have recently been identified as LD binding proteins $(62,95,106,107,138)$. These proteins appear to be involved in the negative regulation of lipolysis and hence in LD morphology and LD dynamics in a perilipin like manner (106). Ectopically overexpressed CideC colocalizes to perilipin (106), suggesting interaction of both proteins in facilitating LD lipolysis. 
CideA is predominantly expressed in BAT, with small amounts of mRNA detected in a.o. cardiac and skeletal muscle. CideC is more widespread, with high levels in WAT and moderate levels in BAT and skeletal muscle (155). Overexpression of CideA and CideC blunts lipid droplet degradation and results in increased ectopic fat storage (106). Downregulation of CideA using RNAi markedly elevates lipolysis in human adipocytes (107). Transcriptional rate of both CideA and CideC are controlled by PPAR $\gamma$. Hence, treating mice with rosiglitazone induced CideA gene expression and lipid deposition in WAT (107). In humans, expression of CideA and CideC correlates positively with insulin sensitivity. A third member of this family, CideB appears to be involved in hepatic fat storage. Indeed, CideB knock-out mice possessed reduced high fat diet-induced hepatic steatosis, lower circulatory plasma TG's and were insulin sensitive (75).

In search for binding proteins to pigment epithelium derived factors (PEDF), Notari et al. serendipitously identified ATGL as a PEDF binding protein (96) where ATGL exerts lipase activity to phospholipids (96). Interestingly, PEDF co-precipitates with ATGL in hepatocytes (22) and the lack of PEDF with subsequent reintroduction was associated with significant increases in steatosis and normalization towards control values, respectively (22). Thus, via binding to ATGL, PEDF may have a role in hepatic triglyceride homeostasis, and hence insulin sensitivity. Indeed, it has recently been shown that administrating PEDF to mice stimulated adipose tissue lipolysis, augmented ectopic lipid deposition, and reduced insulin sensitivity. On the other hand, antibody-based neutralisation of PEDF in obese mice enhanced insulin sensitivity (24). Overall, these results identify a causal role for PEDF in obesity-induced insulin resistance.

At this stage, it seems save to conclude that next to the PAT proteins, also other proteins start to emerge with a role in LD dynamics. It is, however, not yet fully understood how these proteins may interact to exert their role in modulation of LD dynamics. 


\section{Lipid droplet formation}

Information on formation, maturation and potential trafficking of LD in different cell types or tissues is still fragmentary, and not always consistent. As reviewed by several authors $(16,82,92,93,150)$, it has been hypothesized that neutral lipids are deposited between the leaflets of the ER membrane and then budded into the cytoplasm to form a primordial LD. LD coating proteins might be either integral ER membrane proteins or may be added to the growing LD from the cytosol. Proteins coating the LD may originate from proteins resident in the cytoplasmic leaflet of ER membranes $(16,99)$. In contrast it has been shown that the fatty acid composition of LD phospholipids differed from that of rough ER phospholipids (135), reducing the likeliness that these droplets indeed originally budded from the ER. Alternatively, LD may be formed at specialized ADRP-enriched domains on the cytoplasmic surface of the ER (108).

At present, none of the existing models fully explains how TAG is incorporated into ER associated LD.

\section{Lipid droplet growth}

Upon formation, LD continue to grow until they reach their mature size and the amount of TAG in the LD increases. The rate limiting enzyme in TAG synthesis is diacylglycerol acyl-transferase (DGAT) which converts DAG into TAG. Hence, involvement of DGAT in TAG accretion in the LD and hence increased LD size is anticipated (see figure 2). DGAT is present in 2 isoforms. DGAT1 and DGAT2 both have been located to the ER, albeit at distinct regions $(18,19)$. Fluorescence microscopy of polyene labeled lipids revealed the presence of DAG to the outside of LD in COS7 cells (70). It has been shown that DGAT2 localizes to the ER under basal conditions and was targeted to the surface of LD in COS7 cells upon oleate loading (129) and that endogenous DGAT2 was localized to the vicinity of LD in 3T3-L1 adipocytes (70). This model is compatible with the origin of LD from the ER and demonstrates that LD can grow in size by inflow of TAG synthesized by DGAT2. Whether DGAT2 and DAG also localize to the LD in other cell types than fibroblasts 
and adipocytes, and how newly formed TAG enters the lipid droplet is not yet known.

Recently, Olofsson et al. hypothesized that primordial droplets are trafficking in the cytosol and fuse in vicinity of other LD (11). Fusion of LD requires membrane fusion of the lipid droplet coating phospholipids monolayers, in a process facilitated by SNAP23 (11). Physical interaction of myocellular LD under TAG storing conditions (DGAT 1 overexpression combined with high fat diet) is shown in figure $2 b$. Interestingly, fusion of GLUT4 containing vesicles with the sarcolemma upon insulin stimulation also requires SNAP23 (for review see Huang and Czech (53)). Increasing the amount of SNAP23 to the membrane of LD upon oleate loading resulted in reduced GLUT4 fusion with the sarcolemma possibly due to the low levels of SNAP remaining for GLUT4 membrane fusion (11). In line with this, overexpressing SNAP23 rescued oleate mediated insulin resistance (11).
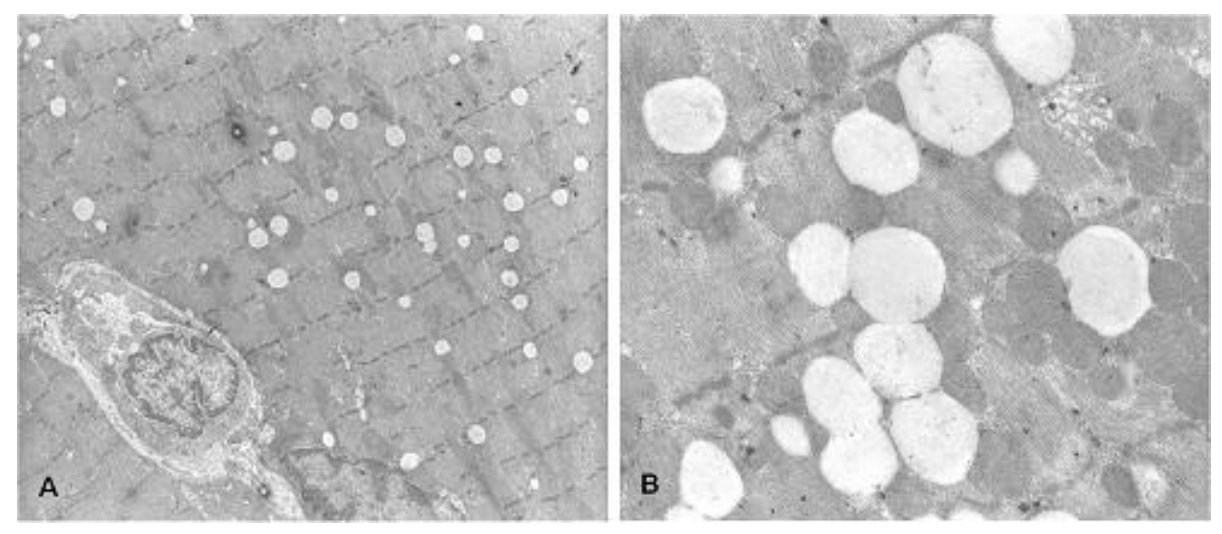

Figure 2. Transmission electron microscopy image of glutaraldehyde fixed, osmiumtetroxide post-fixed, epon embedded and uranylacetate stained ultra-thin section of muscle overexpressing DGAT1 along with consumption of a high-fat diet (113). This model resulted in large LD scattered throughout the muscle cell (panel A) and some LD appear physically very close or even interconnected creating the physical condition for LD fusion (panel B).

Involvement of PAT proteins in trafficking of LD has been hypothesized and partly been proven by Wolins et al. (150). In his model PAT proteins are classified based on their stability if not bound to neutral lipids (150). Perilipin and ADRP can be classified as proteins requiring neutral lipids to maintain stability in the absence of neutral lipids. Perilipin and ADRP are degraded via the ubiquitin/proteasome $(156,157)$. 
Tip47, S3-12 and OXPAT, on the other hand, are situated in the cytosolic pool under non-lipid loading conditions and may translocate to nascent LD upon lipid loading (150). In line with this, in 3T3-L1 cells incubated with long chain fatty acids TAGfilled droplets coated with TIP47, S3-12 and ADRP appear. Subsequent, S3-12 and TIP47 coat the smallest and most peripheral LD, whereas ADRP coats a more medial population of larger $\operatorname{LD}(151,154)$, and the largest droplets are coated with perilipin. While part of this hypothesis has been confirmed in adipocytes, it should be noted that only adipocytes express all 5 members of the PAT family at significant levels. Most other cell types express 2, or at most 3 PAT proteins.

\section{Lipid droplet dynamics and insulin resistance}

Obviously, tight interaction of PAT proteins and well balanced activity of lipases is required to effectively store fatty acids in LD in times of lipid overflow and for controlled release of fatty acids in times of enhanced demand. Dysregulation of any of these processes might lead to disturbed LD synthesis and/or LD degradation resulting in a rise in insulin desensitizing intermediates. It is therefore of importance to improve our understanding of regulation of lipid synthesis and degradation in ectopically stored LD and the proteins involved. This type of information in humans, and especially in patient populations, is largely lacking and mainly associative. For example, lower perilipin protein levels have been reported in adipose tissue from obese vs. lean women $(91,144)$. Another study investigated the relation between ADRP and insulin sensitivity in skeletal muscle after a weight loss intervention program and after a pharmacological intervention program with troglitazone (103). Although a correlation between ADRP and insulin sensitivity was not detectable at baseline, ADRP in skeletal muscle was significant increased after treatment and correlated with improved insulin sensitivity (103). Furthermore, a population of 85 nondiabetic subjects with a wide range of BMI and insulin sensitivity was investigated and a negative correlation between OXPAT gene expression in adipose tissue and BMI was found (152). From these data cause and consequence can not be separated and other processes which were not examined may also contribute to, or even cause, the observed correlation between OXPAT and BMI (152). 


\section{Perspective and significance}

For decades, intracellular lipid droplets (LD) in non-adipose tissue have been considered to be relatively inert sites of fat storage which are well preserved across species and can be found in a wide variety of sizes and quantities in various tissues. In lipid bodies in adipocytes, however, it has been recognized that synthesis and degradation of lipid in LD is a fairly dynamic process. Predominantly arising from reports in adipocytes and progress in the imaging of lipid droplets in live cells, the body of knowledge on LD dynamics and the proteins involved has rapidly expanded recently. Defects in LD dynamics have been linked to multiple disorders in lipid and lipoprotein metabolism, and may contribute to the insulin desensitizing effects of lipid intermediates (partly originating from LD), in insulin responsive tissues like adipose tissue, liver and cardiac and skeletal muscle.

Hydrolysis of lipid stored in LD is catalyzed by the concerted action of distinct lipases which differ in their affinity for triacyl-, diacyl or monoacylglycerol. In muscle, the 2 most abundant and best described lipases identified so far are HSL and ATGL. These lipases regulate -both positively and negatively- the rate of lipolysis by tight cooperation with a family of structurally related lipid droplet coating proteins (Perilipin, ADRP, TIP47, S3-12 and OXPAT, collectively referred to as PAT proteins) and with co-activators like CGI-58. While expression of perilipin appears to be restricted to adipose tissue, the other PAT proteins can be found in other cell types as well. Adrenergic stimulated lipolysis in adipose tissues results in PKA mediated phosphorylation of perilipin which recruits HSL to the LD surface to stimulate lipolysis. In addition, PKA activation results in dissociation of CGI-58 from the LD in a perilipin dependent manner allowing ATGL based lipolysis. Prolonged PKA mediated lipolysis results in smaller LD decorated with ADRP, TIP47 and S3-12.

While interaction of CGI-58 with ADRP has been described as well, it remains unclear if and in which tissues this interaction affects lipolytic rate. In muscle, interaction of OXPAT with CGI-58 appears to be critical in regulating lipolytic activity of ATGL, but more work is needed to test to what extent information derived from other tissues or cell types can be translated towards (human) skeletal muscle. 
The rapid expansion of our knowledge on involvement of PAT proteins, their putative interaction with lipases in the regulation of lipolysis of lipid droplets plus the emerging body of knowledge from cell studies towards LD growth and fusion extends the field to further explore the mechanisms involved in (dys)regulation of LD dynamics in ectopically stored fat in insulin responsive tissues like liver and (skeletal) muscle. With this area of research emerging, targets to modulate ectopic fat storage, in terms of synthesis, degradation and lipid turnover, may be identified in the near future and may shed new light on routes to rescue myocellular insulin resistance, the hallmark in the development of overt type 2 diabetes. 


\section{References}

1. Aboulaich N, Vener AV, and Stralfors P. Hormonal control of reversible translocation of perilipin $\mathrm{B}$ to the plasma membrane in primary human adipocytes. J Biol Chem 281: 11446-11449, 2006.

2. Abumrad NA, Tepperman HM, and Tepperman J. Control of endogenous triglyceride breakdown in the mouse diaphragm. J Lipid Res 21: 149-155, 1980.

3. Akiyama M, Sakai K, Ogawa M, McMillan JR, Sawamura D, and Shimizu H. Novel duplication mutation in the patatin domain of adipose triglyceride lipase (PNPLA2) in neutral lipid storage disease with severe myopathy. Muscle Nerve 36: 856-859, 2007.

4. Alsted TJ, Nybo L, Schweiger M, Fledelius C, Jacobsen P, Zimmermann R, Zechner R, and Kiens B. Adipose triglyceride lipase in human skeletal muscle is upregulated by exercise training. Am J Physiol Endocrinol Metab 296: E445-453, 2009.

5. Anthonsen MW, Ronnstrand L, Wernstedt C, Degerman E, and Holm C. Identification of novel phosphorylation sites in hormone-sensitive lipase that are phosphorylated in response to isoproterenol and govern activation properties in vitro. J Biol Chem 273: 215 221, 1998.

6. Arimura N, Horiba T, Imagawa M, Shimizu M, and Sato R. The peroxisome proliferatoractivated receptor gamma regulates expression of the perilipin gene in adipocytes. J Biol Chem 279: 10070-10076, 2004.

7. Athenstaedt K and Daum G. Tg14p and Tgl5p, two triacylglycerol lipases of the yeast Saccharomyces cerevisiae are localized to lipid particles. J Biol Chem 280: 37301-37309, 2005.

8. Barbero P, Buell E, Zulley S, and Pfeffer SR. TIP47 is not a component of lipid droplets. J Biol Chem 276: 24348-24351, 2001.

9. Berndt J, Kralisch S, Kloting N, Ruschke K, Kern M, Fasshauer M, Schon MR, Stumvoll $\mathrm{M}$, and Bluher M. Adipose triglyceride lipase gene expression in human visceral obesity. Exp Clin Endocrinol Diabetes 116: 203-210, 2008.

10. Blanchette-Mackie EJ, Dwyer NK, Barber T, Coxey RA, Takeda T, Rondinone CM, Theodorakis JL, Greenberg AS, and Londos C. Perilipin is located on the surface layer of intracellular lipid droplets in adipocytes. J Lipid Res 36: 1211-1226, 1995.

11. Bostrom P, Andersson L, Rutberg M, Perman J, Lidberg U, Johansson BR, FernandezRodriguez J, Ericson J, Nilsson T, Boren J, and Olofsson SO. SNARE proteins mediate fusion between cytosolic lipid droplets and are implicated in insulin sensitivity. Nat Cell Biol 9: 1286-1293, 2007.

12. Bostrom P, Rutberg M, Ericsson J, Holmdahl P, Andersson L, Frohman MA, Boren J, and Olofsson SO. Cytosolic lipid droplets increase in size by microtubule-dependent complex formation. Arterioscler Thromb Vasc Biol 25: 1945-1951, 2005.

13. Brasaemle DL, Barber T, Wolins NE, Serrero G, Blanchette-Mackie EJ, and Londos C. Adipose differentiation-related protein is an ubiquitously expressed lipid storage dropletassociated protein. J Lipid Res 38: 2249-2263, 1997.

14. Brasaemle DL, Levin DM, Adler-Wailes DC, and Londos C. The lipolytic stimulation of 3T3-L1 adipocytes promotes the translocation of hormone-sensitive lipase to the surfaces of lipid storage droplets. Biochim Biophys Acta 1483: 251-262, 2000.

15. Brasaemle DL, Rubin B, Harten IA, Gruia-Gray J, Kimmel AR, and Londos C. Perilipin A increases triacylglycerol storage by decreasing the rate of triacylglycerol hydrolysis. $\mathrm{J}$ Biol Chem 275: 38486-38493, 2000.

16. Brown DA. Lipid droplets: proteins floating on a pool of fat. Curr Biol 11: R446-449, 2001. 
17. Bulankina AV, Deggerich A, Wenzel D, Mutenda K, Wittmann JG, Rudolph MG, Burger $\mathrm{KN}$, and Honing S. TIP47 functions in the biogenesis of lipid droplets. J Cell Biol 185: 641-655, 2009.

18. Cases S, Smith SJ, Zheng YW, Myers HM, Lear SR, Sande E, Novak S, Collins C, Welch $\mathrm{CB}$, Lusis AJ, Erickson SK, and Farese RV, Jr. Identification of a gene encoding an acyl CoA:diacylglycerol acyltransferase, a key enzyme in triacylglycerol synthesis. Proc Natl Acad Sci U S A 95: 13018-13023, 1998.

19. Cases S, Stone SJ, Zhou P, Yen E, Tow B, Lardizabal KD, Voelker T, and Farese RV, Jr. Cloning of DGAT2, a second mammalian diacylglycerol acyltransferase, and related family members. J Biol Chem 276: 38870-38876, 2001.

20. Chang BH, Li L, Paul A, Taniguchi S, Nannegari V, Heird WC, and Chan L. Protection against fatty liver but normal adipogenesis in mice lacking adipose differentiation-related protein. Mol Cell Biol 26: 1063-1076, 2006.

21. Chawla A, Lee CH, Barak Y, He W, Rosenfeld J, Liao D, Han J, Kang H, and Evans RM. PPARdelta is a very low-density lipoprotein sensor in macrophages. Proc Natl Acad Sci U S A 100: 1268-1273, 2003.

22. Chung C, Doll JA, Gattu AK, Shugrue C, Cornwell M, Fitchev P, and Crawford SE. Antiangiogenic pigment epithelium-derived factor regulates hepatocyte triglyceride content through adipose triglyceride lipase (ATGL). J Hepatol 48: 471-478, 2008.

23. Clifford GM, Londos C, Kraemer FB, Vernon RG, and Yeaman SJ. Translocation of hormone-sensitive lipase and perilipin upon lipolytic stimulation of rat adipocytes. J Biol Chem 275: 5011-5015, 2000.

24. Crowe S, Wu LE, Economou C, Turpin SM, Matzaris M, Hoehn KL, Hevener AL, James DE, Duh EJ, and Watt MJ. Pigment epithelium-derived factor contributes to insulin resistance in obesity. Cell Metab 10: 40-47, 2009.

25. Dalen KT, Dahl T, Holter E, Arntsen B, Londos C, Sztalryd C, and Nebb HI. LSDP5 is a PAT protein specifically expressed in fatty acid oxidizing tissues. Biochim Biophys Acta 1771: 210-227, 2007.

26. Dalen KT, Schoonjans K, Ulven SM, Weedon-Fekjaer MS, Bentzen TG, Koutnikova H, Auwerx J, and Nebb HI. Adipose tissue expression of the lipid droplet-associating proteins S3-12 and perilipin is controlled by peroxisome proliferator-activated receptorgamma. Diabetes 53: 1243-1252, 2004.

27. Dalen KT, Ulven SM, Arntsen BM, Solaas K, and Nebb HI. PPARalpha activators and fasting induce the expression of adipose differentiation-related protein in liver. J Lipid Res 47: 931-943, 2006.

28. Degerman E, Landstrom TR, Wijkander J, Holst LS, Ahmad F, Belfrage P, and Manganiello V. Phosphorylation and activation of hormone-sensitive adipocyte phosphodiesterase type 3B. Methods 14: 43-53, 1998.

29. Diaz E and Pfeffer SR. TIP47: a cargo selection device for mannose 6-phosphate receptor trafficking. Cell 93: 433-443, 1998.

30. Donsmark M, Langfort J, Holm C, Ploug T, and Galbo H. Contractions activate hormonesensitive lipase in rat muscle by protein kinase $\mathrm{C}$ and mitogen-activated protein kinase. $\mathrm{J}$ Physiol 550: 845-854, 2003.

31. Eastmond PJ. SUGAR-DEPENDENT1 encodes a patatin domain triacylglycerol lipase that initiates storage oil breakdown in germinating Arabidopsis seeds. Plant Cell 18: 665675, 2006.

32. Egan JJ, Greenberg AS, Chang MK, and Londos C. Control of endogenous phosphorylation of the major cAMP-dependent protein kinase substrate in adipocytes by insulin and beta-adrenergic stimulation. J Biol Chem 265: 18769-18775, 1990.

33. Egan JJ, Greenberg AS, Chang MK, Wek SA, Moos MC, Jr., and Londos C. Mechanism of hormone-stimulated lipolysis in adipocytes: translocation of hormone-sensitive lipase to the lipid storage droplet. Proc Natl Acad Sci U S A 89: 8537-8541, 1992. 
34. Eisinger DP and Serrero G. Structure of the gene encoding mouse adipose differentiationrelated protein (ADRP). Genomics 16: 638-644, 1993.

35. Fischer J, Lefevre C, Morava E, Mussini JM, Laforet P, Negre-Salvayre A, Lathrop M, and Salvayre R. The gene encoding adipose triglyceride lipase (PNPLA2) is mutated in neutral lipid storage disease with myopathy. Nat Genet 39: 28-30, 2007.

36. Fredrikson G, Stralfors P, Nilsson NO, and Belfrage P. Hormone-sensitive lipase of rat adipose tissue. Purification and some properties. J Biol Chem 256: 6311-6320, 1981.

37. Fredrikson G, Tornqvist H, and Belfrage P. Hormone-sensitive lipase and monoacylglycerol lipase are both required for complete degradation of adipocyte triacylglycerol. Biochim Biophys Acta 876: 288-293, 1986.

38. Gao J and Serrero G. Adipose differentiation related protein (ADRP) expressed in transfected COS-7 cells selectively stimulates long chain fatty acid uptake. J Biol Chem 274: 16825-16830, 1999.

39. Garcia A, Subramanian V, Sekowski A, Bhattacharyya S, Love MW, and Brasaemle DL. The amino and carboxyl termini of perilipin a facilitate the storage of triacylglycerols. $\mathrm{J}$ Biol Chem 279: 8409-8416, 2004.

40. Goodpaster BH, He J, Watkins S, and Kelley DE. Skeletal muscle lipid content and insulin resistance: evidence for a paradox in endurance-trained athletes. J Clin Endocrinol Metab 86: 5755-5761, 2001.

41. Granneman JG, Moore HP, Granneman RL, Greenberg AS, Obin MS, and Zhu Z. Analysis of lipolytic protein trafficking and interactions in adipocytes. J Biol Chem 282: 5726$5735,2007$.

42. Granneman JG, Moore HP, Mottillo EP, and Zhu Z. Functional interactions between Mldp (LSDP5) and Abhd5 in the control of intracellular lipid accumulation. J Biol Chem 284: 3049-3057, 2009.

43. Greenberg AS, Egan JJ, Wek SA, Garty NB, Blanchette-Mackie EJ, and Londos C. Perilipin, a major hormonally regulated adipocyte-specific phosphoprotein associated with the periphery of lipid storage droplets. J Biol Chem 266: 11341-11346, 1991.

44. Greenberg AS, Egan JJ, Wek SA, Moos MC, Jr., Londos C, and Kimmel AR. Isolation of cDNAs for perilipins A and B: sequence and expression of lipid droplet-associated proteins of adipocytes. Proc Natl Acad Sci U S A 90: 12035-12039, 1993.

45. Greenberg AS, Shen WJ, Muliro K, Patel S, Souza SC, Roth RA, and Kraemer FB. Stimulation of lipolysis and hormone-sensitive lipase via the extracellular signal-regulated kinase pathway. J Biol Chem 276: 45456-45461, 2001.

46. Gronke S, Mildner A, Fellert S, Tennagels N, Petry S, Muller G, Jackle H, and Kuhnlein RP. Brummer lipase is an evolutionary conserved fat storage regulator in Drosophila. Cell Metab 1: 323-330, 2005.

47. Haemmerle G, Lass A, Zimmermann R, Gorkiewicz G, Meyer C, Rozman J, Heldmaier G, Maier R, Theussl C, Eder S, Kratky D, Wagner EF, Klingenspor M, Hoefler G, and Zechner R. Defective lipolysis and altered energy metabolism in mice lacking adipose triglyceride lipase. Science 312: 734-737, 2006.

48. Haemmerle G, Zimmermann R, Hayn M, Theussl C, Waeg G, Wagner E, Sattler W, Magin TM, Wagner EF, Zechner R, and van Ea. Hormone-sensitive lipase deficiency in mice causes diglyceride accumulation in adipose tissue, muscle, and testis. J Biol Chem 277: 4806-4815, 2002.

49. He J, Goodpaster BH, and Kelley DE. Effects of weight loss and physical activity on muscle lipid content and droplet size. Obes Res 12: 761-769, 2004.

50. Heid HW, Moll R, Schwetlick I, Rackwitz HR, and Keenan TW. Adipophilin is a specific marker of lipid accumulation in diverse cell types and diseases. Cell Tissue Res 294: 309321, 1998.

51. Holm C, Kirchgessner TG, Svenson KL, Fredrikson G, Nilsson S, Miller CG, Shively JE, Heinzmann C, Sparkes RS, Mohandas T, and et al. Hormone-sensitive lipase: sequence, 
expression, and chromosomal localization to 19 cent-q13.3. Science 241: 1503-1506, 1988.

52. Holm C, Osterlund T, Laurell H, and Contreras JA. Molecular mechanisms regulating hormone-sensitive lipase and lipolysis. Annu Rev Nutr 20: 365-393, 2000.

53. Huang S and Czech MP. The GLUT4 glucose transporter. Cell Metab 5: 237-252, 2007.

54. Huijsman E, van de Par C, Economou C, van der Poel C, Lynch GS, Schoiswohl G, Haemmerle G, Zechner R, and Watt MJ. Adipose triacylglycerol lipase deletion alters whole body energy metabolism and impairs exercise performance in mice. Am J Physiol Endocrinol Metab 297: E505-513, 2009.

55. Imai Y, Varela GM, Jackson MB, Graham MJ, Crooke RM, and Ahima RS. Reduction of hepatosteatosis and lipid levels by an adipose differentiation-related protein antisense oligonucleotide. Gastroenterology 132: 1947-1954, 2007.

56. Itani SI, Ruderman NB, Schmieder F, and Boden G. Lipid-induced insulin resistance in human muscle is associated with changes in diacylglycerol, protein kinase C, and IkappaB-alpha. Diabetes 51: 2005-2011, 2002.

57. Jacob S, Machann J, Rett K, Brechtel K, Volk A, Renn W, Maerker E, Matthaei S, Schick F, Claussen CD, and Haring HU. Association of increased intramyocellular lipid content with insulin resistance in lean nondiabetic offspring of type 2 diabetic subjects. Diabetes 48: 1113-1119, 1999.

58. Jenkins CM, Mancuso DJ, Yan W, Sims HF, Gibson B, and Gross RW. Identification, cloning, expression, and purification of three novel human calcium-independent phospholipase A2 family members possessing triacylglycerol lipase and acylglycerol transacylase activities. J Biol Chem 279: 48968-48975, 2004.

59. Jiang HP and Serrero G. Isolation and characterization of a full-length cDNA coding for an adipose differentiation-related protein. Proc Natl Acad Sci U S A 89: 7856-7860, 1992.

60. Jocken JW and Blaak EE. Catecholamine-induced lipolysis in adipose tissue and skeletal muscle in obesity. Physiol Behav 94: 219-230, 2008.

61. Jocken JW, Langin D, Smit E, Saris WH, Valle C, Hul GB, Holm C, Arner P, and Blaak EE. Adipose TriGlyceride Lipase (ATGL) and Hormone-Sensitive Lipase (HSL) protein expression is decreased in the obese insulin resistant state. J Clin Endocrinol Metab, 2007.

62. Keller P, Petrie JT, De Rose P, Gerin I, Wright WS, Chiang SH, Nielsen AR, Fischer CP, Pedersen BK, and MacDougald OA. Fat-specific protein 27 regulates storage of triacylglycerol. J Biol Chem 283: 14355-14365, 2008.

63. Kershaw EE, Hamm JK, Verhagen LA, Peroni O, Katic M, and Flier JS. Adipose triglyceride lipase: function, regulation by insulin, and comparison with adiponutrin. Diabetes 55: 148-157, 2006.

64. Kershaw EE, Schupp M, Guan HP, Gardner NP, Lazar MA, and Flier JS. PPARgamma regulates adipose triglyceride lipase in adipocytes in vitro and in vivo. Am J Physiol Endocrinol Metab 293: E1736-1745, 2007.

65. Kim JY, Tillison K, Lee JH, Rearick DA, and Smas C. The Adipose Tissue Triglyceride Lipase ATGL/PNPLA2 is Downregulated by Insulin and TNF \{alpha\} in 3T3-L1 Adipocytes and is a Target for Transactivation by PPAR \{gamma\}. Am J Physiol Endocrinol Metab, 2006.

66. Kobayashi K, Inoguchi T, Maeda Y, Nakashima N, Kuwano A, Eto E, Ueno N, Sasaki S, Sawada F, Fujii M, Matoba Y, Sumiyoshi S, Kawate H, and Takayanagi R. The lack of the C-terminal domain of adipose triglyceride lipase causes neutral lipid storage disease through impaired interactions with lipid droplets. J Clin Endocrinol Metab 93: $2877-$ 2884, 2008.

67. Kraemer FB, Patel S, Saedi MS, and Sztalryd C. Detection of hormone-sensitive lipase in various tissues. I. Expression of an HSL/bacterial fusion protein and generation of antiHSL antibodies. J Lipid Res 34: 663-671, 1993. 
68. Kralisch S, Klein J, Lossner U, Bluher M, Paschke R, Stumvoll M, and Fasshauer M. Isoproterenol, TNFalpha, and insulin downregulate adipose triglyceride lipase in 3T3-L1 adipocytes. Mol Cell Endocrinol 240: 43-49, 2005.

69. Krssak M, Falk Petersen K, Dresner A, DiPietro L, Vogel SM, Rothman DL, Roden M, and Shulman GI. Intramyocellular lipid concentrations are correlated with insulin sensitivity in humans: a 1H NMR spectroscopy study. Diabetologia 42: 113-116, 1999.

70. Kuerschner L, Moessinger C, and Thiele C. Imaging of lipid biosynthesis: how a neutral lipid enters lipid droplets. Traffic 9: 338-352, 2008.

71. Lake AC, Sun Y, Li JL, Kim JE, Johnson JW, Li D, Revett T, Shih HH, Liu W, Paulsen JE, and Gimeno RE. Expression, regulation, and triglyceride hydrolase activity of Adiponutrin family members. J Lipid Res 46: 2477-2487, 2005.

72. Langfort J, Ploug T, Ihlemann J, Saldo M, Holm C, and Galbo H. Expression of hormone-sensitive lipase and its regulation by adrenaline in skeletal muscle. Biochem J 340 ( Pt 2): 459-465, 1999.

73. Langin D, Dicker A, Tavernier G, Hoffstedt J, Mairal A, Ryden M, Arner E, Sicard A, Jenkins CM, Viguerie N, van Harmelen V, Gross RW, Holm C, and Arner P. Adipocyte lipases and defect of lipolysis in human obesity. Diabetes 54: 3190-3197, 2005.

74. Lass A, Zimmermann R, Haemmerle G, Riederer M, Schoiswohl G, Schweiger M, Kienesberger P, Strauss JG, Gorkiewicz G, and Zechner R. Adipose triglyceride lipasemediated lipolysis of cellular fat stores is activated by CGI-58 and defective in ChanarinDorfman Syndrome. Cell Metab 3: 309-319, 2006.

75. Li JZ, Ye J, Xue B, Qi J, Zhang J, Zhou Z, Li Q, Wen Z, and Li P. Cideb regulates dietinduced obesity, liver steatosis, and insulin sensitivity by controlling lipogenesis and fatty acid oxidation. Diabetes 56: 2523-2532, 2007.

76. Listenberger LL, Ostermeyer-Fay AG, Goldberg EB, Brown WJ, and Brown DA. Adipocyte differentiation-related protein reduces lipid droplet association of adipose triglyceride lipase and slows triacylglycerol turnover. J Lipid Res, 2007.

77. Liu LF, Purushotham A, Wendel AA, Koba K, DeIuliis J, Lee K, and Belury MA. Regulation of adipose triglyceride lipase by rosiglitazone. Diabetes Obes Metab 11: 131-142, 2009.

78. Londos C, Honnor RC, and Dhillon GS. cAMP-dependent protein kinase and lipolysis in rat adipocytes. III. Multiple modes of insulin regulation of lipolysis and regulation of insulin responses by adenylate cyclase regulators. J Biol Chem 260: 15139-15145, 1985.

79. Lu X, Gruia-Gray J, Copeland NG, Gilbert DJ, Jenkins NA, Londos C, and Kimmel AR. The murine perilipin gene: the lipid droplet-associated perilipins derive from tissuespecific, mRNA splice variants and define a gene family of ancient origin. Mamm Genome 12: 741-749, 2001.

80. Magnusson B, Asp L, Bostrom P, Ruiz M, Stillemark-Billton P, Linden D, Boren J, and Olofsson SO. Adipocyte Differentiation-Related Protein Promotes Fatty Acid Storage in Cytosolic Triglycerides and Inhibits Secretion of Very Low-Density Lipoproteins. Arterioscler Thromb Vasc Biol, 2006.

81. Mairal A, Langin D, Arner P, and Hoffstedt J. Human adipose triglyceride lipase (PNPLA2) is not regulated by obesity and exhibits low in vitro triglyceride hydrolase activity. Diabetologia, 2006.

82. Martin S and Parton RG. Lipid droplets: a unified view of a dynamic organelle. Nat Rev Mol Cell Biol 7: 373-378, 2006.

83. Martinez-Botas J, Anderson JB, Tessier D, Lapillonne A, Chang BH, Quast MJ, Gorenstein $\mathrm{D}$, Chen $\mathrm{KH}$, and Chan L. Absence of perilipin results in leanness and reverses obesity in Lepr(db/db) mice. Nat Genet 26: 474-479, 2000.

84. Masuda Y, Itabe H, Odaki M, Hama K, Fujimoto Y, Mori M, Sasabe N, Aoki J, Arai H, and Takano T. ADRP/adipophilin is degraded through the proteasome-dependent pathway during regression of lipid-storing cells. J Lipid Res 47: 87-98, 2006. 
85. McManaman JL, Zabaronick W, Schaack J, and Orlicky DJ. Lipid droplet targeting domains of adipophilin. J Lipid Res 44: 668-673, 2003.

86. Minnaard R, Schrauwen P, Schaart G, Jorgensen JA, Lenaers E, Mensink M, and Hesselink MKC. Adipocyte Differentiation-Related Protein and OXPAT in rat and human skeletal muscle: involvement in lipid accumulation and Type 2 Diabetes Mellitus Accepted in Journal of Clinical Endocrinology and Metabolism, 2009.

87. Miura S, Gan JW, Brzostowski J, Parisi MJ, Schultz CJ, Londos C, Oliver B, and Kimmel AR. Functional conservation for lipid storage droplet association among Perilipin, ADRP, and TIP47 (PAT)-related proteins in mammals, Drosophila, and Dictyostelium. J Biol Chem 277: 32253-32257, 2002.

88. Miyoshi H, Souza SC, Zhang HH, Strissel KJ, Christoffolete MA, Kovsan J, Rudich A, Kraemer FB, Bianco AC, Obin MS, and Greenberg AS. Perilipin promotes hormonesensitive lipase-mediated adipocyte lipolysis via phosphorylation-dependent and independent mechanisms. J Biol Chem 281: 15837-15844, 2006.

89. Mooney RA and Bordwell KL. Counter-regulation by insulin and isoprenaline of a prominent fat-associated phosphoprotein doublet in rat adipocytes. Biochem J 274 ( Pt 2): 433 438, 1991.

90. Motomura W, Inoue M, Ohtake T, Takahashi N, Nagamine M, Tanno S, Kohgo Y, and Okumura T. Up-regulation of ADRP in fatty liver in human and liver steatosis in mice fed with high fat diet. Biochem Biophys Res Commun 340: 1111-1118, 2006.

91. Mottagui-Tabar S, Ryden M, Lofgren P, Faulds G, Hoffstedt J, Brookes AJ, Andersson I, and Arner P. Evidence for an important role of perilipin in the regulation of human adipocyte lipolysis. Diabetologia 46: 789-797, 2003.

92. Murphy DJ. The biogenesis and functions of lipid bodies in animals, plants and microorganisms. Prog Lipid Res 40: 325-438, 2001.

93. Murphy DJ and Vance J. Mechanisms of lipid-body formation. Trends Biochem Sci 24: 109-115, 1999.

94. Nishino N, Tamori Y, and Kasuga M. Insulin Efficiently Stores Triglycerides in Adipocytes by Inhibiting Lipolysis and Repressing PGC-1alpha Induction. Kobe J Med Sci 53: 99-106, 2007.

95. Nishino N, Tamori Y, Tateya S, Kawaguchi T, Shibakusa T, Mizunoya W, Inoue K, Kitazawa R, Kitazawa S, Matsuki Y, Hiramatsu R, Masubuchi S, Omachi A, Kimura K, Saito M, Amo T, Ohta S, Yamaguchi T, Osumi T, Cheng J, Fujimoto T, Nakao H, Nakao K, Aiba A, Okamura H, Fushiki T, and Kasuga M. FSP27 contributes to efficient energy storage in murine white adipocytes by promoting the formation of unilocular lipid droplets. J Clin Invest 118: 2808-2821, 2008.

96. Notari L, Baladron V, Aroca-Aguilar JD, Balko N, Heredia R, Meyer C, Notario PM, Saravanamuthu S, Nueda ML, Sanchez-Sanchez F, Escribano J, Laborda J, and Becerra SP. Identification of a lipase-linked cell membrane receptor for pigment epitheliumderived factor. J Biol Chem 281: 38022-38037, 2006.

97. Ohsaki Y, Maeda T, Maeda M, Tauchi-Sato K, and Fujimoto T. Recruitment of TIP47 to lipid droplets is controlled by the putative hydrophobic cleft. Biochem Biophys Res Commun 347: 279-287, 2006.

98. Okazaki H, Igarashi M, Nishi M, Tajima M, Sekiya M, Okazaki S, Yahagi N, Ohashi K, Tsukamoto K, Amemiya-Kudo M, Matsuzaka T, Shimano H, Yamada N, Aoki J, Morikawa R, Takanezawa Y, Arai H, Nagai R, Kadowaki T, Osuga J, and Ishibashi S. Identification of a novel member of the carboxylesterase family that hydrolyzes triacylglycerol: a potential role in adipocyte lipolysis. Diabetes 55: 2091-2097, 2006.

99. Ostermeyer AG, Paci JM, Zeng Y, Lublin DM, Munro S, and Brown DA. Accumulation of caveolin in the endoplasmic reticulum redirects the protein to lipid storage droplets. $\mathrm{J}$ Cell Biol 152: 1071-1078, 2001.

100. Osuga J, Ishibashi S, Oka T, Yagyu H, Tozawa R, Fujimoto A, Shionoiri F, Yahagi N, Kraemer FB, Tsutsumi O, Yamada N, and abstract e. Targeted disruption of hormone- 
sensitive lipase results in male sterility and adipocyte hypertrophy, but not in obesity. Proc Natl Acad Sci U S A 97: 787-792, 2000.

101. Pan DA, Lillioja S, Kriketos AD, Milner MR, Baur LA, Bogardus C, Jenkins AB, and Storlien LH. Skeletal muscle triglyceride levels are inversely related to insulin action. Diabetes 46: 983-988, 1997.

102. Paulin D and Li Z. Desmin: a major intermediate filament protein essential for the structural integrity and function of muscle. Exp Cell Res 301: 1-7, 2004.

103. Phillips SA, Choe CC, Ciaraldi TP, Greenberg AS, Kong AP, Baxi SC, Christiansen L, Mudaliar SR, and Henry RR. Adipocyte differentiation-related protein in human skeletal muscle: relationship to insulin sensitivity. Obes Res 13: 1321-1329, 2005.

104. Pickersgill L, Litherland GJ, Greenberg AS, Walker M, and Yeaman SJ. Key role for ceramides in mediating insulin resistance in human muscle cells. J Biol Chem 282: 12583-12589, 2007.

105. Prats C, Donsmark M, Qvortrup K, Londos C, Sztalryd C, Holm C, Galbo H, and Ploug T. Decrease in intramuscular lipid droplets and translocation of HSL in response to muscle contraction and epinephrine. J Lipid Res 47: 2392-2399, 2006.

106. Puri V, Konda S, Ranjit S, Aouadi M, Chawla A, Chouinard M, Chakladar A, and Czech MP. Fat specific protein 27: A novel lipid droplet protein that enhances triglyceride storage. J Biol Chem, 2007.

107. Puri V, Ranjit S, Konda S, Nicoloro SM, Straubhaar J, Chawla A, Chouinard M, Lin C, Burkart A, Corvera S, Perugini RA, and Czech MP. Cidea is associated with lipid droplets and insulin sensitivity in humans. Proc Natl Acad Sci U S A 105: 7833-7838, 2008.

108. Robenek H, Hofnagel O, Buers I, Robenek MJ, Troyer D, and Severs NJ. Adipophilinenriched domains in the ER membrane are sites of lipid droplet biogenesis. J Cell Sci 119: 4215-4224, 2006.

109. Robenek H, Lorkowski S, Schnoor M, and Troyer D. Spatial integration of TIP47 and adipophilin in macrophage lipid bodies. J Biol Chem 280: 5789-5794, 2005.

110. Robenek H, Robenek MJ, Buers I, Lorkowski S, Hofnagel O, Troyer D, and Severs NJ. Lipid droplets gain PAT family proteins by interaction with specialized plasma membrane domains. J Biol Chem 280: 26330-26338, 2005.

111. Robenek H, Robenek MJ, and Troyer D. PAT family proteins pervade lipid droplet cores. J Lipid Res 46: 1331-1338, 2005.

112. Roden M, Price TB, Perseghin G, Petersen KF, Rothman DL, Cline GW, and Shulman GI. Mechanism of free fatty acid-induced insulin resistance in humans. J Clin Invest 97: 2859-2865, 1996.

113. Roorda BD, Hesselink MK, Schaart G, Moonen-Kornips E, Martinez-Martinez P, Losen M, De Baets MH, Mensink RP, and Schrauwen P. DGAT1 overexpression in muscle by in vivo DNA electroporation increases intramyocellular lipid content. J Lipid Res 46: 230-236, 2005.

114. Ryden M, Jocken J, van Harmelen V, Dicker A, Hoffstedt J, Wiren M, Blomqvist L, Mairal A, Langin D, Blaak EE, and Arner P. Comparative Studies of the Role of Hormone Sensitive Lipase and Adipose Triglyceride Lipase in Human Fat Cell Lipolysis. Am J Physiol Endocrinol Metab, 2007.

115. Saha PK, Kojima H, Martinez-Botas J, Sunehag AL, and Chan L. Metabolic adaptations in the absence of perilipin: increased beta-oxidation and decreased hepatic glucose production associated with peripheral insulin resistance but normal glucose tolerance in perilipin-null mice. J Biol Chem 279: 35150-35158, 2004.

116. Schadinger SE, Bucher NL, Schreiber BM, and Farmer SR. PPARgamma2 regulates lipogenesis and lipid accumulation in steatotic hepatocytes. Am J Physiol Endocrinol Metab 288: E1195-1205, 2005.

117. Scherer PE, Bickel PE, Kotler M, and Lodish HF. Cloning of cell-specific secreted and surface proteins by subtractive antibody screening. Nat Biotechnol 16: 581-586, 1998. 
118. Schmuth M, Haqq CM, Cairns WJ, Holder JC, Dorsam S, Chang S, Lau P, Fowler AJ, Chuang G, Moser AH, Brown BE, Mao-Qiang M, Uchida Y, Schoonjans K, Auwerx J, Chambon P, Willson TM, Elias PM, and Feingold KR. Peroxisome proliferator-activated receptor (PPAR)-beta/delta stimulates differentiation and lipid accumulation in keratinocytes. J Invest Dermatol 122: 971-983, 2004.

119. Schrauwen-Hinderling VB, Schrauwen P, Hesselink MK, van Engelshoven JM, Nicolay $\mathrm{K}$, Saris WH, Kessels AG, and Kooi ME. The increase in intramyocellular lipid content is a very early response to training. J Clin Endocrinol Metab 88: 1610-1616, 2003.

120. Schweiger M, Schreiber R, Haemmerle G, Lass A, Fledelius C, Jacobsen P, Tornqvist H, Zechner R, and Zimmermann R. Adipose triglyceride lipase and hormone-sensitive lipase are the major enzymes in adipose tissue triacylglycerol catabolism. J Biol Chem 281: 40236-40241, 2006.

121. Shen WJ, Patel S, Yu Z, Jue D, and Kraemer FB. Effects of rosiglitazone and high fat diet on lipase/esterase expression in adipose tissue. Biochim Biophys Acta 1771: 177-184, 2007.

122. Shulman GI. Cellular mechanisms of insulin resistance. J Clin Invest 106: 171-176, 2000.

123. Small CA, Goodacre JA, and Yeaman SJ. Hormone-sensitive lipase is responsible for the neutral cholesterol ester hydrolase activity in macrophages. FEBS Lett 247: 205-208, 1989.

124. Smirnova E, Goldberg EB, Makarova KS, Lin L, Brown WJ, and Jackson CL. ATGL has a key role in lipid droplet/adiposome degradation in mammalian cells. EMBO Rep 7: 106-113, 2006.

125. Souza SC, de Vargas LM, Yamamoto MT, Lien P, Franciosa MD, Moss LG, and Greenberg AS. Overexpression of perilipin A and B blocks the ability of tumor necrosis factor alpha to increase lipolysis in 3T3-L1 adipocytes. J Biol Chem 273: 24665-24669, 1998.

126. Souza SC, Muliro KV, Liscum L, Lien P, Yamamoto MT, Schaffer JE, Dallal GE, Wang X, Kraemer FB, Obin M, and Greenberg AS. Modulation of hormone-sensitive lipase and protein kinase A-mediated lipolysis by perilipin A in an adenoviral reconstituted system. J Biol Chem 277: 8267-8272, 2002.

127. Steinberg GR, Kemp BE, and Watt MJ. Adipocyte triglyceride lipase expression in human obesity. Am J Physiol Endocrinol Metab 293: E958-964, 2007.

128. Steiner S, Wahl D, Mangold BL, Robison R, Raymackers J, Meheus L, Anderson NL, and Cordier A. Induction of the adipose differentiation-related protein in liver of etomoxir-treated rats. Biochem Biophys Res Commun 218: 777-782, 1996.

129. Stone SJ, Levin MC, Zhou P, Han J, Walther TC, and Farese RV, Jr. The endoplasmic reticulum enzyme DGAT2 is found in mitochondria-associated membranes and has a mitochondrial targeting signal that promotes its association with mitochondria. J Biol Chem 284: 5352-5361, 2009.

130. Subramanian V, Rothenberg A, Gomez C, Cohen AW, Garcia A, Bhattacharyya S, Shapiro L, Dolios G, Wang R, Lisanti MP, and Brasaemle DL. Perilipin A mediates the reversible binding of CGI-58 to lipid droplets in 3T3-L1 adipocytes. J Biol Chem 279: 42062 42071, 2004.

131. Sztalryd C, Bell M, Lu X, Mertz P, Hickenbottom S, Chang BH, Chan L, Kimmel AR, and Londos C. Functional compensation for adipose differentiation-related protein (ADFP) by Tip47 in an ADFP null embryonic cell line. J Biol Chem 281: 34341-34348, 2006.

132. Sztalryd C, Xu G, Dorward H, Tansey JT, Contreras JA, Kimmel AR, and Londos C. Perilipin A is essential for the translocation of hormone-sensitive lipase during lipolytic activation. J Cell Biol 161: 1093-1103, 2003.

133. Tansey JT, Sztalryd C, Gruia-Gray J, Roush DL, Zee JV, Gavrilova O, Reitman ML, Deng CX, Li C, Kimmel AR, and Londos C. Perilipin ablation results in a lean mouse with aberrant adipocyte lipolysis, enhanced leptin production, and resistance to dietinduced obesity. Proc Natl Acad Sci U S A 98: 6494-6499, 2001. 
134. Targett-Adams P, McElwee MJ, Ehrenborg E, Gustafsson MC, Palmer CN, and McLauchlan J. A PPAR response element regulates transcription of the gene for human adipose differentiation-related protein. Biochim Biophys Acta 1728: 95-104, 2005.

135. Tauchi-Sato K, Ozeki S, Houjou T, Taguchi R, and Fujimoto T. The surface of lipid droplets is a phospholipid monolayer with a unique Fatty Acid composition. J Biol Chem 277: 44507-44512, 2002.

136. Than NG, Sumegi B, Than GN, Kispal G, and Bohn H. Cloning and sequence analysis of cDNAs encoding human placental tissue protein 17 (PP17) variants. Eur J Biochem 258: 752-757, 1998.

137. Thiberge S, Nechushtan A, Sprinzak D, Gileadi O, Behar V, Zik O, Chowers Y, Michaeli $\mathrm{S}$, Schlessinger J, and Moses E. Scanning electron microscopy of cells and tissues under fully hydrated conditions. Proc Natl Acad Sci U S A 101: 3346-3351, 2004.

138. Toh SY, Gong J, Du G, Li JZ, Yang S, Ye J, Yao H, Zhang Y, Xue B, Li Q, Yang H, Wen Z, and Li P. Up-regulation of mitochondrial activity and acquirement of brown adipose tissue-like property in the white adipose tissue of fsp27 deficient mice. PLoS One 3: e2890, 2008.

139. Tokuyasu KT, Maher PA, and Singer SJ. Distributions of vimentin and desmin in developing chick myotubes in vivo. I. Immunofluorescence study. J Cell Biol 98: 1961-1972, 1984.

140. Varela GM, Antwi DA, Dhir R, Yin X, Singhal NS, Graham MJ, Crooke RM, and Ahima RS. Inhibition of ADRP prevents diet-induced insulin resistance. Am J Physiol Gastrointest Liver Physiol 295: G621-628, 2008.

141. Vaughan M, Berger JE, and Steinberg D. Hormone-Sensitive Lipase and Monoglyceride Lipase Activities in Adipose Tissue. J Biol Chem 239: 401-409, 1964.

142. Villena JA, Roy S, Sarkadi-Nagy E, Kim KH, and Sul HS. Desnutrin, an adipocyte gene encoding a novel patatin domain-containing protein, is induced by fasting and glucocorticoids: ectopic expression of desnutrin increases triglyceride hydrolysis. J Biol Chem 279: 47066-47075, 2004.

143. Wang SP, Laurin N, Himms-Hagen J, Rudnicki MA, Levy E, Robert MF, Pan L, Oligny L, and Mitchell GA. The adipose tissue phenotype of hormone-sensitive lipase deficiency in mice. Obes Res 9: 119-128, 2001.

144. Wang Y, Sullivan S, Trujillo M, Lee MJ, Schneider SH, Brolin RE, Kang YH, Werber Y, Greenberg AS, and Fried SK. Perilipin expression in human adipose tissues: effects of severe obesity, gender, and depot. Obes Res 11: 930-936, 2003.

145. Watt MJ, Heigenhauser GJ, O'Neill M, and Spriet LL. Hormone-sensitive lipase activity and fatty acyl-CoA content in human skeletal muscle during prolonged exercise. J Appl Physiol 95: 314-321, 2003.

146. Watt MJ, Holmes AG, Pinnamaneni SK, Garnham AP, Steinberg GR, Kemp BE, and Febbraio MA. Regulation of HSL serine phosphorylation in skeletal muscle and adipose tissue. Am J Physiol Endocrinol Metab 290: E500-508, 2006.

147. Watt MJ, Steinberg GR, Chan S, Garnham A, Kemp BE, and Febbraio MA. Betaadrenergic stimulation of skeletal muscle HSL can be overridden by AMPK signaling. Faseb J 18: 1445-1446, 2004.

148. Watt MJ, van Denderen BJ, Castelli LA, Bruce CR, Hoy AJ, Kraegen EW, Macaulay L, and Kemp BE. Adipose triglyceride lipase regulation of skeletal muscle lipid metabolism and insulin responsiveness. Mol Endocrinol 22: 1200-1212, 2008.

149. Wijkander J, Landstrom TR, Manganiello V, Belfrage P, and Degerman E. Insulininduced phosphorylation and activation of phosphodiesterase $3 \mathrm{~B}$ in rat adipocytes: possible role for protein kinase B but not mitogen-activated protein kinase or p70 S6 kinase. Endocrinology 139: 219-227, 1998.

150. Wolins NE, Brasaemle DL, and Bickel PE. A proposed model of fat packaging by exchangeable lipid droplet proteins. FEBS Lett 580: 5484-5491, 2006. 
151. Wolins NE, Quaynor BK, Skinner JR, Schoenfish MJ, Tzekov A, and Bickel PE. S3-12, Adipophilin, and TIP47 package lipid in adipocytes. J Biol Chem 280: 19146-19155, 2005.

152. Wolins NE, Quaynor BK, Skinner JR, Tzekov A, Croce MA, Gropler MC, Varma V, Yao-Borengasser A, Rasouli N, Kern PA, Finck BN, and Bickel PE. OXPAT/PAT-1 Is a PPAR-Induced Lipid Droplet Protein That Promotes Fatty Acid Utilization. Diabetes 55: 3418-3428, 2006.

153. Wolins NE, Rubin B, and Brasaemle DL. TIP47 associates with lipid droplets. J Biol Chem 276: 5101-5108, 2001.

154. Wolins NE, Skinner JR, Schoenfish MJ, Tzekov A, Bensch KG, and Bickel PE. Adipocyte protein S3-12 coats nascent lipid droplets. J Biol Chem 278: 37713-37721, 2003.

155. Wu C, Zhang Y, Sun Z, and Li P. Molecular evolution of Cide family proteins: novel domain formation in early vertebrates and the subsequent divergence. BMC Evol Biol 8: $159,2008$.

156. Xu G, Sztalryd C, and Londos C. Degradation of perilipin is mediated through ubiquitination-proteasome pathway. Biochim Biophys Acta 1761: 83-90, 2006.

157. Xu G, Sztalryd C, Lu X, Tansey JT, Gan J, Dorward H, Kimmel AR, and Londos C. Posttranslational regulation of adipose differentiation-related protein by the ubiquitin/proteasome pathway. J Biol Chem 280: 42841-42847, 2005.

158. Yamaguchi T, Matsushita S, Motojima K, Hirose F, and Osumi T. MLDP, a novel PAT family protein localized to lipid droplets and enriched in the heart, is regulated by peroxisome proliferator-activated receptor alpha. J Biol Chem 281: 14232-14240, 2006.

159. Yamaguchi T, Omatsu N, Matsushita S, and Osumi T. CGI-58 interacts with perilipin and is localized to lipid droplets. Possible involvement of CGI-58 mislocalization in Chanarin-Dorfman syndrome. J Biol Chem 279: 30490-30497, 2004.

160. Yamaguchi T, Omatsu N, Morimoto E, Nakashima H, Ueno K, Tanaka T, Satouchi K, Hirose F, and Osumi T. CGI-58 facilitates lipolysis on lipid droplets but is not involved in the vesiculation of lipid droplets caused by hormonal stimulation. J Lipid Res 48: 10781089, 2007.

161. Yamaguchi T, Omatsu N, Omukae A, and Osumi T. Analysis of interaction partners for perilipin and ADRP on lipid droplets. Mol Cell Biochem 284: 167-173, 2006.

162. Zimmermann R, Strauss JG, Haemmerle G, Schoiswohl G, Birner-Gruenberger R, Riederer M, Lass A, Neuberger G, Eisenhaber F, Hermetter A, and Zechner R. Fat mobilization in adipose tissue is promoted by adipose triglyceride lipase. Science 306: 1383-1386, 2004. 


\section{Restoration of muscle mitochondrial function and metabolic flexibility in type 2 diabetes by exercise training is paralleled by increased myocellular fat storage and improved insulin sensitivity.}

\begin{abstract}

\section{Objective}

Mitochondrial dysfunction and fat accumulation in skeletal muscle (IMCL) has been linked to the development of type 2 diabetes. We examined if exercise training could restore mitochondrial function and insulin sensitivity in patients with type 2 diabetes (T2D).
\end{abstract}

\section{Methods}

18 male T2D and 20 healthy male control subjects (C) of comparable body weight, BMI, age and VO2max, performed a 12 week combined progressive training program ( $3 \mathrm{x} /$ week, 45 minutes/session). In vivo mitochondrial function (MRS), insulin sensitivity (clamp), metabolic flexibility (indirect calorimetry) and IMCL content (histochemically) were measured before and after training.

\section{Results}

Mitochondrial function was lower in T2D compared to $\mathrm{C}(\mathrm{p}=0.03)$, improved by training in $\mathrm{C}(+28 \%, \mathrm{p}=0.02)$ and restored to control values in T2D $(+48 \%, \mathrm{p}<0.01)$. Insulin sensitivity tended to improve in $\mathrm{C}$ (delta $\mathrm{Rd}+8 \%, \mathrm{p}=0.08$ ) and improved significantly in T2D (delta Rd $+63 \%, \mathrm{p}<0.01)$. Suppression of insulin stimulated endogenous glucose production improved in both groups (EGP $-64 \%, \mathrm{p}<0.01$ in $\mathrm{C}$ and $52 \%, \mathrm{p}<0.01$ in T2D). After training, metabolic flexibility in T2D was restored (delta RER $+63 \%, \mathrm{p}=0.01$ ), but was unchanged in $\mathrm{C}$ (delta RER $+7 \%, \mathrm{p}=0.22$ ). Starting with comparable pre-training IMCL levels, training tended to increase IMCL content in T2D $(+27 \%$, $\mathrm{p}=0.10$ ), especially in type 2 muscle fibers.

\section{Conclusion}

Exercise training restored in vivo mitochondrial function in T2D. Insulin mediated glucose disposal and metabolic flexibility improved in T2D in the face of near significantly increased IMCL content. This indicates that increased capacity to store IMCL and restoration of improved mitochondrial function contribute to improved muscle insulin sensitivity.

\author{
Ruth C.R. Meex \\ Vera Schrauwen-Hinderling \\ Esther Moonen-Kornips \\ Gert Schaart \\ Marco Mensink \\ Esther Phielix \\ Tineke van de Wijer \\ Jean-Pierre Sels \\ Patrick Schrauwen \\ Matthijs Hesselink \\ Diabetes \\ 59(3):572-9, 2010
}




\section{Introduction}

Skeletal muscle insulin resistance is one of the earliest hallmarks in the development of type 2 diabetes mellitus. The combination of increased intramyocellular lipid (IMCL) and a low oxidative capacity are key features in the development of muscular insulin resistance (1-3). Thus, mitochondrial dysfunction has been suggested to be involved in accretion of IMCL.

In type 2 diabetes, smaller and damaged mitochondria have been reported (4). In line with this, gene expression of a key transcriptional co-factor in mitochondrial biogenesis (PGC1 $\alpha$ ), and its target genes encoding key enzymes in oxidative mitochondrial metabolism, was lower in (pre-) diabetic subjects $(5 ; 6)$. We confirmed lower expression of PGC1 $\alpha$ in type 2 diabetic patients and a restoration towards control values upon treatment with rosiglitazone (7), indicating that PGC1 $\alpha$ mediated defects in mitochondria are reversible.

Importantly, these defects can translate into lower in vivo ATP synthesis rate in firstdegree relatives of type 2 diabetic patients, as determined using 31P-Magnetic Resonance Spectroscopy (8). Using an alternative 31P-MRS method, we recently reported that type 2 diabetic patients are also characterized by a reduced in vivo mitochondrial function, as reflected by a prolonged post-exercise phosphocreatine resynthesis rate (9). More recently, we extended this observation with ex vivo data indicating intrinsic mitochondrial defects in patients with type 2 diabetes (10). Under all these conditions, compromised mitochondrial function was observed in overweight to obese, BMI matched populations with a comparable IMCL content.

Together, these data support the hypothesis that a low oxidative capacity may contribute to the development of insulin resistance in the presence of a high IMCL content (11).

Current ADA/AHA-based guidelines in prevention and treatment of type 2 diabetes target diet-induced weight loss of 5-10\% body weight and physical activity of at least 150 minutes of moderate activity per week (12). Interestingly, although both are insulin sensitizing interventions, diet-induced weight loss and physical exercise training differentially affect IMCL content. While a diet-induced reduction in body mass 
resulted in declined IMCL content (13), exercise training leads to IMCL accretion (11; 14-16). The net effect of combined dietary and exercise interventions may hence be similar IMCL levels pre- and post-intervention. Indeed, in patients with type 2 diabetes it has been shown that a combined exercise-dietary intervention improved insulin sensitivity without changes in IMCL, but with an improvement in mitochondrial function (13). On the other hand, diet-induced weight loss alone reduces IMCL content, without affecting mitochondrial capacity, suggesting that to improve muscular insulin resistance the balance between IMCL content and oxidative capacity is critical (13).

At present, the effect of exercise without dietary restrictions and without targeted weight loss on IMCL content, mitochondrial function and insulin sensitivity is unknown. In addition, it is not known if the response to exercise training in type 2 diabetes -with respect to insulin sensitivity, mitochondrial content and function and IMCL- differs from the response in BMI matched normoglycemic control subjects. Therefore, we aimed to investigate the effect of a well-controlled 12 week training program in type 2 diabetic patients and carefully matched obese healthy controls on insulin sensitivity, in vivo mitochondrial function and content, and intramyocellular lipid content.

\section{Research design and methods}

\section{Subjects characteristics}

18 male type 2 diabetic subjects (T2D) and 20 healthy male control subjects (C) matched for body weight, body mass index (BMI) and age were included. Exclusion criteria were cardiac disease, impaired liver or renal function, BMI $>35 \mathrm{~kg} / \mathrm{m}^{2}$, diabetic complications, exogenous insulin therapy and prior participation in training studies. For control subjects, a family history of type 2 diabetes was added to the exclusion criteria. Glucose tolerance was examined by an oral glucose tolerance test (OGTT) (17). Diabetic patients were diagnosed with type 2 diabetes for at least 1 year before the start of the study, had well-controlled diabetes $(\mathrm{HbA} 1 \mathrm{c}= \pm 7.2 \%)$ and were using oral anti-diabetic agents (metformin only, or in combination with SU 
derivatives). Medication use did not change during the study. None of the subjects were on a diet and all had a sedentary lifestyle. The institutional medical ethical committee approved the study. Body composition was measured through hydrostatic weighing (18), and maximal work load and oxygen uptake was assessed during a graded cycling test until exhaustion (19).

\section{Exercise training protocol}

Subjects enrolled in a tightly controlled exercise program for 12 weeks. Aerobic exercise was carried out on a cycling ergometer twice a week for 30 minutes at $55 \%$ of a previously determined maximal work load (Wmax). Resistance exercise was performed once a week and comprised 1 series of 8 repetitions at $55 \%$ of their previously determined maximal voluntary contraction (MVC) and 2 series of 8 repetitions at $75 \% \mathrm{MVC}$ and focussed on large muscle groups (Chest press, leg extension, lat pull down, leg press, triceps curls, biceps curls, abdominal crunches, horizontal row). The MVC test was preceded by a familiarization trial. Warming-up and cooling-down sessions of 5 minutes were performed on a stationary bike at $45 \%$ Wmax. Every 4 weeks, MVC was re-assessed; maximal aerobic capacity was re-assessed after 6 weeks and training loads were readjusted accordingly. Supervised training sessions were performed with 4 subjects at a time.

\section{Hyperinsulinemic-euglycemic clamp}

A 6-hour hyperinsulinemic-euglycemic insulin clamp $\left(40 \mathrm{mU} / \mathrm{m}^{2} / \mathrm{min}\right)$ was performed before and after the training period essentially as described previously (7). Dietary habits were stable and physical exercise was avoided 3 days prior to the clamp. Diabetic subjects discontinued anti-diabetic medication 7 days prior to the clamp. Glucose tracer $([6,6-2 \mathrm{H} 2]$ glucose $)$ was used to determine rates of glucose appearance $(R \mathrm{a})$ and disposal $(R \mathrm{~d})$. The first three hours $(\mathrm{t}=0-180 \mathrm{~min})$ were used to determine non-insulin stimulated $\mathrm{Ra}$ and $\mathrm{Rd}$. At $\mathrm{t}=180$, a primed constant infusion of insulin started and glucose infusion rates was adjusted to maintain euglycemia. In the final 30 minutes of the non-insulin stimulated period $(\mathrm{t}=150-180)$ and under steady clamp conditions ( $\mathrm{t}=330-360)$, blood was sampled and indirect calorimetry (ventilated 58 
hood) was performed. Muscle biopsies from the m. vastus lateralis were obtained under local anaesthesia (2\%lidocaine), before and after the clamp.

\section{Tracer calculations}

Isotopic enrichment of plasma glucose was determined by electron ionization gas chromatography-mass spectrometry. Steele's single-pool non-steady-state equations (20) were used to calculate glucose $R \mathrm{a}$ and $R \mathrm{~d}$. Volume of distribution was assumed to be $0.1601 / \mathrm{kg}$ for glucose. Insulin stimulated glucose disposal was computed as the difference between $R \mathrm{~d}$ under insulin stimulated conditions and $R \mathrm{~d}$ under basal noninsulin-stimulated conditions (delta $R \mathrm{~d}$ ). Endogenous glucose production (EGP) was calculated as $R$ a minus exogenous glucose infusion rate. Non-oxidative glucose disposal was calculated as $R \mathrm{~d}$ minus carbohydrate oxidation.

\section{Blood sample analysis}

Arterialised blood samples were collected from a hand vein. Plasma free fatty acids (FFAs) and glucose were measured spectrophotometrically). Insulin concentration was determined using a radioimmunoassay (Linco Research, St. Charles, MO).

\section{Metabolic flexibility}

Fat and carbohydrate oxidation in the basal and insulin stimulated state was calculated according to Frayn (21) with protein oxidation considered negligible. Metabolic flexibility was expressed as the change in respiratory exchange ratio (RER) from the fasted state to the insulin-stimulated condition.

\section{${ }^{31} P$-MRS-based measurement of mitochondrial function}

${ }^{31} \mathrm{P}-\mathrm{MRS}$ measurements were performed in vastus lateralis muscle on a $1.5 \mathrm{~T}$ whole body scanner (Intera, Philips Health Care, Best, the Netherlands) essentially according to (9). Pre- and post training leg extension exercise was performed at 0.5 $\mathrm{Hz}$ to an acoustic cue on an MR compatible ergometer and a weight corresponding to 
$60 \%$ of the predetermined maximum. Spectra were fitted in the time domain with the AMARES algorithm (22) in the jMRUI software (23). Five peaks were fitted with gaussian curves (Pi, PCr, and 3 ATP peaks). The time-course of the PCr amplitude $(\operatorname{PCr}(\mathrm{t}))$ during the last 20 seconds of exercise (steady state) and during the recovery period was fitted as described previously (9), asssuming a monoexponential PCr recovery. Post-exercise, PCr resynthesis is driven almost purely oxidatively (24) and the resynthesis rate reflects in vivo mitochondrial function in health (25) and disease (for reviews see $(26 ; 27)$. Data are expressed as rate constant (ln 2/ PCr recovery time in seconds). The higher the rate constant (s-1), the better in vivo mitochondrial function.

\section{Intramyocellular lipid content}

Intramyocellular lipid (IMCL) content was assessed histochemically in muscle crosssections using a modified oil red $\mathrm{O}$ staining for fluorescence microscopy (28) and combined with muscle fiber typing. Muscle fiber typing was performed using a monoclonal primary antibody against the slow isoform of myosin heavy chain 1 (MHC1), which was visualized using a secondary FITC conjugated secondary antibody. Thus, MHC1 positive cells were considered type 1 muscle fibers whereas MHC1 negative cells were considered type 2 muscle fibers. Immunolabelling of the basement membrane protein laminin was performed to identify the cellular border. Thus, we were able to identify the typology of individual muscle cells. Tresholding the oil red $\mathrm{O}$ signal allowed us to compute the relative fraction of cell area containing lipid droplets per individual muscle fiber of either type.

\section{Western blotting}

UCP3 protein content was determined by Western blotting, using a rabbit polyclonal antibody. Five different structural components of the electron transport chain were measured at the protein level as a reflection of mitochondrial density. The components include ND6 subunit of complex I, the $30 \mathrm{kDa}$ Ip subunit of complex II, the 47 $\mathrm{kDa}$ core protein 2 of complex III, subunit II of cytochrome C oxidase (COXII) and the alpha subunit of the F1F0 ATP synthase (complex V) and were measured using 60 
monoclonal antibodies (MitoSciences, Oregon, USA) (29). Gels were loaded with equal amounts of protein of pre- and post training lysates of 2 control and 2 type 2 diabetic subjects per gel to allow valid comparison between pre- and post training samples. To adjust for inter-gel variation, and hence variation in the mean of the control group and the type 2 diabetic group, the optical density of the band of interest per subject was normalized to the mean optical density of the complete gel. Protein content was expressed as arbitrary units (AU).

\section{Statistics}

Data are presented as mean \pm SE. In 4 control and 3 T2D no pre- or post data for MRS analyses could be obtained due to claustrophobia or metal parts in their body. Statistical analyses were performed two-sided using SPSS for Windows 15.0 software (SPSS, Chicago,IL. Statistical significance was set at $\mathrm{p}<0.05$. A two-way ANOVA model for repeated measures was applied using control and type 2 diabetics as between subject variables and pre- and post training data as repeated within subject variables. Using this model we did not find significant interaction effects.

\section{Results}

\section{Subjects characteristics}

Control subjects (C) and type 2 diabetic patients (T2D) were included and matched for body weight $(94.7 \pm 2.7$ and $93.8 \pm 2.9 \mathrm{~kg}), \mathrm{BMI}(29.7 \pm 0.8$ and $30.0 \pm 0.8$ $\left.\mathrm{kg} / \mathrm{m}^{2}\right)$ and age $(59.0 \pm 0.8$ and $59.4 \pm 1.1$ years in C and T2D). Training induced a modest but near significant decline in body weight and BMI in C $(94.7 \pm 2.7$ to 93.6 $\pm 2.7 \mathrm{~kg}$ and $29.7 \pm 0.8$ to $29.4 \pm 0.8 \mathrm{~kg} / \mathrm{m}^{2}$ respectively, both $\left.\mathrm{p}=0.06\right)$, but did not result in significant changes in T2D (table 1). Fat mass tended to decline in C (30.0 \pm $1.8 \mathrm{~kg}$ to $29.2 \pm 2.0 \mathrm{~kg}$ after training; $\mathrm{p}=0.09$ ) and declined modestly but significantly after training in T2D $(29.4 \pm 1.9 \mathrm{~kg}$ to $28.0 \pm 1.8 \mathrm{~kg}$; $\mathrm{p}=0.04)$. Fat free mass was similar between both groups and did not change after training (table 1). 


\section{CHA P TER 3}

\section{Exercise capacity}

Before training, maximal oxygen uptake was comparable in both groups and increased upon training $(+6.4 \pm 2.6 \%, \mathrm{p}=0.04$ in $\mathrm{C}$ and $+11.3 \pm 2.2 \%, \mathrm{p}<0.01$ in T2D). Maximal oxygen uptake and Wmax increased similarly in C and T2DM (+15.0 \pm 2.4 $\%$ and $+16.9 \pm 3.0 \%$ in $\mathrm{C}$ and $\mathrm{T} 2 \mathrm{D}$ respectively, $\mathrm{p}<0.01)$ and persisted after correction for body mass. Resistance training profoundly improved muscle strength $(+22.2$ $\pm 2.0 \%$ and $+23.9 \pm 1.9 \%$ in $\mathrm{C}$ and $\mathrm{T} 2 \mathrm{D}$ respectively, $\mathrm{p}<0.01$, table 1 ).

Table 1: subject characteristics

\begin{tabular}{lcccc}
\hline & \multicolumn{3}{c}{ C } & \multicolumn{2}{c}{ T2D } \\
\cline { 2 - 5 } Subject characteristics & Pre-training & Post-training & Pre-training & Post-training \\
\hline Age (years) & $59.0 \pm 0.8$ & $/$ & $59.4 \pm 1.1$ & $/$ \\
Years since diagnosis & $/$ & $/$ & $3.9 \pm 0.9$ & $/$ \\
Weight $(\mathrm{kg})$ & $94.7 \pm 2.7$ & $93.6 \pm 2.7$ & $93.8 \pm 2.9$ & $92.8 \pm 3.1$ \\
Height $(\mathrm{cm})$ & $178.5 \pm 1.3$ & $/$ & $176.7 \pm 1.3$ & $/$ \\
BMI $\left(\mathrm{kg} / \mathrm{m}^{2}\right)$ & $29.7 \pm 0.8$ & $29.4 \pm 0.8$ & $30.0 \pm 0.8$ & $29.8 \pm 0.9$ \\
Body fat $(\%)$ & $31.5 \pm 1.4$ & $30.6 \pm 1.6$ & $31.1 \pm 1.4$ & $29.9 \pm 1.3 *$ \\
FM $(\mathrm{kg})$ & $30.0 \pm 1.8$ & $29.2 \pm 2.0$ & $29.4 \pm 1.9$ & $28.0 \pm 1.8 *$ \\
FFM $(\mathrm{kg})$ & $64.6 \pm 2.0$ & $65.4 \pm 2.0$ & $64.3 \pm 1.7$ & $64.8 \pm 1.8$ \\
VO2max $(\mathrm{ml} / \mathrm{min} / \mathrm{kg})$ & $28.8 \pm 1.0$ & $30.2 \pm 1.2 *$ & $27.5 \pm 1.2$ & $31.1 \pm 1.2 *$ \\
Wmax $($ Watt $)$ & $207 \pm 10$ & $236 \pm 9 *$ & $202 \pm 9$ & $233 \pm 9 *$ \\
Average strength $(\mathrm{kg})$ & $85.8 \pm 3.2$ & $104.0 \pm 3.5 *$ & $83.7 \pm 3.5$ & $102.4 \pm 4.2 *$ \\
Fasting glucose $(\mathrm{mmol} / \mathrm{l})$ & $5.9 \pm 0.1$ & $5.5 \pm 0.1 *$ & $9.0 \pm 0.4 \#$ & $9.0 \pm 0.4 \#$ \\
HbA1c $(\%)$ & $5.8 \pm 0.1$ & $5.7 \pm 0.1 *$ & $7.2 \pm 0.2 \#$ & $7.2 \pm 0.2 \#$ \\
Triacylglycerol $(\mathrm{mmol} / \mathrm{l})$ & $1.52 \pm 0.13$ & $1.49 \pm 0.15$ & $1.77 \pm 0.16$ & $1.68 \pm 0.14$ \\
\hline
\end{tabular}

Data are expressed as mean \pm SE., \#T2D significantly different from control group, *post-training significantly different from pre-training. Whole-body insulin-stimulated glucose disposal

\section{Whole-body insulin-stimulated glucose disposal}

Insulin-stimulated glucose disposal (delta $R \mathrm{~d}$ ) was considerably higher in $\mathrm{C}$ than in T2D (table 2). Training induced a near significant increase in delta $R \mathrm{~d}$ in C $(17.1 \pm$ 2.4 to $18.4 \pm 2.1 \mu \mathrm{mol} / \mathrm{kg} / \mathrm{min}, \mathrm{p}=0.08$ ) and a profound significant increase in $\mathrm{T} 2 \mathrm{D}$ (from $6.8 \pm 1.4$ to $11.1 \pm 1.4 \mu \mathrm{mol} / \mathrm{kg} / \mathrm{min}, \mathrm{p}<0.01$ ). The significant increase observed in patients with type 2 diabetes originates from a reduction in basal glucose 
disposal rate as well as from improved disposal rate under insulin stimulated conditions (table 2). Nevertheless, insulin-stimulated glucose disposal remained higher in $\mathrm{C}$ after training compared to T2D. Basal endogenous glucose production before training tended $(\mathrm{p}=0.07)$ to be lower in $\mathrm{C}$ than in T2D. Insulin sensitivity of the liver in $\mathrm{C}$ and T2D improved significantly (endogenous glucose production drops from $2.8 \pm$ 0.8 pre-training to $1.0 \pm 1.0$ in $\mathrm{C}, \mathrm{p}=0.01$ and from $2.9 \pm 0.5$ pre-training to $1.4 \pm 0.3$ $\mu \mathrm{mol} / \mathrm{kg} / \mathrm{min}$ in $\mathrm{T} 2 \mathrm{D}, \mathrm{p}<0.01)$. Insulin-mediated non-oxidative glucose disposal was significantly higher in $\mathrm{C}$ than in T2D and was not significantly affected by exercise training ( $\mathrm{p}=0.14$ and 0.13 in $\mathrm{C}$ and $\mathrm{T} 2 \mathrm{D}$ respectively, table 2 ), In contrast, delta glucose oxidation in $\mathrm{T} 2 \mathrm{D}$ restored to control values (table 2).

\section{In vivo mitochondrial function by ${ }^{31} P-M R S$}

We confirmed compromised mitochondrial function in T2D compared to BMI matched controls (rate constant: $0.036 \pm 0.002^{-1}$ and $0.030 \pm 0.001 \mathrm{~s}^{-1}$ in $\mathrm{C}$ and T2D respectively, $\mathrm{p}=0.03$ ). Mitochondrial function improved after training in $\mathrm{C}$ and $\mathrm{T} 2 \mathrm{D}$ $(+28 \%$ and $+48 \%$ respectively), resulting in similar in vivo mitochondrial function after training $(\mathrm{p}=0.84)$ (figure 1). There was no difference in end-exercise $\mathrm{pH}$ values between the $\mathrm{C}$ and T2D and no difference between pre- and post training values (7.05 \pm 0.02 and $7.02 \pm 0.02$ for $C$ pre- and post-training and $7.01 \pm 0.02$ and $6.99 \pm 0.03$ for T2D pre- and post training respectively).

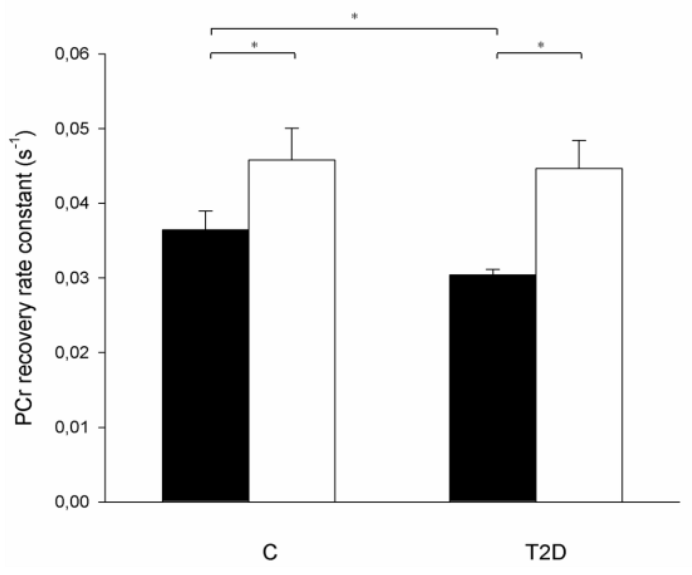

Figure 1: In vivo mitochondrial function measured in vastus lateralis muscle expressed as rate constant $\left(\mathrm{s}^{-1}\right)$, before (black bars) and after training (white bars). A high rate constant reflects high in vivo mitochondrial function. Data are expressed as mean $\pm \mathrm{SE}$., \#T2D significantly different from control group, *post-training significantly different from pre-training. 


\section{Metabolic flexibility}

Prior to training, metabolic flexibility was significantly higher in control subjects compared to T2D (figure 2), due to a more profound increase in insulin stimulated glucose oxidation $(5.9 \pm 0.7$ and $3.6 \pm 0.8 \mu \mathrm{mol} / \mathrm{kg} / \mathrm{min}$ in $\mathrm{C}$ and T2DM respectively, $\mathrm{p}=0.04)$, with a concomitant tendency $(\mathrm{p}=0.10)$ to more profound insulin-mediated suppression of fat oxidation $(-0.46 \pm 0.05$ and $-0.32 \pm 0.06 \mu \mathrm{mol} / \mathrm{kg} / \mathrm{min}$ in $\mathrm{C}$ and T2DM respectively) (table 2). Exercise training did not affect metabolic flexibility in $\mathrm{C}$ but fully restored flexibility in $\mathrm{T} 2 \mathrm{D}$ ( $\mathrm{C}$ versus $\mathrm{T} 2 \mathrm{D} ; \mathrm{p}=0.84$, figure 2 ), due to im-

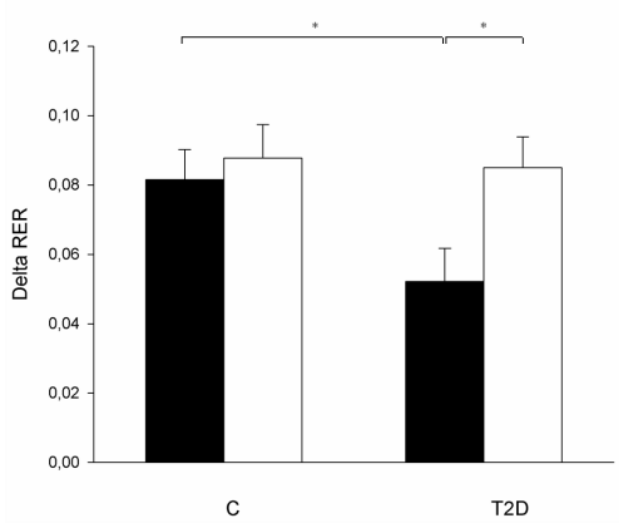

Figure 2: Metabolic flexibility, measured as the change in respiratory quotient from the fasted state to the insulin-stimulated state, before (black bars) and after training (white bars). Data are expressed as mean $\pm \mathrm{SE}$., \#T2D significantly different from control group, *posttraining significantly different from pre-training. proved insulin stimulated increases in glucose oxidation (from $3.61 \pm$ 0.78 to $5.94 \pm 0.72 \mu \mathrm{mol} / \mathrm{kg} / \mathrm{min}$; $\mathrm{p}=0.02$ ) and suppression of fat oxidation (from $-0.32 \pm 0.06$ to $0.49 \pm 0.06 \mu \mathrm{mol} / \mathrm{kg} / \mathrm{min} ; \mathrm{p}=0.01)$ (table 2). Remarkably, insulinstimulated substrate oxidation rates were comparable between T2D and $\mathrm{C}$ after training, indicating that the lower insulin-stimulated glucose uptake after training in T2D was completely accounted for by a lower insulin-stimulated nonoxidative glucose uptake.

\section{Intramyocellular lipid content}

IMCL content pre-training was comparable in both groups and did not change after training in $\mathrm{C}$ (figure 3). In T2D however, training tended to increase IMCL content (from $1.5 \pm 0.2$ to $1.9 \pm 0.3 \mathrm{AU} ; \mathrm{p}=0.10$ ) which was predominantly accounted for by a near significant increase in IMCL in type 2 muscle fibers (from $1.1 \pm 0.2$ to 1.5 $\pm 0.3 \mathrm{AU} ; \mathrm{p}=0.07$, figure 3 ). 

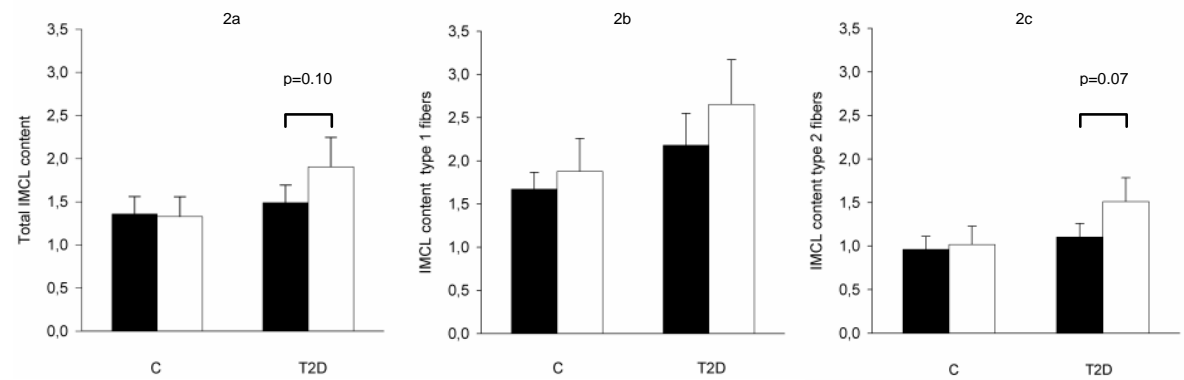

Figure 3: Intramyocellular lipid content in all muscle fibers (panel 2a), in type 1 muscle fibers (panel $2 b$ ) and in type 2 muscle fibers (panel 2c). Data are expressed as mean \pm SE., \#T2D significantly different from control group, *post-training significantly different from pre-training.

\section{Blood sample analysis}

Fasting glucose levels and HbA1c were significantly lower in $\mathrm{C}$ than in T2D prior to the training program. Twelve weeks of exercise training induced a slight but significant decrease in HbA1c and in fasting glucose levels in $\mathrm{C}$. There was no change in $\mathrm{HbA1c}$ or fasting glucose levels in T2D (table 1). Fasting plasma insulin levels were comparable pre-training and decreased significantly in both groups after training (table 2). Fasting plasma free fatty acid (FFA) levels were similar across groups and did not change after training. Under insulin stimulation, however, FFA levels tended to be lower in C compared to T2D and decreased significantly after training in both groups (table 2), suggesting improved insulin mediated suppression of adipose tissue lipolysis post-training in both groups.

\section{Markers of mitochondrial density}

Mitochondrial density was evaluated by measuring protein content of 5 structural subunits of the distinct complexes of the electron transport chain. Neither the individual complexes (table 3), nor averaging the protein content of these complexes revealed difference in mitochondrial density between $C$ and T2D pre-training $(0.66 \pm$ 0.11 and $0.59 \pm 0.08 \mathrm{AU}$ in $\mathrm{C}$ and T2D, NS). Training resulted in increased mitochondrial density in both groups after training (table 3). The increase in mitochondrial density tended to be more pronounced in T2D compared to $\mathrm{C}(\mathrm{p}=0.07)$. 
Table 2: Substrate kinetics pre- and post training

\begin{tabular}{|c|c|c|c|c|}
\hline & \multicolumn{2}{|c|}{$\mathrm{C}$} & \multicolumn{2}{|c|}{$\mathrm{T} 2 \mathrm{D}$} \\
\hline & Pre-training & Post training & Pre-training & Post training \\
\hline \multicolumn{5}{|c|}{ Plasma insulin (mU/l) } \\
\hline Basal & $18.1 \pm 2.4$ & $16.1 \pm 2.1^{*}$ & $16.4 \pm 1.2$ & $14.6 \pm 0.8^{*}$ \\
\hline Clamp & $112.5 \pm 5.4$ & $112.1 \pm 5.5$ & $107.6 \pm 4.8$ & $103.1 \pm 2.7$ \\
\hline \multicolumn{5}{|c|}{ Plasma FFA $(\mu \mathrm{mol} / 1)$} \\
\hline Basal & $479.0 \pm 22.9$ & $454.9 \pm 28.3$ & $519.4 \pm 25.3$ & $500.1 \pm 34.1$ \\
\hline Clamp & $84.7 \pm 7.2$ & $67.5 \pm 6.9 *$ & $107.1 \pm 8.7$ & $87.6 \pm 8.7 *$ \\
\hline \multicolumn{5}{|c|}{ Rd glucose $(\mu \mathrm{mol} / \mathrm{kg} / \mathrm{min})$} \\
\hline Basal & $8.7 \pm 0.7$ & $8.3 \pm 0.6$ & $11.6 \pm 0.7 \#$ & $9.9 \pm 0.6 *$ \\
\hline Clamp & $25.8 \pm 2.3$ & $26.7 \pm 2.3$ & $18.4 \pm 1.4 \#$ & $21.0 \pm 1.4 \# *$ \\
\hline Delta & $17.1 \pm 2.4$ & $18.4 \pm 2.1$ & $6.8 \pm 1.4 \#$ & $11.1 \pm 1.4 \# *$ \\
\hline \multicolumn{5}{|c|}{$\mathrm{EGP}(\mu \mathrm{mol} / \mathrm{kg} / \mathrm{min})$} \\
\hline Basal & $8.7 \pm 0.6$ & $8.7 \pm 0.6$ & $10.3 \pm 0.6$ & $9.1 \pm 0.7$ \\
\hline Clamp & $2.8 \pm 0.8$ & $1.0 \pm 1.0 *$ & $2.9 \pm 0.5$ & $1.4 \pm 0.3 *$ \\
\hline Delta & $-5.7 \pm 1.1$ & $-7.2 \pm 1.2$ & $-7.9 \pm 0.6$ & $-7.7 \pm 0.8$ \\
\hline \multicolumn{5}{|c|}{ CHO oxidation $(\mu \mathrm{mol} / \mathrm{kg} / \mathrm{min})$} \\
\hline Basal & $6.5 \pm 0.5$ & $7.1 \pm 0.5$ & $8.1 \pm 0.6$ & $7.3 \pm 0.4$ \\
\hline Clamp & $12.5 \pm 0.8$ & $13.0 \pm 0.7$ & $11.7 \pm 0.8$ & $13.2 \pm 0.8$ \\
\hline Delta & $5.9 \pm 0.7$ & $5.9 \pm 0.6$ & $3.6 \pm 0.8 \#$ & $5.9 \pm 0.7 *$ \\
\hline \multicolumn{5}{|c|}{ NOGD $(\mu \mathrm{mol} / \mathrm{kg} / \mathrm{min})$} \\
\hline Basal & $2.3 \pm 0.7$ & $1.1 \pm 0.6$ & $3.5 \pm 0.9$ & $2.6 \pm 0.8$ \\
\hline Clamp & $13.5 \pm 1.7$ & $13.7 \pm 2.3$ & $6.7 \pm 1.2 \#$ & $8.0 \pm 1.2 \#$ \\
\hline Delta & $11.3 \pm 1.9$ & $12.6 \pm 1.9$ & $3.2 \pm 1.4 \#$ & $5.3 \pm 1.2 \#$ \\
\hline \multicolumn{5}{|c|}{ Lipid oxidation $(\mu \mathrm{mol} / \mathrm{kg} / \mathrm{min})$} \\
\hline Basal & $1.08 \pm 0.05$ & $1.03 \pm 0.05$ & $1.08 \pm 0.05$ & $1.09 \pm 0.05$ \\
\hline Clamp & $0.63 \pm 0.04$ & $0.55 \pm 0.04$ & $0.75 \pm 0.04 \#$ & $0.59 \pm 0.05 *$ \\
\hline Delta & $-0.46 \pm 0.05$ & $-0.48 \pm 0.06$ & $-0.32 \pm 0.06$ & $-0.49 \pm 0.06 *$ \\
\hline
\end{tabular}

Data are expressed as mean \pm SE., \#T2D significantly different from control group, *post-training significantly different from pre-training.

\section{UCP3 protein content}

We confirm our previous reports showing a $~ 50 \%$ lower UCP3 content in T2D than in $\mathrm{C}(30 ; 31)$ (table 3). Training increased UCP3 protein content two-fold in C and almost 4-fold in T2D. This resulted in similar UCP3 content in C and T2D after training (table 3). 
Table 3: Mitochondrial density and UCP3 protein content (AU).

\begin{tabular}{lllll}
\hline & \multicolumn{3}{c}{ C } & \multicolumn{2}{c}{ T2D } \\
\cline { 2 - 5 } & Pre-training & Post training & Pre-training & Post training \\
\hline Complex I & $0.61 \pm 0.19$ & $1.11 \pm 0.32$ & $0.66 \pm 0.18$ & $1.65 \pm 0.42$ \\
Complex II & $0.61 \pm 0.18$ & $1.13 \pm 0.30$ & $0.60 \pm 0.15$ & $1.74 \pm 0.37 *$ \\
Complex III & $0.73 \pm 0.06$ & $1.18 \pm 0.12 *$ & $0.60 \pm 0.05$ & $1.55 \pm 0.13 \# *$ \\
Complex IV & $0.66 \pm 0.07$ & $1.21 \pm 0.09 *$ & $0.57 \pm 0.07$ & $1.63 \pm 0.12 \# *$ \\
Complex V & $0.76 \pm 0.12$ & $1.06 \pm 0.12 *$ & $0.62 \pm 0.07$ & $1.51 \pm 0.14 \# *$ \\
Average of the complexes & $0.66 \pm 0.11$ & $1.14 \pm 0.16 *$ & $0.59 \pm 0.08$ & $1.62 \pm 0.20 *$ \\
UCP3 & $0.71 \pm 0.12$ & $1.43 \pm 0.20 *$ & $0.39 \pm 0.05 \#$ & $1.50 \pm 0.22 *$ \\
UCP3 & $1.22 \pm 0.21$ & $1.37 \pm 0.16$ & $0.73 \pm 0.09 \#$ & $1.03 \pm 0.11 *$ \\
\hline
\end{tabular}

Data are expressed as mean $\pm \mathrm{SE}$, \#T2D significantly different from control group, *post-training significantly different from pre-training. ${ }^{1}$ Normalized to mitochondrial density

\section{Discussion}

Mitochondrial dysfunction has been reported in type 2 diabetic patients $(4 ; 32 ; 33)$ and in young, lean, insulin-resistant offspring of parents with type 2 diabetes (2), although not all studies support this $(34 ; 35)$. The present study confirms our previous observation of compromised mitochondrial function measured in vivo in patients with type 2 diabetes $(9 ; 10)$. Importantly, exercise training in patients with type 2 diabetes completely restored mitochondrial function towards values observed in control subjects after training. In patients with type 2 diabetes, restoration of mitochondrial function was paralleled by improved (but not restored) insulin stimulated glucose disposal and by complete restoration of metabolic flexibility and insulinstimulated substrate oxidation towards control values, both in face of a near significant increase in IMCL content. In control subjects, training also improved mitochondrial function while insulin stimulated glucose disposal increased only marginally and metabolic flexibility and IMCL content remained unaltered.

The ability of patients with type 2 diabetes to increase mitochondrial function indicates that despite aberrations in transcriptional control of mitochondrial biogenesis $(5 ; 6)$, a lifestyle intervention comprising physical exercise is potent enough to overcome these apparent defects. Increased mitochondrial content and improved function 
has previously been observed in type 2 diabetes following a combined dietary exercise intervention targeting more than $7 \%$ body weight loss (13). Here we show that exercise training, even without substantial loss of body mass, not only improves mitochondrial function but even results in complete restoration towards control values observed in age and BMI matched normoglycemic control subjects. The observation of compromised mitochondrial function in patients with type 2 diabetes compared to control subjects, whilst having comparable mitochondrial density (as indicated by measuring protein content of 5 structural components in the electron transport chain), supports previous findings of intrinsic defects in mitochondria of patients with type 2 diabetes $(10 ; 36)$. Interestingly, mitochondrial protein content markedly increased after exercise training, suggesting that at least a major part of the restoration of mitochondrial function after training is due to increased mitochondrial biogenesis. Although it remains to be established if exercise training also improves intrinsic mitochondrial function, it is of interest to note that protein expression of UCP3, a protein with a putative role in ameliorating lipotoxicity and oxidative stress via mild uncoupling (37) was significantly lower in type 2 diabetic patients compared to controls, confirming previous work $(30 ; 31)$. UCP3 content restored to control values after training in type 2 diabetes, even after adjustment for the increase in structural components of the electron transport chain. This may indicate that exercise training in patients with type 2 diabetes not only improves mitochondrial content but also results in adaptive responses within mitochondria to cope better with the myocellular metabolic stress in the insulin resistant state.

Part of the metabolic stress in type 2 diabetes may originate from myocellular fat storage. IMCL content correlates negatively with insulin sensitivity in untrained subjects $(11 ; 38 ; 39)$. On the other hand, endurance trained athletes also have high levels of IMCL $(11 ; 40)$, while being insulin sensitive. It has hence been suggested that low fat oxidative capacity and a concomitant increase in fatty acid metabolites induces insulin resistance, rather than IMCL levels per se $(11 ; 41)$. Our present study confirms previous findings of reduced mitochondrial function in T2D with a similar IMCL content between control subjects and type 2 diabetic patients $(9 ; 10)$. This suggests that high IMCL levels combined with compromised mitochondrial function 
may contribute to impeded insulin sensitivity. This notion is substantiated by our observation that exercise training improved mitochondrial function and alleviated muscular insulin resistance in patients with type 2 diabetes even though IMCL levels increased post-training.

Training-induced increases in IMCL content may originate from improved partitioning of fatty acids in IMCL due to exercise-induced increases in diacylglycerol-acyl transferase (DGAT1) $(42 ; 43)$, the rate limiting enzyme in IMCL synthesis. Indeed enhancing IMCL storage capacity by overexpression of DGAT1 improved insulin sensitivity (42). These findings support the idea that the capacity to effectively store fatty acids as IMCL along with appropriate mitochondrial function are major determinants of myocellular insulin sensitivity. We observed increased IMCL content in type 2 diabetic patients after combined endurance and resistance training in glycolytic type 2 muscle fibers, which in human posses lower IMCL levels than the more oxidative type 1 fibers. It could hence be suggested that, due to the resistance exercise, previously inactive type 2 fibers were now recruited and increased their storage capacity for fatty acids as IMCL, thereby contributing to the insulin sensitizing effect of training. This implies that it might be of added value for insulin sensitizing training interventions to include also exercise at an intensity which requires recruitment of type 2 muscle fibers.

Metabolic inflexibility is another characteristic of insulin resistant muscles (44), possibly reflecting a reduced ability of mitochondria to shift fuel selection. Metabolic inflexibility in insulin resistance may reflect reduced insulin stimulated glucose uptake, thereby reducing the availability of glucose for oxidation rather than a mitochondrial defect in substrate selection (45). The present study partly supports this notion. Impaired metabolic flexibility in T2D before training was indeed accompanied by a reduced insulin-stimulated rate of glucose disappearance. Moreover, upon training, insulin stimulated glucose disposal improved in the T2D in conjunction with improved metabolic flexibility. Although the improvement in insulin-stimulated glucose disposal completely matched the restoration of metabolic flexibility, restoration of mitochondrial function may be needed to facilitate this. In control subjects, training did not alter metabolic flexibility and also only marginally improved insulin- 
stimulated glucose disposal. It thus seems that after training, insulin-stimulated glucose oxidation was working at its maximal capacity in both C and T2D. Very interestingly, despite a restoration of metabolic flexibility, mitochondrial function and insulin-stimulated glucose oxidation, insulin-stimulated glucose disposal was still lower in T2D compared to $\mathrm{C}$. This was completely accounted for by a lower non-oxidative glucose disposal. Thus, upon exercise training the oxidative component of insulinstimulated glucose disposal is fully restored, in contrast to non-oxidative glucose disposal. Compromised non-oxidative glucose disposal in type 2 diabetes has been reported previously (46) and treating insulin resistant first-degree relatives of type 2 diabetes with metformin normalizes non-oxidative glucose disposal (47), supporting the notion that restoring non-oxidative glucose disposal may be crucial to normalize insulin sensitivity and possibly plasma glucose in type 2 diabetes.

In a model of one-legged exercise training, non-oxidative glucose disposal improved along with increased fractional velocity of glycogen synthase (48). The different training regimes applied (one vs. two-legged exercise, 6 times per week vs. 3 times per week, and aerobic exercise solely vs. a combination of aerobic and resistance exercise) in the one-legged exercise study vs. the present study are likely to explain the differences. It should be noted that also in the present study, in patients with type 2 diabetes, non-oxidative glucose disposal improved with $\sim 30 \%$, albeit nonsignificantly but was still lower than control values. More recently, restoration of non-oxidative glucose disposal upon exercise training in type 2 diabetes has been reported (49). In that study, however, non-oxidative glucose disposal was measured as the residual of glucose disposal rate minus oxidative glucose disposal and may hence be biased by hepatic glucose production and therefore are hard to compare to the data from the present study. Future studies are needed to examine the underlying mechanisms, and to examine exercise training could be combined with other means augments non-oxidative glucose disposal and thereby further improve insulin sensitivity.

While skeletal muscle insulin resistance is the hallmark of type 2 diabetes, insulin resistance of liver and adipose tissue also contributes to the pathogenesis of type 2 diabetes. In this respect it is of relevance to note that physical exercise training also 
resulted in beneficial adaptations beyond those reported for muscle. Likewise we observed that under hyperinsulinemic clamp conditions plasma free fatty acid levels were significantly lower post- than pre-training, possibly reflecting improved antilipolytic activity of insulin in adipose tissue. In addition, exercise training in type 2 diabetic patients improved the ability of insulin to inhibit hepatic glucose output. At present, the routes or mechanisms responsible for these beneficial training-mediated multiple organ adaptations are unknown and warrant further study.

In conclusion, restoration of mitochondrial dysfunction in type 2 diabetes by physical exercise improves insulin mediated glucose disposal in the presence of increased IMCL storage. Restoration of mitochondrial function and metabolic flexibility in type 2 diabetes by exercise is at least partly accounted for by increased mitochondrial content and possibly intrinsic mitochondrial adaptations. The insulin sensitizing effect of physical exercise training occurs in the absence of major changes in body mass and is not restricted to improved muscle insulin sensitivity but extends to improved hepatic- and adipose tissue insulin sensitivity. 


\section{References}

1. Befroy DE, Petersen KF, Dufour S, Mason GF, de Graaf RA, Rothman DL, Shulman GI: Impaired mitochondrial substrate oxidation in muscle of insulin-resistant offspring of type 2 diabetic patients. Diabetes 56:1376-1381, 2007

2. Petersen KF, Dufour S, Shulman GI: Decreased insulin-stimulated ATP synthesis and phosphate transport in muscle of insulin-resistant offspring of type 2 diabetic parents. PLoS Med 2:e233, 2005

3. Roden M: Muscle triglycerides and mitochondrial function: possible mechanisms for the development of type 2 diabetes. Int J Obes (Lond) 29 Suppl 2:S111-115, 2005

4. Kelley DE, He J, Menshikova EV, Ritov VB: Dysfunction of mitochondria in human skeletal muscle in type 2 diabetes. Diabetes 51:2944-2950, 2002

5. Mootha VK, Lindgren CM, Eriksson KF, Subramanian A, Sihag S, Lehar J, Puigserver P, Carlsson E, Ridderstrale M, Laurila E, Houstis N, Daly MJ, Patterson N, Mesirov JP, Golub TR, Tamayo P, Spiegelman B, Lander ES, Hirschhorn JN, Altshuler D, Groop LC: PGC-1alpha-responsive genes involved in oxidative phosphorylation are coordinately downregulated in human diabetes. Nat Genet 34:267-273, 2003

6. Patti ME, Butte AJ, Crunkhorn S, Cusi K, Berria R, Kashyap S, Miyazaki Y, Kohane I, Costello M, Saccone R, Landaker EJ, Goldfine AB, Mun E, DeFronzo R, Finlayson J, Kahn CR, Mandarino LJ: Coordinated reduction of genes of oxidative metabolism in humans with insulin resistance and diabetes: Potential role of PGC1 and NRF1. Proc Natl Acad Sci U S A 100:8466-8471, 2003

7. Mensink M, Hesselink MK, Russell AP, Schaart G, Sels JP, Schrauwen P: Improved skeletal muscle oxidative enzyme activity and restoration of PGC-1 alpha and PPAR beta/delta gene expression upon rosiglitazone treatment in obese patients with type 2 diabetes mellitus. Int J Obes (Lond) 31:1302-1310, 2007

8. Petersen KF, Dufour S, Befroy D, Garcia R, Shulman GI: Impaired mitochondrial activity in the insulin-resistant offspring of patients with type 2 diabetes. N Engl J Med 350:664671,2004

9. Schrauwen-Hinderling VB, Kooi ME, Hesselink MK, Jeneson JA, Backes WH, van Echteld CJ, van Engelshoven JM, Mensink M, Schrauwen P: Impaired in vivo mitochondrial function but similar intramyocellular lipid content in patients with type 2 diabetes mellitus and BMI-matched control subjects. Diabetologia 50:113-120, 2007

10. Phielix E, Schrauwen-Hinderling VB, Mensink M, Lenaers E, Meex R, Hoeks J, Kooi ME, Moonen-Kornips E, Sels JP, Hesselink MK, Schrauwen P: Lower intrinsic ADPstimulated mitochondrial respiration underlies in vivo mitochondrial dysfunction in muscle of male type 2 diabetic patients. Diabetes 57:2943-2949, 2008

11. Goodpaster BH, He J, Watkins S, Kelley DE: Skeletal muscle lipid content and insulin resistance: evidence for a paradox in endurance-trained athletes. J Clin Endocrinol Metab 86:5755-5761, 2001

12. Standards of medical care in diabetes--2009. Diabetes Care 32 Suppl 1:S13-61, 2009

13. Toledo FG, Menshikova EV, Azuma K, Radikova Z, Kelley CA, Ritov VB, Kelley DE: Mitochondrial capacity in skeletal muscle is not stimulated by weight loss despite increases in insulin action and decreases in intramyocellular lipid content. Diabetes 57:987-994, 2008

14. Schrauwen-Hinderling VB, Schrauwen P, Hesselink MK, van Engelshoven JM, Nicolay $\mathrm{K}$, Saris WH, Kessels AG, Kooi ME: The increase in intramyocellular lipid content is a very early response to training. J Clin Endocrinol Metab 88:1610-1616, 2003 
15. Tarnopolsky MA, Rennie CD, Robertshaw HA, Fedak-Tarnopolsky SN, Devries MC, Hamadeh MJ: Influence of endurance exercise training and sex on intramyocellular lipid and mitochondrial ultrastructure, substrate use, and mitochondrial enzyme activity. Am J Physiol Regul Integr Comp Physiol 292:R1271-1278, 2007

16. Thamer C, Machann J, Bachmann O, Haap M, Dahl D, Wietek B, Tschritter O, Niess A, Brechtel K, Fritsche A, Claussen C, Jacob S, Schick F, Haring HU, Stumvoll M: Intramyocellular lipids: anthropometric determinants and relationships with maximal aerobic capacity and insulin sensitivity. J Clin Endocrinol Metab 88:1785-1791, 2003

17. Alberti KG: Impaired glucose tolerance: what are the clinical implications? Diabetes Res Clin Pract 40 Suppl:S3-8, 1998

18. Siri WE: The gross composition of the body. Adv Biol Med Phys 4:239-280, 1956

19. Kuipers H, Verstappen FT, Keizer HA, Geurten P, van Kranenburg G: Variability of aerobic performance in the laboratory and its physiologic correlates. Int J Sports Med 6:197-201, 1985

20. Steele R: Influences of glucose loading and of injected insulin on hepatic glucose output. Ann N Y Acad Sci 82:420-430, 1959

21. Frayn KN: Calculation of substrate oxidation rates in vivo from gaseous exchange. $J$ Appl Physiol 55:628-634, 1983

22. Vanhamme L, van den Boogaart A, Van Huffel S: Improved method for accurate and efficient quantification of MRS data with use of prior knowledge. J Magn Reson 129:3543, 1997

23. Naressi A, Couturier C, Devos JM, Janssen M, Mangeat C, de Beer R, Graveron-Demilly D: Java-based graphical user interface for the MRUI quantitation package. MAGMA 12:141-152, 2001

24. Sahlin K, Harris RC, Hultman E: Resynthesis of creatine phosphate in human muscle after exercise in relation to intramuscular $\mathrm{pH}$ and availability of oxygen. Scand J Clin Lab Invest 39:551-558, 1979

25. Kemp GJ, Taylor DJ, Radda GK: Control of phosphocreatine resynthesis during recovery from exercise in human skeletal muscle. NMR Biomed 6:66-72, 1993

26. Arias-Mendoza F: In vivo magnetic resonance spectroscopy in the evaluation of mitochondrial disorders. Mitochondrion 4:491-501, 2004

27. Mattei JP, Bendahan D, Cozzone P: P-31 magnetic resonance spectroscopy. A tool for diagnostic purposes and pathophysiological insights in muscle diseases. Reumatismo 56:9-14, 2004

28. Koopman R, Schaart G, Hesselink MK: Optimisation of oil red O staining permits combination with immunofluorescence and automated quantification of lipids. Histochem Cell Biol 116:63-68, 2001

29. Hoeks J, Hesselink MK, Sluiter W, Schaart G, Willems J, Morrisson A, Clapham JC, Saris WH, Schrauwen P: The effect of high-fat feeding on intramuscular lipid and lipid peroxidation levels in UCP3-ablated mice. FEBS Lett 580:1371-1375, 2006

30. Schrauwen P, Hesselink MK, Blaak EE, Borghouts LB, Schaart G, Saris WH, Keizer HA: Uncoupling protein 3 content is decreased in skeletal muscle of patients with type 2 diabetes. Diabetes 50:2870-2873, 2001

31. Schrauwen P, Mensink M, Schaart G, Moonen-Kornips E, Sels JP, Blaak EE, Russell AP, Hesselink MK: Reduced skeletal muscle uncoupling protein-3 content in prediabetic subjects and type 2 diabetic patients: restoration by rosiglitazone treatment. J Clin Endocrinol Metab 91:1520-1525, 2006

32. Szendroedi J, Schmid AI, Chmelik M, Toth C, Brehm A, Krssak M, Nowotny P, Wolzt M, Waldhausl W, Roden M: Muscle mitochondrial ATP synthesis and glucose transport/phosphorylation in type 2 diabetes. PLoS Med 4:e154, 2007

33. Abdul-Ghani MA, DeFronzo RA: Mitochondrial dysfunction, insulin resistance, and type 2 diabetes mellitus. Curr Diab Rep 8:173-178, 2008 
34. De Feyter HM, Lenaers E, Houten SM, Schrauwen P, Hesselink MK, Wanders RJ, Nicolay K, Prompers JJ: Increased intramyocellular lipid content but normal skeletal muscle mitochondrial oxidative capacity throughout the pathogenesis of type 2 diabetes. FASEB J 22:3947-3955, 2008

35. Boushel R, Gnaiger E, Schjerling P, Skovbro M, Kraunsoe R, Dela F: Patients with type 2 diabetes have normal mitochondrial function in skeletal muscle. Diabetologia 50:790796, 2007

36. Mogensen M, Sahlin K, Fernstrom M, Glintborg D, Vind BF, Beck-Nielsen H, Hojlund $\mathrm{K}$ : Mitochondrial respiration is decreased in skeletal muscle of patients with type 2 diabetes. Diabetes 56:1592-1599, 2007

37. Schrauwen P, Hesselink MK: Oxidative capacity, lipotoxicity, and mitochondrial damage in type 2 diabetes. Diabetes 53:1412-1417, 2004

38. Krssak M, Falk Petersen K, Dresner A, DiPietro L, Vogel SM, Rothman DL, Roden M, Shulman GI: Intramyocellular lipid concentrations are correlated with insulin sensitivity in humans: a 1H NMR spectroscopy study. Diabetologia 42:113-116, 1999

39. Pan DA, Lillioja S, Kriketos AD, Milner MR, Baur LA, Bogardus C, Jenkins AB, Storlien LH: Skeletal muscle triglyceride levels are inversely related to insulin action. Diabetes 46:983-988, 1997

40. van Loon LJ, Koopman R, Manders R, van der Weegen W, van Kranenburg GP, Keizer HA: Intramyocellular lipid content in type 2 diabetes patients compared with overweight sedentary men and highly trained endurance athletes. Am J Physiol Endocrinol Metab 287:E558-565, 2004

41. Bruce CR, Anderson MJ, Carey AL, Newman DG, Bonen A, Kriketos AD, Cooney GJ, Hawley JA: Muscle oxidative capacity is a better predictor of insulin sensitivity than lipid status. J Clin Endocrinol Metab 88:5444-5451, 2003

42. Liu L, Zhang Y, Chen N, Shi X, Tsang B, Yu YH: Upregulation of myocellular DGAT1 augments triglyceride synthesis in skeletal muscle and protects against fat-induced insulin resistance. J Clin Invest 117:1679-1689, 2007

43. Schenk S, Horowitz JF: Acute exercise increases triglyceride synthesis in skeletal muscle and prevents fatty acid-induced insulin resistance. J Clin Invest 117:1690-1698, 2007

44. Kelley DE, Mandarino LJ: Fuel selection in human skeletal muscle in insulin resistance: a reexamination. Diabetes 49:677-683, 2000

45. Galgani JE, Heilbronn LK, Azuma K, Kelley DE, Albu JB, Pi-Sunyer X, Smith SR, Ravussin E: Metabolic flexibility in response to glucose is not impaired in people with type 2 diabetes after controlling for glucose disposal rate. Diabetes 57:841-845, 2008

46. Shulman GI, Rothman DL, Jue T, Stein P, DeFronzo RA, Shulman RG: Quantitation of muscle glycogen synthesis in normal subjects and subjects with non-insulin-dependent diabetes by 13C nuclear magnetic resonance spectroscopy. $N$ Engl J Med 322:223-228, 1990

47. Widen EI, Eriksson JG, Groop LC: Metformin normalizes nonoxidative glucose metabolism in insulin-resistant normoglycemic first-degree relatives of patients with NIDDM. Diabetes 41:354-358, 1992

48. Dela F, Larsen JJ, Mikines KJ, Ploug T, Petersen LN, Galbo H: Insulin-stimulated muscle glucose clearance in patients with NIDDM. Effects of one-legged physical training. Diabetes 44:1010-1020, 1995

49. Yokoyama H, Mori K, Emoto M, Araki T, Teramura M, Mochizuki K, Tashiro T, Motozuka K, Inoue Y, Nishizawa Y: Non-oxidative glucose disposal is reduced in type 2 diabetes, but can be restored by aerobic exercise. Diabetes Obes Metab 10:400-407, 2008 


\title{
CHAPTER 4
}

\author{
Increased expression of myocellular PAT \\ proteins and improved control of basal \\ lipolysis and metabolic flexibility after a 12 \\ week insulin-sensitizing exercise program \\ in type 2 diabetic subjects.
}

\begin{abstract}

\section{Objective}

We studied the hypothesis that changes in lipid droplet (LD) coating proteins and proteins involved in LD synthesis and degradation contributes to insulin resistance in type 2 diabetic patients (T2D) and examined the effect of exercise training as an insulin-sensitizing intervention on protein abundance of LD coating proteins.
\end{abstract}

\section{Research Design and Methods}

18 male T2D and 20 BMI and age-matched normoglycemic control subjects (C) exercise-trained for 12 weeks. Myocellular lipid, LD coating proteins and indices of muscle lipolysis were measured before and after training, and evaluated in the light of changes in insulin sensitivity and substrate selection.

\section{Results}

Pre-training, TIP-47/perilipin 3 was significantly lower in T2D, along with similar LD content, ADRP/perilipin2, OXPAT/perilipin5, TAGhydrolysis and ATGL. Training restored TIP-47/perilipin3 in T2D towards C levels. Post-training muscle lipid increased only modestly ( $>0.05$ ), while ADRP/perilipin2 and OXPAT/perilipin5 protein content increased $\sim 2$-fold in C and T2D $(\mathrm{p}<0.05)$. Training increased ATGL protein in T2D only. Changes in LD coating proteins correlated with changes in substrate selection under basal and insulin-stimulated conditions.

\section{Conclusions}

T2D subjects restored their capacity to mature nascent LD indicated by restoration of TIP-47/perilipin3. Exercise-training increased ADRP/perilipin2 and OXPAT/perilipin5 and hence reduced TAG hydrolase activity despite increased ATGL content. Correlative analysis revealed that these changes may be are implicated in regulating exercise- and insulin-mediated changes in substrate selection. These changes, however, did not associate with exercise training-mediated changes in insulin-stimulated glucose uptake. 


\section{Introduction}

Fatty acids stored in adipose tissue as triacylglycerol are quantitatively important substrates for oxidative energy metabolism. Storage of fatty acids in triacylglycerol dense lipid droplets (LD) can occur in virtually all tissues (ectopic fat storage). Ectopic fat storage in insulin sensitive tissues like skeletal muscle correlates negatively with insulin sensitivity in untrained subjects $(1 ; 2)$. Hence, it has been suggested that ectopic fat storage may impede insulin sensitivity by inhibiting post-receptor insulin signalling (3). In subjects with a high oxidative capacity (e.g. endurance trained athletes) however, high levels of ectopic fat storage are observed in parallel with high insulin sensitivity $(4 ; 5)$. Intriguingly, while examining obese normoglycemic subjects and BMI and age-matched insulin resistant type 2 diabetic patients we observed the same fat content but lower mitochondrial oxidative capacity (6), suggesting that augmented ectopic fat storage per se is insufficient to impede insulin signaling. Indeed, intermediates in the synthesis and the degradation of ectopically stored fat have been hypothesized to impede insulin signaling (3). Along these lines it is of interest to note that improved partitioning of fat into myocellular LD reduces the susceptibility to lipid-induced insulin resistance $(7 ; 8)$.

Incorporation of fatty acids in ectopically stored LD as well as the controlled release of fatty acids from LD (jointly referred to as LD dynamics) has been subject to research for decades. Recent progress in this field identified the involvement of multiple lipases, co-activators and lipid droplet coating (PAT) proteins, all involved in the well orchestrated regulation of LD dynamics as reviewed recently (9-11)

Acute physical exercise $(8 ; 12)$ as well as short- (7) and medium (13) term exercise training already augments fat storage in muscle in healthy lean subjects, in a fatty acid dependent manner $(12 ; 14 ; 15)$. Conversely, it has convincingly been shown in healthy lean subjects that intramyocellular fatty acids mobilized from LD are used as substrates during exercise (16). In rats selectively bred for low intrinsic exercise capacity, compromised ectopic fat mobilisation was associated with whole body insulin resistance (17). Interestingly, in obese subjects beta-adrenergic stimulation of lipolysis from ectopically stored lipid was blunted (18). These data indicate that exercise training augments ectopic fat storage capacity while obesity and a low exer- 
cise capacity are associated with blunted lipolysis. Dysregulation of LD dynamics and the proteins involved herein are likely to contribute to myocellular insulin resistance but information on this in muscle from patients with type 2 diabetes has not been shown so far.

Here we studied the hypothesis that changes of the proteins involved in LD degradation and synthesis contributes to myocellular insulin resistance in obese type 2 diabetics. Furthermore, we studied the hypothesis that an insulin-sensitising exercise program goes along with adaptive responses in LD dynamics.

To this end, we examined in muscle biopsies from obese normoglycemic and obese type 2 diabetics protein content of adipose triglyceride lipase (ATGL), its regulatory co-factor comparative gene interaction-58 (CGI-58), the lipid droplet coating proteins of the PAT family (ADRP/Perilipin2, TIP-47/Perilipin3 and OXPAT/Perilipin5) and triacylglycerol- (TAG) and diacylglycerol (DAG) hydrolase activity before and after a 12 week insulin sensitizing exercise training program.

\section{Research design and methods}

\section{Subjects characteristics}

Male type 2 diabetic subjects (T2D, n=18) and normoglycemic control subjects (C, $\mathrm{n}=20$ ) matched for body weight, body mass index (BMI) and age were included. Glucose tolerance was examined by an oral glucose tolerance test (OGTT) (19). Diabetic patients were diagnosed with type 2 diabetes for at least 1 year before the start of the study, had well-controlled diabetes $(\mathrm{HbA} 1 \mathrm{c}= \pm 7.2 \%)$ and were only using oral anti-diabetic agents (metformin only, or in combination with SU derivatives). All medication was maintained throughout the study. All subjects had a sedentary lifestyle as recorded by a questionnaire. The ethical committee of the Maastricht University Medical Centre approved the study and all subjects gave written informed consent before participation. Body composition was measured through hydrostatic weighing and maximal work load and oxygen uptake was assessed during a graded cycling test until exhaustion. 


\section{Exercise training protocol}

Subjects performed a 12-week heart rate monitored progressive exercise training program in small groups $(n=3-4)$, which were individually supervised. Aerobic exercise on a cycling ergometer was performed twice a week for 30 minutes at $55 \%$ of a predetermined maximal work load (Wmax). Maximal workload was tested during a graded exercise test on a stationary bike and workload was considered maximal if at least 2 out of the following 4 criteria were met; a plateau in oxygen consumption, a respiratory quotient $>1.10$, heart rate $>220$ minus age, or when the cadence dropped below 60 revolutions per minute. Maximal workload was reassessed after 6 weeks and training load was adjusted accordingly. All tests were performed under standardized conditions and fat oxidation measurements were performed (indirect calorimetry) during the steady-state phase of stage 75 and 125 Watt. Resistance exercise was performed once a week and comprised 1 series of 8 repetitions at $55 \%$ of previously determined maximal voluntary contraction (MVC) and 2 series of 8 repetitions at $75 \% \mathrm{MVC}$ and focused on large muscle groups (Chest press, leg extension, lat pull down, leg press, triceps curls, biceps curls, abdominal crunches, horizontal row). To determine MVC, subjects were instructed to lift a load 10 times (=1 set). After successfully completing the set the work load was increased, until 10 repetitions could no longer be attained. From this work load, the MVC was calculated. We targeted achieving maximal work load within 4 sets at maximal, and with 5 repetitions maximally in the final set. Successive sets were separated by a 2 -minute rest period. The MVC test to assess maximal work load was preceded by a familiarization trial. Every 4 weeks, MVC was reassessed and training loads was readjusted accordingly. Each

training session was preceded and ended with 5 minutes of warming up/cooling down on the cycling ergometer at $45 \% \mathrm{Wmax}$.

\section{Hyperinsulinemic-euglycemic clamp}

A 6-hour hyperinsulinemic-euglycemic insulin clamp $\left(40 \mathrm{mU} / \mathrm{m}^{2} / \mathrm{min}\right)$ was performed before and after the training period after an overnight fast as described previously (20). Antidiabetic medication was discontinued 7 days prior to the clamp. Subjects refrained from any physical exercise at least 48 hours prior to the clamp. Rates of 78 
glucose disposal $(R \mathrm{~d})$ was determined using [6,6-2H2]glucose and used to calculate insulin sensitivity index ( $\mathrm{Si})$. In the final 30 minutes of the non-insulin stimulated period $(\mathrm{t}=150-180)$ and under steady hyperinsulinemic conditions $(\mathrm{t}=330-360)$, blood was sampled and indirect calorimetry (ventilated hood) was performed. Pre- and post exercise training needle muscle biopsies from the vastus lateralis muscle were obtained (3 snaps using a $5.0 \mathrm{~mm}$ Bergstrom needle with suction applied) in the 30 minutes preceding the clamp. Muscle biopsies obtained were freed from any visible detectable fat and connective tissue, snap frozen in melting isopentane and transported under liquid nitrogen and stored at $-80^{\circ} \mathrm{C}$ until analysis.

\section{Blood sample analysis}

Arterialised blood samples were collected in EDTA coated tubes, from a hot-box heated hand vein. Plasma free fatty acids (FFAs) and glucose were measured with enzymatic assays automated on a Cobas Fara/Mira (FFA: Wako Nefa C test kit; Wako Chemicals, Neuss, Germany) (glucose: hexokinase method; LaRoche, Basel, Switzerland). Plasma insulin levels were measured by a radioimmunoassay (Linco Research, St. Charles, MO).

\section{Lipid droplet content and fiber typing}

Muscle fiber typing and intramyocellular lipid content was assessed histochemically in muscle cross-sections using a modified oil red $\mathrm{O}$ staining for fluorescence microscopy (21). Muscle cell membranes were stained blue using a monoclonal IgG antibody against the basal membrane marker laminin (2E8, Developmental Hybridoma Bank, Iowa City, IA 52242, USA). Type 1 muscle fibers (slow myosin type 1, MHC1) were stained green using a monoclonal $\operatorname{IgM}$ antibody against myosin heavy chain type 1 (A4.840, Developmental Hybridoma Bank, Iowa City, IA 52242, USA). By tresholding the blue signal, individual muscle fibers were detected and counted semi-automatically. By tresholding the green signal, the type 1 muscle fibers were identified and counted; the remainder of the fibers was classified as type 2 fibers. By tresholding the red signal, LD were identified and content was expressed as the cumulative area of the LD relative to the cell area and expressed as area fraction. Image 
capturing and threshold settings were kept the same for pre- and post training samples of the individual subjects. A previously written macro was used and all analyses were performed by an experienced microscopist blinded for subject group and intervention to avoid inter-observer bias. For each subject a minimum of 150 fibers were examined pre and post training. Representative histological slides are presented in figure 1 .

\section{Western blotting}

Muscle samples were homogenized in ice-cold PBS containing 1\% Nonidet-P40, $0.5 \%$ sodium dodecyl sulfate, $0.1 \mathrm{mM}$ phenylmethylsulfonyl fluoride, complete inhibitor (Roche, Almere, The Netherlands) and processed for standard SDS-PAGE and Western blotting. Protein concentration was assessed, and gels were loaded with equal amounts of protein of pre- and post training lysates of 2 control and 2 type diabetic subjects per gel to allow valid comparison between pre- and post training samples. Membranes were incubated with antibodies against OXPAT/perililipin5 (GP31, Progen, Heidelberg, Germany), ADRP/perilipin2 (GP40, Progen), ATGL (2138; Cell Signalling Technology; Bioké; Leiden, The Netherlands), CGI58 (NB110-41576; Novus Biologicals, Littleton, CO, USA) and TIP47/Perilipin3 (GP30, Progen). Blots incubated with OXPAT/perilipin5, ADRP/perilipin2, and TIP47/Perilipin3 were probed with appropriate IRDye800-conjugated secondary antibodies (Rockland, Gilbertsville, PA, USA and LICOR Biosciences, Westburg, Leusden, The Netherlands), and bands at a molecular weight corresponding to the control samples were quantified using the Odyssey infrared imaging system (LICOR Biosciences, Westburg, the Netherlands). Blots detecting ATGL and CGI58 were probed with the appropriate horseradish-conjugated antibodies and after incubation specific protein bands were visualized by chemiluminescence and analyzed by Chemidoc XRS system (Bio-Rad, Veenendaal, the Netherlands). Protein content was expressed as arbitrary units (AU). 


\section{TAG and DAG hydrolase activity}

TAG and DAG hydrolase activities were measured on muscle tissue homogenates as previously described (22). Briefly, triolein and 1(3)-mono-oleyl-2-O-monooleylglycerol were emulsified with phospholipids by sonication. Triolein is a triglyceride containing three oleic acid specifically used to determine TAG hydrolase activity. 1(3)-mono-oleyl-2-O-mono-oleylglycerol is a DAG analog used to measure specifically the DAG hydrolase activity as it is not a substrate for monoacylglycerol lipase. Lipase activity data were normalized to total protein content determined in each sample and expressed in nanomoles per minute per milligram.

\section{Statistics}

Statistical analyses were performed two-sided using SPSS for Windows 15.0 software (SPSS, Chicago, IL). A two-way ANOVA model for repeated measures was applied using control and type 2 diabetics as between subject variables and pre- and post training data as repeated within subject variables. In case of a significant F-ratio, differences were allocated using Bonferonni post-hoc tests. Differential responses between $\mathrm{C}$ and T2D were examined using the interaction terms, but no significant interaction effects were detected. Correlations reported were computed as Spearman correlation coefficients. The level of statistical significance was set at $\mathrm{p}<0.05$.

\section{Results}

\section{Subject characteristics}

Control subjects (C) and type 2 diabetic patients (T2D) were carefully matched for body weight, BMI and age. Fat free mass was similar between T2D and C and was unaffected by training (table 1). Maximal oxygen uptake before training was comparable in both groups and increased upon training $(+6.4 \pm 2.6 \%, \mathrm{p}=0.04$ in $\mathrm{C}$ and $+11.3 \pm 2.2 \%, \mathrm{p}<0.01$ in T2D). Fasting plasma free fatty acid (FFA) levels were similar across groups and were unaffected by training (table 1). 
CHA P T E R 4

Table 1: subject characteristics

\begin{tabular}{lcccc}
\hline & \multicolumn{3}{c}{ C } & \multicolumn{2}{c}{ T2D } \\
\cline { 2 - 4 } Subject characteristics & Pre-training & Post-training & Pre-training & Post-training \\
\hline Age (years) & $59.0 \pm 0.8$ & $/$ & $59.4 \pm 1.1$ & $/$ \\
Years since diagnosis & $/$ & $/$ & $3.9 \pm 0.9$ & $/$ \\
Weight (kg) & $94.7 \pm 2.7$ & $93.6 \pm 2.7$ & $93.8 \pm 2.9$ & $92.8 \pm 3.1$ \\
Height (cm) & $178.5 \pm 1.3$ & $/$ & $176.7 \pm 1.3$ & $/$ \\
BMI (kg/m ${ }^{2}$ ) & $29.7 \pm 0.8$ & $29.4 \pm 0.8$ & $30.0 \pm 0.8$ & $29.8 \pm 0.9$ \\
Body fat (\%) & $31.5 \pm 1.4$ & $30.6 \pm 1.6$ & $31.1 \pm 1.4$ & $29.9 \pm 1.3 *$ \\
FM (kg) & $30.0 \pm 1.8$ & $29.2 \pm 2.0$ & $29.4 \pm 1.9$ & $28.0 \pm 1.8 *$ \\
FFM (kg) & $64.6 \pm 2.0$ & $65.4 \pm 2.0$ & $64.3 \pm 1.7$ & $64.8 \pm 1.8$ \\
VO2max (ml/min/kg) & $28.8 \pm 1.0$ & $30.2 \pm 1.2 *$ & $27.5 \pm 1.2$ & $31.1 \pm 1.2 *$ \\
Wmax (Watt) & $207 \pm 10$ & $236 \pm 9 *$ & $202 \pm 9$ & $233 \pm 9 *$ \\
Average strength (kg) & $85.8 \pm 3.2$ & $104.0 \pm 3.5 *$ & $83.7 \pm 3.5$ & $102.4 \pm 4.2 *$ \\
Fasting glucose (mmol/l) & $5.9 \pm 0.1$ & $5.5 \pm 0.1 *$ & $9.0 \pm 0.4 \#$ & $9.0 \pm 0.4 \#$ \\
HbA1c (\%) & $5.8 \pm 0.1$ & $5.7 \pm 0.1 *$ & $7.2 \pm 0.2 \#$ & $7.2 \pm 0.2 \#$ \\
Triacylglycerol (mmol/l) & $1.52 \pm 0.13$ & $1.49 \pm 0.15$ & $1.77 \pm 0.16$ & $1.68 \pm 0.14$ \\
Type 1 muscle fibers (\%) & $40.0 \pm 2.3$ & $39.5 \pm 2.8$ & $40.0 \pm 3.9$ & $36.5 \pm 2.5$ \\
Type 2 muscle fibers (\%) & $60.0 \pm 2.3$ & $60.5 \pm 2.8$ & $60.0 \pm 3.9$ & $63.5 \pm 2.5$ \\
\hline
\end{tabular}

Data are expressed as mean \pm SE., \#T2D significantly different from control group, *post-training significantly different from pre-training.

\section{Insulin sensitivity index}

Insulin sensitivity index $(\mathrm{Si}, \mu \mathrm{mol} / \mathrm{kg} / \mathrm{min} / \mathrm{mU})$ was considerably lower in $\mathrm{T} 2 \mathrm{D}$ than in $C$ (table 2). Exercise training significantly $(\mathrm{p}<0.01)$ improved insulin sensitivity in T2D and C (table 2).

\section{Lipid oxidation}

Under insulin stimulation, suppression of lipid oxidation was less pronounced in T2D than in $\mathrm{C}$ before training (metabolic inflexibility). After training, suppression of lipid oxidation in T2D restored to levels similar to age- and BMI matched control subjects (table 2), reflecting restoration of metabolic flexibility. Lipid oxidation during submaximal exercise (at 75 and $125 \mathrm{~W}$ ) was comparable in $\mathrm{C}$ and $\mathrm{T} 2 \mathrm{D}$ before training $(1.77 \pm 0.57$ and $1.97 \pm 0.57 \mu \mathrm{mol} / \mathrm{kg} / \mathrm{min}$ at 75 watt in $\mathrm{C}$ and $\mathrm{T} 2 \mathrm{D}$ respectively; 
$0.95 \pm 0.07$ and $0.84 \pm 0.07 \mu \mathrm{mol} / \mathrm{kg} / \mathrm{min}$ at 125 watt in $\mathrm{C}$ and $\mathrm{T} 2 \mathrm{D}$ respectively). Training improved lipid oxidation in $\mathrm{C}$ and T2D at 75 Watts $(3.05 \pm 0.48$ in $\mathrm{C}, \mathrm{p}<0.01$ and 3.99 \pm 0.43 in $\mathrm{T} 2 \mathrm{D}, \mathrm{p}<0.01)$ as well as at 125 Watts $(2.84 \pm 0.65$ in $\mathrm{C}, \mathrm{p}<0.05$ and $3.13 \pm 0.42$ in $\mathrm{T} 2 \mathrm{D}, \mathrm{p}<0.05)$.

Table 2: Substrate kinetics pre- and post training

\begin{tabular}{ccccc}
\hline & \multicolumn{3}{c}{ C } & T2D \\
\cline { 2 - 4 } & Pre-training & Post-training & Pre-training & Post-training \\
\hline Plasma insulin $(\mathrm{mU} / \mathrm{l})$ & & & \\
Basal & $18.1 \pm 2.4$ & $16.1 \pm 2.1 *$ & $16.4 \pm 1.2$ & $14.6 \pm 0.8^{*}$ \\
Clamp & $112.5 \pm 5.4$ & $112.1 \pm 5.5$ & $107.6 \pm 4.8$ & $103.1 \pm 2.7$ \\
Plasma FFA $(\mu \mathrm{mol} / \mathrm{l})$ & & & \\
Basal & $479.0 \pm 22.9$ & $454.9 \pm 28.3$ & $519.4 \pm 25.3$ & $500.1 \pm 34.1$ \\
Clamp & $84.7 \pm 7.2$ & $67.5 \pm 6.9 *$ & $107.1 \pm 8.7$ & $87.6 \pm 8.7 *$ \\
Si (ml/kg/min per uU/ml) & $0.029 \pm 0.005$ & $0.034 \pm 0.005 *$ & $0.013 \pm 0.002 \#$ & $0.023 \pm 0.003 *$ \\
Lipid oxidation & & & & \\
$(\mu \mathrm{mol} / \mathrm{kg} / \mathrm{min})$ & & & & $1.09 \pm 0.05$ \\
Basal & $1.08 \pm 0.05$ & $1.03 \pm 0.05$ & $1.08 \pm 0.05$ & $0.59 \pm 0.05 *$ \\
Clamp & $0.63 \pm 0.04$ & $0.55 \pm 0.04$ & $0.75 \pm 0.04 \#$ \\
Delta & $-0.46 \pm 0.05$ & $-0.48 \pm 0.06$ & $-0.32 \pm 0.06$ & $-0.49 \pm 0.06 *$ \\
\hline
\end{tabular}

Data are expressed as mean \pm SE., \#T2D significantly different from control group, *post-training significantly different from pre-training.

\section{Muscle Lipid droplet content and lipid droplet coating proteins}

Immnohistochemical analyses of percentage MHCI and MHCII positive muscle fibers was similar at baseline and did not change significantly upon training (table 1 and figure 1). Pre-training, LD content (presented as arbitrary units AU) was comparable in both (BMI matched) groups $(1.36 \pm 0.20$ and $1.49 \pm 0.20$ in $\mathrm{C}$ and T2D respectively, $\mathrm{p}=0.65$ ). LD content did not change after training in $\mathrm{C}$ (from $1.36 \pm 0.20$ to $1.33 \pm 0.23$ post-training; $\mathrm{p}=0.89$ ), whereas in $\mathrm{T} 2 \mathrm{D}$ LD content increased modestly and near significantly (from $1.49 \pm 0.20$ to $1.91 \pm 0.34 ; \mathrm{p}=0.10$ ). Representative images of the combined LD and fiber typing are shown in figure 1. Before training, the protein abundance (expressed as AU) of the lipid droplet coating protein ADRP/perilipin2 as well as OXPAT/perilipin5 was comparable between $\mathrm{C}$ and T2D 
(ADRP/perilipin2: $0.59 \pm 0.06$ and $0.71 \pm 0.09$ in $\mathrm{C}$ and $\mathrm{T} 2 \mathrm{D}$ respectively; OXPAT/perilipin5: $0.70 \pm 0.14$ and $0.70 \pm 0.10$ in $\mathrm{C}$ and $\mathrm{T} 2 \mathrm{D}$ respectively) and increased after exercise similarly in both groups (ADRP/perilipin2: from $0.59 \pm 0.06$ to $1.17 \pm 0.14$ in $\mathrm{C}$ and from $0.71 \pm 0.09$ to $1.55 \pm 0.20$ in $\mathrm{T} 2 \mathrm{D}, \mathrm{p}<0.01$ in both groups; OXPAT/perilipin5: from $0.70 \pm 0.14$ to $1.29 \pm 0.19$ in $\mathrm{C}$ and from $0.70 \pm 0.10$ to $1.27 \pm 0.20$ in $\mathrm{T} 2 \mathrm{D}, \mathrm{p}<0.05$ in both groups, figure $1 \mathrm{e}$ and $1 \mathrm{~g})$. Pre-training, TIP47/perilipin3 was significantly higher in C compared to T2D (1.10 \pm 0.11 and $0.81 \pm 0.08$ in $\mathrm{C}$ and $\mathrm{T} 2 \mathrm{D}$ respectively, $\mathrm{p}=0.04$ ). After training TIP-47/perilipin3 in T2D restored to levels similar to age- and BMI matched control subjects $(1.09 \pm 0.09$ and $1.00 \pm 0.08$ in $\mathrm{C}$ and T2D respectively, $\mathrm{p}=0.46$ ) (Figure 1f).
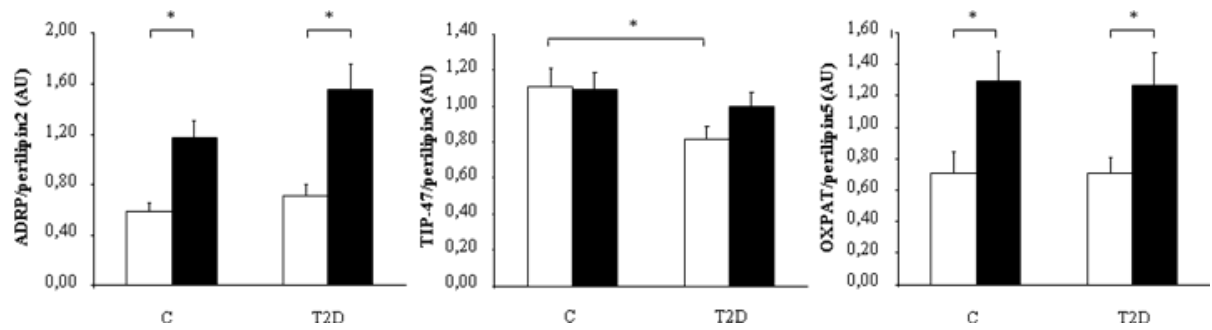

Figure 1: Protein expression of ADRP/perilipin2 (figure 1a), TIP47/perilipin3 (figure 1b) and OXPAT/perilipin5 (figure 1c) in vastus lateralis muscle, before (white bars) and after training (black bars). Data are expressed as mean (in arbitrary units) \pm SE. *significantly different with $\mathrm{p}<0.05$.

\section{ATGL and CGI-58}

Pre-training, ATGL protein content was comparable between groups $(0.73 \pm 0.14$ and $0.87 \pm 0.20$ in $\mathrm{C}$ and $\mathrm{T} 2 \mathrm{D}$ respectively, $\mathrm{p}=0.58$ ) and tended to increase in T2D (from $0.87 \pm 0.20$ to $1.70 \pm 0.34, \mathrm{p}=0.06$ ) after training but not in $\mathrm{C}$ (from $0.73 \pm 0.14$ to $0.77 \pm 0.20 ; \mathrm{p}=0.85$, figure $2 \mathrm{a}$ ). After training, ATGL protein content was significantly higher in T2D than in $\mathrm{C}(\mathrm{p}=0.02)$. CGI-58 protein content tended to be different between groups before training (1.09 \pm 0.11 and 0.810 .10 in $\mathrm{C}$ and T2D respectively, $\mathrm{p}=0.06$ ) and was not significantly affected in either group (from $1.03 \pm 0.12$ to 1.24 $\pm 0.13, \mathrm{p}=0.12$ in $\mathrm{C}$ and from $0.81 \pm 0.10$ to $0.92 \pm 0.08, \mathrm{p}=0.21$ in $\mathrm{T} 2 \mathrm{D}$, figure $2 \mathrm{~b}$ ). After training, CGI-58 protein levels were significantly lower in T2D than in C $(\mathrm{p}=0.03)$. 

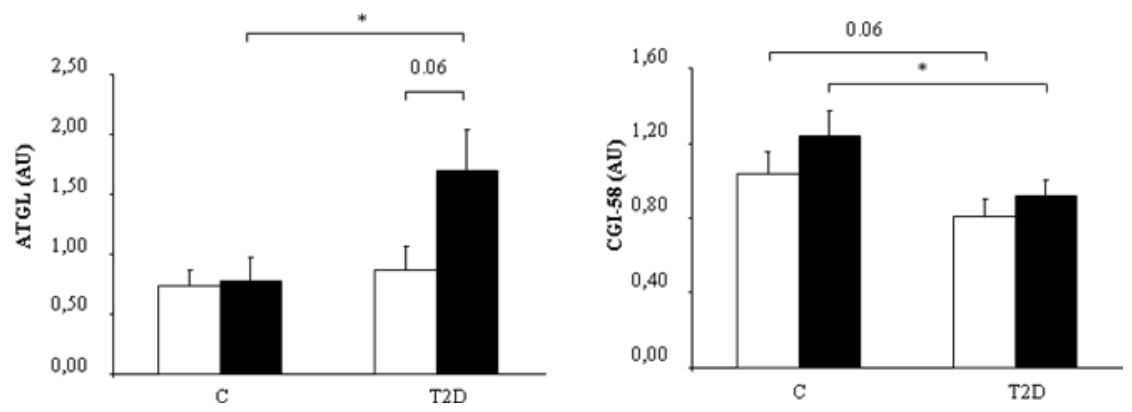

Figure 2: Protein expression of ATGL and CGI-58 in in vastus lateralis muscle, before (white bars) and after training (black bars). Data are expressed as mean (in arbitrary units) \pm SE. *significantly different with $\mathrm{p}<0.05$.

\section{TAG and DAG hydrolase activity}

Pre-training, TAG hydrolase activity was comparable between groups $(0.85 \pm 0.16$ $\mathrm{nmol} / \mathrm{mg} / \mathrm{h}$ and $0.90 \pm 0.11 \mathrm{nmol} / \mathrm{mg} / \mathrm{h}$ in $\mathrm{C}$ and T2D respectively) and decreased to a similar extent in both groups upon training (from $0.85 \pm 0.16$ to $0.59 \pm 0.11 \mathrm{nmol} / \mathrm{mg} / \mathrm{h}$ in $\mathrm{C}$ and from $0.90 \pm 0.11$ to $0.72 \pm 0.10 \mathrm{nmol} / \mathrm{mg} / \mathrm{h}$ in $\mathrm{T} 2 \mathrm{D} ; \mathrm{p}<0.05$ in both groups, figure 3a). DAG hydrolase activity was comparable between groups before training $(10.57 \pm 1.47$ and $12.08 \pm 1.02 \mathrm{nmol} / \mathrm{mg} / \mathrm{h}$ in $\mathrm{C}$ and $\mathrm{T} 2 \mathrm{D}$ respectively). Upon training, there was a slight but insignificant decrease in DAG hydrolase activity (from $10.57 \pm 1.47$ to $8.31 \pm 0.93 \mathrm{nmol} / \mathrm{mg} / \mathrm{h}, \mathrm{p}=0.13$ in $\mathrm{C}$ and $12.08 \pm 1.02$ to $9.82 \pm 0.78$ $\mathrm{nmol} / \mathrm{mg} / \mathrm{h} \mathrm{p}=0.12$ in T2D, figure $3 \mathrm{~b}$ ).
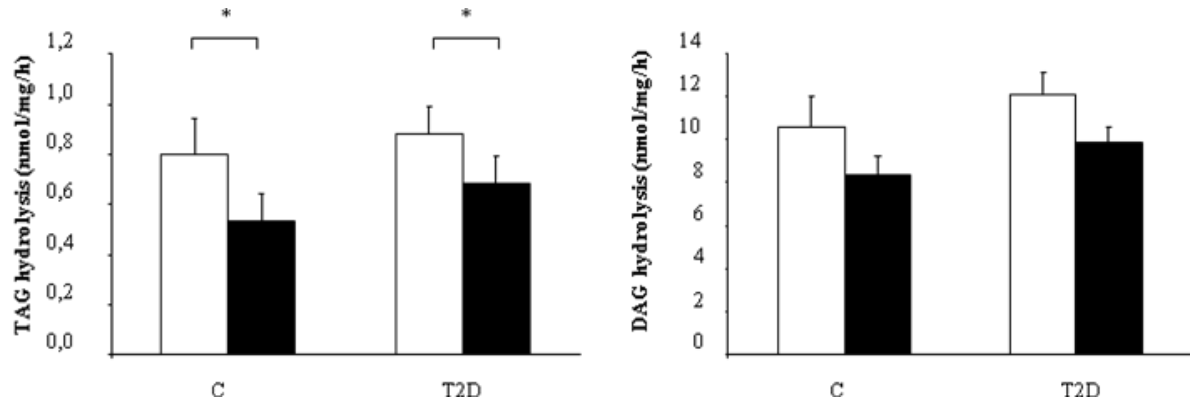

Figure 3: TAG hydrolase and DAG hydrolase activity in vastus lateralis muscle, before (white bars) and after training (black bars). Data are expressed as mean (in arbitrary units) \pm SE. *significantly different with $\mathrm{p}<0.05$. 


\section{Correlative analysis}

Training-induced changes in ADRP/perilipin2 and OXPAT/perilipin5 protein abundance tightly correlated $(\mathrm{r}=0.476, \mathrm{p}=0.007)$. In addition, the increase in ADRP/perilipin2 correlated positively with the training-induced change in resting fat oxidation $(0.519, \mathrm{p}=0.003)$ and negatively with glucose oxidation $(-0.546, \mathrm{p}=0.002)$. Interestingly, training-induced increased ATGL and OXPAT/perilipin5 protein expression was related to training-induced improvement of metabolic flexibility; training-induced increase in ATGL and OXPAT/perilipin5 content correlated positively with the training-induced improvement in insulin mediated suppression in fat oxidation $(0.364, \mathrm{p}=0.048$ and $0.438, \mathrm{p}=0.022$, respectively) and negatively with the change in insulin-stimulated glucose oxidation $(-0.364, \mathrm{p}=0.048$ and $-0.347, \mathrm{p}=0.083$, respectively).

\section{Discussion}

In the present study we show that, in the face of similar LD content, the protein content of the nascent lipid droplet coating protein TIP-47/perilipin3 is significantly lower in muscle samples of obese type 2 diabetic patients (T2D) than in obese normoglycemic control subjects (C). At baseline, the other myocellular LD coating proteins and ATGL were similar across groups while CGI-58, the co-factor for ATGL, tended to be lower in T2D. This was observed in conjunction with similar TAG and DAG hydrolase activity at baseline. Upon exercise training all myocellular PAT proteins increased significantly. ATGL protein content increased after training in T2D, while after training the co-activator CGI-58 was lower in T2D than in C. These changes translated into lower ex vivo TAG hydrolase activity post-training and occurred in the face of improved insulin stimulated glucose uptake, improved metabolic flexibility and increased fat oxidation during sub-maximal exercise in both groups. 


\section{Pre-training comparison between obese diabetic and obese non-diabetic subjects}

The data of the present study partly support our initial hypothesis that dysregulation of myocellular LD dynamics would contribute to compromised muscle insulin sensitivity. Of the PAT and lipolytic proteins examined, only TIP-47/perilipin3 was lower in the T2D patients. While the precise role of TIP-47/perilipin3 has not yet been identified, knock-down of TIP-47/perilipin3 in Hela cells prevents nascent lipid droplet from maturation, hence incorporation of fatty acids into neutral lipid droplets is decreased (23). Thus, lower levels of TIP-47/perilipin3 in muscle cells may blunt maturation of LD and augment the fraction of micro-lipid droplets which are undetectable by light microscopy. These small LD may accumulate insulin desensitizing lipid intermediates like diacylglycerol (23). Unfortunately, we could not test this suggestion as the limited size of the muscle biopsies obtained prevented us from performing analysis of diacylglycerol and/or ceramides.

Levels of ADRP/perilipin2, a protein mainly preventing interaction of ATGL with the LD droplet and hence augmenting TG storage in LD (24) was similar across groups. This may contribute to the lack of difference in basal TAG hydrolase activity measured ex vivo. Protein expression of OXPAT/perilipin5 was also similar between groups. OXPAT/perilipin5 may be involved in preventing uncontrolled LD lipolyis in an ADRP/perilipin2-like manner (25) while at the same time it has been shown that ectopically expressing OXPAT/perilipin5 in COS-7 cells enhances fat oxidation (26). Comparable levels of ADRP/perilipin2 and OXPAT/perilipin5 in muscle from obese diabetic and BMI-matched non-diabetic subjects is in line with previous findings from our lab (27) and may indicate that, at least in the obese insulin resistant state and in muscle with similar LD content, PAT proteins are no major contributors to compromised muscle insulin sensitivity.

\section{Training effects}

Exercise training improved insulin-stimulated glucose disposal, metabolic flexibility and fat oxidative capacity during submaximal exercise in T2D, with only a modest effect on LD content. It has convincingly been shown that during submaximal exercise fat stored in muscle can be used as an energy source $(13 ; 16)$. In addition, LD 
derived fat oxidation in trained athletes is higher (in absolute as well as in relative terms), compared to obese control and obese T2D subjects while exercising at the same relative workload (28). Recent data in exercising mice lacking ATGL in skeletal muscle indicate that ATGL is obligatory to liberate fatty-acids as substrates from intramyocellular LD during exercise $(29 ; 30)$. In this respect it is of interest to note that training increased ATGL protein content in T2D, such that it was higher in T2D than in C. Similar observations have previously been reported in young healthy subjects (31). For reasons not yet understood, training did not affect ATGL content in muscle of obese normoglycemic controls.

Interestingly, after training, TAG hydrolase activity decreased similarly in $\mathrm{C}$ and T2D. This drop in ex vivo TAG hydrolase activity occurred in face of a profound increase in ADRP/perilipin2 and OXPAT/perilipin5. TIP-47/perilipin3 restored to levels similar to age- and BMI matched control subjects in T2D post-training. So far, most of the studies indicate that the protein content of OXPAT/perilipin5 and ADRP/perilipin2 tracks with the amount of fat stored. Here however, we observed that exercise training can profoundly increase ADRP/perilipin2, OXPAT/perilipin5 as well as TIP-47/perilipin3, with only a modest increase in LD content. The correlation between training-induced increase in ADRP/perilipin2 and OXPAT/perilipin5 suggests that these proteins may be co-regulated by exercise training. Restoration of TIP-47/perilipin3 in T2D by exercise training may facilitate the maturation of nascent lipid droplets, which in turn are shielded from uncontrolled basal lipolysis by the increase in ADRP/perilipin2 and OXPAT/perilipin5. The correlation between training-induced increases in ADRP/perilipin2 and the training-induced changes in resting fat and carbohydrate oxidation rates indicates that ADRP/perilipin2 may be involved in substrate switching and somehow balances the release of fatty acids from the LD with fat oxidation rates. Interestingly, the observation of PAT proteins being involved in substrate switching extends to the insulin-mediated substrate switching (metabolic flexibility) and the training-induced improvement herein. Thus, the increase in ADRP/perilipin2 and OXPAT/perilipin5 content correlated positively with the training-induced improvement in insulin mediated suppression in fat oxidation and negatively with the change in insulin-stimulated glucose oxidation. This correlation does not permit conclusions with respect to causality, nor does it give an indica- 
tion whether the observation that training-mediated changes in PAT proteins correlate with changes in lipid oxidation under insulin-stimulated conditions directly reflects an effect of PAT proteins on lipid oxidation or is secondary to the changes in carbohydrate oxidation. While we did not detect direct associations between any of the PAT proteins or ATGL with insulin mediated-glucose uptake, the present study shows that exercise training results in adaptive responses in PAT proteins and ATGL, priming the muscle to increase lipolytic flux in times of increased demand, as suggested previously (30). At the same time these adaptive responses may contribute to improved post-prandial substrate selection.

It should be noted that $35 \%$ of the obese control subjects and $44 \%$ of the T2D subjects were on lipid-lowering medication and all but two T2D subjects were on sulphonylureas to control their diabetes. While we did not observe an effect of lipid lowering medication on any of the PAT proteins or lipolytic markers examined and despite the fact that subjects were withdrawn from anti-diabetic medication for 7 days prior to the muscle biopsy procedure and the clamp, we cannot exclude that the medication regime introduced some variation on the data obtained.

In conclusion, the present study is the first to examine the protein content of PAT proteins along with indices of LD lipolysis in skeletal muscle of obese type 2 diabetic patients and age and BMI matched normoglycemic control subjects with similar fitness, before and after a 12 week insulin-sensitizing training programme. We observed that the nascent lipid droplet coating protein TIP-47/perilipin3 was downregulated in patients with type 2 diabetes and restored to control values upon exercise training. We did not observe major differences in any of the other PAT protein and markers of lipolysis between patients with type 2 diabetes and obese control subjects. Training however, increased protein expression of muscle PAT proteins in obese normoglycemic as well as in obese type 2 diabetic subjects, without a major effect on LD content and with a concomitant reduction in ex vivo TAG hydrolase activity. Pretraining data of most of the PAT proteins or indices of muscle lipolysis examined indicate that these proteins may not play a direct role in the development of reduced insulin-stimulated glucose uptake in type 2 diabetic patients. Training-induced increases in PAT protein content, correlates with recognized markers of exercise medi- 
ated improvement in insulin sensitivity, like changes in substrate selection during submaximal exercise and improved metabolic flexibility under insulin-stimulated conditions, but did not associate with exercise training-mediated changes in insulinstimulated glucose uptake. 


\section{References}

1. Krssak M, Falk Petersen K, Dresner A, DiPietro L, Vogel SM, Rothman DL, Roden M, Shulman GI: Intramyocellular lipid concentrations are correlated with insulin sensitivity in humans: a 1H NMR spectroscopy study. Diabetologia 42:113-116, 1999

2. Perseghin G, Scifo P, De Cobelli F, Pagliato E, Battezzati A, Arcelloni C, Vanzulli A, Testolin G, Pozza G, Del Maschio A, Luzi L: Intramyocellular triglyceride content is a determinant of in vivo insulin resistance in humans: a $1 \mathrm{H}-13 \mathrm{C}$ nuclear magnetic resonance spectroscopy assessment in offspring of type 2 diabetic parents. Diabetes 48:1600-1606, 1999

3. Shulman GI: Cellular mechanisms of insulin resistance. J Clin Invest 106:171-176, 2000

4. van Loon LJ, Koopman R, Manders R, van der Weegen W, van Kranenburg GP, Keizer HA: Intramyocellular lipid content in type 2 diabetes patients compared with overweight sedentary men and highly trained endurance athletes. Am J Physiol Endocrinol Metab 287:E558-565, 2004

5. Goodpaster BH, He J, Watkins S, Kelley DE: Skeletal muscle lipid content and insulin resistance: evidence for a paradox in endurance-trained athletes. J Clin Endocrinol Metab $86: 5755-5761,2001$

6. Schrauwen-Hinderling VB, Kooi ME, Hesselink MK, Jeneson JA, Backes WH, van Echteld CJ, van Engelshoven JM, Mensink M, Schrauwen P: Impaired in vivo mitochondrial function but similar intramyocellular lipid content in patients with type 2 diabetes mellitus and BMI-matched control subjects. Diabetologia 50:113-120, 2007

7. Liu L, Zhang Y, Chen N, Shi X, Tsang B, Yu YH: Upregulation of myocellular DGAT1 augments triglyceride synthesis in skeletal muscle and protects against fat-induced insulin resistance. J Clin Invest 117:1679-1689, 2007

8. Schenk S, Horowitz JF: Acute exercise increases triglyceride synthesis in skeletal muscle and prevents fatty acid-induced insulin resistance. J Clin Invest 117:1690-1698, 2007

9. Bickel PE, Tansey JT, Welte MA: PAT proteins, an ancient family of lipid droplet proteins that regulate cellular lipid stores. Biochim Biophys Acta 1791:419-440, 2009

10. Meex RC, Schrauwen P, Hesselink MK: Modulation of myocellular fat stores: lipid droplet dynamics in health and disease. Am J Physiol Regul Integr Comp Physiol 297:R913-924, 2009

11. Watt MJ, Spriet LL: Triacylglycerol lipases and metabolic control: implications for health and disease. Am J Physiol Endocrinol Metab 299:E162-168, 2010

12. Schrauwen-Hinderling VB, van Loon LJ, Koopman R, Nicolay K, Saris WH, Kooi ME: Intramyocellular lipid content is increased after exercise in nonexercising human skeletal muscle. J Appl Physiol 95:2328-2332, 2003

13. Schrauwen-Hinderling VB, Schrauwen P, Hesselink MK, van Engelshoven JM, Nicolay K, Saris WH, Kessels AG, Kooi ME: The increase in intramyocellular lipid content is a very early response to training. J Clin Endocrinol Metab 88:1610-1616, 2003

14. Newsom SA, Schenk S, Li M, Everett AC, Horowitz JF: High fatty acid availability after exercise alters the regulation of muscle lipid metabolism. Metabolism, 2010

15. Larson-Meyer DE, Newcomer BR, Hunter GR: Influence of endurance running and recovery diet on intramyocellular lipid content in women: a $1 \mathrm{H}$ NMR study. Am J Physiol Endocrinol Metab 282:E95-E106, 2002

16. van Loon LJ, Koopman R, Stegen JH, Wagenmakers AJ, Keizer HA, Saris WH: Intramyocellular lipids form an important substrate source during moderate intensity exercise in endurance-trained males in a fasted state. J Physiol 553:611-625, 2003 
17. Lessard SJ, Rivas DA, Chen ZP, van Denderen BJ, Watt MJ, Koch LG, Britton SL, Kemp BE, Hawley JA: Impaired skeletal muscle beta-adrenergic activation and lipolysis are associated with whole-body insulin resistance in rats bred for low intrinsic exercise capacity. Endocrinology 150:4883-4891, 2009

18. Blaak EE, Schiffelers SL, Saris WH, Mensink M, Kooi ME: Impaired beta-adrenergically mediated lipolysis in skeletal muscle of obese subjects. Diabetologia 47:1462-1468, 2004

19. Alberti KG: Impaired glucose tolerance: what are the clinical implications? Diabetes Res Clin Pract 40 Suppl:S3-8, 1998

20. Meex RC, Schrauwen-Hinderling VB, Moonen-Kornips E, Schaart G, Mensink M, Phielix E, van de Weijer T, Sels JP, Schrauwen P, Hesselink MK: Restoration of muscle mitochondrial function and metabolic flexibility in type 2 diabetes by exercise training is paralleled by increased myocellular fat storage and improved insulin sensitivity. Diabetes 59:572-579, 2009

21. Koopman R, Schaart G, Hesselink MK: Optimisation of oil red O staining permits combination with immunofluorescence and automated quantification of lipids. Histochem Cell Biol 116:63-68, 2001

22. Moro C, Galgani JE, Luu L, Pasarica M, Mairal A, Bajpeyi S, Schmitz G, Langin D, Liebisch G, Smith SR: Influence of gender, obesity, and muscle lipase activity on intramyocellular lipids in sedentary individuals. J Clin Endocrinol Metab 94:3440-3447, 2009

23. Bulankina AV, Deggerich A, Wenzel D, Mutenda K, Wittmann JG, Rudolph MG, Burger KN, Honing S: TIP47 functions in the biogenesis of lipid droplets. J Cell Biol 185:641655, 2009

24. Prats C, Donsmark M, Qvortrup K, Londos C, Sztalryd C, Holm C, Galbo H, Ploug T: Decrease in intramuscular lipid droplets and translocation of HSL in response to muscle contraction and epinephrine. J Lipid Res 47:2392-2399, 2006

25. Granneman JG, Moore HP, Mottillo EP, Zhu Z: Functional interactions between Mldp (LSDP5) and Abhd5 in the control of intracellular lipid accumulation. J Biol Chem 284:3049-3057, 2009

26. Wolins NE, Quaynor BK, Skinner JR, Tzekov A, Croce MA, Gropler MC, Varma V, YaoBorengasser A, Rasouli N, Kern PA, Finck BN, Bickel PE: OXPAT/PAT-1 Is a PPARInduced Lipid Droplet Protein That Promotes Fatty Acid Utilization. Diabetes 55:3418 3428, 2006

27. Minnaard R, Schrauwen P, Schaart G, Jorgensen JA, Lenaers E, Mensink M, Hesselink MK: Adipocyte differentiation-related protein and OXPAT in rat and human skeletal muscle: involvement in lipid accumulation and type 2 diabetes mellitus. J Clin Endocrinol Metab 94:4077-4085, 2009

28. van Loon LJ: Use of intramuscular triacylglycerol as a substrate source during exercise in humans. J Appl Physiol 97:1170-1187, 2004

29. Huijsman E, van de Par C, Economou C, van der Poel C, Lynch GS, Schoiswohl G, Haemmerle G, Zechner R, Watt MJ: Adipose triacylglycerol lipase deletion alters whole body energy metabolism and impairs exercise performance in mice. Am J Physiol Endocrinol Metab 297:E505-513, 2009

30. Schoiswohl G, Schweiger M, Schreiber R, Gorkiewicz G, Preiss-Landl K, Taschler U, Zierler KA, Radner FP, Eichmann TO, Kienesberger PC, Eder S, Lass A, Haemmerle G, Alsted TJ, Kiens B, Hoefler G, Zechner R, Zimmermann R: Adipose triglyceride lipase plays a key role in the supply of the working muscle with fattyacids. J Lipid Res, 2009

31. Alsted TJ, Nybo L, Schweiger M, Fledelius C, Jacobsen P, Zimmermann R, Zechner R, Kiens B: Adipose triglyceride lipase in human skeletal muscle is upregulated by exercise training. Am J Physiol Endocrinol Metab 296:E445-453, 2009 


\section{CHAPTER 5}

\section{The use of statins potentiates the insulin sensitizing effects of exercise training in obese males with and without type 2 diabetes.}

\begin{abstract}

\section{Objective}

Exercise-training is advocated in insulin resistance and statins are used to treat hyperlipidemia, two cardiometabolic risk-factors often presenting concurrently. Statin intake may blunt mitochondrial function and the adaptive response to exercise training. Thus, combining exercise training with statins administration may have adverse effects. We examined if improvements in cardiometabolic risk-factors, insulin sensitivity and mitochondrial function mediated by progressive exercise training are affected by statin use.
\end{abstract}

\section{Methods}

Fourteen obese elderly males on statins (ST) and 22 matched control subjects (C) were examined. Results on in vivo mitochondrial function (MRS), mitochondrial density (western blot), insulin sensitivity (clamp) and metabolic flexibility (indirect calorimetry) were compared before and after the 12 week combined progressive training program (3x/week, 45 minutes/session).

\section{Results}

Except for LDL cholesterol, all pre-training values were comparable between statin users and control subjects. In vivo mitochondrial function (MRS) and mitochondrial density (western blot) improved by training in both groups. Interestingly, blood-lipid profile, insulin sensitivity $(+72 \%)$ (clamp), non-oxidative and oxidative glucose disposal $(+38 \%$ and $+112 \%)$ and insulin-mediated suppression of fat oxidation $(-62 \%)$ (indirect calorimetry) improved only in ST.

\section{Conclusion}

Statin treatment did not impede exercise performance or tolerance, mitochondrial function or mass. In addition, training-induced improvements in glucose homeostasis were preserved in ST. Strikingly, the insulin sensitizing effect of training was more prominent in ST than in $\mathrm{C}$. The combined prescription of statins along with exercise training is safe and should be considered for subjects prone to develop insulin resistance.
Ruth C.R. Meex

Esther Phielix

Vera B. Schrauwen-Hinderling

Esther Moonen-Kornips

Gert Schaart

Patrick Schrauwen

Matthijs K. C. Hesselink

Clinical Science (London) 25;119(7):293-301, 2010 


\section{Introduction}

Hyperlipidemia and hyperglycemia are frequently reported in obese subjects and are highly associated with the development of cardiovascular disorders, the primary cause of death in obesity. Whereas treatment with HMG-CoA reductase inhibitors like statins is often prescribed in case of hyperlipidemia [1, 2], implementing routine physical exercise in daily life is advocated in treatment of hyperglycemia [3]. Hyperlipidemia and hyperglycaemia, however, often present concurrently. Hence, combining the current guidelines would imply combining statin treatment with physical exercise. Recently released guidelines from the American Diabetes Association state that in diabetic individuals $>40$ years of age, statin use should be added to lifestyle therapy in order to reach target levels of LDL cholesterol $<.6 \mathrm{mmol} / \mathrm{l}$ in patients with type 2 diabetes (T2D) or $<1.80 \mathrm{mmol} / \mathrm{l}$ in T2D with established CVD [4]. The use of statins, however, has been associated with myotoxicity, mitochondrial dysfunction [5-9] and muscular damage [7, 10]. In addition, it has been suggested that statin use may blunt the adaptive response to exercise training $[11,12]$.

To examine the role of statins in exercise training-mediated improvements in cardiometabolic risk-factors, markers of in vivo mitochondrial function and insulin sensitivity, we here evaluate these effects after 12 weeks of training in a group of elderly male obese healthy and T2D subjects, stratified to the use of statins.

\section{Research design and methods}

\section{Subject recruitment and stratification}

Initially, we recruited 38 sedentary elderly male obese subjects of which 18 subjects had been diagnosed with T2D for at least one year [13]. Diabetic patients had wellcontrolled diabetes $(\mathrm{HbA1c}= \pm 7.2 \%)$ and were using oral anti-diabetic agents (metformin only, or in combination with SU derivatives). The other 20 subjects were categorized as normoglycemic. Glycemic control was checked for by measuring $\mathrm{HbA1c}$, and glucose tolerance by performing an oral glucose tolerance test. Subjects 94 
were informed about the nature and risks of the experimental procedures before their written informed consent was obtained. The study has been carried out in accordance with the Declaration of Helsinki (2000) of the World Medical Association and was approved by the institutional medical ethical committee.

Retrospectively, the entire group of 38 subjects was stratified according to the use of statins. Two subjects on fibrates were excluded from analysis. Statin use was defined as using any type of statins, for over a year at the onset of the study, irrespective of dosage. Individual data on statin use can be found in the supplementary material. Stratification resulted in 14 subjects on statins (ST) and 22 subjects without statin treatment $(\mathrm{C})$ with $8 \mathrm{~T} 2 \mathrm{D}$ subjects in both groups. None of the baseline characteristics was significantly different between the C and ST group, except for LDL cholesterol which was lower in the patients using statins (subject characteristics see table 1). To examine if the type of statin and the dosage used may have affected the outcome of the present study, we ranked the statins on their reported LDL lowering potency, taking into account the dosage used. Using this marker of potency as an independent variable we performed correlative analysis with all parameters under investigation.

\section{Exercise training protocol}

All subjects were engaged in an exercise program for 12 weeks, consisting of a combination of aerobic and resistance exercise. Subjects were monitored extensively during the training period and attention has been paid to follow up conversations with respect to their motivation. Aerobic exercise was carried out on a cycling ergometer twice a week for 30 minutes at $55 \%$ of their previously determined maximal work load. Training sessions took place in small groups of 3 to 4 persons and as a measure of exercise intensity, heart rate was monitored and registered in a training diary every 5 minutes. Maximal workload was re-evaluated after 6 weeks of training and training load was adjusted accordingly.

Resistance exercise was performed once a week for 40 minutes. The training involved a "circuit" of eight exercises, focussing on large muscle groups (i.e., chest 
press, leg extension, lat pull down, leg press, triceps curl, biceps curl, crunches and horizontal row). A first series of 8 repetitions was performed at $55 \%$ of their predetermined maximal voluntary contraction (MVC), followed by 2 series of 8 repetitions at $75 \%$ MVC [13]. Resistance training was given individually and MVC was re-assessed every 4 weeks.

\section{Hyperinsulinemic-euglycemic clamp}

Dietary habits were stable, physical exercise was avoided the 2 days prior to the clamp procedure and anti-diabetic medication was withdrawn 7 days prior to the clamp. The use of statins was continued throughout the study. Insulin sensitivity was measured by a 3-hour hyperinsulinemic-euglycemic clamp, before and after the training period. A primed constant infusion of glucose tracer $([6,6-2 \mathrm{H} 2]$ glucose) was initiated at $\mathrm{t}=0$ minutes to determine non-insulin stimulated rates of glucose appearance $(R \mathrm{a})$ and disposal $(R \mathrm{~d})$. At $\mathrm{t}=180$, the actual clamp procedure was started with a primed constant infusion of insulin $\left(40 \mathrm{mU} / \mathrm{m}^{2} / \mathrm{min}\right)$ [13]. Endogenous glucose production (EGP) was calculated as Ra minus exogenous glucose infusion rate. Nonoxidative glucose disposal was calculated as $R \mathrm{~d}$ minus carbohydrate oxidation. In the non-insulin stimulated period $(\mathrm{t}=150-180)$ and under steady clamp conditions $(\mathrm{t}=330$ 360), blood samples and indirect calorimetry measurements (ventilated hood) were obtained. A needle muscle biopsy was obtained from the $\mathrm{m}$. vastus lateralis before starting the tracer infusion.

\section{Blood sample analysis}

Blood was sampled and analysed as described previously [13]. Concentrations of total cholesterol (ABX Diagnostics, Montpelier, France), HDL cholesterol (precipitation method; Roche Diagnostics Corporation, Indianapolis, IN), and triglycerides corrected for free glycerol (Sigma-Aldrich Chemie, Steinheim, Germany) were analysed enzymatically. Serum LDL cholesterol concentrations were calculated by using the formula of Friedewald. High sensitive C-reactive protein (hsCRP) was measured on Cobas Mira with a commercially available kit (Kamiya Biomedical Company, Seattle, WA, USA). 


\section{Metabolic flexibility}

Metabolic flexibility is the ability to switch from predominantly fat oxidation in the fasted state to glucose oxidation under insulin stimulated conditions [14]. Metabolic flexibility was expressed as the change in respiratory exchange ratio (RER) from the fasted state to the insulin-stimulated condition. Substrate oxidation was calculated according to Frayn with protein oxidation considered negligible (carbohydrate oxidation $(\mathrm{umol} / \mathrm{min} / \mathrm{kg})=\left(4,585 * \mathrm{VCO}_{2}-3,226 * \mathrm{VO}_{2}\right) / \mathrm{BW} / 180 * 1000$ and lipid oxidation rates $\left.(\mathrm{umol} / \mathrm{min} / \mathrm{kg})=\left(1,695 * \mathrm{VO}_{2}-1,701 * \mathrm{VCO}_{2}\right) / \mathrm{BW} / 860 * 1000\right)[15]$.

\section{MRS-based measurement of mitochondrial function}

Maximal muscle strength during one-legged knee-extension exercise was assessed a few days prior to the actual ${ }^{31} \mathrm{P}-\mathrm{MRS}$ measurement with an incremental protocol in an MRS compatible exercise device. During this test subjects were asked to perform knee-extensions at $0.5 \mathrm{~Hz}$, while increasing the load to be lifted every 30 seconds by $500 \mathrm{~g}$, with an initial weight of $5 \mathrm{~kg}$. The test was performed until exhaustion or until the frequency of $0.5 \mathrm{~Hz}$ could no longer be maintained (maximal load). The phosphocreatine (PCr) lowering exercise session during the test-day was performed at $60 \%$ of this pre-determined load. Baseline ${ }^{31} \mathrm{P}$-MRS measurements were performed on a $1.5 \mathrm{~T}$ whole body scanner (Intera, Philips Health Care, Best, the Netherlands). A $6 \mathrm{~cm}$ surface coil was used for localization and was fixed in the middle of the vastus lateralis muscle. A series of partially saturated spectra (free induction decays) was acquired (TR $=4$ seconds, 1 measurement, spectral bandwidth $1500 \mathrm{~Hz}$, adiabatic pulse). Knee extension exercise was performed at $0.5 \mathrm{~Hz}$ to an acoustic cue on a home-built MR compatible ergometer with a pulley system. The $\mathrm{PCr}$ lowering exercise was performed with identical weights before and after training. The acquisition time during time series was structured as follows: $40 \mathrm{sec}$ of rest, 5 minutes of knee-extension exercise and 5 minutes of recovery. After application of phase correction, line-broadening and DC correction, spectra were fitted in the time domain with the AMARES algorithm [16] in the jMRUI software (http:// www.mrui.uab.es) [17] using prior knowledge. Five peaks were fitted with gaussian curves ( $\mathrm{Pi}, \mathrm{PCr}$, and 3 ATP peaks) in the partially saturated spectra of the 
time-serie. To determine the $\mathrm{pH}$ during the exercise period, five consecutive spectra of the time-series were added and the $\mathrm{pH}$ was calculated in jMRUI from the frequency shift between PCr and Pi peak. The time-course of the PCr amplitude $(\operatorname{PCr}(\mathrm{t}))$ during the last 20 seconds of exercise (steady state) and during the recovery period was fitted with MATLAB software (The Mathworks. Inc.), as described earlier [18], asssuming a monoexponential PCr recovery. Post-exercise PCr resynthesis rate is an almost exclusively oxidative process and is hence a good reflection of mitochondrial oxidative function. The rate constant of the monoexponential recovery is given. The higher the rate constant $\left(\mathrm{s}^{-1}\right)$, the better in vivo mitochondrial function.

\section{Mitochondrial density}

Five different structural components of the electron transport chain were measured at the protein level as a reflection of mitochondrial density [13]. The ND6 subunit of complex I, the $30-\mathrm{kDa}$ Ip subunit of complex II, the $47-\mathrm{kDa}$ core protein 2 of complex III, subunit II of cytochrome c oxidase (COXII), and the subunit of the F1F0 ATP synthase (complex V) were measured using a monoclonal antibody cocktail of 5 monoclonal antibodies directed to the subunits mentioned (MitoSciences,Eugene, OR) as previously described [19]. As these subunits differ considerably in molecular mass, this antibody gives 5 distinct bands in human samples. Each individual band reflects one of the mitochondrial subunits. In short, muscle biopsies were homogenized in ice-cold Tris-EDTA buffer at $\mathrm{pH} 7.4$, and then the homogenates were sonicated for $15 \mathrm{sec}$. Subsequently, two volumes of each skeletal muscle homogenate and one volume of SDS-sample buffer were boiled for $4 \mathrm{~min}$. Next, $13 \%$ polyacrylamide gels containing $0.1 \%$ SDS were loaded with equal amounts of protein from each sample, and electrophoresis was performed using a Mini-Protean 3 Electrophoresis Cell (Bio-Rad Laboratories, Hercules, CA). After gel electrophoresis, the gel was scanned and the optical density of all individual bands (per subject per subunit) was measured. To adjust for inter-gel variation, the optical density of the band of interest per subject was normalized to the mean optical density of the complete gel. Protein content is expressed as arbitrary units (AU). 


\section{Statistics}

Statistical analyses were performed two-sided using SPSS for Windows 15.0 software (SPSS, Chicago,IL. Statistical significance was set at $\mathrm{p}<0.05$. A two-way ANOVA model for repeated measures was applied using control and statin users as between subject variables and pre- and post training data as repeated within subject variables. Differential responses between statin users and non statin users were examined using the interaction terms. Also, in case of a significant training effect, differential responses of T2D and healthy subjects within statin users and non statin users were examined.

\section{Results}

\section{Subjects}

Before training, body weight (BW) $(94.9 \pm 2.8$ and $93.2 \pm 2.9 \mathrm{~kg}), \mathrm{BMI}(30.1 \pm 0.8$ and $30.0 \pm 0.9 \mathrm{~kg} / \mathrm{m} 2)$, and age (59.2 \pm 1.0 and $58.4 \pm 0.9$ years) were comparable in $\mathrm{C}$ and ST respectively. Training did not alter body weight and BMI in $\mathrm{C}$ while body weight but not BMI tended to decline in ST (from $93.2 \pm 3.2$ to $91.9 \pm 3.1 \mathrm{~kg}, \mathrm{p}=0.09$ and from $30.0 \pm 0.9$ to $29.6 \pm 0.8 \mathrm{~kg} / \mathrm{m}^{2}$ ). Fat mass declined in $\mathrm{C}$ (from $31.2 \pm 1.8$ to $30.4 \pm 1.8 \mathrm{~kg}$ after training, $\mathrm{p}=0.02$ ) whereas there was a tendency towards a decreased fat mass in ST (from $27.9 \pm 2.3$ to $26.4 \pm 2.2 \mathrm{~kg}$ after training; $\mathrm{p}=0.10$ ). Fat free mass was similar between both groups and was unaffected by training.

Before training, maximal oxygen uptake $\left(\mathrm{VO}_{2} \mathrm{max} / \mathrm{kg} \mathrm{BW}\right)$ and maximal workload was comparable in both groups (VO2max/ $\mathrm{kgBW} 28.6 \pm 1.0 \mathrm{ml} / \mathrm{kg}$ and $27.7 \pm 1.5 \mathrm{ml} / \mathrm{kg}$ in C and ST respectively, p=0.63; workload 208 \pm 9 Watt 201 \pm 10 Watt in C and ST respectively, $\mathrm{p}=0.61$ ). Exercise training improved $\mathrm{VO}_{2} \mathrm{max} / \mathrm{kg}$ body weight and maximal workload significantly and to the same extent in $\mathrm{C}$ and $\mathrm{ST}\left(\mathrm{VO}_{2} \max \right.$ $+7.0 \pm 2.2 \%$ and $+11.7 \pm 3.2 \%$ respectively, $\mathrm{p}<0.01$; workload $+14.6 \pm 2.7 \%$ and $+16.1 \pm 2.3 \%$ in $\mathrm{C}$ and ST respectively, $\mathrm{p}<0.01$ ). Muscle strength was comparable before training $(83.5 \pm 3.2 \mathrm{~kg}$ and $87.4 \pm 4.0 \mathrm{~kg}$ in $\mathrm{C}$ and $\mathrm{ST}$ respectively, $\mathrm{p}=0.46)$ and 
improved significantly and to the same extent in both groups $(+24.7 \pm 1.9 \%$ and $+21.6 \pm 2.1 \%$ in $\mathrm{C}$ and $\mathrm{ST}$ respectively, $\mathrm{p}<0.01$ ). In the rare occasion of missing a training session, this session was rescheduled within a week of the original training date. As maximally achieved workload during the maximal test was similar in both groups and the number of training sessions performed was identical, total workload performed during the training sessions across groups was comparable.

\section{Glucose and insulin profile}

Fasting glucose levels $(7.2 \pm 0.4 \mathrm{mmol} / \mathrm{l}$ and $7.5 \pm 0.5 \mathrm{mmol} / \mathrm{l}$ in $\mathrm{C}$ and ST) and $\mathrm{HbA} 1 \mathrm{c}$ levels $(6.4 \pm 0.2 \%$ and $6.6 \pm 0.3 \%$ in $\mathrm{C}$ and ST) were similar at the onset of the training program. Twelve weeks of exercise training did not change HbA1c or fasting glucose levels in either group. Fasting plasma insulin levels did not differ significantly before onset of the training program between $\mathrm{C}$ and ST $(17.2 \pm 2.0$ vs. $17.9 \pm 2.0 \mathrm{mU} / 1$ in $\mathrm{C}$ and $\mathrm{ST}$ ) but decreased significantly in both groups after training (from $17.2 \pm 2.0 \mathrm{mU} / \mathrm{l}$ to $15.7 \pm 1.7 \mathrm{mU} / 1$ in $\mathrm{C}$ and from $17.9 \pm 2.0 \mathrm{mU} / 1$ to $15.0 \pm 1.7 \mathrm{mU} / 1$ in $\mathrm{ST}, \mathrm{p}<0.05$ in both groups).

\section{Lipid profile}

Pre-training, insulin-mediated suppression of lipolysis, measured as the drop in plasma FFA upon insulin infusion, was comparable between groups. Training did not affect insulin-mediated suppression of lipolysis in $\mathrm{C}$ (suppression pre-training $81.7 \pm 1.6 \%$ vs $83.0 \pm 1.5 \%$ post-training), but improved significantly in ST (from $77.7 \pm 1.8 \%$ to $82.9 \pm 1.7 \%, \mathrm{p}=0.01)$.

Triglycerides were comparable between groups and were unaffected by training. Also total cholesterol before training was similar in C and ST. Training reduced total cholesterol significantly in ST (from 5.0 \pm 0.2 to $4.6 \pm 0.2 \mathrm{mmol} / \mathrm{l}, \mathrm{p}=0.03$ ), but not in $\mathrm{C}$ (from $5.4 \pm 0.2$ to $5.2 \pm 0.1 \mathrm{mmol} / \mathrm{l}$ ), resulting in a tendency towards lower total cholesterol values in ST compared to $\mathrm{C}(\mathrm{p}=0.07)$. LDL cholesterol was significantly higher in C compared to ST pre-training $(3.5 \pm 0.1 \mathrm{mmol} / 1$ vs $2.9 \pm 0.2 \mathrm{mmol} / 1$ in $\mathrm{C}$ and $\mathrm{ST}$, $\mathrm{p}=0.05$ ) and tended to decline in both groups (from $3.5 \pm 0.1$ to $3.3 \pm 0.2 \mathrm{mmol} / 1 \mathrm{in} \mathrm{C}$, 
$\mathrm{p}=0.07$ and from $2.9 \pm 0.2$ to $2.7 \pm 0.2 \mathrm{mmol} / \mathrm{l}$ in $\mathrm{ST}, \mathrm{p}=0.07)$. HDL cholesterol and hsCRP was comparable in C and ST and was unaffected by training (Table 1).

Table 1: subject characteristics

\begin{tabular}{|c|c|c|c|c|}
\hline & \multicolumn{2}{|l|}{$\mathrm{C}$} & \multicolumn{2}{|l|}{ ST } \\
\hline & Pre-training & Post-training & Pre-training & Post-training \\
\hline Age (years) & $59.2 \pm 1.0$ & & $58.4 \pm 0.9$ & \\
\hline $\mathrm{T} 2 \mathrm{D}$ & 8 & & 8 & \\
\hline Weight (kg) & $94.9 \pm 2.8$ & $94.4 \pm 2.9$ & $93.2 \pm 3.2$ & $91.9 \pm 3.1$ \\
\hline Height $(\mathrm{cm})$ & $177.6 \pm 1.3$ & & $177.2 \pm 1.5$ & \\
\hline BMI $\left(\mathrm{kg} / \mathrm{m}^{2}\right)$ & $30.1 \pm 0.8$ & $30.0 \pm 0.9$ & $30.0 \pm 0.9$ & $29.6 \pm 0.8$ \\
\hline Body fat (\%) & $32.4 \pm 1.3$ & $31.6 \pm 1.3 *$ & $29.6 \pm 1.8$ & $28.4 \pm 1.8$ \\
\hline FM (kg) & $31.2 \pm 1.8$ & $30.4 \pm 1.8^{*}$ & $27.9 \pm 2.3$ & $26.4 \pm 2.2$ \\
\hline FFM (kg) & $64.5 \pm 1.9$ & $64.9 \pm 1.9$ & $65.3 \pm 2.1$ & $65.5 \pm 2.1$ \\
\hline $\mathrm{VO} 2 \mathrm{max}(\mathrm{ml} / \mathrm{min} / \mathrm{kg})$ & $28.6 \pm 1.1$ & $30.5 \pm 1.2 *$ & $28.5 \pm 1.4$ & $31.7 \pm 1.7 *$ \\
\hline Wmax (Watt) & $208 \pm 9$ & $236 \pm 9 *$ & $201 \pm 10$ & $231 \pm 10^{*}$ \\
\hline Average strength (kg) & $83.5 \pm 3.2$ & $102.9 \pm 3.7^{*}$ & $87.4 \pm 4.0$ & $105.3 \pm 4.4^{*}$ \\
\hline Fasting glucose $(\mathrm{mmol} / \mathrm{l})$ & $7.2 \pm 0.4$ & $6.9 \pm 0.4$ & $7.5 \pm 0.5$ & $7.3 \pm 0.6$ \\
\hline HbA1c $(\%)$ & $6.4 \pm 0.2$ & $6.3 \pm 0.2$ & $6.6 \pm 0.3$ & $6.7 \pm 0.3$ \\
\hline Triglycerides (mmol/l) & $1.6 \pm 0.1$ & $1.6 \pm 0.2$ & $1.7 \pm 0.2$ & $1.6 \pm 0.1$ \\
\hline Total Cholesterol (mmol/l) & $5.4 \pm 0.1$ & $5.2 \pm 0.2$ & $5.0 \pm 0.2$ & $4.6 \pm 0.2 *$ \\
\hline $\mathrm{LDL}(\mathrm{mmol} / \mathrm{l})$ & $3.5 \pm 0.1$ & $3.3 \pm 0.2$ & $2.9 \pm 0.2 \#$ & $2.7 \pm 0.2 \#$ \\
\hline $\mathrm{HDL}(\mathrm{mmol} / \mathrm{l})$ & $1.2 \pm 0.0$ & $1.2 \pm 0.1$ & $1.3 \pm 0.1$ & $1.3 \pm 0.1$ \\
\hline HsCRP (mg/l) & $2.0 \pm 0.3$ & $1.8 \pm 0.3$ & $1.6 \pm 0.5$ & $1.6 \pm 0.5$ \\
\hline
\end{tabular}

Data are expressed as mean \pm SE., \#ST significantly different from control group, *post-training significantly different from pre-training,

\section{Whole-body insulin-stimulated glucose uptake}

Insulin-stimulated glucose uptake, as determined by the delta glucose disposal rate during the hyperinsulinemic euglycemic clamp (delta $\mathrm{Rd}$ ), was not different between $\mathrm{C}$ and ST pre-training (12.7 \pm 2.1 and $9.5 \pm 2.5 \mathrm{umol} / \mathrm{kg} / \mathrm{min}$ in $\mathrm{C}$ and $\mathrm{ST}, \mathrm{p}=0.33)$. C and ST responded differentially to training as indicated by significant interaction $(\mathrm{p}<0.01)$. Delta $\mathrm{Rd}$ did not change after training in $\mathrm{C}$ (from $12.7 \pm 2.1$ to $13.6 \pm 1.9$ umol/kg/min), but improved significantly in ST (from 9.5 \pm 2.5 to $16.3 \pm 2.3$ umol/kg/min, $\mathrm{p}<0.01$ ). Non-oxidative glucose disposal (from $4.7 \pm 2.1$ to $10.0 \pm 2.1$ umol $/ \mathrm{kg} / \mathrm{min}, \mathrm{p}<0.01$ ) as well as oxidative glucose disposal (from $4.7 \pm 0.9$ to $6.5 \pm 0.7$ 
umol/kg/min, $\mathrm{p}<0.01)$ improved significantly in ST upon training, but did not change in $\mathrm{C}$ (tabel 2, with a significant interaction effect between groups for NOGD; $\mathrm{p}<0.01$ ). Insulin mediated suppression of endogenous glucose production (delta EGP) was comparable pre-training $(-6.8 \pm 0.8$ and $-7.1 \pm 1.5 \mathrm{umol} / \mathrm{kg} / \mathrm{min}$ in C and ST respectively) and was not significantly affected by training, despite a significant interaction effect (Table 2). Data of insulin and glucose disposal is presented in table 2.

Table 2: Substrate kinetics pre- and post training

\begin{tabular}{|c|c|c|c|c|}
\hline & \multicolumn{2}{|l|}{$\mathrm{C}$} & \multicolumn{2}{|l|}{ ST } \\
\hline & Pre-training & Post training & Pre-training & Post training \\
\hline \multicolumn{5}{|c|}{ Plasma insulin $(\mathrm{mU} / \mathrm{l})$} \\
\hline Basal & $17.2 \pm 2.0$ & $15.7 \pm 1.7 *$ & $17.9 \pm 2.0$ & $15.0 \pm 1.7 *$ \\
\hline Clamp & $109.4 \pm 5.4$ & $107.8 \pm 4.2$ & $111.2 \pm 4.5$ & $107.9 \pm 5.1$ \\
\hline \multicolumn{5}{|c|}{ Plasma FFA $(\mu \mathrm{mol} / \mathrm{l})$} \\
\hline Basal & $498.6 \pm 18.3$ & $498.7 \pm 31.1$ & $473.3 \pm 31.0$ & $421.4 \pm 27.9$ \\
\hline Clamp & $90.2 \pm 7.7$ & $81.5 \pm 8.2$ & $103.9 \pm 10.0$ & $71.1 \pm 8.3^{*} \S$ \\
\hline \multicolumn{5}{|c|}{$\mathrm{Rd}$ glucose $(\mu \mathrm{mol} / \mathrm{kg} / \mathrm{min})$} \\
\hline Basal & $10.0 \pm 0.8$ & $8.7 \pm 0.7$ & $10.9 \pm 0.9$ & $8.7 \pm 0.7 *$ \\
\hline Clamp & $22.7 \pm 2.0$ & $22.3 \pm 2.1$ & $20.3 \pm 2.2$ & $25.0 \pm 2.1 * \S$ \\
\hline Delta & $12.7 \pm 2.1$ & $13.6 \pm 1.9$ & $9.5 \pm 2.5$ & $16.3 \pm 2.3^{*} \S$ \\
\hline \multicolumn{5}{|c|}{$\mathrm{EGP}(\mu \mathrm{mol} / \mathrm{kg} / \mathrm{min})$} \\
\hline Basal & $9.7 \pm 0.6$ & $9.3 \pm 0.6$ & $9.7 \pm 0.7$ & $7.9 \pm 0.8$ \\
\hline Clamp & $2.8 \pm 0.4$ & $0.8 \pm 0.5^{*}$ & $2.7 \pm 1.0$ & $1.8 \pm 1.3$ \\
\hline Delta & $-6.8 \pm 0.8$ & $-8.5 \pm 0.7$ & $-7.1 \pm 1.5$ & $-6.5 \pm 1.5 \S$ \\
\hline \multicolumn{5}{|c|}{$\mathrm{CHO}$ ox $(\mu \mathrm{mol} / \mathrm{kg} / \mathrm{min})$} \\
\hline Basal & $6.8 \pm 0.5$ & $7.3 \pm 0.5$ & $7.8 \pm 0.8$ & $7.0 \pm 0.5$ \\
\hline Clamp & $11.5 \pm 0.7$ & $12.9 \pm 0.8$ & $12.6 \pm 1.1$ & $13.5 \pm 0.7$ \\
\hline Delta & $4.7 \pm 0.7$ & $5.2 \pm 0.8$ & $4.7 \pm 0.9$ & $6.5 \pm 0.7^{*}$ \\
\hline \multicolumn{5}{|c|}{ NOGD $(\mu \mathrm{mol} / \mathrm{kg} / \mathrm{min})$} \\
\hline Basal & $3.3 \pm 0.8$ & $1.2 \pm 0.6^{*}$ & $3.0 \pm 1.0$ & $1.8 \pm 1.1$ \\
\hline Clamp & $11.2 \pm 1.5$ & $9.5 \pm 1.8$ & $7.8 \pm 1.9$ & $11.9 \pm 2 . * \S$ \\
\hline Delta & $7.9 \pm 1.7$ & $8.4 \pm 1.7$ & $4.7 \pm 2.1$ & $10.0 \pm 2.1 * \S$ \\
\hline \multicolumn{5}{|c|}{ Lipid ox $(\mu \mathrm{mol} / \mathrm{kg} / \mathrm{min})$} \\
\hline Basal & $1.10 \pm 0.06$ & $1.02 \pm 0.04 *$ & $1.06 \pm 0.05$ & $1.15 \pm 0.08$ \\
\hline Clamp & $0.69 \pm 0.04$ & $0.57 \pm 0.06^{*}$ & $0.71 \pm 0.06$ & $0.60 \pm 0.04$ \\
\hline Delta & $-0.41 \pm 0.05$ & $-0.45 \pm 0.07$ & $-0.34 \pm 0.07$ & $-0.55 \pm 0.06^{*}$ \\
\hline
\end{tabular}

Data are expressed as mean \pm SE., \#ST significantly different from control group, *post-training significantly different from pre-training, § significant interaction effect between C and ST. 


\section{Markers of mitochondrial density}

Mitochondrial density was evaluated by measuring protein content of 5 structural subunits of the distinct complexes of the electron transport chain. Neither the individual complexes, nor the mean protein content of these complexes revealed a difference in mitochondrial density between $\mathrm{C}$ and ST pre-training $(0.56 \pm 0.10$ and 0.71 $\pm 0.10 \mathrm{AU}$ in $\mathrm{C}$ and ST, NS). Training resulted in increased mitochondrial density in both groups after training $(0.56 \pm 0.10$ to $1.29 \pm 0.16 \mathrm{AU}$ in $\mathrm{C}, \mathrm{p}<0.01$ and $0.71 \pm 0.10$ to $1.22 \pm 0.16 \mathrm{AU}$ in $\mathrm{ST}, \mathrm{p}=0.03$ ) (Figure 1 panel a).

\section{MRS measurement}

Pre-training in vivo mitochondrial function in $\mathrm{C}$ was similar to ST (rate constant: $0.034 \pm 0.002$ and $0.034 \pm 0.003 \mathrm{~s}^{-1}$ in $\mathrm{C}$ and $\mathrm{ST}$ respectively) while after training in vivo mitochondrial function improved with $34 \%$ and $46 \%$ (from $0.034 \pm 0.002$ to $0.044 \pm 0.003 \mathrm{~s}^{-1}$ in $\mathrm{C}, \mathrm{p}<0.01$ and from $0.034 \pm 0.003$ to $0.049 \pm 0.006 \mathrm{~s}^{-1}$ in $\mathrm{ST}, \mathrm{p}=0.02$ ) (Figure 1 panel b).

\section{Metabolic flexibility}

Prior to training, metabolic flexibility $(\triangle \mathrm{RER} 0.071 \pm 0.008$ and $0.062 \pm 0.012, \mathrm{p}=$ 0.51 ), insulin stimulated glucose oxidation ( $\triangle \mathrm{CHOox} 4.7 \pm 0.7$ and $4.7 \pm 0.9$ umol $/ \mathrm{kg} / \mathrm{min}, \mathrm{p}=0.99$ ) and suppressed fat oxidation ( $\Delta$ FATox $-0.41 \pm 0.05$ and $0.34 \pm 0.07 \mathrm{umol} / \mathrm{kg} / \mathrm{min}, \mathrm{p}=0.47$ ) was comparable between C and ST. Exercise training did not affect metabolic flexibility in $\mathrm{C}$ ( $\triangle \mathrm{RER}$ from $0.071 \pm 0.008$ to $0.083 \pm 0.011, \mathrm{p}=0.22$ ) whereas metabolic flexibility improved significantly in ST ( $\triangle$ RER from $0.062 \pm 0.012$ to $0.089 \pm 0.008, \mathrm{p}=0.01$ ), reflecting a concomitant increase in insulin stimulate glucose oxidation (from $4.7 \pm 0.9$ to $6.5 \pm 0.7 \mathrm{umol} / \mathrm{kg} / \mathrm{min}, \mathrm{p}=0.01$ ) (Figure 1 panel c) and suppression of fat oxidation (from $-0.34 \pm 0.07$ to $-0.55 \pm 0.06$ umol/kg/min, p=0.01) (Figure 1 panel d). 

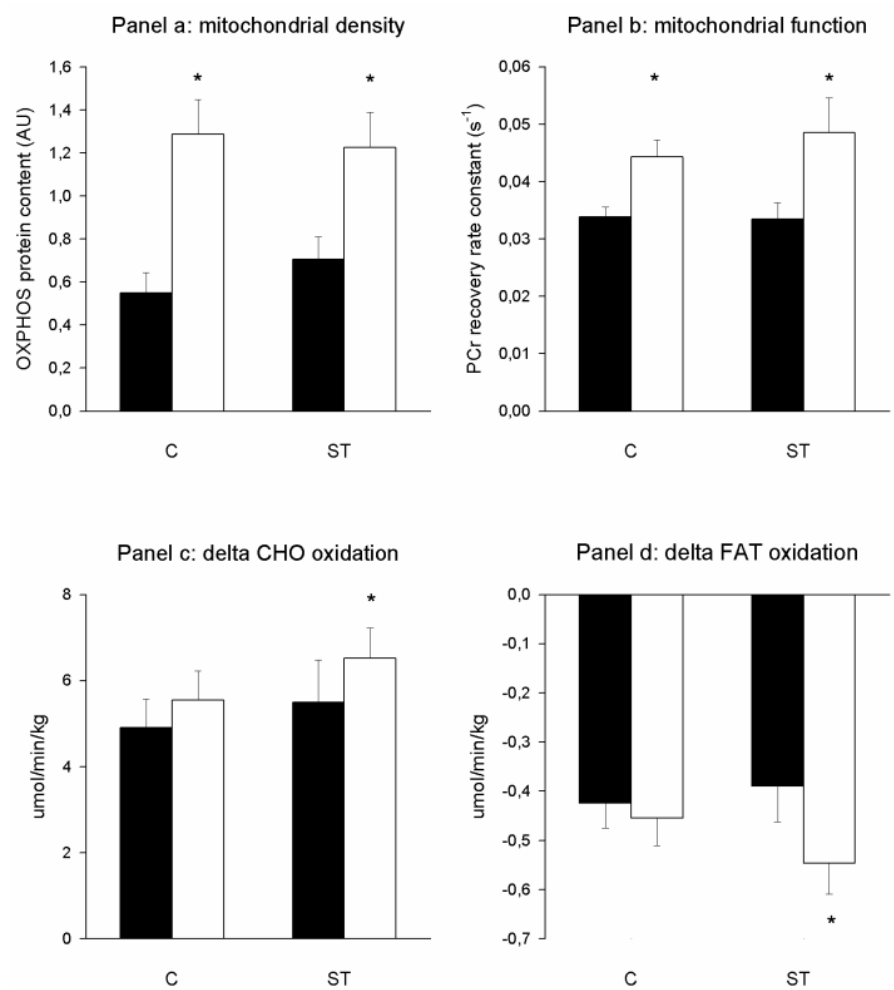

Panel 1a: mitochondrial density as determined by the mean of five different structural components of the electron transport chain, measured at the protein level, before (black bars) and after training (white bars). Data are expressed as mean \pm SE., *post-training significantly different from pre-training. Panel $1 \mathrm{~b}$ : In vivo mitochondrial function as determined by post-exercise PCr recovery rate as described previously[18], before (black bars) and after training (white bars). Data are expressed as rate constant (s-1). A higher rate constant corresponds with a high in vivo mitochondrial function. Data are expressed as mean \pm SE., *posttraining significantly different from pre-training. Panel 1c and Panel 1d: delta carbohydrate oxidation and delta fat oxidation, measured as the change from the fasted state to the insulin-stimulated state, before (black bars) and after training (white bars). Data are expressed as mean \pm SE., *post-training significantly different from pre-training. $\S$ significant interaction effect between control group and statin group.

\section{Discussion}

We examined the effect of training on cardiometabolic risk-factors, markers of in vivo mitochondrial function and insulin sensitivity in male obese elderly with and without type 2 diabetes who were on lipid lowering drugs (statins, ST group) and compared these effects with a control group (C) not taking statins.

Maximal exercise capacity and markers of mitochondrial content and function were not negatively impacted by statins. In addition, training-induced improvements in 
markers of cardiometabolic risk, insulin sensitivity and fuel selection were more prominent, and sometimes even exclusively detectable in ST compared to C. Exercise training mediated improvements in mitochondrial density and function were as prominent in ST as in C. The present study hence shows that exercise prescription on top of statin treatment is safe and at least as beneficial -and for some parameters even more beneficial- for cardiometabolic health, glucose homeostasis and mitochondrial function than exercise training without statins.

We did not find correlations between statin potency and other parameters, suggesting that the findings do not scale with the dosage or potency of the statin used. Furthermore, no interaction effects were detected between healthy subjects and diabetic subjects, indicating that differences were not specific for healthy or diabetic subjects solely.

\section{Pre-training pleiotropic effects of statins}

After stratification to the use of statins, both groups were comparable for all subject characteristics, except for LDL cholesterol (table 1). Also markers for insulin sensitivity, substrate metabolism and mitochondrial function were similar (table 2). Interestingly, this is in contrast with previous studies in rodents [20, 21] and humans, [22] showing improved insulin sensitivity on whole body level and in liver. Another study report a decrease in mtDNA copy number [8], suggesting that statins may affect these parameters somehow. In a more recent study, however, a high dose of statins (80 mg/day simvastatin) did not affect insulin-mediated glucose disposal, hepatic glucose production and myocellular lipid deposition [23].

\section{Exercise tolerance on statins}

Classical measures of physical fitness were similar in C as in ST, which is in line with previous reports [24]. A 12-week interval cycling training combined with resistance exercise did not provoke statin-related muscle pain or stiffness and was equally well tolerated in $\mathrm{C}$ as in ST. Self-reported muscle-stiffness due to unfamiliar exercise occurred predominantly in the first 1.5 weeks and rapidly disappeared after familiarization to the exercise program. Training-mediated improvements in exercise capacity 
were similar in both groups. Hence, the data of the present study do not support the hypothesis that the use of statins provokes muscle pathology or may blunt the adaptive responses to exercise training, as suggested previously [25]. However, the present study applied a tailored progressive exercise training program to avoid the development of muscle soreness, whereas other investigations applied eccentric exercise and exercise bouts on maximal intensity [11, 12], types of exercise prone to the development of muscle soreness. Also, none of the ST subjects in the present study reported muscle related complaints under resting conditions after starting their statin treatment. We can hence not exclude that the subjects in the present study represent a statin-tolerating subgroup and that this may contribute to the fact that none of them experienced muscle related problems whilst exercising.

\section{Post-training pleiotropic effects of statins}

In contrast to previous reports in humans [6] we did not detect any (negative) effects of statin use on mitochondrial content and function pre-training and showed similar improvements upon training. It should be noted though, that in the present study the dosage of statins used was in general lower [6].

Intriguingly, exercise training in ST improved insulin stimulated glucose disposal, both by an increase in oxidative as well as in non-oxidative glucose disposal, without an effect on hepatic insulin sensitivity. The improvement in non-oxidative glucose disposal is of particular interest, as we previously identified non-oxidative glucose disposal as the non-responsive culprit for training-mediated improvements in type 2 diabetic patients [13]. In contrast, in C, insulin-stimulated non-oxidative glucose disposal did not improve significantly after training.

One of the characteristics of insulin resistant muscle is metabolic inflexibility (delta RER). Here we observed that metabolic flexibility improved upon training in ST, indicating that statin use does not interfere with training-induced metabolic improvements. The improvement in metabolic flexibility was less pronounced (and non-significant) in $\mathrm{C}$. 


\section{Putative mechanisms of statin-mediated potentiation of the beneficial effect of} exercise training

We strikingly observed that the insulin sensitizing effects of exercise training were potentiated by the use of statins, but the precise mechanism(s) remains to be established. Candidate mechanisms include a statin mediated reduction in superoxideinduced cell damage [26], statin mediated-reduction of low-grade inflammation [27], or a reduction in FFA acid flux and hepatic fat storage [28] resulting in improved hepatic insulin sensitivity. The present study does not allow conclusions on the putative effects of statins on superoxide production or superoxide mediated cell damage. Using hsCRP as a marker for low-grade inflammation, we report no differences in low-grade inflammation pre-training between C and ST and did not detect any training effects on hsCRP. Recently it has been shown that even a high-dose of simvastatin (80 mg/daily) does not affect hepatic lipid stores or insulin sensitivity significantly [23]. This is in line with the present study showing similar insulin mediated suppression of hepatic glucose output pre-training in C and ST.

Many patients taking statins also are taking other drugs targeting cardiovascular risk control. The most clear design to examine the effects of the use of statins on exercise mediated improvements in glucose homeostasis and cardiovascular risk would be a double blind, placebo controlled, randomized clinical trial. A disadvantage, however, would be that only subjects can be included who were not on statins before the start of the study while in daily life patients usually been taking statins for quite some time even before they are advocated to physical exercise. Hence, we feel that the design of the present study provides a valuable and valid representation of what happens when subjects implement regular exercise in their daily life, on top of any medication they are taking already. The drawback of our design is that the statin group is not homogeneous for some of the output parameters examined. The fact that we indeed do observe significant differences for the key outcome parameters, however, indicates the effects reported are strong enough to reach significance, even with the relatively small group size shown.

In conclusion, the present study shows in elderly males with moderate obesity that statin treatment did not inhibit exercise-induced improvements with respect to mitochondrial density and function. Rather, improvements in total cholesterol, insulin 
stimulated lipolysis, insulin sensitivity, non-oxidative glucose disposal, metabolic flexibility, and substrate oxidation were more pronounced and/or even exclusively detectable when exercise and statin use was combined. This study suggests that combining physical exercise training in subjects who well-tolerate statin treatment under resting conditions may be at least as beneficial, and for some parameters even more beneficial, than exercise training exclusively. Thus, the present findings indicate that the recently published guidelines of the ADA to prescribe statins to all type 2 diabetic subjects over the age of 40 can be safely combined with previous guidelines on lifestyle interventions. 


\section{References}

1 Snow, V., Aronson, M. D., Hornbake, E. R., Mottur-Pilson, C., Weiss, K. B. (2004) Lipid control in the management of type 2 diabetes mellitus: a clinical practice guideline from the American College of Physicians. Ann Intern Med 140, 644-649

2 Downs, J. R., Beere, P. A., Whitney, E., Clearfield, M., Weis, S., Rochen, J., Stein, E. A., Shapiro, D. R., Langendorfer, A., Gotto, A. M., Jr. (1997) Design \& rationale of the Air Force/Texas Coronary Atherosclerosis Prevention Study (AFCAPS/TexCAPS). Am J Cardiol 80, 287-293

3 Sigal, R. J., Kenny, G. P., Wasserman, D. H., Castaneda-Sceppa, C., White, R. D. (2006) Physical activity/exercise and type 2 diabetes: a consensus statement from the American Diabetes Association. Diabetes Care 29, 1433-1438

4 Eldor, R., Raz, I. (2009) American Diabetes Association indications for statins in diabetes: is there evidence? Diabetes Care 32 Suppl 2, S384-391

5 Ghirlanda, G., Oradei, A., Manto, A., Lippa, S., Uccioli, L., Caputo, S., Greco, A. V., Littarru, G. P. (1993) Evidence of plasma CoQ10-lowering effect by HMG-CoA reductase inhibitors: a double-blind, placebo-controlled study. J Clin Pharmacol 33, 226229

6 Paiva, H., Thelen, K. M., Van Coster, R., Smet, J., De Paepe, B., Mattila, K. M., Laakso, J., Lehtimaki, T., von Bergmann, K., Lutjohann, D., Laaksonen, R. (2005) High-dose statins and skeletal muscle metabolism in humans: a randomized, controlled trial. Clin Pharmacol Ther 78, 60-68

7 Phillips, P. S., Haas, R. H., Bannykh, S., Hathaway, S., Gray, N. L., Kimura, B. J., Vladutiu, G. D., England, J. D. (2002) Statin-associated myopathy with normal creatine kinase levels. Ann Intern Med 137, 581-585

8 Schick, B. A., Laaksonen, R., Frohlich, J. J., Paiva, H., Lehtimaki, T., Humphries, K. H., Cote, H. C. (2007) Decreased skeletal muscle mitochondrial DNA in patients treated with high-dose simvastatin. Clin Pharmacol Ther 81, 650-653

9 Sirvent, P., Mercier, J., Lacampagne, A. (2008) New insights into mechanisms of statinassociated myotoxicity. Curr Opin Pharmacol 8, 333-338

10 Draeger, A., Monastyrskaya, K., Mohaupt, M., Hoppeler, H., Savolainen, H., Allemann, C., Babiychuk, E. B. (2006) Statin therapy induces ultrastructural damage in skeletal muscle in patients without myalgia. J Pathol 210, 94-102

11 Urso, M. L., Clarkson, P. M., Hittel, D., Hoffman, E. P., Thompson, P. D. (2005) Changes in ubiquitin proteasome pathway gene expression in skeletal muscle with exercise and statins. Arterioscler Thromb Vasc Biol 25, 2560-2566

12 Thompson, P. D., Zmuda, J. M., Domalik, L. J., Zimet, R. J., Staggers, J., Guyton, J. R. (1997) Lovastatin increases exercise-induced skeletal muscle injury. Metabolism 46, $1206-1210$

13 Meex, R. C., Schrauwen-Hinderling, V. B., Moonen-Kornips, E., Schaart, G., Mensink, M., Phielix, E., van de Weijer, T., Sels, J. P., Schrauwen, P., Hesselink, M. K. (2009) Restoration of muscle mitochondrial function and metabolic flexibility in type 2 diabetes by exercise training is paralleled by increased myocellular fat storage and improved insulin sensitivity. Diabetes 59, 572-579

14 Kelley, D. E., Mandarino, L. J. (2000) Fuel selection in human skeletal muscle in insulin resistance: a reexamination. Diabetes 49, 677-683

15 Frayn, K. N. (1983) Calculation of substrate oxidation rates in vivo from gaseous exchange. J Appl Physiol 55, 628-634 
16 Vanhamme, L., van den Boogaart, A., Van Huffel, S. (1997) Improved method for accurate and efficient quantification of MRS data with use of prior knowledge. J Magn Reson 129, 35-43

17 Naressi, A., Couturier, C., Castang, I., de Beer, R., Graveron-Demilly, D. (2001) Javabased graphical user interface for MRUI, a software package for quantitation of in vivo/medical magnetic resonance spectroscopy signals. Comput Biol Med 31, 269-286

18 Schrauwen-Hinderling, V. B., Kooi, M. E., Hesselink, M. K., Jeneson, J. A., Backes, W. H., van Echteld, C. J., van Engelshoven, J. M., Mensink, M., Schrauwen, P. (2007) Impaired in vivo mitochondrial function but similar intramyocellular lipid content in patients with type 2 diabetes mellitus and BMI-matched control subjects. Diabetologia 50, 113-120

19 Schrauwen, P., Mensink, M., Schaart, G., Moonen-Kornips, E., Sels, J. P., Blaak, E. E., Russell, A. P., Hesselink, M. K. (2006) Reduced skeletal muscle uncoupling protein-3 content in prediabetic subjects and type 2 diabetic patients: restoration by rosiglitazone treatment. J Clin Endocrinol Metab 91, 1520-1525

20 Wong, V., Stavar, L., Szeto, L., Uffelman, K., Wang, C. H., Fantus, I. G., Lewis, G. F. (2006) Atorvastatin induces insulin sensitization in Zucker lean and fatty rats. Atherosclerosis 184, 348-355

21 Naples, M., Federico, L. M., Xu, E., Nelken, J., Adeli, K. (2008) Effect of rosuvastatin on insulin sensitivity in an animal model of insulin resistance: evidence for statin-induced hepatic insulin sensitization. Atherosclerosis 198, 94-103

22 Paniagua, J. A., Lopez-Miranda, J., Escribano, A., Berral, F. J., Marin, C., Bravo, D., PazRojas, E., Gomez, P., Barcos, M., Moreno, J. A., Perez-Jimenez, F. (2002) Cerivastatin improves insulin sensitivity and insulin secretion in early-state obese type 2 diabetes. Diabetes 51, 2596-2603

23 Szendroedi, J., Anderwald, C., Krssak, M., Bayerle-Eder, M., Esterbauer, H., Pfeiler, G., Brehm, A., Nowotny, P., Hofer, A., Waldhausl, W., Roden, M. (2009) Effects of highdose simvastatin therapy on glucose metabolism and ectopic lipid deposition in nonobese type 2 diabetic patients. Diabetes Care 32, 209-214

24 Traustadottir, T., Stock, A. A., Harman, S. M. (2008) High-dose statin use does not impair aerobic capacity or skeletal muscle function in older adults. Age (Dordr) 30, 283 291

25 Thompson, P. D., Clarkson, P., Karas, R. H. (2003) Statin-associated myopathy. JAMA 289, 1681-1690

26 Wassmann, S., Laufs, U., Muller, K., Konkol, C., Ahlbory, K., Baumer, A. T., Linz, W., Bohm, M., Nickenig, G. (2002) Cellular antioxidant effects of atorvastatin in vitro and in vivo. Arterioscler Thromb Vasc Biol 22, 300-305

27 Forrester, J. S., Libby, P. (2007) The inflammation hypothesis and its potential relevance to statin therapy. Am J Cardiol 99, 732-738

28 Isley, W. L., Harris, W. S., Miles, J. M. (2006) The effect of high-dose simvastatin on free fatty acid metabolism in patients with type 2 diabetes mellitus. Metabolism 55, 758762 


\section{CHAPTER 6}

\section{High oxidative capacity protects against lipid-induced insulin resistance}

\begin{abstract}

\section{Objective}

Fat accumulation in skeletal muscle, combined with low mitochondrial oxidative capacity, is associated with insulin resistance. Endurancetrained athletes, characterized by a high oxidative capacity, have elevated intramyocellular lipids, yet are highly insulin sensitive. This suggests that a high oxidative capacity may prevent lipid-induced insulin resistance.
\end{abstract}

\section{Methods}

To test the hypothesis that a high oxidative capacity protects against lipid-induced insulin resistance, insulin sensitivity and detailed ex vivo mitochondrial function were studied in endurance trained and untrained subjects upon infusion with glycerol and lipid.

\section{Results}

Baseline mitochondrial respiration was higher in endurance trained subjects, compared to untrained subjects. This was caused by increased mitochondrial content rather than improved intrinsic mitochondrial function. Baseline insulin sensitivity was higher in trained subjects which could entirely be attributed to a difference in insulinstimulated glucose oxidation. Lipid infusion reduced insulin sensitivity in both groups but the reduction was less pronounced in endurance trained subjects $(-29 \%)$, compared to untrained subjects $(-63 \%)$. Oxidative glucose disposal decreased to a similar extent in both groups. In contrast non-oxidative glucose oxidation was only affected by lipid-infusion in the untrained group. Markedly, lipid-induced insulin resistance was not accompanied by a decreased mitochondrial function in either group.

\section{Conclusion}

High oxidative capacity in endurance trained subjects could be explained by an increased mitochondrial content and was shown to protect against lipid-induced insulin resistance via maintenance of non-oxidative glucose disposal.

\author{
Esther Phielix \\ Ruth C.R. Meex \\ Joris Hoeks \\ Lauren Sparks \\ Gert Schaart \\ Esther Moonen-Kornips \\ Matthijs Hesselink \\ Patrick Schrauwen \\ Submitted
}




\section{Introduction}

In sedentary subjects, fat accumulation in skeletal muscle strongly associates with development of muscle insulin resistance; the main risk factor in the development of type 2 diabetes. Indeed, elevated ectopic fat accumulation in the form of triacylglycerols (TG) in skeletal muscle (IMCL) has been associated with obesity and type 2 diabetes (1-6). The causal link between fat accumulation and muscular insulin resistance has been widely studied, indicating that fatty acid intermediates can impede insulin signalling in muscle cells (7). However, the question why IMCL accumulates in skeletal muscle has not yet been answered. In recent years, mitochondrial dysfunction has received large attention as a putative candidate to underlie fat accumulation in muscle and thereby the development of insulin resistance. Several studies showed compromised in vivo and ex vivo mitochondrial function as a contributor to the development of insulin resistance and type 2 diabetes (8-12). Studies have shown that both intrinsic mitochondrial function (i.e. respiratory capacity per mitochondria) (1013) as well as mitochondrial content $(14 ; 15)$ is reduced in type 2 diabetic patients and in first-degree relatives of patients with type 2 diabetes, suggesting that compromised mitochondrial function predisposes to the development of insulin resistance. It remains however to be established if a high mitochondrial function and/or content may prevent the susceptibility to develop lipid-induced muscular fat accumulation and insulin resistance.

Insulin resistance can be induced acutely upon infusion of lipid emulsions even in healthy humans. Acute lipid infusion results in elevated circulatory fatty acids, IMCL accumulation and fatty acid intermediates with concomitant insulin resistance within 3-4 hours after the onset of lipid infusion (16-21). This model is therefore very well suited to investigate the importance of mitochondrial function and/or content in the development of lipid-induced insulin resistance. Thus, the primary aim of our study was to test the hypothesis that high mitochondrial oxidative capacity could prevent the development of lipid-induced insulin resistance. To this end, in the present study the development of lipid-induced insulin resistance was examined in endurancetrained athletes, as classified by high maximal oxygen uptake and compared to untrained, but otherwise healthy, subjects. 
Recent research reports also suggest that high circulatory fatty acid levels may actually compromise mitochondrial function (22), indicative of mitochondrial lipotoxicity. For example, 60 hours of fasting lead to a massive increase in circulatory fatty acids and IMCL resulting in a reduction of mitochondrial respiratory capacity (23). Therefore, as a secondary aim of the present study, we also determined mitochondrial function after lipid infusion to determine whether short-term elevation of circulatory fatty acids negatively impacts mitochondrial function.

\section{Research Design and Methods}

\section{Subjects}

Ten healthy, sedentary, young untrained males and 9 endurance-trained males, matched for age $(21.9 \pm 0.9$ and $23.4 \pm 0.9 \mathrm{y}$, respectively), were included in this study. Medication use, a family history of diabetes and unstable dietary habits were exclusion criteria. All subjects underwent an incremental aerobic cycling test until exhaustion was reached (24). Subjects were included as trained if they participated in endurance-exercise activities such as running and/or cycling 3 times each week for at least 2 years, and if their maximal oxygen uptake (VO2max) peak was above $55 \mathrm{ml}$ $\mathrm{kg}^{-1} \mathrm{~min}^{-1}$. Subjects were included as untrained if they had a sedentary lifestyle and did not participate in any physical exercise for at least two years, and if they had a VO2max peak below $45 \mathrm{ml} \mathrm{kg}^{-1} \mathrm{~min}^{-1}$, The institutional medical ethical committee approved the study, and all participants gave their written informed consent. Subjects were recruited through advertisements within the medical university and local sport facilities. All subjects underwent hydrostatic weighing (25) to determine body composition.

\section{Hyperinsulinemic-euglycemic clamp}

Each subject underwent two test days at which insulin sensitivity was measured during a 6-h hyperinsulinemic-euglycemic $\left(40 \mathrm{mU} / \mathrm{m}^{2} / \mathrm{min}^{-1}\right)$ clamp, according to DeFronzo et al. (26) with a primed infusion of $[6,6]-{ }^{2} \mathrm{H}_{2}$ glucose $(0.03 \mathrm{mg} / \mathrm{kg} / \mathrm{min})$ to 
calculate rates of glucose appearance $\left(\mathrm{R}_{\mathrm{a}}\right)$, glucose disposal $\left(\mathrm{R}_{\mathrm{d}}\right)$ and hepatic glucose production (EGP) (27). Test days with either the infusion of glycerol $(1.32 \mathrm{ml} / \mathrm{min}$ as control condition) or a heparinised $(0.2 \mathrm{U} / \mathrm{kg} / \mathrm{min})$ infusion of long-chain triacylglycerols (1.35 ml/min LCT; Intralipid, Braun, The Netherlands) were randomly assigned. Two days before both test days, subjects refrained from exercise. On the day of the clamp, subjects reported to the lab at 7.30 am after an overnight fast. A fasting blood sample was drawn to measure glucose, insulin and free fatty acids (FFA) followed by the start of the primed $[6,6]-{ }^{2} \mathrm{H}_{2}$ glucose infusion. Baseline blood samples were drawn, and indirect calorimetry measurements (ventilated hood) were performed to measure carbohydrate and lipid oxidation and to calculate non-oxidative glucose disposal (28). A muscle biopsy was taken from the $m$. vastus lateralis under local anaesthesia (1\% lidocaïne) according to the technique of Bergström et al. (29). After the muscle biopsy, the infusion of insulin and $20 \%$-variable glucose was started $(\mathrm{t}=0)$, combined with simultaneous infusion of $20 \%$ LCT $(1.35 \mathrm{ml} / \mathrm{min})$, or $4 \%$ glycerol $(1.32 \mathrm{ml} / \mathrm{min})$ as a control trial to match the amount of infused glycerol during the LCT trial. Indirect calorimetry measurements were repeated during the last 30 minutes of the clamp ( $\mathrm{t}=330)$. Throughout the test-day and during the last half hour, blood samples were drawn for the analyses of glucose, insulin and FFA. Every 5 to 10 minutes $0.5 \mathrm{ml}$ blood samples were drawn to measure glucose concentration. Blood glucose was maintained euglycemic, around $5.0 \mathrm{mmol} / \mathrm{l}$. A second muscle biopsy was taken immediately after the clamp.

\section{Plasma assays}

Blood was collected in tubes containing EDTA and immediately centrifuged. Plasma was frozen in liquid nitrogen and stored at $-80{ }^{\circ} \mathrm{C}$ until assayed. Plasma FFA, glucose and insulin concentration as well as isotopic enrichment of plasma glucose, were determined as previously described (10).

\section{Muscle biopsy handling}

About $20 \mathrm{mg}$ of the total muscle biopsy was directly placed in a conservation medium (BIOPS; Oroboros Instruments, Innsbruck, Austria) for measurement of mito- 
chondrial function. The remaining tissue of the muscle biopsy was immediately frozen in liquid nitrogen and stored at $-80^{\circ} \mathrm{C}$ for later analyses. For the measurement of mitochondrial function, the muscle fibers were separated on a petri-dish using small needles, and the muscle membrane was permeabilized with saponin (stock solution: 5 $\mathrm{mg} / \mathrm{ml}$ BIOPS) as previously described (10). Subsequent to several washing steps with respiration medium (MiR05; Oroboros Instruments, Innsbruck, Austria) to ensure removal of saponin, 3-4 mg wet-weight fiber / measurement was transferred into the oxygraph and respiratory measurements were performed at $37^{\circ} \mathrm{C}$.

\section{Mitochondrial density}

Mitochondrial DNA (mtDNA) copy number was determined in whole muscle as measure of mitochondrial density as previously described (10) and expressed as arbitrary units (AU).

\section{$I M C L$}

Fresh cryosections of $5 \mu \mathrm{m}$ were stained for IMCL by Oil Red O staining combined with fiber typing and immunolabeling of the basal membrane marker laminin to allow for quantification as previously described (30).

\section{High resolution respirometry}

Ex vivo mitochondrial respiration was measured using high-resolution respirometry in a two-chamber Oxygraph (Oroboros, Innsbruck, Austria) and expressed as $\mathrm{pmol} / \mathrm{mg}$ muscle fiber wet weight/s. With the addition of multiple substrates, different respiratory states were revealed to analyze mitochondrial function. In protocol 1, malate $(\mathrm{M})$, glutamate (MG) and ADP (MG3) were subsequently added to reach state 3 respiration on complex I-linked substrates. In addition, succinate was added upon MG3 to reach state 3 respiration upon parallel electron input into complex I and complex II (MGS3). Then, cytochrome c was added upon MGS3 to check for mitochondrial membrane integrity followed by the addition oligomycin to inhibit the ATP-synthase (state $\mathrm{O} 4$ respiration). In protocol 2, malate (M), octanoyl-carnitine 
(MO) and ADP (MO3) were subsequently added to reach state 3 respiration on octanoyl-carnitine. Then glutamate (MOG3) and succinate (MOGS3) were added followed by the addition of cytochrome c. Finally, FCCP was titrated to determine maximal mitochondrial oxidative capacity. All measurements were performed in duplicate and substrates were added in excess to avoid substrate limitation. The final concentrations were: $4 \mathrm{mM}$ malate, $10 \mathrm{mM}$ glutamate, $10 \mathrm{mM}$ succinate, $10 \mu \mathrm{M}$ cytochrome c, $1 \mathrm{mM}$ octanoyl-carnitine, $2 \mathrm{mM}$ ADP, $2 \mu \mathrm{g} / \mathrm{ml}$ oligomycin and FCCP was titrated with steps of $0.5 \mathrm{nM}$.

\section{Calculations}

Calculations for non-steady state $R_{a}$ and $R_{d}$ were performed as described by Steele et al. (27). EGP was calculated as $R_{a}$ minus glucose infusion rate. Fat and carbohydrate oxidation were calculated as described by Frayn et al. (28). In addition, NOGD was calculated as $\mathrm{R}_{\mathrm{d}}$ minus whole body carbohydrate oxidation derived from the ventilated hood measurements.

\section{Statistics}

Data are reported as mean \pm SE. Statistical analyses were performed using the statistical computer program SPSS 16.0.2 for Mac OS X. Differences between groups and between conditions were analyzed by a two-way ANOVA in which comparisons between groups for repeated measures were computed with a Bonferroni post-hoc correction. Pearson correlation coefficients were computed to correlate parameter values. Differences were considered significant when $p<0.05$.

\section{Results}

\section{Subject characteristics}

Subject characteristics are shown in table 1. By design, endurance-trained subjects had a higher $\mathrm{VO}_{2}$ max and significant lower body mass index (BMI) compared to 
untrained subjects $\left(\mathrm{VO}_{2} \max : 61.5 \pm 1.2\right.$ vs. $43.0 \pm 1.1 \mathrm{ml} \mathrm{kg}^{-1} \mathrm{~min}^{-1} ; p<0.01$ and BMI: $21.2 \pm 0.6$ vs. $\left.22.8 \pm 0.6 \mathrm{~kg} / \mathrm{m}^{2} ; p=0.05\right)$. Importantly, fat free mass mainly determined by muscle mass, was comparable between groups $(60.0 \pm 2.5$ vs. $61.2 \pm$ $2.1 \mathrm{~kg}$ in trained vs. untrained respectively, $\mathrm{p}>0.05$ ).

a. Comparison trained and untrained subjects upon glycerol infusion

\section{Plasma metabolites}

Fasting glucose and insulin levels were comparable between trained and untrained subjects. Fasting FFA levels, however, were significantly lower in trained compared to untrained subjects ( $342 \pm 32$ vs. $469 \pm 34 \mu \mathrm{mol} /, p<0.05$, respectively) (Table 1$)$.

Table 1: subject characteristics

\begin{tabular}{lccc}
\hline Subject characteristics & $\begin{array}{c}\text { Untrained } \\
(\mathrm{n}=10)\end{array}$ & $\begin{array}{c}\text { Trained } \\
(\mathrm{n}=9)\end{array}$ & $\begin{array}{c}\text { Sig. } \\
\text { Age }(\mathrm{y})\end{array}$ \\
Body weight $(\mathrm{kg})$ & $21.9 \pm 0.9$ & $23.4 \pm 0.9$ & Ns \\
BMI $(\mathrm{kg} / \mathrm{m} 2)$ & $75.8 \pm 3.0$ & $67.8 \pm 2.8$ & $\mathrm{p}=0.07$ \\
Fat $(\%)$ & $22.8 \pm 0.6$ & $21.2 \pm 0.6$ & $\mathrm{p}=0.05$ \\
Fat free mass $(\mathrm{kg})$ & $19.1 \pm 1.4$ & $11.7 \pm 1.1$ & $\mathrm{p}<0.01$ \\
VO2max $(\mathrm{ml} / \mathrm{kg} / \mathrm{min})$ & $61.2 \pm 2.1$ & $60.0 \pm 2.5$ & $\mathrm{NS}$ \\
Wmax $($ Watt $/ \mathrm{kg})$ & $43.0 \pm 1.1$ & $61.5 \pm 1.2$ & $\mathrm{p}<0.01$ \\
Fasting glucose $(\mathrm{mmol} / \mathrm{l})$ & $3.7 \pm 0.2$ & $5.3 \pm 0.2$ & $\mathrm{p}<0.01$ \\
Fasting insulin $(\mathrm{mU} / \mathrm{ml})$ & $5.1 \pm 0.1$ & $5.0 \pm 0.1$ & $\mathrm{Ns}$ \\
Fasting FFA $(\mu \mathrm{mol} / \mathrm{l})$ & $10.3 \pm 1.2$ & $10.5 \pm 1.3$ & $\mathrm{Ns}$ \\
\hline
\end{tabular}

Subject characteristics. Data are mean \pm SE. (BMI, body mass index; FFA, free fatty acids; ns, nonsignificant).

\section{Mitochondrial metabolism}

As expected, endurance trained subjects showed significantly higher mitochondrial oxidative capacity compared to the untrained subjects for both multi-substrate protocols including malate, glutamate and succinate with and without the addition of octanoyl-carnitine (Figure 1A). In addition, mitochondrial mass, measured as mtDNA 
copy number was $27 \%$ higher in trained vs. untrained subjects. Interestingly, when respiratory values were normalized to mitochondrial content, the difference in ex vivo mitochondrial respiration between trained and untrained disappeared (Figure 1B), indicating similar intrinsic mitochondrial function.
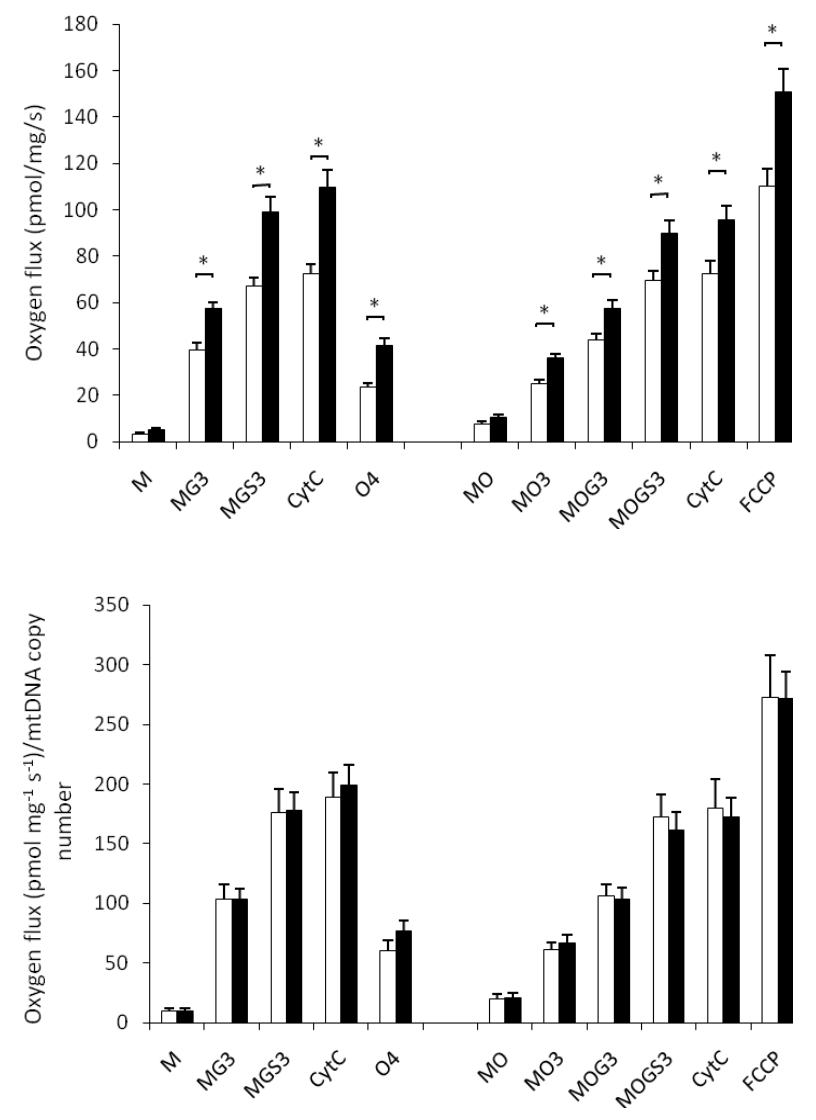

Figure 1: Mitochondrial oxygen flux (pmol mg-1 s-1) measured in permeabilized muscle fibers in trained (black) and untrained (white) subjects (A) and normalized to mitochondrial content (B). *p<0.05 trained vs untrained subjects. (M, malate; MG3, malate glutamate and ADP; MGS3, MG3 and succinate; cytc, cytochrome c; O4, oligomycin; MO, malate octanoyl-carnitine; MO3, MO and ADP; MOG3, MO3 and glutamate; MOGS3, MOG3 and succinate; FCCP, fluoro-carbonyl cyanide phenylhydrazone).

\section{Insulin sensitivity}

Insulin-stimulated glucose uptake ( $\Delta \mathrm{R}_{\mathrm{d}}$; clamp minus basal), was significantly higher in trained compared to untrained subjects $(45.9 \pm 3.6$ vs. $35.7 \pm 2.7 \mu \mathrm{mol} / \mathrm{kg} / \mathrm{min}$ 
respectively, $p<0.05$, Table 2 ). The difference in insulin sensitivity was entirely due to a higher insulin-stimulated oxidative glucose disposal in trained compared to untrained subjects $(+14.2 \pm 1.9$ vs. $+7.4 \pm 1.7 \mu \mathrm{mol} / \mathrm{kg} / \mathrm{min}$ respectively, $\mathrm{p}<0.05)$. Insulin-stimulated increase in non-oxidative glucose disposal was similar between trained and untrained subjects $(+31.8 \pm 2.8$ vs. $+29.1 \pm 2.7 \mu \mathrm{mol} / \mathrm{kg} / \mathrm{min}$ respectively, nonsignificant (ns), Table 2). In line, insulin-induced suppression of lipid oxidation was also more pronounced in trained compared to untrained subjects $(-0.6 \pm 0.1$ vs. -1.1 $\pm 0 . \mu \mathrm{mol} / \mathrm{kg} / \mathrm{min}$ respectively, $\mathrm{p}<0.05$, Table 2 ). Another way to express these findings is to define metabolic flexibility, which reflects the increase in respiratory exchange ratio (RER) from baseline to insulin-stimulated condition. This metabolic flexibility was significantly higher in trained compared to untrained subjects ( $\triangle$ RER: $+0.14 \pm 0.02$ vs. $+0.09 \pm 0.02$ respectively, $\mathrm{p}<0.05$, Table 2 ). No differences in basal parameters of glucose homeostasis or insulin-induced suppression of hepatic glucose output were observed between trained and untrained subjects (Table 2).

b. Comparison trained and untrained subjects upon lipid infusion

\section{Lipid-induced insulin resistance}

Upon the infusion of intralipid, FFA concentrations rose to a similar extent in trained and untrained subjects (Figure 2). Lipid infusion markedly lowered insulinstimulated glucose uptake by $\sim 63 \%$ in untrained subjects $(35.7 \pm 2.7$ vs. $12.0 \pm 3.1$ $\mu \mathrm{mol} \mathrm{kg}{ }^{-1} \mathrm{~min}^{-1}, p<0.05$, Figure 3A). This effect of lipid infusion was significantly blunted in trained subjects, in whom insulin-stimulated glucose uptake only decreased by $\sim 29 \%(45.9 \pm 3.6$ vs. $31.6 \pm 3.0 \mu \mathrm{mol} / \mathrm{kg} / \mathrm{min}, \mathrm{p}<0.05$, Figure $3 \mathrm{~A})$. The difference in lipid-induced insulin resistance between trained and untrained subjects was entirely due to a differential effect of lipid-induced lowering of non-oxidative glucose disposal; insulin-stimulated non-oxidative glucose disposal decreased by $52 \%$ in untrained subjects upon lipid infusion $(29.1 \pm 2.7$ vs. $14.0 \pm 3.4 \mu \mathrm{mol} / \mathrm{kg} / \mathrm{min}$, $\mathrm{p}<0.05$, Figure $3 \mathrm{C})$, whereas this was completely unaffected in trained subjects $(31.8$ \pm 2.8 vs. $32.1 \pm 3.4 \mu \mathrm{mol} / \mathrm{kg} / \mathrm{min}, \mathrm{ns}$, Figure $3 \mathrm{C}$ ). 


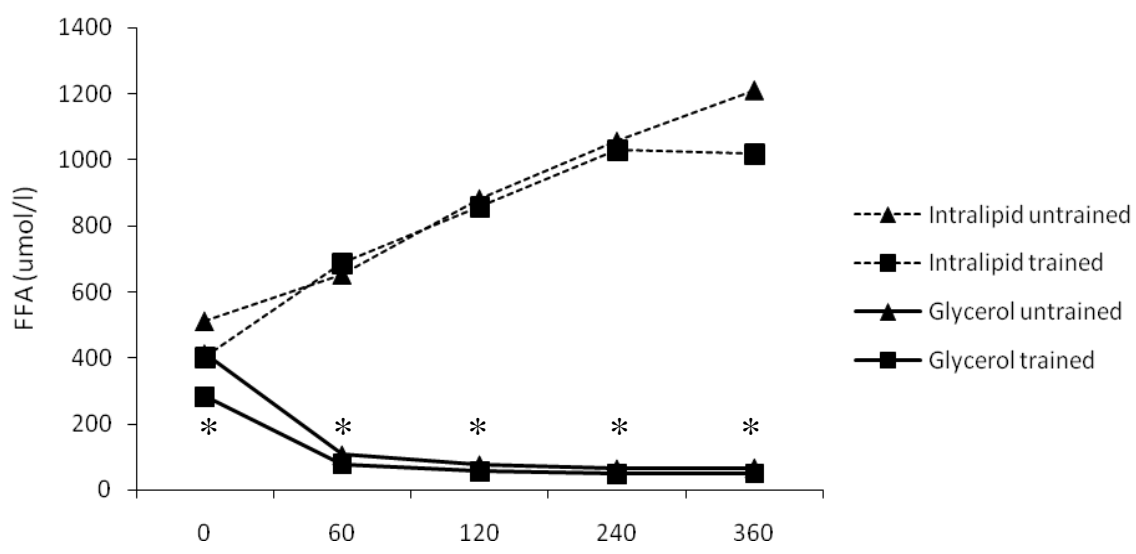

Figure 2: FFA concentration in trained (red) and untrained subjects (black) during the hyper-insulinemic clamp with co-infusion of glycerol or LCT (dashed line). ${ }^{*} p<0.05$ between trained vs untrained subjects in glycerol clamp.

Consequently, the $29 \%$ decrease in insulin sensitivity upon lipid infusion in trained subjects was completely accounted for by a reduction of insulin-stimulated glucose oxidation $(+14.2 \pm 1.9$ vs. $+0.9 \pm 1.3 \mu \mathrm{mol} / \mathrm{kg} / \mathrm{min}, \mathrm{p}<0.05$, Figure $3 \mathrm{~B})$, which was similar to untrained subjects $(+7.4 \pm 1.7$ vs. $-0.9 \pm 1.3 \mu \mathrm{mol} / \mathrm{kg} / \mathrm{min}, \mathrm{p}<0.05$, Figure 3B). Accordingly, the suppression of lipid oxidation that is observed upon insulinstimulation in insulin sensitive subjects was completely abolished upon lipid infusion in both trained $(-1.1 \pm 0.1$ vs. $+0.2 \pm 01 \mu \mathrm{mol} / \mathrm{kg} / \mathrm{min}, \mathrm{p}<0.05$, Table 2$)$ and untrained subjects $(-0.6 \pm 0.1$ vs. $+0.3 \pm 0.1 \mu \mathrm{mol} / \mathrm{kg} / \mathrm{min}, \mathrm{p}<0.05$, Table 2$)$. This is also reflected in a reduced metabolic flexibility upon lipid infusion, which was similar in both groups $(0.14 \pm 0.02$ vs. $-0.001 \pm 0.01$ in trained subjects and $0.09 \pm 0.02$ vs. $0.02 \pm 0.02$ in untrained subjects, $p<0.05$, Table 2 ). 

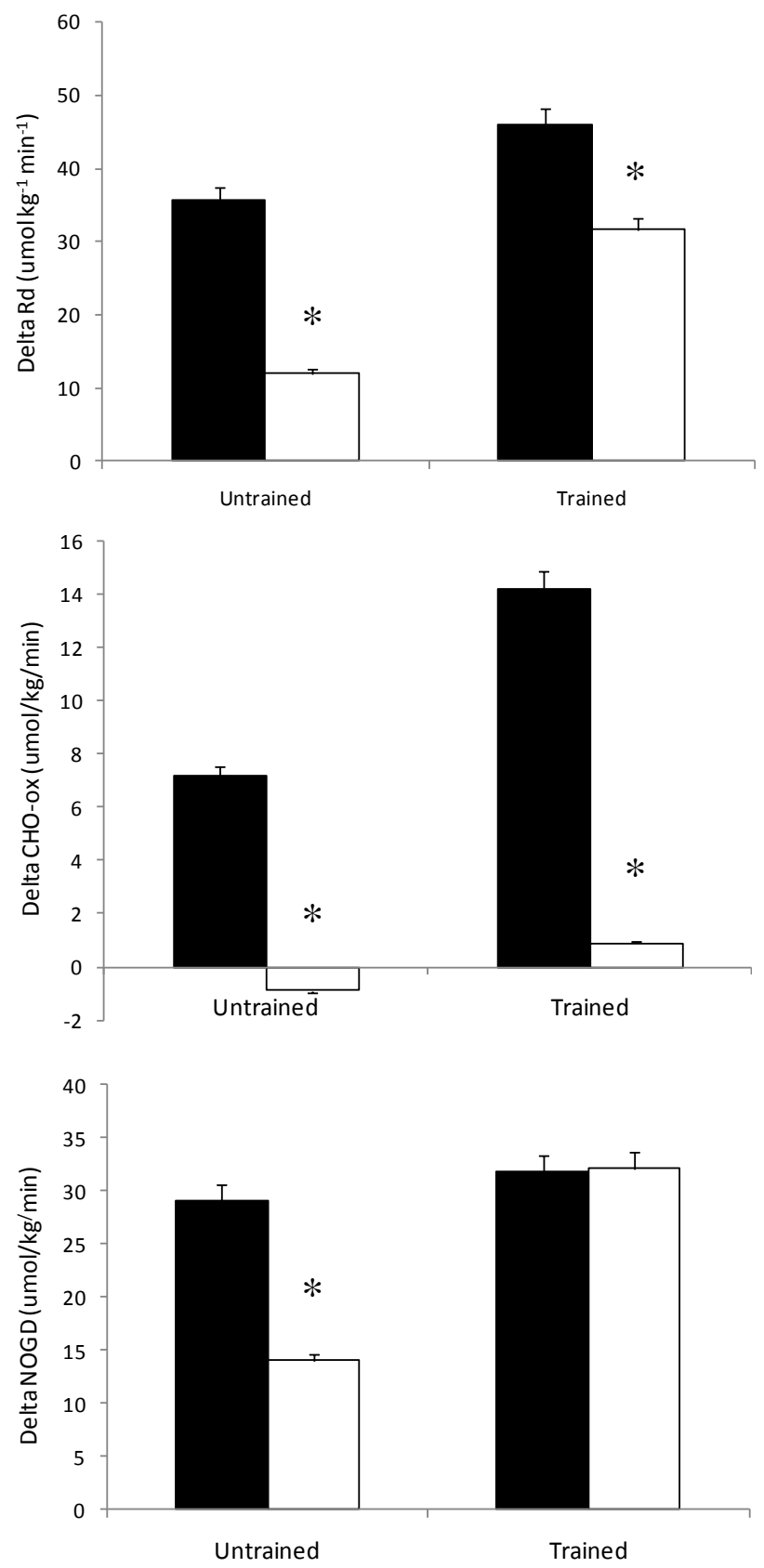

Figure 3: Insulin sensitivity expressed as delta $\mathrm{Rd}(\mathrm{A})$, delta carbohydrate oxidation (B) and delta nonoxidative glucose disposal (C) (all parameters expressed as $\mu \mathrm{mol} / \mathrm{kg} / \mathrm{min}$ ), in trained and untrained subjects during a hyperinsulinemic-euglycemic clamp with simultaneous infusion of glycerol (black bars) or LCT (white bars). Data expressed as mean $\pm \mathrm{SE},{ }^{*} p<0.05$ different from glycerol. 


\begin{tabular}{|c|c|c|c|c|}
\hline & \multicolumn{2}{|c|}{ Glycerol } & \multicolumn{2}{|c|}{ LCT } \\
\hline & Untrained & Trained & Untrained & Trained \\
\hline \multicolumn{5}{|c|}{$\mathrm{Rd}$ glucose $(\mu \mathrm{mol} / \mathrm{kg} / \mathrm{min})$} \\
\hline Basal & $15.9 \pm 0.6$ & $14.3 \pm 0.8$ & $18.4 \pm 2.3$ & $13.9 \pm 0.6$ \\
\hline Clamp & $51.6 \pm 2.6^{*}$ & $60.2 \pm 2.5^{*}$ & $30.4 \pm 2.0 \#$ & $45.4 \pm 4.1 * \#$ \\
\hline Delta & $35.7 \pm 2.7 *$ & $45.9 \pm 2.8^{*}$ & $12.0 \pm 3.1 \#$ & $31.6 \pm 3.0 * \#$ \\
\hline \multicolumn{5}{|c|}{$\mathrm{EGP}(\mu \mathrm{mol} / \mathrm{kg} / \mathrm{min})$} \\
\hline Basal & $15.6 \pm 0.6$ & $14.0 \pm 0.8$ & $18.1 \pm 2.3$ & $13.5 \pm 0.6$ \\
\hline Clamp & $-0.5 \pm 1.0 \#$ & $-1.5 \pm 1.3 \#$ & $4.8 \pm 1.1 \#$ & $2.4 \pm 1.5 \#$ \\
\hline Delta & $-16.1 \pm 1.2$ & $-15.1 \pm 1.3$ & $-13.3 \pm 2.0$ & $-11.2 \pm 2.0$ \\
\hline \multicolumn{5}{|l|}{ CHO oxidation } \\
\hline \multicolumn{5}{|l|}{$(\mu \mathrm{mol} / \mathrm{kg} / \mathrm{min})$} \\
\hline Basal & $9.8 \pm 0.6$ & $9.9 \pm 1.6$ & $10.3 \pm 1.4$ & $7.0 \pm 1.1$ \\
\hline Clamp & $17.3 \pm 1.2^{*}$ & $24.2 \pm 1.0 *$ & $9.1 \pm 1.3 \#$ & $8.7 \pm 1.2 \#$ \\
\hline Delta & $7.4 \pm 1.7 *$ & $14.2 \pm 1.9 *$ & $-0.9 \pm 1.3 \#$ & $0.9 \pm 1.3 \#$ \\
\hline \multicolumn{5}{|c|}{ NOGD $(\mu \mathrm{mol} / \mathrm{kg} / \mathrm{min})$} \\
\hline Basal & $7.4 \pm 1.7$ & $3.9 \pm 1.2$ & $6.0 \pm 1.6$ & $6.5 \pm 1.0$ \\
\hline Clamp & $34.3 \pm 2.9 *$ & $36.0 \pm 2.3 *$ & $21.4 \pm 2.1 \#$ & $36.8 \pm 4.3 *$ \\
\hline Delta & $29.1 \pm 2.7 *$ & $31.8 \pm 2.8^{*}$ & $14.0 \pm 3.4 \#$ & $32.1 \pm 3.4 *$ \\
\hline \multicolumn{5}{|l|}{ Lipid oxidation } \\
\hline \multicolumn{5}{|l|}{$(\mu \mathrm{mol} / \mathrm{kg} / \mathrm{min})$} \\
\hline Basal & $1.2 \pm 0.1 *$ & $1.5 \pm 0.1^{*}$ & $1.2 \pm 0.1^{*}$ & $1.7 \pm 0.1 *$ \\
\hline Clamp & $0.6 \pm 0.1^{*}$ & $0.4 \pm 0.1^{*}$ & $1.5 \pm 0.1 \#$ & $1.8 \pm 0.1 * \#$ \\
\hline Delta & $-0.6 \pm 0.1^{*}$ & $-1.1 \pm 0.1^{*}$ & $0.3 \pm 0.1 \#$ & $0.2 \pm 0.1 \#$ \\
\hline \multicolumn{5}{|l|}{ RER } \\
\hline Basal & $0.82 \pm 0.01 *$ & $0.80 \pm 0.02 *$ & $0.82 \pm 0.02 *$ & $0.78 \pm 0.01 *$ \\
\hline Clamp & $0.91 \pm 0.01 *$ & $0.95 \pm 0.01 *$ & $0.80 \pm 0.01 *$ & $0.78 \pm 0.01 *$ \\
\hline Delta & $0.09 \pm 0.02 *$ & $0.14 \pm 0.02 *$ & $-0.02 \pm 0.02 \#$ & $-0.001 \pm 0.01 \#$ \\
\hline
\end{tabular}

Data are expressed as mean \pm SE., $* \mathrm{p}<0.05$ between T vs UT and \#p<0.05 between LCT vs glycerol trial. (Rd, glucose disposal; EGP, endogenous glucose production; NOGD, non-oxidative glucose disposal; RER, respiratory exchange ratio).

\section{Intramyocellular triacylglycerol accumulation}

The increase in mean IMCL area fraction upon intralipid (\%) in muscle fibers identified as slow, oxidative type 1 fibers, was significantly lower in trained compared to untrained subjects $(0.2 \pm 1.2$ vs $4.1 \pm 1.1 \%, p<0.05)$. In type II muscle fibers, the 
mean IMCL area fraction did not change upon intralipid (\%) in trained neither in untrained subjects $(-0.2 \pm 0.5$ vs. $0.5 \pm 0.9 \%, p=$ n.s. $)$.

\section{Mitochondrial respiration}

Mitochondrial respiration was not affected upon the infusion of intralipid. For both groups, the respiratory values upon the infusion of LCT and insulin were not different from the respiratory values upon the infusion of glycerol and insulin (Table 3).

Table 3: mitochondrial respiration

\begin{tabular}{lllll}
\hline & \multicolumn{3}{l}{ GCT } \\
\cline { 2 - 5 } & Trained & Untrained & Trained & Untrained \\
\hline M & $3.8 \pm 1.4$ & $3.3 \pm 1.1$ & $2.9 \pm 1.6$ & $4.4 \pm 1.0$ \\
MG3 & $41.7 \pm 7.4$ & $41.8 \pm 5.2$ & $49.0 \pm 4.8$ & $40.4 \pm 5.0$ \\
MGS3 & $71.4 \pm 9.3$ & $63.3 \pm 6.8$ & $88.2 \pm 6.6$ & $77.1 \pm 7.6$ \\
Cytc & $81.1 \pm 11.3$ & $73.8 \pm 7.2$ & $105.1 \pm 8.2$ & $102.4 \pm 8.7$ \\
O4 & $29.9 \pm 4.2$ & $28.5 \pm 3.3$ & $53.1 \pm 5.2$ & $57.0 \pm 7.6$ \\
MO & $11.0 \pm 3.2$ & $8.6 \pm 3.2$ & $9.7 \pm 1.1$ & $7.0 \pm 1.4$ \\
MO3 & $26.1 \pm 3.2$ & $21.4 \pm 1.9$ & $28.2 \pm 2.3$ & $23.7 \pm 2.1$ \\
MOG3 & $46.9 \pm 6.6$ & $38.8 \pm 2.3$ & $46.9 \pm 5.0$ & $42.1 \pm 4.9$ \\
MOGS3 & $68.5 \pm 8.0$ & $59.0 \pm 4.2$ & $74.5 \pm 6.5$ & $75.5 \pm 6.0$ \\
Cytc & $73.7 \pm 9.1$ & $64.4 \pm 5.3$ & $83.6 \pm 7.1$ & $86.7 \pm 6.4$ \\
FCCP & $104.4 \pm 12.2$ & $101.7 \pm 7.8$ & $130.9 \pm 8.8$ & $124.4 \pm 11$ \\
\hline
\end{tabular}

Mitochondrial respiration values between trained and untrained subjects upon the glycerol and intralipid clamp. (M, malate; MG3, malate glutamate and ADP; MGS3, MG3 plus succinate; cytc, cytochrome c; O4, oligomycin; MO, malate octanoyl-carnitine; MO3, MO plus ADP; MOG3, MO3 plus glutamate; MOGS3, MOG3 plus succinate; FCCP, fluoro-carbonyl cyanide phenylhydrazone).

\section{Correlations}

Baseline mitochondrial respiratory values $(\mathrm{pmol} / \mathrm{mg} / \mathrm{s}$ ) correlated positively with insulin sensitivity defined as insulin-stimulated glucose uptake (clamp minus basal $\left.\Delta \mathrm{R}_{\mathrm{d}} ; \mu \mathrm{mol} / \mathrm{kg} / \mathrm{min}\right)$. Figure 4 shows the relation between state 3 respiration on glutamate and succinate $\left(\mathrm{pmol} / \mathrm{mg}^{\prime} \mathrm{s}\right)$ with insulin sensitivity $(\mathrm{R}=0.62, p<0.01$; Figure $4 \mathrm{~A}$ ), and state 3 respiration on glutamate, succinate and octanoyl-carnitine (pmol/mg/ s) with insulin sensitivity $(\mathrm{R}=0.60, p<0.01$; Figure $4 \mathrm{~B})$. All other respiratory states 
correlated with insulin sensitivity as well (data not shown). In addition, mtDNA copy number (AU) correlated positively with insulin sensitivity $\left(\Delta \mathrm{R}_{\mathrm{d}} ; \mu \mathrm{mol} / \mathrm{kg} / \mathrm{min}\right)$ $(\mathrm{R}=0.50, p<0.05)$.
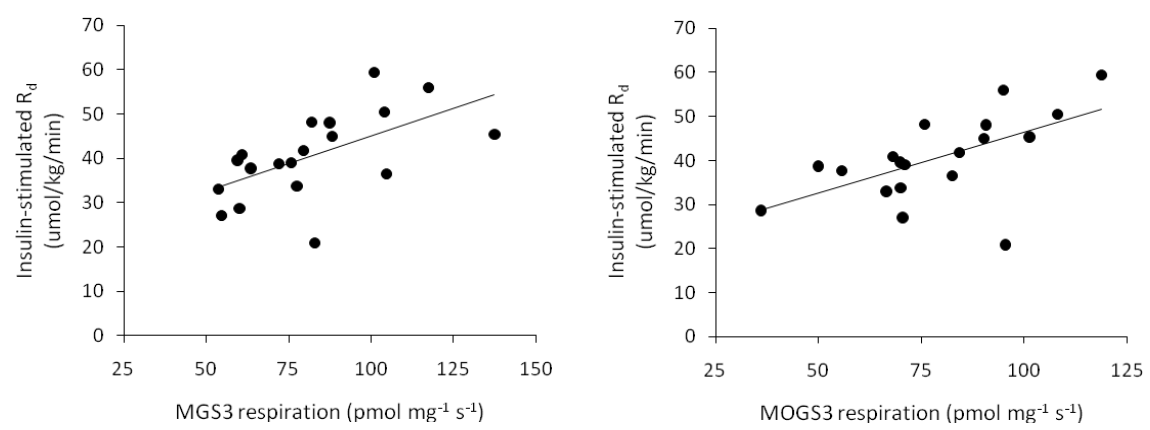

Figure 4: Correlations between insulin sensitivity (insulin-stimulated Rd $\mu \mathrm{mol} \mathrm{kg-1} \mathrm{min-1)} \mathrm{and} \mathrm{respiratory}$ values (pmol mg $\mathrm{m}^{-1} \mathrm{~s}^{-1}$ ) on glutamate and succinate (A) and glutamate, succinate and octanoyl-carnitine (B).

\section{Discussion}

Lower mitochondrial oxidative capacity - both reflected as lower mitochondrial density and lower intrinsic mitochondrial function - has been suggested to underlie the accumulation of fat in skeletal muscle that is associated with the development of insulin resistance. Consistent with this notion, we show here that a high oxidative capacity is indeed able to partly prevent lipid-induced insulin resistance. Thus, endurance-trained athletes with a higher oxidative capacity, reflected by higher mitochondrial content but not by enhanced intrinsic mitochondrial function, only reduced insulin sensitivity by $29 \%$ upon lipid infusion versus $63 \%$ in untrained subjects. Lipid infusion reduced insulin-stimulated glucose oxidation to a similar extent in trained and untrained subjects. Interestingly, the protective effect of having a high oxidative capacity was entirely attributable to the maintenance of high rates of nonoxidative glucose disposal.

It is well known that endurance training improves whole-body and muscular insulin sensitivity in young, healthy, lean individuals, as well as in obese subjects and type 2 
diabetic patients (31-33). Also in the present study, baseline insulin sensitivity was higher in trained subjects compared to the age-matched untrained individuals. Interestingly, this difference in insulin sensitivity could entirely be attributed to a difference in insulin-stimulated glucose oxidation, also referred to as metabolic flexibility, and was not due to differences in non-oxidative glucose disposal. In other words, trained subjects have higher insulin sensitivity because of an increased capability to switch between fat and glucose oxidation upon insulin-stimulation. This finding is in accordance with our recent report, showing that a 12 -week endurance and strength training program improved insulin sensitivity in type 2 diabetic patients, solely explained by an increase in insulin-stimulated glucose oxidation and without any change in insulin-stimulated non-oxidative glucose disposal (32). In these subjects, mitochondrial function and content improved after the 12-week training program (34). Jointly, these data indicate that mitochondrial oxidative capacity (mitochondrial content and/or intrinsic mitochondrial function) is indeed an important determinant of the oxidative part of muscular insulin sensitivity. In the present study this finding is substantiated by the positive correlations between insulin sensitivity and respiratory mitochondrial fluxes, as well as mitochondrial density. Importantly, glucose oxidation and storage are suggested to be two independently regulated mechanisms, and as these and previous results (32) indicate, exercise training affects merely the oxidative part instead of the non-oxidative part. In addition, the endurance trained subjects in the present study had lower free fatty-acid availability during baseline which persisted under insulin-stimulated conditions. This implies that free fatty acid concentrations and lipid oxidation may regulate muscular insulin sensitivity, i.e. glucose uptake into muscle, as was originally proposed by Randle (35).

Interestingly, here we show that trained subjects have a higher mitochondrial oxidative capacity in skeletal muscle, but that intrinsic mitochondrial function was similar between trained and untrained subjects. This is in line with the increased mitochondrial function in obese control and type 2 diabetic patients after the 12-week training program, which could predominantly be attributed to increased mitochondrial mass rather than intrinsic mitochondrial function per se (34). 
Both, a reduced mitochondrial function or lower whole body oxidative capacity, have been suggested to underlie the development of insulin resistance via increased accumulation of fat in skeletal muscle. To test this hypothesis, we examined if subjects with an increased mitochondrial capacity would be protected against the development of lipid-induced insulin resistance. We indeed showed that trained subjects were protected against the development of insulin resistance upon experimentally elevating circulatory fatty acids, although the development of insulin resistance could not completely be prevented. Insulin-stimulated glucose and -fat oxidation - also termed metabolic flexibility - was reduced to a similar extend upon lipid infusion in trained and untrained subjects. However, whereas untrained subjects also showed a reduced non-oxidative glucose disposal upon lipid infusion, trained athletes were completely protected against a lipid-induced reduction in non-oxidative glucose disposal.

In general, lipid-induced insulin resistance has been explained by an inhibitory effect of muscular fatty acid intermediates on insulin signalling, resulting in reduced glucose uptake into muscle cells $(7 ; 36)$. As a result of this reduced glucose uptake, both oxidative and non-oxidative glucose disposal are reduced. The results obtained in our untrained - but not trained - subjects upon lipid infusion are consistent with this model, as lipid infusion both reduced oxidative and non-oxidative glucose disposal. Alternatively, it has been postulated by Randle et al. (35) that lipid-induced insulin resistance is due to competition between glucose and fat for oxidation: with high fatty acid availability fat oxidation would prevail over glucose oxidation, thereby leading to the accumulation of metabolites upstream of glucose oxidation such as glucose-6-phosphate, which subsequently would reduce glucose uptake. However, in that scenario non-oxidative glucose disposal would not be affected as glucose-6phosphate would still be converted to glycogen (35). The finding that in trained subjects only insulin-stimulated glucose oxidation was affected upon lipid infusion would fit with the Randle hypothesis (35), and may suggest that trained subjects are protected from the accumulation of lipid intermediates that interfere with insulinstimulated GLUT4 translocation. In that respect, it was recently shown that one bout of acute exercise was able to prevent lipid-induced insulin resistance by the efficient 
shuttling of fatty acids into inert triglyceride stores in muscle, thereby preventing the accumulation of lipid intermediates (37). To this finding here we add in showing that subjects with a high oxidative capacity actually do not increase their IMCL levels and thereby probably also not fatty acid intermediates - upon lipid infusion, whereas untrained subjects do show an increase in IMCL upon lipid infusion. Although we can not reveal the precise underlying mechanism, our results do indicate that a high oxidative capacity prevents the interference of fatty acids with muscular glucose uptake upon intralipid infusion.

Finally, we show here that mitochondrial capacity, determined ex vivo, was not affected upon intralipid infusion, despite the development of insulin resistance. This supports the notion that the development of insulin resistance does not require mitochondrial dysfunction per se. This in line with previous data in which we showed that insulin resistance develops progressively in the absence of lower mitochondrial function in zucker diabetic fatty rats (38). However, we cannot exclude that the duration of the infusion was too short to induce a reduction in mitochondrial function, and we cannot therefore rule out a toxic effect of high fatty acid levels on mitochondrial function. In that respect, we recently showed that prolonged fasting $(60 \mathrm{~h})$, resulting in markedly elevated plasma fatty acid levels, resulted in a reduction of mitochondrial function (23).

Overall, we conclude that high maximal oxygen uptake as a consequence of regular exercise training prevents against lipid-induced insulin resistance, and specifically against a lipid-induced reduction in non-oxidative glucose disposal. In addition, intrinsic mitochondrial capacity was similar between trained and untrained subjects and was unaffected upon the infusion of intralipid. 


\section{References}

1. Jacob S, Machann J, Rett K, Brechtel K, Volk A, Renn W, Maerker E, Matthaei S, Schick F, Claussen CD, Haring HU: Association of increased intramyocellular lipid content with insulin resistance in lean nondiabetic offspring of type 2 diabetic subjects. Diabetes 48:1113-1119, 1999

2. Perseghin G, Scifo P, De Cobelli F, Pagliato E, Battezzati A, Arcelloni C, Vanzulli A, Testolin G, Pozza G, Del Maschio A, Luzi L: Intramyocellular triglyceride content is a determinant of in vivo insulin resistance in humans: a $1 \mathrm{H}-13 \mathrm{C}$ nuclear magnetic resonance spectroscopy assessment in offspring of type 2 diabetic parents. Diabetes 48:1600-1606, 1999

3. Goodpaster BH, Theriault R, Watkins SC, Kelley DE: Intramuscular lipid content is increased in obesity and decreased by weight loss. Metabolism 49:467-472, 2000

4. Pan DA, Lillioja S, Kriketos AD, Milner MR, Baur LA, Bogardus C, Jenkins AB, Storlien LH: Skeletal muscle triglyceride levels are inversely related to insulin action. Diabetes 46:983-988, 1997

5. Kelley DE, Goodpaster BH, Storlien L: Muscle triglyceride and insulin resistance. Annu Rev Nutr 22:325-346, 2002

6. Krssak M, Roden M: The role of lipid accumulation in liver and muscle for insulin resistance and type 2 diabetes mellitus in humans. Rev Endocr Metab Disord 5:127-134, 2004

7. Morino K, Petersen KF, Dufour S, Befroy D, Frattini J, Shatzkes N, Neschen S, White MF, Bilz S, Sono S, Pypaert M, Shulman GI: Reduced mitochondrial density and increased IRS-1 serine phosphorylation in muscle of insulin-resistant offspring of type 2 diabetic parents. J Clin Invest 115:3587-3593, 2005

8. Mogensen M, Sahlin K, Fernstrom M, Glintborg D, Vind BF, Beck-Nielsen H, Hojlund K: Mitochondrial respiration is decreased in skeletal muscle of patients with type 2 diabetes. Diabetes 56:1592-1599, 2007

9. Petersen KF, Dufour S, Befroy D, Garcia R, Shulman GI: Impaired mitochondrial activity in the insulin-resistant offspring of patients with type 2 diabetes. N Engl J Med 350:664671, 2004

10. Phielix E, Schrauwen-Hinderling VB, Mensink M, Lenaers E, Meex R, Hoeks J, Kooi ME, Moonen-Kornips E, Sels JP, Hesselink MK, Schrauwen P: Lower intrinsic ADPstimulated mitochondrial respiration underlies in vivo mitochondrial dysfunction in muscle of male type 2 diabetic patients. Diabetes 57:2943-2949, 2008

11. Schrauwen-Hinderling VB, Kooi ME, Hesselink MK, Jeneson JA, Backes WH, van Echteld CJ, van Engelshoven JM, Mensink M, Schrauwen P: Impaired in vivo mitochondrial function but similar intramyocellular lipid content in patients with type 2 diabetes mellitus and BMI-matched control subjects. Diabetologia 50:113-120, 2007

12. Szendroedi J, Schmid AI, Chmelik M, Toth C, Brehm A, Krssak M, Nowotny P, Wolzt M, Waldhausl W, Roden M: Muscle mitochondrial ATP synthesis and glucose transport/phosphorylation in type 2 diabetes. PLoS Med 4:e154, 2007

13. Ritov VB, Menshikova EV, He J, Ferrell RE, Goodpaster BH, Kelley DE: Deficiency of subsarcolemmal mitochondria in obesity and type 2 diabetes. Diabetes 54:8-14, 2005

14. Boushel R, Gnaiger E, Schjerling P, Skovbro M, Kraunsoe R, Dela F: Patients with type 2 diabetes have normal mitochondrial function in skeletal muscle. Diabetologia 50:790796, 2007

15. Kelley DE, He J, Menshikova EV, Ritov VB: Dysfunction of mitochondria in human skeletal muscle in type 2 diabetes. Diabetes 51:2944-2950, 2002 
16. Boden G, Lebed B, Schatz M, Homko C, Lemieux S: Effects of acute changes of plasma free fatty acids on intramyocellular fat content and insulin resistance in healthy subjects. Diabetes 50:1612-1617, 2001

17. Boden G, Shulman GI: Free fatty acids in obesity and type 2 diabetes: defining their role in the development of insulin resistance and beta-cell dysfunction. Eur J Clin Invest 32 Suppl 3:14-23, 2002

18. Dresner A, Laurent D, Marcucci M, Griffin ME, Dufour S, Cline GW, Slezak LA, Andersen DK, Hundal RS, Rothman DL, Petersen KF, Shulman GI: Effects of free fatty acids on glucose transport and IRS-1-associated phosphatidylinositol 3-kinase activity. $J$ Clin Invest 103:253-259, 1999

19. Griffin ME, Marcucci MJ, Cline GW, Bell K, Barucci N, Lee D, Goodyear LJ, Kraegen EW, White MF, Shulman GI: Free fatty acid-induced insulin resistance is associated with activation of protein kinase $\mathrm{C}$ theta and alterations in the insulin signaling cascade. Diabetes 48:1270-1274, 1999

20. Roden M, Price TB, Perseghin G, Petersen KF, Rothman DL, Cline GW, Shulman GI: Mechanism of free fatty acid-induced insulin resistance in humans. J Clin Invest 97:28592865, 1996

21. Yu C, Chen Y, Cline GW, Zhang D, Zong H, Wang Y, Bergeron R, Kim JK, Cushman SW, Cooney GJ, Atcheson B, White MF, Kraegen EW, Shulman GI: Mechanism by which fatty acids inhibit insulin activation of insulin receptor substrate-1 (IRS-1)associated phosphatidylinositol 3-kinase activity in muscle. J Biol Chem 277:5023050236, 2002

22. Brehm A, Krssak M, Schmid AI, Nowotny P, Waldhausl W, Roden M: Increased lipid availability impairs insulin-stimulated ATP synthesis in human skeletal muscle. Diabetes 55:136-140, 2006

23. Hoeks J, van Herpen NA, Mensink M, Moonen-Kornips E, van Beurden D, Hesselink MK, Schrauwen P: Prolonged fasting identifies skeletal muscle mitochondrial dysfunction as consequence rather than cause of human insulin resistance. Diabetes 59:2117-2125, 2010

24. Kuipers H, Verstappen FT, Keizer HA, Geurten P, van Kranenburg G: Variability of aerobic performance in the laboratory and its physiologic correlates. Int J Sports Med 6:197-201, 1985

25. Siri WE: The gross composition of the body. Adv Biol Med Phys 4:239-280, 1956

26. DeFronzo RA, Tobin JD, Andres R: Glucose clamp technique: a method for quantifying insulin secretion and resistance. Am J Physiol 237:E214-223, 1979

27. Steele R: Influences of glucose loading and of injected insulin on hepatic glucose output. Ann N Y Acad Sci 82:420-430, 1959

28. Frayn $\mathrm{KN}$ : Calculation of substrate oxidation rates in vivo from gaseous exchange. $J$ Appl Physiol 55:628-634, 1983

29. Bergstrom J, Hermansen L, Hultman E, Saltin B: Diet, muscle glycogen and physical performance. Acta Physiol Scand 71:140-150, 1967

30. Koopman R, Schaart G, Hesselink MK: Optimisation of oil red O staining permits combination with immunofluorescence and automated quantification of lipids. Histochem Cell Biol 116:63-68, 2001

31. Hawley JA, Lessard SJ: Exercise training-induced improvements in insulin action. Acta Physiol (Oxf) 192:127-135, 2008

32. Meex RC, Schrauwen-Hinderling VB, Moonen-Kornips E, Schaart G, Mensink M, Phielix E, van de Weijer T, Sels JP, Schrauwen P, Hesselink MK: Restoration of muscle mitochondrial function and metabolic flexibility in type 2 diabetes by exercise training is paralleled by increased myocellular fat storage and improved insulin sensitivity. Diabetes 59:572-579, 2009

33. Ryder JW, Chibalin AV, Zierath JR: Intracellular mechanisms underlying increases in glucose uptake in response to insulin or exercise in skeletal muscle. Acta Physiol Scand 171:249-257, 2001 
34. Phielix E, Meex R, Moonen-Kornips E, Hesselink MK, Schrauwen P: Exercise training increases mitochondrial content and ex vivo mitochondrial function similarly in patients with type 2 diabetes and in control individuals. Diabetologia 53:1714-1721, 2010

35. Randle PJ, Garland PB, Hales CN, Newsholme EA: The glucose fatty-acid cycle. Its role in insulin sensitivity and the metabolic disturbances of diabetes mellitus. Lancet 1:785789, 1963

36. Petersen KF, Shulman GI: Etiology of insulin resistance. Am J Med 119:S10-16, 2006

37. Schenk S, Horowitz JF: Acute exercise increases triglyceride synthesis in skeletal muscle and prevents fatty acid-induced insulin resistance. J Clin Invest 117:1690-1698, 2007

38. Lenaers E, De Feyter HM, Hoeks J, Schrauwen P, Schaart G, Nabben M, Nicolay K, Prompers JJ, Hesselink MK: Adaptations in mitochondrial function parallel, but fail to rescue, the transition to severe hyperglycemia and hyperinsulinemia: a study in Zucker diabetic fatty rats. Obesity (Silver Spring) 18:1100-1107, 2010 


\section{CHAPTER 7}

\section{Stimulation of human whole-body energy expenditure by salsalate is fuelled by higher lipid oxidation under fasting conditions and by higher oxidative glucose disposal under insulin stimulated conditions.}

\begin{abstract}

\section{Objective}

Non-steroidal anti inflammatory drugs appear to improve insulin sensitivity and are currently tested in clinical trials. Salsalate, however, may blunt mitochondrial function, an unwarranted side-effect for type 2 diabetics. We examined the effect of salsalate on ex vivo mitochondrial function and lipid-induced insulin resistance.
\end{abstract}

\section{Methods}

In a cross-over design nine volunteers underwent a hyperinsulinemiceuglycemic clamp with simultaneous infusion of glycerol (CON), intralipid (LIPID) or intralipid preceded by 4 days of salsalate ( 4000 mg Disalsid, LIPID+SAL). Oxidative (CHOox) and non-oxidative glucose disposal (NOGD); metabolic flexibility, energy expenditure (EE), and ex vivo muscle mitochondrial function were measured.

\section{Results}

Lipid infusion reduced insulin-stimulated glucose disposal by $\sim 40 \%$, CHOox by $\sim 50 \%$ and NOGD by $\sim 35 \%$. Lipid-induced whole-body insulin resistance and decreased NOGD were not ameliorated by salsalate. However, salsalate repressed lipid-induced reduction in CHOox and reduced insulin clearance, resulting in higher insulin levels under basal as well as under clamp conditions ( $25 \%$ and $~ 39 \%$ respectively). Intriguingly, EE was higher after administration of salsalate $(\sim 18 \%$ and $\sim 16 \%$ under basal and clamp conditions respectively) and was fuelled by increased FATox in the basal state and increased CHOox upon insulin stimulation. Salsalate did not affect mitochondrial function and coupling.

\section{Conclusion}

We conclude that salsalate failed to improve whole-body insulin sensitivity, but increased basal FATox and insulin-stimulated CHOox, indicating improved metabolic flexibility. The beneficial effects of salsalate on CHOox can be attributed to elevated insulin levels. Mitochondrial respirometry revealed no indications that the changes in substrate selection and EE could be attributed to changes in skeletal muscle mitochondrial capacity or mitochondrial coupling.

\author{
Ruth C.R. Meex \\ Esther Phielix \\ Esther Moonen-Kornips \\ Matthijs Hesselink \\ Patrick Schrauwen
}

J Clin Endocrinol Metab Feb, 2011. Epub ahead of print 


\section{Introduction}

Muscle insulin resistance is a hallmark in the development of type 2 diabetes (1) and has been associated with compromised mitochondrial function $(2,3)$, impeded insulin mediated changes in fuel selection (4), increased storage of fat in the muscle $(5,6)$ and increased activity of the inhibitor of $\kappa \mathrm{B}(\mathrm{I} \kappa \mathrm{B}) /$ nuclear factor $\kappa \mathrm{B}(\mathrm{NF} \kappa \mathrm{B})$ inflammatory pathway (7). Fasting plasma FFA inversely relates to insulin sensitivity (8). Likewise, elevating plasma FFA levels by acute lipid infusion results in acute insulin resistance (9) along with downregulation of genes involved in mitochondrial biogenesis and oxidative capacity $(10,11)$, metabolic inflexibility; and in obese and high fat fed rodents with activation of the $\mathrm{I} \kappa \mathrm{B} / \mathrm{NF} \kappa \mathrm{B}$ inflammatory pathway $(12,13)$. Intriguingly, the use of non-steroidal anti inflammatory drugs like salicylate has been shown to improve glucose homeostasis in humans (14-18) and insulin sensitivity in rodent (19). In addition, data indicate that the use of salicylates ameliorates lipidinduced insulin resistance in rats and mice (20), possibly by blunting lipid-induced activation of $\mathrm{I} \kappa \mathrm{B} / \mathrm{NF} \kappa \mathrm{B}(19,20)$. Based on these promising outcomes, multiple clinical trials examining the putative beneficial effect of salsalate (a heterodimer of salicylic acid) have been initiated, one of which recently published the first intriguing results (21).

Interestingly, in concentration ranges mimicking the doses used therapeutically, salicylate has also been recognized to impede mitochondrial function in mitochondria isolated from rodent tissues (22). Likewise, mitochondrial coupling and oxidative phosphorylation were shown to be attenuated in liver mitochondria treated with salicylate $(23,24)$. Mild uncoupling of mitochondria might be beneficial in terms of reducing superoxide production and possibly enhancing whole-body energy expenditure. Reduced oxidative phosphorylation has not only been reported patients with type 2 diabetes but also in pre-diabetic first degree relatives of type 2 diabetes (25) and is therefore considered an important player in the development of insulin resistance. It is hence of importance to examine the effect of salicylate on mitochondrial function in humans.

To this end, we aimed to examine the effect of short-term administration of a high dosage of salsalate on ex vivo muscle mitochondrial function in lean, young, insulin 
sensitive male subjects. In the same subjects, we applied the model of lipid-induced insulin resistance to study the hypothesis that lipid-induced insulin resistance could be rescued by the use of salsalate. We therefore studied the effect of salsalate on insulin sensitivity, oxidative and non-oxidative glucose disposal and whole-body energy expenditure and metabolic flexibility.

\section{Research design and methods}

\section{Subjects characteristics}

Nine healthy, male, lean volunteers with a small range in body weight, body mass index (BMI), and without a family history of diabetes mellitus were included. None of the subjects was on a diet and all had a sedentary lifestyle. The institutional medical ethical committee approved the study and all subjects gave written informed consent before participation. Body composition was measured through hydrostatic weighing (26), and maximal work load and oxygen uptake was assessed during a graded cycling test until exhaustion.

\section{Experimental design}

The study had a double-blind and placebo controlled randomised cross-over design. All subjects underwent three hyperinsulinemic euglycemic clamps, one with coinfusion of glycerol (CON), one with co-infusion of Intralipid® (LIPID), and one with co-infusion of Intralipid® preceded by 4 days ingestion of salsalate (LIPID+SAL). Three days prior to the clamps, subjects were asked to keep a constant eating pattern and to refrain from intense physical exercise. Clamps were randomized by design were separated by at least 1 week. In practice, for 5 subjects the salsalate condition was the last test-condition. In the other subjects, the time span between the salsalate trial and the next trial averaged 31 days, with the shortest time span being 14 days. Thus, carry-over effects of salsalate to the next trial have most likely been negligible, as convincingly indicated by the undetectably low levels of salicylate in the placebo condition. 


\section{Treatment}

Salsalate (Disalsid ${ }^{\mathrm{TM}}$ ) was taken orally for 4 days $(4000 \mathrm{mg} /$ day) after meals: three 500-milligram tablets in the morning and the evening and two 500-milligram tablets in the afternoon. Steady plasma levels of the salsalate derivative salicylate are known to be achieved within 3-4 days (13). Hence, salsalate administration in the present study was maintained for 4 days. On the morning of the test day, just prior to the onset of the clamp an additional $1500 \mathrm{mg}$ was given. Plasma values of salsalate after oral administration are known to peak after 1.4 hours and the plasma half life-time of salicylate ranges from 3.5-4.5 hours. In the CON and LIPID trial, salsalate was replaced by placebo tablets. Compliance was checked for by measuring salicylic acid levels in plasma on the morning of the clamp.

\section{Hyperinsulinemic-euglycemic clamp}

Subjects reported to the university after an overnight fast. A needle muscle biopsy of the vastus lateralis muscle was obtained under local anesthesia (2\% lidocaïne) and a fasted blood sample was taken to assess plasma salicylate levels. Glucose tracer ([6,6-2H2]glucose) infusion started at $\mathrm{t}=-60$ to determine rates of glucose appearance ( $\mathrm{Ra}$ ) and disappearance $(\mathrm{Rd})$ in the basal condition ( $\mathrm{t}=-30-0 \mathrm{~min}$ ), and during the insulin stimulated condition $(\mathrm{t}=330-360)$. At $\mathrm{t}=0$, a constant infusion of insulin (40 $\mathrm{mU} / \mathrm{m}^{2} / \mathrm{min}$ ) was started combined with the infusion of either lipid or glycerol and with the infusion of a variable amount of glucose (glucose solution 20\%) to maintain euglycemia. Lipid (20\% triacylglycerol emulsion (Intralipid; Fresenius Kabi, Bad Homburg, Germany) was infused at $81 \mathrm{ml} / \mathrm{h}$ for $6 \mathrm{~h}(9,10)$ with heparine $(1 \mathrm{ml}$ of heparine per $500 \mathrm{ml}$ of intralipid). Glycerol $(4.15 \mathrm{~g} / 100 \mathrm{ml})$ was infused at a rate of $73 \mathrm{ml} / \mathrm{h}$ to match the infused amounts of glycerol in the lipid condition. In the basal period ( $\mathrm{t}=-30-0)$ and under steady clamp conditions $(\mathrm{t}=330-360)$, blood was sampled and indirect calorimetry (ventilated hood) was performed using a custom built device. After 6 hours the clamp was ended. Previous studies revealed that using this design, insulin-desensitizing lipid intermediates increased (27), insulin stimulation of PI3 kinase was blunted in the lipid but not in the glycerol condition (28) and stable glucose infusion rates were achieved after 6 hours of infusion (10) 


\section{Tracer calculations}

Isotopic enrichment of plasma glucose was determined by electron ionization gas chromatography-mass spectrometry. Steele's single-pool steady-state equations (29) were used to calculate glucose $R \mathrm{a}$ and $R \mathrm{~d}$ in the basal period and non-steady-state equations were used for the insulin stimulated period. Insulin stimulated glucose disposal was computed as the difference between $R \mathrm{~d}$ under insulin stimulated conditions and $R \mathrm{~d}$ under basal non-insulin-stimulated conditions (delta $R \mathrm{~d}$ ). Endogenous glucose production (EGP) was calculated as $R$ a minus exogenous glucose infusion rate. Non-oxidative glucose disposal was calculated as $R \mathrm{~d}$ minus carbohydrate oxidation, derived from ventilated hood measurements.

\section{Blood sample analysis}

Arterialised blood samples (hotbox heated) were collected from a hand vein. Plasma free fatty acids (FFAs) and glucose were measured spectrophotometrically. Insulin concentration was determined using a radioimmunoassay (Linco Research, St. Charles, MO). Insulin clearance was calculated by dividing insulin infusion rate during the hyperinsulinemic euglycemic clamp, by the incremental insulin concentration (insulin stimulated values minus basal values), expressed in L/min (30).

\section{Markers of mitochondrial function}

Energy expenditure was measured under resting conditions in supine position by a custom built ventilated hood system. Energy expenditure was computed according to Weir $\left(\mathrm{kcal} / \mathrm{min}=3.9 * \mathrm{VO}_{2}(1 / \mathrm{min})+1.1 * \mathrm{VCO}_{2}(1 / \mathrm{min})(31)\right.$. Metabolic flexibility was expressed as the change in respiratory exchange ratio (RER) from the fasted state to the insulin-stimulated condition. Substrate oxidation was calculated according to Frayn (32) with protein oxidation considered negligible

Ex vivo mitochondrial function was measured using high resolution respirometry in a two-chamber oxygraph (Oroboros Instruments, Innsbruck, Austria) in permeabilized muscle fibers taken prior to and immediately after the clamp. Detailed procedures on muscle fiber handling and respirometry measurements are previously described (25). 
In brief, ADP driven state 3 respiration was measured on a cocktail of lipid and TCA cycle derived substrates producing $\mathrm{NADH}$ and $\mathrm{FADH}_{2}$ as reducing equivalents, hence resulting in parallel input in the electron transport chain. Adding oligomycin to block ATP-synthase activity was performed to measure respiration due to proton leak and not coupled to ATP synthesis (state 4 respiration). As an index of how well the mitochondria were coupled the respiratory control ratio (RCR) was computed as the ratio of state 3 respiration over state 4 respiration. A high RCR hence reflects a tightly coupled, energy efficient mitochondrion. Maximal capacity of the electron transport chain was measured after titration of FCCP (state U respiration). As a marker of mitochondrial density mtDNA (ND1) copy number was assessed relative to a nuclear encoded gene (LPL).

\section{Statistics}

Data are presented as mean \pm SE. Statistical analyses were performed two-sided using SPSS for Windows 15.0 software (SPSS, Chicago,IL). Statistical significance was set at $\mathrm{p}<0.05$. A Two-way ANOVA model for repeated measures was applied. In case of a significant F-ratio, differences were allocated using Bonferonni post-hoc tests.

\section{Results}

\section{Subjects characteristics}

Nine young healthy lean male subjects (body weight: $77.2 \pm 3.0 \mathrm{~kg}$; BMI: $22.9 \pm 0.6$ $\mathrm{kg} / \mathrm{m}^{2}$; age: $21.8 \pm 1.0$ years) were included. Body fat percentage $(19.6 \pm 1.4 \%)$ and VO2 max $/ \mathrm{kg}$ values $(42.6 \pm 1.2 \mathrm{ml} / \mathrm{kg})$ were in the normal range for healthy, untrained, young, male subjects. 


\section{Blood sample analysis}

Salsalate is partly hydrolyzed in the small intestine and partly in the body into two molecules of salicylic acid. Salicylic acid levels in plasma, as measured immediately before the clamp, were increased in the salsalate trial, compared to the placebo trial. (not detectable $(<30 \mathrm{mg} / \mathrm{l})$ and $212.7 \pm 21.2 \mathrm{mg} / \mathrm{l}$ in CON and LIPID+SAL respectively, $\mathrm{p}<0.01)$. This value is on the upper limit of the therapeutic range (100-250 $\mathrm{mg} / \mathrm{l})$. Basal plasma free fatty acid levels were not different between trials $(387 \pm 43$, $512 \pm 52$ and $470 \pm 61 \mu \mathrm{mol} / 1$ in CON, LIPID and LIPID+SAL respectively, $\mathrm{p}=0.32$ ). In both lipid infusion trials, free fatty acid levels gradually increased as anticipated and were significantly higher at all time points in LIPID and LIPID+SAL, compared to $\mathrm{CON}(\mathrm{p}<0.01)$ (Figure 1a). Glucose infusion rate was comparable between trials until $t=60$ but differed significantly from CON in LIPID from $t=90$ onwards and in LIPID+SAL from $t=220$ onwards (figure 1b). Salsalate significantly decreased insulin clearance $(0.95 \pm 0.05,1.04 \pm 0.07$ and $0.73 \pm 0.05 \mathrm{~L} / \mathrm{min}$ in CON, LIPID and LIPID+SAL respectively, p<0.01) (table 1). The salsalate-mediated decrease in insulin clearance was paralleled by higher basal plasma insulin levels (10.9 $\pm 1.6,10.0 \pm 1.3$ and $12.5 \pm 1.6 \mathrm{uU} / \mathrm{ml}$ in CON, LIPID and LIPID+SAL respectively, $\mathrm{p}<0.01$ ) (figure $2 \mathrm{a}$ ). These higher plasma insulin levels were maintained throughout the hyperinsulinemic clamp $(96.1 \pm 5.1,90.2 \pm 7.0$ and $125.6 \pm 9.2 \mathrm{uU} / \mathrm{ml}$ in $\mathrm{CON}$, LIPID and LIPID+SAL respectively, $\mathrm{p}=0.01)($ table 1).

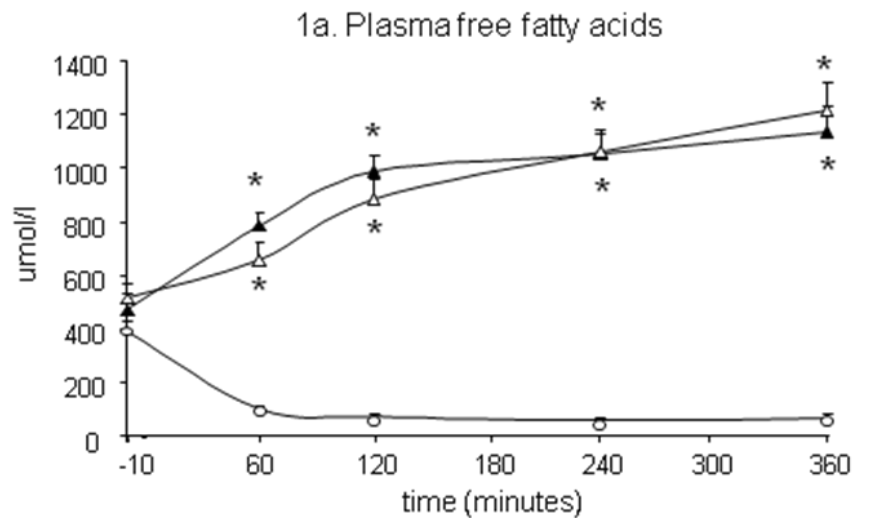

Figure 1a: Plasma free fatty acid levels in CON (open circles), LIPID (open triangles) and LIPID+SAL (closed triangles) during the hyperinsulinemic euglycemic clamp. Data are expressed as mean \pm SE., * significantly different from CON ( $p<0.05)$. 
1b. Glu cose infu sion rate

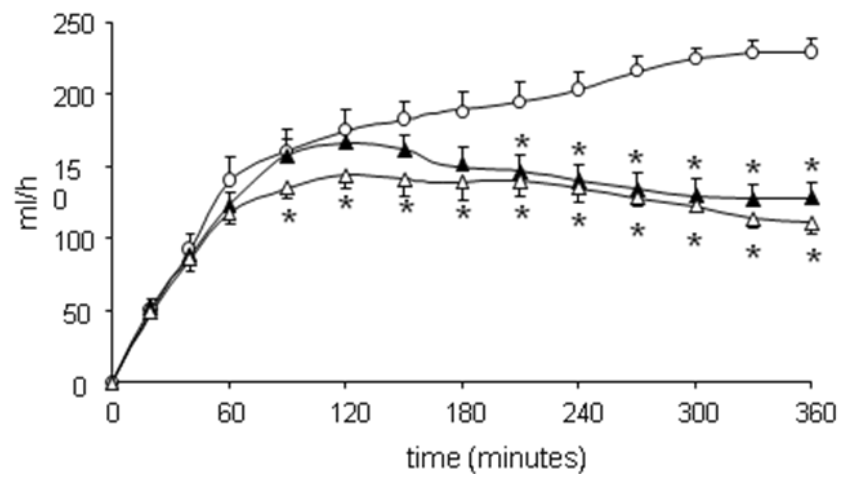

Figure 1b: Glucose infusion rate in $\mathrm{CON}$ (open circles), LIPID (open triangles) and LIPID+SAL (closed triangles) during the hyperinsulinemic euglycemic clamp. Data are expressed as mean \pm SE., * significantly different from CON $(p<0.05)$.

Whole-body insulin-stimulated glucose disposal

Although basal insulin values were increased in the SAL trial, basal glucose disposal rate was not different between the trials $(15.8 \pm 0.7,16.1 \pm 0.8$ and $15.3 \pm 0.8$ $\mu \mathrm{mol} / \mathrm{kg} / \mathrm{min}$ for CON, LIPID and LIPID+SAL respectively, table 1). Lipid infusion resulted in lipid-induced insulin resistance as indicated by a significantly lower $(\mathrm{p}<0.01)$ insulin-stimulated glucose disposal $(\Delta \mathrm{Rd})$ in the LIPID trial compared to CON $(14.3 \pm 1.8$ and $35.1 \pm 2.8 \mu \mathrm{mol} / \mathrm{kg} / \mathrm{min}$, respectively). Lipid-induced insulin resistance was not significantly $(\mathrm{p}=0.32)$ improved by salsalate $(\Delta \mathrm{Rd} 19.2 \pm 2.8$ $\mu \mathrm{mol} / \mathrm{kg} / \mathrm{min}$ in LIPID+SAL, table 1$)$, indicating that administration of salsalate did not rescue lipid-induced insulin resistance.

Lipid infusion resulted in a near-significant drop in non-oxidative glucose disposal rate upon insulin stimulation (NOGD $5.89 \pm 0.50$ and $3.83 \pm 0.37 \mathrm{mg} / \mathrm{kg} / \mathrm{min}$ in CON and LIPID, respectively, $\mathrm{p}=0.07$, table 1$)$. This was not restored by salsalate $(4.20 \pm$ $0.52 \mathrm{mg} / \mathrm{kg} / \mathrm{min}$ in LIPID+SAL, $\mathrm{p}=1.0$ compared to LIPID). Oxidative glucose disposal rate, though, was significantly higher in the LIPID+SAL condition than in the LIPID (see under metabolic flexibility).

Basal hepatic glucose output (endogenous glucose production, EGP) was not different between the trials $(15.5 \pm 0.7,15.8 \pm 0.8$ and $15.0 \pm 0.8 \mu \mathrm{mol} / \mathrm{kg} / \mathrm{min}$ for $\mathrm{CON}$, LIPID and LIPID+SAL respectively). EGP under insulin stimulated conditions was different between groups $(-0.4 \pm 1.0,+5.0 \pm 1.1$ and $+5.1 \pm 2.1 \mu \mathrm{mol} / \mathrm{kg} / \mathrm{min}$ for CON, LIPID and LIPID+SAL respectively, $\mathrm{p}<0.05$ ), indicating that lipid-infusion 138 
resulted in hepatic insulin resistance, which was not blunted by salsalate. A complete overview of the data on insulin-stimulated glucose disposal is presented in table 1.
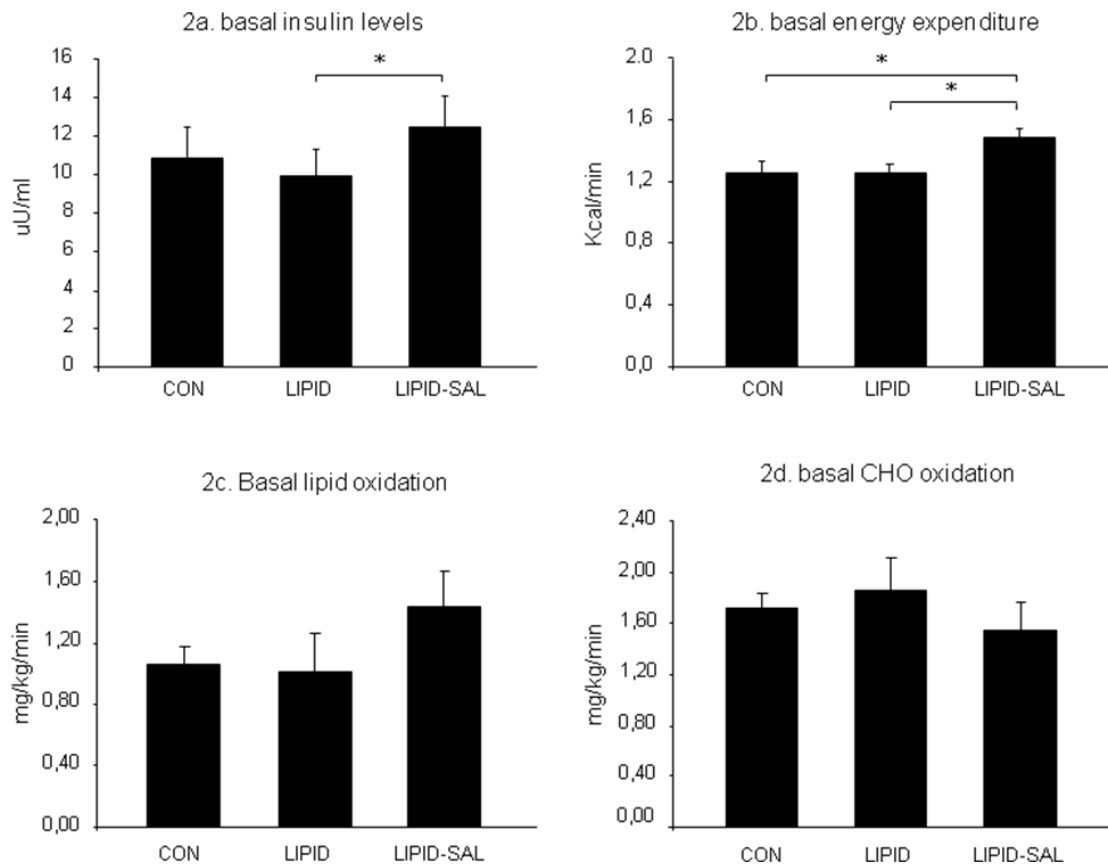

Figure 2: Basal insulin levels (2a), basal energy expenditure (2b), basal lipid oxidation (2c) and basal CHO oxidation (2d) in CON, LIPID and LIPID+SAL. Data are expressed as mean \pm SE., * significantly different $(\mathrm{p}<0.05)$.

\section{Energy expenditure}

In the basal state, energy expenditure was higher in LIPID+SAL than in CON and in LIPID $(1.49 \pm 0.05 \mathrm{kcal} / \mathrm{min}$ in LIPID+SAL vs. $1.26 \pm 0.07 \mathrm{kcal} / \mathrm{min}$ and $1.26 \pm 0.05$ $\mathrm{kcal} / \mathrm{min}$ in CON and LIPID respectively, $\mathrm{p}=0.01$ ) (figure $2 \mathrm{~b}$ ). Under basal conditions, the increase in energy expenditure in LIPID+SAL was entirely fuelled by an increased lipid oxidation $(1.43 \pm 0.17 \mathrm{mg} / \mathrm{kg} / \mathrm{min}$ in LIPID+SAL vs. $1.06 \pm 0.07$ and $1.101 \pm 0.11 \mathrm{mg} / \mathrm{kg} / \mathrm{min}$ in CON and LIPID, respectively) (Figure 2c).

Also in the insulin stimulated state, energy expenditure (measured from $t=330-360$ ) maintained higher in the LIPID+SAL group than in LIPID $(1.60 \pm 0.05$ and $1.38 \pm$ $0.05 \mathrm{kcal} / \mathrm{min}$ in LIPID+SAL and LIPID respectively, $\mathrm{p}<0.01)$. Though, the increase in energy expenditure in LIPID+SAL was especially fuelled by an increased carbo- 
hydrate oxidation (as indicated by the higher oxidative glucose disposal in LIPID+SAL than in LIPID (Table 1).

\section{Metabolic flexibility}

Metabolic flexibility was significantly blunted by lipid infusion $(\triangle \mathrm{RER} \quad 0.101 \pm$ $0.017,-0.023 \pm 0.018$ and $0.022 \pm 0.022$ in CON, LIPID and LIPID+SAL respectively, $\mathrm{p}<0.01$ ) (figure $3 \mathrm{a}$ ). Blunted metabolic flexibility was reflected in lower insulin-stimulated glucose oxidation (oxidative glucose disposal) in LIPID compared to CON (CHOox $3.27 \pm 0.17 \mathrm{mg} / \mathrm{kg} / \mathrm{min}$ in CON and $1.63 \pm 0.23 \mathrm{mg} / \mathrm{kg} / \mathrm{min}$ in LIPID).

Salsalate partly, but significantly, rescues the blunting effect of lipid on insulinstimulated oxidative glucose disposal, resulting in significantly higher rates of insulin-stimulated oxidative glucose disposal in LIPID+SAL $(2.19 \pm 0.27 \mathrm{mg} / \mathrm{kg} / \mathrm{min})$ than in LIPID (Table 1). As anticipated, the blunting of insulin-stimulated oxidative glucose disposal in the LIPID trial was mirrored by higher lipid oxidation rates in the LIPID trial under insulin stimulated conditions (lipid oxidation $0.47 \pm 0.06$ and 1.27 $\pm 0.08 \mathrm{in} \mathrm{mg} / \mathrm{kg} / \mathrm{min}$ in CON and LIPID respectively, $\mathrm{p}<0.01)$. Interestingly, lipid oxidation rates under insulin stimulated conditions were unaffected by salsalate compared to the LIPID trial $(1.33 \pm 0.07 \mathrm{mg} / \mathrm{kg} / \mathrm{min}$ in LIPID+SAL) (table 1$)$.
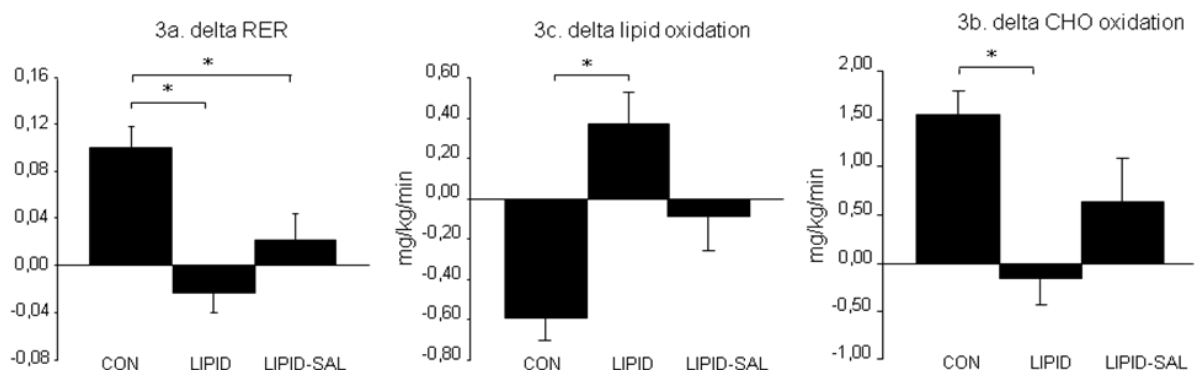

Figure 3: Metabolic flexibility (delta RER) (3a), delta CHO oxidation (3b) and delta lipid oxidation (3c), measured as the change from the fasted state to the insulin-stimulated state, in CON, LIPID and LIPID+SAL Data are expressed as mean \pm SE., * significantly different $(\mathrm{p}<0.05)$. 
Table 1: Substrate kinetics

\begin{tabular}{|c|c|c|c|}
\hline & $\mathrm{CON}$ & LIPID & LIPID+SAL \\
\hline \multicolumn{4}{|l|}{ Glucose (mmol/l) } \\
\hline Basal & $5.1 \pm 0.1$ & $5.2 \pm 0.2$ & $5.0 \pm 0.2$ \\
\hline Clamp & $5.8 \pm 0.1$ & $5.7 \pm 0.2$ & $5.6 \pm 0.1$ \\
\hline \multicolumn{4}{|l|}{ Plasma insulin (uU/ml) } \\
\hline Basal & $10.9 \pm 1.6$ & $10.0 \pm 1.3$ & $12.5 \pm 1.6 \S$ \\
\hline Clamp & $96.1 \pm 5.1$ & $90.2 \pm 7.0$ & $125.6 \pm 9.2 * \S$ \\
\hline Insulin clearance $(\mathrm{L} / \mathrm{min})$ & $0.95 \pm 0.05$ & $1.04 \pm 0.07$ & $0.73 \pm 0.05^{*} \S$ \\
\hline \multicolumn{4}{|l|}{ Rd glucose $(\mu \mathrm{mol} / \mathrm{kg} / \mathrm{min})$} \\
\hline Basal & $15.8 \pm 0.7$ & $16.1 \pm 0.8$ & $15.3 \pm 0.8$ \\
\hline Clamp & $50.9 \pm 2.7$ & $30.4 \pm 2.0 *$ & $34.5 \pm 3.2 *$ \\
\hline Delta & $35.1 \pm 2.8$ & $14.3 \pm 1.8 *$ & $19.2 \pm 2.8 *$ \\
\hline \multicolumn{4}{|l|}{$\mathrm{EGP}(\mu \mathrm{mol} / \mathrm{kg} / \mathrm{min})$} \\
\hline Basal & $15.5 \pm 0.7$ & $15.8 \pm 0.8$ & $15.0 \pm 0.8$ \\
\hline Clamp & $-0.4 \pm 1.0$ & $5.0 \pm 1.1 *$ & $5.1 \pm 2.1$ \\
\hline Delta & $-15.9 \pm 1.3$ & $-10.8 \pm 1.5$ & $-9.9 \pm 1.7$ \\
\hline \multicolumn{4}{|c|}{$\mathrm{CHO}$ oxidation (mg/kg/min) } \\
\hline Basal & $1.72 \pm 0.12$ & $1.86 \pm 0.25$ & $1.54 \pm 0.23$ \\
\hline Clamp & $3.27 \pm 0.17$ & $1.63 \pm 0.23 *$ & $2.19 \pm 0.27 * \S$ \\
\hline Delta & $1.55 \pm 0.24$ & $-0.16 \pm 0.27 *$ & $0.65 \pm 0.44$ \\
\hline \multicolumn{4}{|l|}{ NOGD $(\mathrm{mg} / \mathrm{kg} / \mathrm{min})$} \\
\hline Basal & $1.13 \pm 0.19$ & $1.08 \pm 0.29$ & $1.19 \pm 0.34$ \\
\hline Clamp & $5.89 \pm 0.50$ & $3.83 \pm 0.37$ & $4.20 \pm 0.52$ \\
\hline Delta & $4.76 \pm 0.53$ & $2.50 \pm 0.32$ & $3.01 \pm 0.38$ \\
\hline \multicolumn{4}{|l|}{ Lipid oxidation (mg/kg/min) } \\
\hline Basal & $1.06 \pm 0.07$ & $1.01 \pm 0.11$ & $1.43 \pm 0.17$ \\
\hline Clamp & $0.47 \pm 0.06$ & $1.27 \pm 0.08 *$ & $1.33 \pm 0.07 *$ \\
\hline Delta & $-0.59 \pm 0.11$ & $0.37 \pm 0.15 *$ & $-0.09 \pm 0.17$ \\
\hline \multicolumn{4}{|l|}{ RER } \\
\hline Basal & $0.815 \pm 0.009$ & $0.824 \pm 0.017$ & $0.791 \pm 0.016$ \\
\hline Clamp & $0.916 \pm 0.011$ & $0.797 \pm 0.013 *$ & $0.813 \pm 0.011 *$ \\
\hline Delta & $0.101 \pm 0.017$ & $-0.023 \pm 0.018 *$ & $0.022 \pm 0.022 *$ \\
\hline \multicolumn{4}{|c|}{ Energy expenditure (kcal/min) } \\
\hline Basal & $1.26 \pm 0.07$ & $1.26 \pm 0.05$ & $1.49 \pm 0.05 * \S$ \\
\hline Clamp & $1.27 \pm 0.04$ & $1.38 \pm 0.05 *$ & $1.60 \pm 0.05 * \S$ \\
\hline Delta & $0.01 \pm 0.04$ & $0.14 \pm 0.01$ & $0.11 \pm 0.03$ \\
\hline
\end{tabular}

Data are expressed as mean \pm SE., * LIPID significantly different from CON, * LIPID+SAL significantly different from CON, § LIPID+SAL significantly different from LIPID. 


\section{Ex vivo mitochondrial function}

Analyses of mitochondrial density in the muscle fibres samples under basal conditions and processed for respirometry assays revealed no significant differences in mitochondrial density with and without salsalate $(4177 \pm 586,4197 \pm 474$ and 4183 \pm 429 for CON, LIPID and LIPID+SAL respectively, $\mathrm{p}=0.61$ ), permitting valid comparison of absolute rates of respiration between the trials. High resolution respirometry revealed no significant differences in state 3 respiration with and without salsalate $(74.6 \pm 8.7,63.4 \pm 4.7$ and $66.9 \pm 7.3 \mathrm{pmol} / \mathrm{s} / \mathrm{mg})$ for CON, LIPID and LIPID+SAL respectively, $\mathrm{p}=0.67)$, oligomycin-induced state 4 respiration $(25.7 \pm$ $1.6,21.6 \pm 2.9$ and $24.9 \pm 21 \mathrm{pmol} / \mathrm{s} / \mathrm{mg}$ for CON, LIPID and LIPID+SAL respectively, $\mathrm{p}=0.40$ ), maximal electron transport chain capacity after titration of FCCP (state U) $(114.5 \pm 12.7,98.57 \pm 11.89$ and $105.5 \pm 13.1 \mathrm{pmol} / \mathrm{s} / \mathrm{mg}$ for CON, LIPID and LIPID+SAL respectively, $\mathrm{p}=0.50$ ) or respiratory control ratio (RCR) on any of the substrate cocktails used $(2.91 \pm 0.24,3.14 \pm 0.24$ and $2.96 \pm 0.22$ for CON, LIPID and LIPID+SAL respectively, $\mathrm{p}=0.55)$.

\section{Discussion}

In the present study we showed that 4 days of salsalate intake did not ameliorate lipid-induced whole body insulin resistance. Interestingly though, we observed that salsalate blunted the inhibitory effect of lipid-induced insulin resistance on insulinstimulated oxidative glucose disposal (resulting in higher rates of insulin stimulated oxidative glucose disposal rates in the salsalate trial) while non-oxidative glucose disposal or hepatic glucose production was not differentially affected. Fasting insulin levels as well as insulin levels under conditions of exogenous hyperinsulinemia were higher in the salsalate trial. Moreover, we observed a striking increase in resting energy expenditure after salsalate administration under basal conditions, which was entirely fuelled by increased lipid oxidation in the salsalate trial. Under hyperinsulinemic clamp conditions energy expenditure remained higher in the salsalate than in the placebo condition and here, the higher energy expenditure was entirely fuelled by oxidative glucose disposal without a concomitant decrease in lipid oxidation. De- 
tailed mitochondrial respirometry studies in permeabilised muscle fibers revealed no indications that the changes in energy expenditure and substrate selection upon salsalate administration could be attributed to changes in skeletal muscle mitochondrial capacity or mitochondrial coupling, nor that salsalate had detrimental effects on mitochondrial function.

Insulin resistance is a key characteristic in the pathogenesis of type 2 diabetes mellitus and is strongly associated with elevated plasma free fatty acid levels (8). In line, acute insulin resistance can be provoked by acute lipid infusion (9). The precise mechanism how fatty acids cause insulin resistance is not known yet, but activation of the inflammatory $\mathrm{NFkB} / \mathrm{IkB}$ pathway is suggested to play an important role herein. IKK is an activator of $\mathrm{I} \kappa \mathrm{B} / \mathrm{NF} \kappa \mathrm{B}$ pathway. Cell experiments and studies in high fat fed rats and ob/ob mice showed that after knock down of IKK, the I $\kappa / \mathrm{NF} \kappa \mathrm{B}$ pathway remained inactivated and insulin resistance was prevented, whereas overexpression of IKK led to activation of this pathway, resulting in an increase in insulin resistance (19). These results suggest that IKK is an important kinase in the regulation of insulin resistance. However, in another study, disruption of IKK failed to prevent obesity-induced insulin resistance (33). In addition, salicylates such as aspirin and salsalate have been suggested to improve insulin sensitivity though inhibition of IKK. However, although animal studies may seem fairly consistent $(19,20)$, results in human trials are equivocal. Several human trials indeed showed improved insulin sensitivity after aspirin and salsalate intake and although increased insulin levels were suggested to contribute to some extent to the observed improvement in insulin sensitivity, IKK was considered to be the main responsible target (34-36). In addition, other studies report unchanged $(30,37)$ or even a decreased insulin sensitivity $(38,39)$ after intake of salicylate derived compounds.

In the present study, we observed that lipid-induced insulin resistance measured as insulin stimulated glucose disposal was not alleviated by salsalate. Oxidative glucose disposal, however, improved slightly but significantly. Interestingly, we observed that salsalate resulted in a decreased insulin clearance rate. This decrease in clearance of insulin was reflected in higher fasting plasma insulin levels and was maintained throughout hyperinsulinemia period during the clamp. Decreased clearance of insulin 
by salsalate has previously been reported (30) and was shown to fully account for the beneficial effect of salicylates on insulin-stimulated glucose disposal in obese nondiabetic patients (30). The increase in oxidative glucose disposal observed here may thus be due to an elevated insulin concentration, rather than to an improved insulin action per se.

Intriguingly, we observed that 4 days administration of salsalate resulted in increased whole body resting energy expenditure under basal conditions. During the hyperinsulineamic euglycemic clamp with simultaneous lipid infusion, we confirmed the previously reported increase in energy expenditure (40). Notably, in the salsalate condition, the salsalate-mediated increase in resting energy expenditure was sufficiently potent to maintain throughout the clamp period. While increased energy expenditure in the basal condition was entirely fuelled by increased lipid oxidation, the elevated energy expenditure the insulin stimulated state was mainly fuelled by increased glucose oxidation. Increased lipid oxidation under fasting conditions and increased glucose oxidation under hyperinsulinemia -often referred to as 'metabolic flexibility'both are considered favorable metabolic adaptations, somehow mimicking the adaptations observed after physical exercise training (4). Although it should be stressed that these observations were made in healthy subjects rendered insulin resistant using lipid-infusion, (pre)diabetic subjects are likely to improve their metabolic flexibility and possibly post-prandial glucose homeostasis similarly.

Plasma free fatty acid levels did not change upon salsalate intake, which is consistent with another salsalate study (30). Some other studies in older obese type 2 diabetic patients, however, did observe decreased FFA levels upon salsalate and aspirin intake (34-36). It should be noted though that fasting plasma FFA levels in the present study were within the normal range, while in de studies observing an effect of salicylate on plasma FFA levels, the baseline FFA levels were high compared to values observed in lean healthy controls. In addition, differences in the drug used (salsalate versus aspirin, the longer duration and the difference in age are likely to contribute to this apparent discrepancy.

Resting energy expenditure is a reflection of energy demand or energy wasting in the form of mitochondrial uncoupling. Thus, increased energy expenditure after salsalate 
administration could either be a reflection of mitochondrial uncoupling (increased mitochondrial respiration to maintain transmembrane potential not coupled to ATP synthesis) or can be due to increased energy requirements. In this regard it is important to note that loose coupling of mitochondria in salicylate treated cells has long been recognized $(23,41-43)$. In the present study, however, in vivo administration of salsalate did not increase mitochondrial respiration in permeabilized muscle fibers after blocking ATP-synthase activity by oligomycin (sate 4 respiration), indicating that uncoupling of muscle mitochondria cannot explain the observed increase in whole-body energy expenditure. Assuming that energy requirements did not change upon salsalate, these results could indicate that other tissues or other energy wasting processes (such as futile cycles) are responsible for the salsalate-induced increase in energy expenditure. On the other hand, salsalate has been suggested to impair mitochondrial function $(23,24)$. To this end we examined mitochondrial respiratory capacity in permeabilised muscle fibers sampled under basal resting conditions, as well as at the end of the 6 hour clamp period, on a series of substrates under ADP-driven state 3 respiration and stimulated maximal mitochondrial respiration. On none of the substrates used or any of the conditions tested we were able to detect differences in mitochondrial respiration or respiratory control ratio between salsalate and placebo. This suggests that, at least in human muscle mitochondria examined ex vivo, administration of salsalate, even in high dosages, did not impede mitochondrial respiratory capacity or increased mitochondrial uncoupling. We can, however, not exclude the possibility that salsalate modestly increases in vivo basal rates of respiration or mitochondrial uncoupling in other tissues than leg skeletal muscle or to an extent which does not reflect adaptive responses at the maximal capacity level as tested ex vivo.

Taken together, in the present study, we show that 4 days of high dosage of salsalate intake in young healthy men did not ameliorate lipid induced insulin resistance. Insulin stimulated oxidative glucose disposal however, and metabolic flexibility was slightly improved by salsalate. Intriguingly, insulin levels and energy expenditure were elevated in the basal as well as in the insulin stimulated condition. Increased resting energy expenditure was not due loose coupling of muscle mitochondria and was almost entirely fuelled by increased lipid oxidation rates. 
In conclusion, the salsalate mediated increase in fasting insulin, the increase in resting energy expenditure which was entirely fuelled by lipid oxidation and improved insulin-stimulated oxidative glucose disposal are favourable adaptive responses which occur in the absence of any negative effect of salsalate on mitochondrial function assessed in permeabilised muscle fibers by high-resolution respirometry. 


\section{References}

1. Nielsen MF, Nyholm B, Caumo A, Chandramouli V, Schumann WC, Cobelli C, Landau BR, Rizza RA, Schmitz O 2000 Prandial glucose effectiveness and fasting gluconeogenesis in insulin-resistant first-degree relatives of patients with type 2 diabetes. Diabetes 49:2135-2141

2. Meex RC, Schrauwen-Hinderling VB, Moonen-Kornips E, Schaart G, Mensink M, Phielix E, van de Weijer T, Sels JP, Schrauwen P, Hesselink MK 2009 Restoration of muscle mitochondrial function and metabolic flexibility in type 2 diabetes by exercise training is paralleled by increased myocellular fat storage and improved insulin sensitivity. Diabetes 59:572-579

3. Lowell BB, Shulman GI 2005 Mitochondrial dysfunction and type 2 diabetes. Science 307:384-387

4. Kelley DE, Mandarino LJ 2000 Fuel selection in human skeletal muscle in insulin resistance: a reexamination. Diabetes 49:677-683

5. Krssak M, Falk Petersen K, Dresner A, DiPietro L, Vogel SM, Rothman DL, Roden M, Shulman GI 1999 Intramyocellular lipid concentrations are correlated with insulin sensitivity in humans: a 1H NMR spectroscopy study. Diabetologia 42:113-116

6. Perseghin G, Scifo P, De Cobelli F, Pagliato E, Battezzati A, Arcelloni C, Vanzulli A, Testolin G, Pozza G, Del Maschio A, Luzi L 1999 Intramyocellular triglyceride content is a determinant of in vivo insulin resistance in humans: a $1 \mathrm{H}-13 \mathrm{C}$ nuclear magnetic resonance spectroscopy assessment in offspring of type 2 diabetic parents. Diabetes 48:1600-1606

7. Sriwijitkamol A, Christ-Roberts C, Berria R, Eagan P, Pratipanawatr T, Defronzo RA, Mandarino LJ, Musi N 2006 Reduced Skeletal Muscle Inhibitor of \{kappa\}B $\{$ beta\} Content Is Associated With Insulin Resistance in Subjects With Type 2 Diabetes: Reversal by Exercise Training. Diabetes 55:760-767

8. Perseghin G, Ghosh S, Gerow K, Shulman GI 1997 Metabolic defects in lean nondiabetic offspring of NIDDM parents: a cross-sectional study. Diabetes 46:1001-1009

9. Boden G, Jadali F, White J, Liang Y, Mozzoli M, Chen X, Coleman E, Smith C 1991 Effects of fat on insulin-stimulated carbohydrate metabolism in normal men. J Clin Invest 88:960-966

10. Hoeks J, Hesselink MK, Russell AP, Mensink M, Saris WH, Mensink RP, Schrauwen P 2006 Peroxisome proliferator-activated receptor-gamma coactivator-1 and insulin resistance: acute effect of fatty acids. Diabetologia 49:2419-2426

11. Richardson DK, Kashyap S, Bajaj M, Cusi K, Mandarino SJ, Finlayson J, DeFronzo RA, Jenkinson CP, Mandarino LJ 2005 Lipid infusion decreases the expression of nuclear encoded mitochondrial genes and increases the expression of extracellular matrix genes in human skeletal muscle. J Biol Chem 280:10290-10297

12. Cai D, Yuan M, Frantz DF, Melendez PA, Hansen L, Lee J, Shoelson SE 2005 Local and systemic insulin resistance resulting from hepatic activation of IKK-beta and NF-kappaB. Nat Med 11:183-190

13. Shoelson SE, Lee J, Yuan M 2003 Inflammation and the IKK beta/I kappa B/NF-kappa B axis in obesity- and diet-induced insulin resistance. Int J Obes Relat Metab Disord 27 Suppl 3:S49-52

14. Reid J, Macdougall AI, Andrews MM 1957 Aspirin and diabetes mellitus. Br Med $\mathrm{J}: 1071-1074$

15. Gilgore SG, Rupp JJ 1961 Response of blood glucose to intravenous salicylate. Metabolism 10:419-421 
16. Field JB, Boyle C, Remer A 1967 Effect of salicylate infusion on plasma-insulin and glucose tolerance in healthy persons and mild diabetics. Lancet 1:1191-1194

17. Hecht A, Goldner MG 1959 Reappraisal of the hypoglycemic action of acetylsalicylate. Metabolism 8:418-428

18. Anderson WF, Thompson J 1963 Aspirin in the Treatment of Diabetes Mellitus in the Elderly. Gerontol Clin (Basel) 22:234-243

19. Yuan M, Konstantopoulos N, Lee J, Hansen L, Li ZW, Karin M, Shoelson SE 2001 Reversal of obesity- and diet-induced insulin resistance with salicylates or targeted disruption of Ikkbeta. Science 293:1673-1677

20. Kim JK, Kim YJ, Fillmore JJ, Chen Y, Moore I, Lee J, Yuan M, Li ZW, Karin M, Perret P, Shoelson SE, Shulman GI 2001 Prevention of fat-induced insulin resistance by salicylate. J Clin Invest 108:437-446

21. Goldfine AB, Fonseca V, Jablonski KA, Pyle L, Staten MA, Shoelson SE 2010 The effects of salsalate on glycemic control in patients with type 2 diabetes: a randomized trial. Ann Intern Med 152:346-357

22. Doi H, Horie T 2010 Salicylic acid-induced hepatotoxicity triggered by oxidative stress. Chem Biol Interact 183:363-368

23. Charnock JS, Opit LJ 1962 The effect of salicylate on adenosine-triphosphatase activity of rat-liver mitochondria. Biochem J 83:596-602

24. Haas R, Parker WD, Jr., Stumpf D, Eguren LA 1985 Salicylate-induced loose coupling: protonmotive force measurements. Biochem Pharmacol 34:900-902

25. Phielix E, Schrauwen-Hinderling VB, Mensink M, Lenaers E, Meex R, Hoeks J, Kooi ME, Moonen-Kornips E, Sels JP, Hesselink MK, Schrauwen P 2008 Lower intrinsic ADP-stimulated mitochondrial respiration underlies in vivo mitochondrial dysfunction in muscle of male type 2 diabetic patients. Diabetes 57:2943-2949

26. Siri WE 1956 The gross composition of the body. Adv Biol Med Phys 4:239-280

27. Itani SI, Ruderman NB, Schmieder F, Boden G 2002 Lipid-induced insulin resistance in human muscle is associated with changes in diacylglycerol, protein kinase $\mathrm{C}$, and IkappaB-alpha. Diabetes 51:2005-2011

28. Dresner A, Laurent D, Marcucci M, Griffin ME, Dufour S, Cline GW, Slezak LA, Andersen DK, Hundal RS, Rothman DL, Petersen KF, Shulman GI 1999 Effects of free fatty acids on glucose transport and IRS-1-associated phosphatidylinositol 3-kinase activity. J Clin Invest 103:253-259

29. Steele R 1959 Influences of glucose loading and of injected insulin on hepatic glucose output. Ann N Y Acad Sci 82:420-430

30. Koska J, Ortega E, Bunt JC, Gasser A, Impson J, Hanson RL, Forbes J, de Courten B, Krakoff J 2009 The effect of salsalate on insulin action and glucose tolerance in obese non-diabetic patients: results of a randomised double-blind placebo-controlled study. Diabetologia 52:385-393

31. Weir JB 1949 New methods for calculating metabolic rate with special reference to protein metabolism. J Physiol 109:1-9

32. Frayn $\mathrm{KN} 1983$ Calculation of substrate oxidation rates in vivo from gaseous exchange. $\mathrm{J}$ Appl Physiol 55:628-634

33. Rohl M, Pasparakis M, Baudler S, Baumgartl J, Gautam D, Huth M, De Lorenzi R, Krone W, Rajewsky K, Bruning JC 2004 Conditional disruption of IkappaB kinase 2 fails to prevent obesity-induced insulin resistance. J Clin Invest 113:474-481

34. Fleischman A, Shoelson SE, Bernier R, Goldfine AB 2008 Salsalate improves glycemia and inflammatory parameters in obese young adults. Diabetes Care 31:289-294

35. Goldfine AB, Silver R, Aldhahi W, Cai D, Tatro E, Lee J, Shoelson SE 2008 Use of Salsalate to Target Inflammation in the Treatment of Insulin Resistance and Type 2 Diabetes. Clin Transl Sci 1:36-43 
36. Hundal RS, Petersen KF, Mayerson AB, Randhawa PS, Inzucchi S, Shoelson SE, Shulman GI 2002 Mechanism by which high-dose aspirin improves glucose metabolism in type 2 diabetes. J Clin Invest 109:1321-1326

37. Xiao C, Giacca A, Lewis GF 2009 The effect of high-dose sodium salicylate on chronically elevated plasma non-esterified fatty acid-induced insulin resistance and \{beta\}-cell dysfunction. Am J Physiol Endocrinol Metab

38. Bratusch-Marrain PR, Vierhapper H, Komjati M, Waldhausl WK 1985 Acetyl-salicylic acid impairs insulin-mediated glucose utilization and reduces insulin clearance in healthy and non-insulin-dependent diabetic man. Diabetologia 28:671-676

39. Newman WP, Brodows RG 1983 Aspirin causes tissue insensitivity to insulin in normal man. J Clin Endocrinol Metab 57:1102-1106

40. Thiebaud D, Acheson K, Schutz Y, Felber JP, Golay A, Defronzo RA, Jequier E 1983 Stimulation of thermogenesis in men after combined glucose-long-chain triglyceride infusion. Am J Clin Nutr 37:603-611

41. Jorgensen TG, Weis-Fogh US, Nielsen HH, Olesen HP 1976 Salicylate- and aspirininduced uncoupling of oxidative phosphorylation in mitochondria isolated from the mucosal membrane of the stomach. Scand J Clin Lab Invest 36:649-654

42. Norman C, Howell KA, Millar AH, Whelan JM, Day DA 2004 Salicylic acid is an uncoupler and inhibitor of mitochondrial electron transport. Plant Physiol 134:492-501

43. Nulton-Persson AC, Szweda LI, Sadek HA 2004 Inhibition of cardiac mitochondrial respiration by salicylic acid and acetylsalicylate. J Cardiovasc Pharmacol 44:591-595 


\section{CHAPTER 8}

\section{General discussion}

Due to changes in eating patterns and due to industrialization and automation of occupational and leisure time activities, the global population has become increasingly sedentary and obese over the last decades. This has contributed to a dramatic increase in the incidence of insulin resistance.

Muscle insulin resistance is a key characteristic of T2D. T2D are also shown to have elevated IntraMyoCellular Lipid levels (IMCL). Initially, increased IMCL levels were assumed to be responsible for the decrease in insulin sensitivity, but whereas a strong correlation between IMCL accumulation and the severity of insulin resistance has indeed been shown in T2D, endurance trained athletes also have elevated IMCL levels while being highly insulin sensitive, making IMCL accumulation per se less plausible as a cause for the development of insulin resistance. Along with decreased insulin sensitivity, T2D also show impaired lipolysis, mitochondrial dysfunction and metabolic inflexibility.

The aim of this thesis is to use insulin sensitising and desensitizing interventions as tools to gain insight in the mechanisms underlying muscle insulin resistance. This chapter discusses how parameters (IMCL, mitochondrial function, metabolic flexibility and lipolysis) changed upon these interventions and how these changes may be related to insulin sensitivity. This chapter will end with an overall conclusion and with aims for future research. 


\section{Outline of the discussion}

The aim of this thesis is to use insulin sensitising and desensitizing interventions, i.e. exercise training, lipid infusion and salsalate treatment, as tools to gain insight in the mechanisms underlying muscle insulin resistance. This chapter starts with a brief overview of these interventions and their effects on insulin sensitivity. It is followed by an integrated discussion on how parameters (IMCL, mitochondrial function, metabolic flexibility and lipolysis) changed upon the interventions and how these changes may be related to insulin sensitivity. Finally, this chapter will end with an overall conclusion and with aims for future research.

\section{The effect of interventions on insulin sensitivity; a brief overview}

\section{Exercise training in T2D and healthy control subjects}

Exercise training is known to be an insulin sensitizing intervention and is highly recommended for the treatment of diabetes. In this $\mathrm{PhD}$ project, a 12 weeks progressive exercise program with endurance- and resistance training, has been applied to a group of older T2D $(n=18)$ and a group of BMI- and age- matched control subjects $(n=20)(C)$. At baseline, control subjects were more insulin sensitive than T2D, as measured by a higher glucose disposal rate during a hyperinsulinemic euglcyemic clamp. While the training program significantly increased insulin sensitivity in T2D, control subjects only showed a modest increase which did not reach statistical significance $(\mathrm{p}=0.08)$. After training, the difference in insulin sensitivity between groups persisted.

\section{Exercise in statin users and non-statin users}

Obese individuals and T2D are often characterized by hyperlipidemia, a condition commonly treated with statins. Statin intake however, has been associated with 
myotoxicity, mitochondrial dysfunction (4-8) muscular damage (6; 9), and a blunted response to exercise training. We therefore retrospectively stratified our group of obese control subjects and obese type 2 diabetic patients according to the use of statins, and investigated the hypothesis that the exercise induced improvements would be less pronounced in statin users compared to non-statin users. Interestingly and unexpectedly, we observed that subjects on statin treatment were more sensitive to the beneficial effects of exercise training. Insulin stimulated glucose disposal rate increased with $70 \%$, whereas there was no change in subjects without statin.

\section{Lipid infusion in young trained and untrained subjects}

Nine healthy, young untrained males and 10 healthy endurance-trained males underwent, in randomised order, two hyperinsulinemic euglycemic clamps with infusion of either glycerol or lipid. Insulin sensitivity in the glycerol infusion trial was higher in endurance trained subjects, compared to their sedentary counterparts. Lipid infusion reduced insulin stimulated glucose disposal in both groups, and as expected, the decreased was less pronounced in endurance trained subjects $(-31 \%)$, compared to untrained subjects $(-66 \%)$.

\section{Lipid infusion + salsalate in young untrained subjects}

Salicylate-related compounds have been suggested to improve glucose homeostasis in humans (10-14) and insulin sensitivity in rodent (15). Data in literature also indicates that the use of salicylates ameliorates lipid-induced insulin resistance in rats and mice (16). In this study, the young healthy untrained subjects were submitted to a $2^{\text {nd }}$ hyperinsulinemic euglycemic clamp with infusion of lipids, but now preceded by 4 days of a high dosage of salsalate (a heterodimer of salicylate). Insulin levels were increased upon salsalate intake; however, in contrast to our hypothesis, lipid induced insulin resistance was not ameliorated compared to lipid infusion without salsalate intake. 


\section{Change of parameters upon insulin sensitizing and desensitizing interventions}

\section{IMCL accumulation}

It has been firmly established that IMCL accumulation in untrained subjects is strongly correlated with the severity of insulin resistance. The so-called athlete paradox suggests however, that high level of IMCL per se are not responsible for the development of insulin resistance $(17 ; 18)$, but that they are merely an indicator of insulin resistance. The findings in this thesis are in line with this statement. T2D showed similar IMCL levels but lower insulin sensitivity compared to age and BMI matched control subjects; and young trained individuals tended to have elevated IMCL levels but higher insulin sensitivity compared to their untrained counterparts. Furthermore, while exercise training increased IMCL levels in T2D along with improved insulin sensitivity, lipid infusion increased IMCL levels in untrained individuals along with pronounced insulin resistance. Thus, given these apparent contrasting results it can be concluded that elevated IMCL levels per se are unlikely to be a direct cause of insulin resistance and that other parameters, or combinations with other parameters, are responsible for the development of insulin resistance.

\section{Mitochondrial function}

One of the parameters suggested to play a key role in insulin resistance is mitochondrial dysfunction. Mitochondrial dysfunction has been reported in T2D $(19 ; 20)$ and was shown to be strongly correlated with insulin resistance (21). Compromised mitochondrial function may be caused by a reduced intrinsic mitochondrial function (i.e. respiratory capacity per mitochondria) $(19 ; 20)$ or by a decreased mitochondrial content (22); both of which may contribute to a reduced in vivo ATP synthesis and PCr resynthesis rate $(19 ; 23)$. The findings of impeded mitochondrial function have added value to previous important findings of Kelley et al., who observed mitochondrial abnormalities with respect to content, size and morphology in T2D (24), and to a study of Mootha et.al, who showed a lower gene expression of a key transcriptional 
co-factor in mitochondrial biogenesis $(\mathrm{PGC} 1 \alpha)$, and a lower gene expression of its target genes encoding key enzymes in oxidative mitochondrial metabolism (25).

The findings reported in this thesis are in line with the above mentioned studies, arguing that mitochondrial dysfunction and insulin resistance are positively related. Baseline levels of mitochondrial function in T2D were lower compared to healthy control subjects and this was accompanied by lower insulin sensitivity. Baseline mitochondrial function in statin users was comparable to non-statin users and this was accompanied by comparable levels of insulin sensitivity; and finally, young endurance-trained athletes, characterized by a high oxidative capacity and high insulin sensitivity only reduced glucose disposal rate by $29 \%$ upon lipid infusion whereas young untrained individuals with a lower oxidative capacity and lower insulin sensitivity decreased their insulin stimulated glucose disposal with $63 \%$.

It is interesting to note that impaired mitochondrial function has also been reported in first degree relatives $(19 ; 26)$, suggesting that mitochondrial dysfunction may be causally related to insulin resistance. However, to date, convincing evidence for a causal relationship is lacking and a number of articles express their doubts about the role of a decreased mitochondrial density and function in relation to the development of insulin resistance. For example, a study reported normal in vivo mitochondrial function in zucker diabetic rats throughout the pathogenesis of type 2 diabetes (27) and likewise, comparable in vivo mitochondrial function was found between normal glycemic subjects, impaired glucose tolerant individuals and T2D (28). In the present thesis it was interesting to note that lipid infusion resulted in the development of insulin resistance in both trained and untrained individuals, but that the deterioration in insulin sensitivity occurred without concomitant changes in mitochondrial function. Thus, based on these results it seems valid to state that reduced mitochondrial function contributes to, but is not necessarily required for, the development of insulin resistance.

Likewise, there are also strong indications that improved mitochondrial function is not necessarily required to improve insulin sensitivity. Studies reported improve- 
ments in insulin sensitivity upon a weight loss program and treatment with rosiglitazone, but these improvements were not paralleled by enhanced mitochondrial function $(29 ; 30)$. In addition, a recent study observed that rosiglitazone and pioglitazone both improved insulin sensitivity; however, mitochondrial function was increased with rosiglitazone treatment, but was in fact decreased after pioglitazone treatment (31).

Also the results of the training program applied in this thesis support the contention that insulin resistance is not only a matter of decreased mitochondrial function; 12 weeks of exercise training completely restored mitochondrial function to control levels, implying that $\mathrm{T} 2 \mathrm{D}$ are able to overcome defects in mitochondrial function despite aberrations in transcriptional control of mitochondrial biogenesis. Insulin resistance however, restored incompletely and was still significantly lower compared to control subjects. Similarly, exercise increased mitochondrial function in both statin users and non-statin users to the same extent, but this only translated into a higher insulin sensitivity in the statin group, suggesting again that both parameters can change independently.

In a recent publication, Holloszy (32) states that decreased mitochondrial content is not likely to play a role in the development of insulin resistance. It has been calculated that skeletal muscle of well trained young individuals contains sufficient mitochondria to increase oxygen uptake $\sim 150$ fold. So even if the assumption is made that mitochondrial function in T2D is only $25 \%$ of the value of trained persons, substrate oxidation is still far in excess (30-40 fold) of the energy demand of resting muscle, and that therefore a decreased mitochondrial content does not mediate insulin resistance (32). Additional support for this concept comes from the recent observation that mitochondrial function in Asian Indian T2D was comparable to mitochondrial function of healthy Indians and higher than in healthy Americans (33). The results of this thesis however, do not support Holloszy's concept. Exercise training increased insulin sensitivity in T2D along with an increase in mitochondrial function. Measurement of mitochondrial proteins revealed that the increase in mitochondrial function was mainly explained by an increased mitochondrial content, indicating that the 
increased mitochondrial content may have been important to establish the improvement in insulin sensitivity. Furthermore, in the young trained and untrained subjects, a positive correlation had been observed between insulin sensitivity and respiratory mitochondrial fluxes. Ex vivo mitochondrial capacity was decreased in untrained compared to trained subjects but these differences disappeared when mitochondrial capacity was normalised to mitochondrial content. Thus, in line with the results in the $\mathrm{T} 2 \mathrm{D}$, also these findings hint towards a prominent role for mitochondrial content in the development of insulin resistance. On top of this it is important to mention that a correlation in young trained and untrained subjects was also present between insulin sensitivity and mitochondrial density, although such a correlation could not be confirmed in the subjects that participated in the training study. At this point, results appear equivocal and therefore it is not yet possible to draw firm conclusions on the role of mitochondria in relation to insulin resistance. There is little doubt that decreased mitochondrial dysfunction is associated with the insulin resistant state, but there is no consensus yet on whether they are causally related or not. Although studies showed that both parameters can change independently, it cannot be excluded that normal mitochondrial content and function is in fact required to prevent the development of insulin resistance.

\section{Oxidative and non-oxidative glucose disposal}

Insulin sensitivity, measured as insulin stimulated glucose disposal rate, can be separated in an oxidative and non-oxidative component. Oxidative glucose disposal comprises the part of glucose that is directed to the mitochondria for generation of ATP, whereas non-oxidative glucose disposal will be stored as glycogen. Both oxidative and non-oxidative glucose disposal were significantly impaired in T2D compared to control subjects before training. In line with the restoration in mitochondrial function after exercise training, also oxidative glucose disposal restored completely towards control levels. In contrast, non-oxidative glucose disposal in T2D showed a nonsignificant $30 \%$ increase and remained significantly lower compared to control subjects. 
Non-oxidative glucose disposal in T2D has already previously been shown to be impaired. Magnetic resonance spectroscopy measurements in T2D revealed reduced incorporation of glucose into glycogen during a labelled glucose infusion and this defect was suggested to play a dominant role in insulin resistance (34). In addition, a prospective study following Pima Indians during their transition from normal glucose tolerance to diabetes, showed that the deterioration in glucose uptake was almost entirely due to a decrease in non-oxidative glucose disposal, indicating that the impairment of insulin action during the development of diabetes is primarily caused by a defect in glucose storage (35).

The similar oxidative glucose disposal rates between T2D and control subjects after training as described in this thesis imply that the difference in insulin sensitivity that was still present, was only accounted for the lower non-oxidative glucose disposal in T2D. The lack of improvement in non-oxidative glucose disposal after training is in contrast with another training study that did find an improvement in non-oxidative glucose disposal (36). This difference in outcome is interesting, but the underlying reason remains speculative. Possibly, differences in study design, exercise mode, frequency, intensity and length may have contributed to contrasting findings.

Also interesting are the results in young trained and untrained individuals upon glycerol and lipid infusion. Insulin sensitivity in the glycerol trial was higher in trained subjects compared to untrained subjects. Non-oxidative glucose disposal was comparable between both groups, indicating that the difference in insulin sensitivity was accounted for by a higher oxidative glucose disposal rate solely. Surprisingly, in both groups oxidative glucose disposal decreased to a similar extent upon lipid infusion, whereas non-oxidative glucose oxidation was only affected in the untrained group. These findings are in line with findings in T2D and they support the notion that an impairment in non-oxidative glucose disposal is an important defect, which contributes largely to the insulin resistant state. Of note, restratification of T2D and healthy subjects according to statin use showed that statin users were in fact able to increase their non-oxidative glucose disposal upon training. This improvement is remarkable in the light of our other findings and should be further investigated. 


\section{Metabolic flexibility}

Metabolic flexibility is defined as the ability to switch from predominantly fat oxidation in the fasted state to glucose oxidation in the insulin stimulated state. Insulin sensitive individuals are characterized as metabolic flexible, whereas insulin resistant persons are shown to be metabolic inflexible. The results in this thesis confirms this as healthy control subjects and endurance trained athletes were characterized by a higher metabolic flexibility, compared to T2D and untrained subjects respectively.

Upon exercise training, metabolic flexibility in T2D restored towards control levels, which is in line with the improved insulin sensitivity and the restored mitochondrial function discussed before. According to Galgani et al., a decreased metabolic flexibility in T2D could be entirely explained by a reduced insulin stimulated glucose disposal and thus by a reduced availability of glucose in the cell. Accordingly, the improvement in metabolic flexibility upon training could be explained by the increase in insulin stimulated glucose disposal. This seems plausible; however, nonpublished results from our training study show a tight correlation between the training-induced improvement in non-oxidative glucose disposal and the improvement in glucose disposal rate $\left(\mathrm{R}^{2}=0.660\right)$, but not between the improvement in oxidative glucose disposal and improvement in glucose disposal rate $\left(\mathrm{R}^{2}=0.0312\right)$. Thus in contrast to what Galgani proposed, these findings suggests that the increase in glucose oxidation -and thus change in metabolic flexibility- is not entirely explained by an increased in glucose uptake into the muscle cell. Possibly, a change in mitochondrial function is one of the factors that should be taken into account. Although there is very little known about how improvements in mitochondrial function may lead to an improved metabolic flexibility, upregulation of mitochondrial proteins may be needed to facilitate the shift in substrate use.

\section{Lipid droplet dynamics}

Fatty acids are the main fuel for the maintenance of whole body energy homeostasis and are derived from the breakdown of TAG stored in lipid droplets. Whereas regulated lipolysis is essential for maintaining energy balance, obese subjects are shown 
to have dysregulated lipid droplet synthesis and breakdown. It is hypothesized that these impairments result in the development of insulin resistance, possibly through a decreased insulin signalling cascade and/or activation of the inflammatory NFkB pathway, and that a well orchestrated regulation is therefore of utmost importance.

ATGL initiates degradation of triacylglycerol in the lipid droplet (37-39) and requires comparative gene identification-58 (CGI-58) for full activation (40). In addition, lipid droplet dynamics in skeletal muscle require the involvement of the lipid droplet coating PAT proteins ADRP, TIP47 and OXPAT. (41; 42). ADRP has been shown to be involved in the uptake of fatty acids from the cytoplasm, in the incorporation of fatty acids in lipid droplets (43-47) and in the control of TAG hydrolysis in lipid droplets $(48 ; 49)$; TIP47 exerts a role with respect to storage of fatty acids in newly formed lipid droplets; and OXPAT promotes both fatty acids esterification into TAG as well as fatty acid utilization (50). However, details about the roles of these proteins are not yet established and also extensive knowledge about the putative role of these proteins in relation to insulin sensitivity is lacking. To date, there are a few investigations supporting a role for ADRP proteins in the regulation of insulin sensitivity $(51 ; 52)$. A weight loss program and treatments with troglitazone and metformin in T2D and control subjects improved insulin sensitivity, and this was parallelled by an increase in skeletal muscle ADRP protein levels (52). Furthermore, another study reported a negative association between BMI and OXPAT levels (50). No conclusions can be drawn from this association, but it may implicate that also OXPAT is related to insulin sensitivity.

In the present thesis, pre-training protein levels of ADRP, OXPAT and ATGL were similar between T2D and control subjects. This supports previous studies stating that these proteins are not likely to play a causal role in the development of insulin resistance $(53 ; 54)$. In contrast, pre-training protein levels of CGI-58 and TIP47 were decreased in T2D when compared to control subjects. As knockdown of TIP47 in Hela cells prevents lipid droplets from maturation (55), decreased TIP47 levels in T2D may point towards a decreased capacity to store free fatty acids into nascent 
lipid droplets. The implications of (modestly) decreased CGI-58 levels in T2D remain to be determined.

Exercise training increased ADRP and OXPAT protein levels in T2D and control subjects, along with a decrease in TAG hydrolase activity. ATGL and TIP47 protein content increased in T2D only. The changes in T2D occurred in the face of improved insulin sensitivity and metabolic flexibility, and a tendency towards increased IMCL accumulation. TIP47 is known to be involved in the storage of fatty acids in newly formed lipid droplets, so the increase in IMCL accumulation upon training may be explained by the restoration of TIP47. However, as ATGL is the key enzyme in TAG lipolysis, the increase in ATGL along with a decreased TAG hydrolase activity seems contradicting. Yet, ADRP is found to reside on the lipid droplet surface and to prevent access of lipases to the lipid droplet. It is therefore hypothesized that increased ADRP levels resulted in a decreased interaction of ATGL with the lipid droplets, thereby inhibiting TAG lipolysis and increasing lipid storage.

Interestingly, there was no association between any of the PAT proteins and insulin sensitivity. However, we did observe a strong positive correlation between traininginduced increases in ADRP- and OXPAT protein content with training-induced improvements in insulin mediated suppression of fat oxidation, and a negative correlation with the increase in insulin-stimulated glucose oxidation. Thus, although PAT protein levels are not directly related to insulin sensitivity, there is strong evidence that an insulin sensitizing exercise training intervention results in favourable changes in lipid droplet associated proteins, leading to an improved storage of fatty acid in lipid droplets, to an improved protection against uncontrolled lipolysis and resulted in an improved metabolic flexibility.

\section{Other mechanisms putatively related to the development of insulin resistance}

So far, several parameters have been discussed in relation to the development of insulin resistance. Although they are all related to the development of insulin resistance, none of them seems to be solely responsible. Yet, this is not entirely surprising 
as it is compatible with the multifactorial character of the disease. Lipids accumulate in several organs in the body and lead to insulin resistance through different pathways; in addition, impairments in certain organs may lead to or aggravate disturbances in other organs by inter organ crosstalk.

As described earlier in this thesis, statin intake in combination with exercise training had beneficial effects on glucose homeostasis. Improvements in total cholesterol, insulin stimulated lipolysis, insulin sensitivity, non-oxidative glucose disposal, metabolic flexibility, and substrate oxidation were more pronounced and/or even exclusively detectable when exercise was combined with statin use, compared to exercise only. The underlying mechanism however, is completely unknown. The differences in response may have been caused by an unequal distribution of healthy subjects and diabetic subjects. However, restratification resulted in 14 subjects on statin treatment and 22 subjects without statin treatment, with $8 \mathrm{~T} 2 \mathrm{D}$ in both groups, and except for LDL levels, all baseline characteristics were comparable between both groups. Furthermore, statistical analysis revealed no interaction effects between T2D and healthy control subjects, indicating that differences were not specific for healthy or diabetic subjects solely. Unfortunately, the retrospective stratification does not allow us to gain insight in underlying mechanisms.

Like statins, also the underlying mechanism of salsalate remains to be explained. As discussed before, salsalate treatment did not ameliorate the development of insulin resistance, but did result in increased insulin levels in the basal and insulin stimulated condition. The increase was likely caused by decreased insulin clearance and went along with increased expenditure, as reflected by an increased lipid oxidation in the fasted state and an enhanced glucose oxidation upon insulin stimulation. Increased insulin levels could underlie the increased energy expenditure. Although there was a profound difference in insulin levels in the insulin stimulated condition, the difference in insulin levels in the fasted condition was only modest and is unlikely to be responsible for the increased energy expenditure. Also measurements of mitochondrial (un)coupling did not identify the underlying mechanism; there was no difference in state 3 respiration when using several different substrates, and also mito- 
chondrial uncoupling was comparable with and without salsalate. Alternatively, organs other than skeletal muscle may account for the increase in energy expenditure.

\section{Future directions}

The studies described in this thesis provided novel information about the effect and underlying mechanisms in relation to the development of insulin resistance. However, there are many questions that need to be addressed in future research.

- Insulin resistance is often accompanied by a decreased mitochondrial function, suggesting that both parameters may be related. However, insulin resistance can develop without a deterioration in mitochondrial function and likewise, insulin sensitivity does not always require increased mitochondrial function to improve. Future research should reveal the importance of mitochondrial content and function in relation to insulin resistance and investigate the mechanisms involved.

- Exercise training is recognised for its insulin sensitizing potential and improvements in oxidative glucose disposal. The lack of improvement in non-oxidative glucose disposal may imply that exercise should be combined with other treatments. More research is needed to reveal which type, frequency and intensity of exercise should be advocated to obtain a maximal increase in oxidative and nonoxidative glucose disposal and to determine which mechanisms underlie these improvements.

- Dysregulation of lipid droplet dynamics is possibly an important factor in the development of insulin resistance. The precise mechanism of how lipid droplet synthesis and breakdown is regulated and how lipid droplet dysregulation relates to the development of insulin resistance is far from clear. Mechanistic cell- and animal studies are needed to understand the precise role of the PAT proteins and translational human intervention studies are needed to understand the regulation of the PAT proteins in multiple tissues, upon different interventions. 
- Exercise training in this thesis not only resulted in an improved insulin sensitivity of skeletal muscle but also of liver and adipose tissue. This was indicated by decreased hepatic glucose output in the insulin stimulated condition and by decreased insulin stimulated plasma FFA levels. Liver and adipose tissue both have key roles in the regulation of glucose homeostasis (56) and in the regulation of intramuscular lipid and glycogen use $(57 ; 58)$. Exploring the effect of exercise training (and other interventions) on these organs is required for a better comprehension of the inter-organ cross-talk and its effect on insulin sensitivity.

- Statin intake combined with exercise is shown to have more beneficial effects with respect to insulin sensitivity and fuel selection compared to exercise only. The underlying mechanism on how exercise-induced improvements were more prominent, or sometimes even exclusively detectable in statin users, is not clear. In order to address this issue, a well designed intervention study should include a homogenous group of T2D and examine the effect of statins and exercise separately, and the effect of statins and exercise combined.

- In contrast to our hypothesis, salsalate intake did not deteriorate lipid-induced insulin resistance. The lack of improvement in insulin sensitivity questions whether inflammation was present and debates the current theory that salsalate improves insulin sensitivity through a decreased inflammatory pathway. In contrast, salsalate did increase insulin levels and energy expenditure. Data in this thesis excludes insulin levels and muscle mitochondrial uncoupling as possible mechanisms underlying the increase in energy expenditure, but it does not hint towards other putative mechanisms. Subsequent studies should examine the role of inflammation in the development of lipid-induced insulin resistance and should investigate the mechanism underlying the increased energy expenditure. 


\section{References}

1. Hu FB, Li TY, Colditz GA, Willett WC, Manson JE: Television watching and other sedentary behaviors in relation to risk of obesity and type 2 diabetes mellitus in women. JAMA 289:1785-1791, 2003

2. Brownson RC, Boehmer TK, Luke DA: Declining rates of physical activity in the United States: what are the contributors? Annu Rev Public Health 26:421-443, 2005

3. Himsworth HP, Kerr RB: Insulin-sensitive and insulin-insensitive types of diabetes mellitus. Clinical science vol 4:120-152, 1939

4. Ghirlanda G, Oradei A, Manto A, Lippa S, Uccioli L, Caputo S, Greco AV, Littarru GP: Evidence of plasma CoQ10-lowering effect by HMG-CoA reductase inhibitors: a doubleblind, placebo-controlled study. J Clin Pharmacol 33:226-229, 1993

5. Paiva H, Thelen KM, Van Coster R, Smet J, De Paepe B, Mattila KM, Laakso J, Lehtimaki T, von Bergmann K, Lutjohann D, Laaksonen R: High-dose statins and skeletal muscle metabolism in humans: a randomized, controlled trial. Clin Pharmacol Ther 78:60-68, 2005

6. Phillips PS, Haas RH, Bannykh S, Hathaway S, Gray NL, Kimura BJ, Vladutiu GD, England JD: Statin-associated myopathy with normal creatine kinase levels. Ann Intern Med 137:581-585, 2002

7. Schick BA, Laaksonen R, Frohlich JJ, Paiva H, Lehtimaki T, Humphries KH, Cote HC: Decreased skeletal muscle mitochondrial DNA in patients treated with high-dose simvastatin. Clin Pharmacol Ther 81:650-653, 2007

8. Sirvent P, Mercier J, Lacampagne A: New insights into mechanisms of statin-associated myotoxicity. Curr Opin Pharmacol 8:333-338, 2008

9. Draeger A, Monastyrskaya K, Mohaupt M, Hoppeler H, Savolainen H, Allemann C, Babiychuk EB: Statin therapy induces ultrastructural damage in skeletal muscle in patients without myalgia. J Pathol 210:94-102, 2006

10. Reid J, Macdougall AI, Andrews MM: Aspirin and diabetes mellitus. Br Med J:1071-1074, 1957

11. Gilgore SG, Rupp JJ: Response of blood glucose to intravenous salicylate. Metabolism 10:419-421, 1961

12. Field JB, Boyle C, Remer A: Effect of salicylate infusion on plasma-insulin and glucose tolerance in healthy persons and mild diabetics. Lancet 1:1191-1194, 1967

13. Hecht A, Goldner MG: Reappraisal of the hypoglycemic action of acetylsalicylate. Metabolism 8:418-428, 1959

14. Anderson WF, Thompson J: Aspirin in the Treatment of Diabetes Mellitus in the Elderly. Gerontol Clin (Basel) 22:234-243, 1963

15. Yuan M, Konstantopoulos N, Lee J, Hansen L, Li ZW, Karin M, Shoelson SE: Reversal of obesity- and diet-induced insulin resistance with salicylates or targeted disruption of Ikkbeta. Science 293:1673-1677, 2001

16. Kim JK, Kim YJ, Fillmore JJ, Chen Y, Moore I, Lee J, Yuan M, Li ZW, Karin M, Perret P, Shoelson SE, Shulman GI: Prevention of fat-induced insulin resistance by salicylate. J Clin Invest 108:437-446, 2001

17. Goodpaster BH, He J, Watkins S, Kelley DE: Skeletal muscle lipid content and insulin resistance: evidence for a paradox in endurance-trained athletes. J Clin Endocrinol Metab 86:5755-5761, 2001

18. van Loon LJ, Goodpaster BH: Increased intramuscular lipid storage in the insulin-resistant and endurance-trained state. Pflugers Arch 451:606-616, 2006 
19. Phielix E, Schrauwen-Hinderling VB, Mensink M, Lenaers E, Meex R, Hoeks J, Kooi ME, Moonen-Kornips E, Sels JP, Hesselink MK, Schrauwen P: Lower intrinsic ADPstimulated mitochondrial respiration underlies in vivo mitochondrial dysfunction in muscle of male type 2 diabetic patients. Diabetes 57:2943-2949, 2008

20. Mogensen M, Sahlin K, Fernstrom M, Glintborg D, Vind BF, Beck-Nielsen H, Hojlund K: Mitochondrial respiration is decreased in skeletal muscle of patients with type 2 diabetes. Diabetes 56:1592-1599, 2007

21. Bruce CR, Thrush AB, Mertz VA, Bezaire V, Chabowski A, Heigenhauser GJ, Dyck DJ: Endurance training in obese humans improves glucose tolerance, mitochondrial fatty acid oxidation and alters muscle lipid content. Am J Physiol Endocrinol Metab, 2006

22. Boushel R, Gnaiger E, Schjerling P, Skovbro M, Kraunsoe R, Dela F: Patients with type 2 diabetes have normal mitochondrial function in skeletal muscle. Diabetologia 50:790796, 2007

23. Schrauwen-Hinderling VB, Kooi ME, Hesselink MK, Jeneson JA, Backes WH, van Echteld CJ, van Engelshoven JM, Mensink M, Schrauwen P: Impaired in vivo mitochondrial function but similar intramyocellular lipid content in patients with type 2 diabetes mellitus and BMI-matched control subjects. Diabetologia 50:113-120, 2007

24. Kelley DE, He J, Menshikova EV, Ritov VB: Dysfunction of mitochondria in human skeletal muscle in type 2 diabetes. Diabetes 51:2944-2950, 2002

25. Mootha VK, Lindgren CM, Eriksson KF, Subramanian A, Sihag S, Lehar J, Puigserver P, Carlsson E, Ridderstrale M, Laurila E, Houstis N, Daly MJ, Patterson N, Mesirov JP, Golub TR, Tamayo P, Spiegelman B, Lander ES, Hirschhorn JN, Altshuler D, Groop LC: PGC-1alpha-responsive genes involved in oxidative phosphorylation are coordinately downregulated in human diabetes. Nat Genet 34:267-273, 2003

26. Petersen KF, Dufour S, Befroy D, Garcia R, Shulman GI: Impaired mitochondrial activity in the insulin-resistant offspring of patients with type 2 diabetes. N Engl J Med 350:664671,2004

27. De Feyter HM, Lenaers E, Houten SM, Schrauwen P, Hesselink MK, Wanders RJ, Nicolay K, Prompers JJ: Increased intramyocellular lipid content but normal skeletal muscle mitochondrial oxidative capacity throughout the pathogenesis of type 2 diabetes. FASEB J 22:3947-3955, 2008

28. De Feyter HM, van den Broek NM, Praet SF, Nicolay K, van Loon LJ, Prompers JJ: Early or advanced stage type 2 diabetes is not accompanied by in vivo skeletal muscle mitochondrial dysfunction. Eur J Endocrinol 158:643-653, 2008

29. Toledo FG, Menshikova EV, Azuma K, Radikova Z, Kelley CA, Ritov VB, Kelley DE: Mitochondrial capacity in skeletal muscle is not stimulated by weight loss despite increases in insulin action and decreases in intramyocellular lipid content. Diabetes 57:987-994, 2008

30. Schrauwen-Hinderling VB, Mensink M, Hesselink MK, Sels JP, Kooi ME, Schrauwen P: The insulin-sensitizing effect of rosiglitazone in type 2 diabetes mellitus patients does not require improved in vivo muscle mitochondrial function. J Clin Endocrinol Metab 93:2917-2921, 2008

31. Rabol R, Boushel R, Almdal T, Hansen CN, Ploug T, Haugaard SB, Prats C, Madsbad S, Dela F: Opposite effects of pioglitazone and rosiglitazone on mitochondrial respiration in skeletal muscle of patients with type 2 diabetes. Diabetes Obes Metab 12:806-814, 2010

32. Holloszy JO: Skeletal muscle "mitochondrial deficiency" does not mediate insulin resistance. Am J Clin Nutr 89:463S-466S, 2009

33. Nair KS, Bigelow ML, Asmann YW, Chow LS, Coenen-Schimke JM, Klaus KA, Guo ZK, Sreekumar R, Irving BA: Asian Indians have enhanced skeletal muscle mitochondrial capacity to produce ATP in association with severe insulin resistance. Diabetes 57:11661175,2008

34. Shulman GI, Rothman DL, Jue T, Stein P, DeFronzo RA, Shulman RG: Quantitation of muscle glycogen synthesis in normal subjects and subjects with non-insulin-dependent 
diabetes by 13C nuclear magnetic resonance spectroscopy. N Engl J Med 322:223-228, 1990

35. Weyer C, Bogardus C, Mott DM, Pratley RE: The natural history of insulin secretory dysfunction and insulin resistance in the pathogenesis of type 2 diabetes mellitus. J Clin Invest 104:787-794, 1999

36. Dela F, Larsen JJ, Mikines KJ, Ploug T, Petersen LN, Galbo H: Insulin-stimulated muscle glucose clearance in patients with NIDDM. Effects of one-legged physical training. Diabetes 44:1010-1020, 1995

37. Zimmermann R, Strauss JG, Haemmerle G, Schoiswohl G, Birner-Gruenberger R, Riederer M, Lass A, Neuberger G, Eisenhaber F, Hermetter A, Zechner R: Fat mobilization in adipose tissue is promoted by adipose triglyceride lipase. Science 306:1383-1386, 2004

38. Villena JA, Roy S, Sarkadi-Nagy E, Kim KH, Sul HS: Desnutrin, an adipocyte gene encoding a novel patatin domain-containing protein, is induced by fasting and glucocorticoids: ectopic expression of desnutrin increases triglyceride hydrolysis. J Biol Chem 279:47066-47075, 2004

39. Jenkins CM, Mancuso DJ, Yan W, Sims HF, Gibson B, Gross RW: Identification, cloning, expression, and purification of three novel human calcium-independent phospholipase A2 family members possessing triacylglycerol lipase and acylglycerol transacylase activities. J Biol Chem 279:48968-48975, 2004

40. Lass A, Zimmermann R, Haemmerle G, Riederer M, Schoiswohl G, Schweiger M, Kienesberger P, Strauss JG, Gorkiewicz G, Zechner R: Adipose triglyceride lipasemediated lipolysis of cellular fat stores is activated by CGI-58 and defective in ChanarinDorfman Syndrome. Cell Metab 3:309-319, 2006

41. Bickel PE, Tansey JT, Welte MA: PAT proteins, an ancient family of lipid droplet proteins that regulate cellular lipid stores. Biochim Biophys Acta 1791:419-440, 2009

42. Meex RC, Schrauwen P, Hesselink MK: Modulation of myocellular fat stores: lipid droplet dynamics in health and disease. Am J Physiol Regul Integr Comp Physiol 297:R913-924, 2009

43. Chang BH, Li L, Paul A, Taniguchi S, Nannegari V, Heird WC, Chan L: Protection against fatty liver but normal adipogenesis in mice lacking adipose differentiation-related protein. Mol Cell Biol 26:1063-1076, 2006

44. Gao J, Serrero G: Adipose differentiation related protein (ADRP) expressed in transfected COS-7 cells selectively stimulates long chain fatty acid uptake. J Biol Chem 274:1682516830, 1999

45. Magnusson B, Asp L, Bostrom P, Ruiz M, Stillemark-Billton P, Linden D, Boren J, Olofsson SO: Adipocyte Differentiation-Related Protein Promotes Fatty Acid Storage in Cytosolic Triglycerides and Inhibits Secretion of Very Low-Density Lipoproteins. Arterioscler Thromb Vasc Biol, 2006

46. McManaman JL, Zabaronick W, Schaack J, Orlicky DJ: Lipid droplet targeting domains of adipophilin. J Lipid Res 44:668-673, 2003

47. Listenberger LL, Ostermeyer-Fay AG, Goldberg EB, Brown WJ, Brown DA: Adipocyte differentiation-related protein reduces lipid droplet association of adipose triglyceride lipase and slows triacylglycerol turnover. J Lipid Res, 2007

48. Wolins NE, Brasaemle DL, Bickel PE: A proposed model of fat packaging by exchangeable lipid droplet proteins. FEBS Lett 580:5484-5491, 2006

49. Prats C, Donsmark M, Qvortrup K, Londos C, Sztalryd C, Holm C, Galbo H, Ploug T: Decrease in intramuscular lipid droplets and translocation of HSL in response to muscle contraction and epinephrine. J Lipid Res 47:2392-2399, 2006

50. Wolins NE, Quaynor BK, Skinner JR, Tzekov A, Croce MA, Gropler MC, Varma V, YaoBorengasser A, Rasouli N, Kern PA, Finck BN, Bickel PE: OXPAT/PAT-1 Is a PPARInduced Lipid Droplet Protein That Promotes Fatty Acid Utilization. Diabetes 55:34183428, 2006 
51. de Wilde J, Smit E, Snepvangers FJ, de Wit NW, Mohren R, Hulshof MF, Mariman EC: Adipophilin protein expression in muscle - a possible protective role against insulin resistance. FEBS J 277:761-773

52. Phillips SA, Choe CC, Ciaraldi TP, Greenberg AS, Kong AP, Baxi SC, Christiansen L, Mudaliar SR, Henry RR: Adipocyte differentiation-related protein in human skeletal muscle: relationship to insulin sensitivity. Obes Res 13:1321-1329, 2005

53. Minnaard R, Schrauwen P, Schaart G, Jorgensen JA, Lenaers E, Mensink M, Hesselink MK: Adipocyte differentiation-related protein and OXPAT in rat and human skeletal muscle: involvement in lipid accumulation and type 2 diabetes mellitus. J Clin Endocrinol Metab 94:4077-4085, 2009

54. Turpin SM, Hoy AJ, Brown RD, Garcia Rudaz C, Honeyman J, Matzaris M, Watt MJ: Adipose triacylglycerol lipase is a major regulator of hepatic lipid metabolism but not insulin sensitivity in mice. Diabetologia, 2010

55. Bulankina AV, Deggerich A, Wenzel D, Mutenda K, Wittmann JG, Rudolph MG, Burger KN, Honing S: TIP47 functions in the biogenesis of lipid droplets. J Cell Biol 185:641655,2009

56. Abdul-Ghani MA, Matsuda M, DeFronzo RA: Strong association between insulin resistance in liver and skeletal muscle in non-diabetic subjects. Diabet Med 25:12891294,2008

57. van Loon LJ, Manders RJ, Koopman R, Kaastra B, Stegen JH, Gijsen AP, Saris WH, Keizer HA: Inhibition of adipose tissue lipolysis increases intramuscular lipid use in type 2 diabetic patients. Diabetologia 48:2097-2107, 2005

58. Watt MJ, Holmes AG, Steinberg GR, Mesa JL, Kemp BE, Febbraio MA: Reduced plasma FFA availability increases net triacylglycerol degradation, but not GPAT or HSL activity, in human skeletal muscle. Am J Physiol Endocrinol Metab 287:E120-127, 2004 


\section{Summary}

Chapter 1 starts with a general introduction with respect to type 2 diabetes. Global prevalence and incidence rates of type 2 diabetes are very high and increase rapidly. It has been estimated that in 2000 approximately 171 million individuals were diagnosed with type 2 diabetes and this number is likely to double by 2030. Type 2 diabetes is characterized by high plasma glucose levels and results from a reduction in insulin secretion from the pancreas, and from a blunted sensitivity (i.e. resistance), of tissues for insulin, the hormone responsible for glucose uptake into the cells. The underlying mechanism of insulin resistance is not yet known. Accumulation of intramyocellular lipids (IMCL) has been associated with the severity of insulin resistance. However, endurance trained athletes also have high IMCL levels while being highly insulin sensitive, making IMCL accumulation per se less plausible as a cause for the development of insulin resistance. It has therefore been suggested that other parameters, such as impaired mitochondrial function, a decreased ability to switch between glucose oxidation and fat oxidation (metabolic inflexibility) and a decreased ability to store glucose, are also important in development of muscle insulin resistance. This PhD-thesis focuses on theses parameters as well as on their role in relation to the development of the insulin resistant state

Fatty acids are derived from the breakdown (lipolysis) of triacylglycerol (TAG) and are quantitatively the most important substrate under resting and fasted conditions. Originally, hormone sensitive lipase (HSL) was considered the only lipase involved in TAG breakdown. More recently, however, adipose triglyceride lipase (ATGL) has been identified as the enzyme catalysing the initial step of lipolysis. The discovery of ATGL greatly expanded our understanding on the regulatory mechanisms of lipid droplet breakdown. In addition to HSL and ATGL, lipid droplets in skeletal muscle are also covered by a variety of other proteins such as CGI-58, ADRP, TIP-47, S3-12 and OXPAT, which are shown to be important in regulating the balance between lipid droplet synthesis and breakdown. Even more so, an increasing amount of evidence suggests that dysregulation of lipid droplet dynamics is possibly an important 
factor in the development of insulin resistance. Chapter 2 gives an overview of current knowledge with respect to lipase activity, lipid droplets and lipid droplet coating proteins, and their roles in relation to muscular insulin sensitivity.

Exercise training is an insulin sensitizing intervention. Chapter 3 discusses the effect of a 12-week progressive exercise program on insulin sensitivity and insulin sensitivity associated parameters in 20 older, obese man with type 2 diabetes and in 18 older, obese, but otherwise healthy men. Before training, type 2 diabetic subjects showed a decreased insulin sensitivity, a compromised mitochondrial function and a blunted metabolic flexibility compared to control subjects, which is in line with reports from earlier studies. Exercise training in patients with type 2 diabetes, however, completely restored in vivo mitochondrial function and metabolic flexibility towards values observed in control subjects. This restoration went along with an improved (but not restored) insulin stimulated glucose disposal. In addition, IMCL levels tended to increase and non-oxidative glucose disposal increased modestly, albeit not significantly. This study is the first to show that mitochondrial function, oxidative glucose disposal and metabolic flexibility in type 2 diabetes patients can be entirely restored upon training. However, the fact that this training program in these subjects did not result in improved non-oxidative glucose disposal suggests that combinations with other training programs or therapies could be considered.

Chapter 4 proceeds on the exercise-induced effects described in chapter 3 (i.e. changes in metabolic flexibility, oxidative capacity and insulin sensitivity) and aims to explain them in the light of observed changes in lipases (ATGL and HSL), lipase activity (TAG hydrolase and DAG hydrolase activity) and lipid droplet coating proteins (CGI-58, ADRP, TIP-47, S3-12 and OXPAT) in skeletal muscle. Pre-training protein levels of TIP47 were lower in type 2 diabetic patients, compared to control subjects, but restored to control levels upon training. Given the role of TIP47 and given the near significant increase in IMCL, this may point towards an improved capacity of type 2 diabetic subjects to store free fatty acids into nascent lipid droplets. In contrast to TIP-47, pre-training protein levels of ADRP, OXPAT and ATGL were similar between type 2 diabetic and control subjects, and support previous studies 
stating that these proteins are not likely to play a causal role in the development of insulin resistance. While exercise training resulted in increased ADRP and OXPAT protein levels and decreased TAG hydrolase activity in type 2 diabetic and control subjects, ATGL protein content increased in T2D only. ATGL is the key enzyme in TAG lipolysis; therefore, the increase in ATGL in type 2 diabetic subjects, along with a decreased TAG hydrolase activity seems contradicting. Yet, ADRP is found to reside on the lipid droplet surface and to prevent access of lipases to the lipid droplet. It is therefore hypothesized that increased ADRP levels resulted in a decreased interaction of ATGL with the lipid droplets, thereby inhibiting TAG lipolysis and increasing lipid storage. Interestingly, we did not observe correlations between any of the PAT proteins and insulin sensitivity. However, we did observe a strong positive correlation between training-induced increases in ADRP- and OXPAT protein content with training-induced improvements in metabolic flexibility. This suggests that although PAT protein levels are not directly related to insulin sensitivity, an insulin sensitizing exercise intervention leads to favourable changes in lipid droplet associated proteins as reflected by an improved storage of fatty acid in lipid droplets and an improved protection of the lipid droplet against uncontrolled lipolysis, and contributes to an improved metabolic flexibility.

Hyperlipidemia and hyperglycaemia are frequently reported in obese subjects. Whereas implementing routine physical exercise in daily life is advocated in treatment of hyperglycaemia, treatment with statins is often prescribed in case of hyperlipidemia. Use of statins has been associated with myotoxicity, mitochondrial dysfunction and muscular damage. In addition, it has been suggested that statin use may blunt the adaptive response to exercise training. To investigate whether exerciseinduced improvements on insulin sensitivity and related parameters were less pronounced in statin users compared to non-statin users, the entire group of diabetes patients and healthy control subjects from chapter 3 and 4 were restratified according to statin use (statin group, $n=14$ and non-statin group, $n=22$ ). The findings are discussed in chapter 5 and show that statin treatment prior to the onset of the training program did not impede mitochondrial function, muscle function or exercise tolerance. Also, training-induced improvements in mitochondrial function and content 
were preserved in ST. Surprisingly, effects of training with respect to blood-lipid profile, insulin sensitivity, non-oxidative and oxidative glucose disposal and insulinmediated suppression of fat oxidation were more prominent in ST than in C. The combined prescription of statins along with exercise training appears safe and should be considered for subjects prone to develop insulin resistance.

Chapter 6 outlines a study in which healthy, young untrained males and healthy, young endurance-trained males were submitted to 2 hyperinsulinemic euglycemic clamps with either glycerol or lipid infusion. Endurance trained men with a high oxidative capacity showed a higher insulin sensitivity during the glycerol clamp compared to the untrained men and the difference in insulin sensitivity could entirely be attributed to a difference in insulin-stimulated glucose oxidation. Lipid infusion reduced insulin stimulated glucose disposal in both groups but was -as expected- less pronounced in endurance trained subjects, compared to untrained subjects. Surprisingly however, oxidative glucose disposal decreased to a similar extent in both groups, whereas non-oxidative glucose oxidation was only affected in the untrained group. These findings are in line with findings in T2D and they support the notion that an impairment in non-oxidative glucose disposal is an important defect which contributes largely the insulin resistant state. Aside, it was interesting to note that when respiratory values were normalized to mitochondrial content, the difference in ex vivo mitochondrial respiration between trained and untrained disappeared, indicating similar intrinsic mitochondrial function. Furthermore, it was remarkable that in both groups lipid-induced insulin resistance occurred without concomitant changes in mitochondrial function.

Chapter 7 extends on the study described in chapter 6 and considers the effect of salsalate on lipid-induced insulin resistance in young healthy untrained male subjects. Salsalate has been suggested to improve insulin sensitivity and glucose homeostasis and to ameliorate lipid-induced insulin resistance. The untrained subjects underwent a $3^{\text {rd }}$ hyperinsulinemic euglycemic clamp, with simultaneous lipid infusion in this case preceded by 4 days of a high dosage of salsalate. The aim of the study was to ameliorate lipid-induced insulin resistance and explore underlying mechanisms. 
Surprisingly, lipid-induced insulin resistance was not blunted upon salsalate treatment. Salsalate did however result in increased insulin levels in the basal and insulin stimulated condition and in a higher energy expenditure. The increase in energy expenditure was reflected by an increased lipid oxidation in the fasted state without a reduction in glucose oxidation, and by an enhanced glucose oxidation upon insulin stimulation without a reduction in lipid oxidation. Measurements of mitochondrial (un)coupling did not detect differences in mitochondrial respiration, leaving the underlying mechanism unravelled.

This thesis ends with a general discussion in chapter 8 . It gives a brief overview of all interventions and their effects on insulin sensitivity, and is followed by an integrated discussion on how changes in parameters (IMCL, mitochondrial function, metabolic flexibility and lipolysis) may be related to the development of insulin sensitivity. Interestingly, none of the parameters discussed seems to be solely responsible. Dysfunction of certain parameters may contribute to the development of insulin resistance in one individual, but are not necessarily defect in another person. Yet, this is not entirely surprising as it is compatible with the multifactorial character of the disease. Although it may be clear that regular exercise, as applied in this thesis or as applied by the endurance-trained subjects may improve insulin stimulated glucose disposal via several pathways, additional research is warranted to gain more insight underlying mechanisms. 


\section{Samenvatting}

Hoofdstuk 1 begint met een algemene inleiding over type 2 diabetes. Type 2 diabetes is één van de meest voorkomende welvaartsziekten wereldwijd; in 2000 werd het aantal mensen met diabetes op 171 miljoen geschat en verwacht wordt dat dit aantal zal verdubbelen tegen 2030. De ziekte wordt gekarakteriseerd door te hoge glucosespiegels in het bloed en wordt voornamelijk veroorzaakt door een verminderde gevoeligheid (i.e.resistentie) van weefsels voor insuline, het hormoon dat de opname van glucose faciliteert. De onderliggende mechanismen van insuline resistentie zijn nog niet bekend. Opstapeling van vetten in de spier is in sterke mate geassocieerd met de ernst van insuline resistentie, maar het feit dat duurgetrainde atleten ook gekenmerkt zijn door hoge vetzuurspiegels in hun spieren terwijl zij juist zeer insuline gevoelig zijn, suggereert dat niet vetopstapeling alleen een rol speelt, maar dat ook andere parameters van belang zijn. Mogelijke kandidaat parameters zijn een verminderde mitochondriele functie, een verminderde mogelijkheid om te switchen in substraatverbranding (metabole inflexibiliteit) en een verminderd vermogen om glucose op te slaan. Dit proefschrift richt zich op deze parameters en op hun mogelijke rol bij het ontstaan van insuline resistentie.

Vetzuren zijn nodig voor het leveren van energie en voor het behoud van homeostase is de cel. Vetzuren worden vrijgemaakt uit vetdruppeltjes onder invloed van lipasen. Eerder was enkel HSL bekend als lipase, maar de recente ontdekking dat ATGL en zijn co-activator CGI-58 ook een belangrijke rol spelen bij de afbraak van vetdruppels hebben geleid tot een verschuiving in het wetenschappelijk paradigma. Naast HSL, ATGL en CGI-58, zijn ook andere eiwitten van belang. De zogenaamde PAT-eiwitten, bestaande uit perilipine, ADRP, TIP-47, S3-12 en OXPAT, bevinden zich op of rond vetdruppels en hebben allen een functie in de opbouw en afbraak van vetdruppels. Een toenemend aantal wetenschappelijke publicaties wijst er op dat dysregulatie van deze vetdruppel-geassocieerde eiwitten mogelijk gerelateerd is met het ontstaan van insuline resistentie. Hoofdstuk 2 geeft een stand van zaken met 
betrekking tot de bestaande kennis over de regulatie van deze eiwitten in de spier en beschrijft mogelijke verbanden met het ontstaan van insuline resistentie.

Inspanning in een manier om insuline gevoeligheid te verbeteren. Hoofdstuk 3 beschrijft het effect van een 12-weken durende inspanningsstudie op insuline gevoeligheid en op insuline gevoeligheid geassocieerde parameters in 20 oudere, obese mannen met type 2 diabeten en in 18 oudere, obese, maar overigens gezonde mannen. De studie bevestigt een eerder gerapporteerde verlaging in insuline gevoeligheid, een verminderde mitochondriele functie en een verminderde metabole flexibilteit in de mannen met type 2 diabeten ten opzichte van de gezonden mannen voordat beide groepen aan het trainingsprogramma deelnamen. $\mathrm{Na}$ de trainingsperiode echter bleek de mitochondriele functie en de metabole flexibiliteit in de type 2 diabeten volledig hersteld en dit ging gepaard met een verbetering (maar geen volledig herstel) van de insuline gevoeligheid. Verder werd ook een bijnasignificante verhoging van de vetaccumulatie waargenomen evenals een bescheiden, doch niet significante verhoging van de niet-oxidatieve glucose opname. Deze studie is de eerste die laat zien dat mitochondriele functie, oxidatieve glucose opname, en metabole flexibiliteit in type 2 diabeten volledig hersteld kunnen worden door training. Het feit dat de studie ook laat zien dat dit trainingsprogramma niet in staat was om in deze patientenpopulatie de niet-oxidatieve glucose opname te verbeteren suggereert dat combinaties met andere trainingsprogramma's of therapien mogelijk overwogen moeten worden.

Hoofdstuk 4 gaat verder op de inspannings geinduceerde effecten beschreven in hoofdstuk 3 en poogt deze verder te bestuderen in het licht van veranderingen in lipasen (ATGL en HSL), lipase activiteit (TAG hydrolase en DAG hydrolase activiteit) en vetdruppel-geassocieerde eiwitten (CGI-58, ADRP, TIP-47, S3-12 en OXPAT) in de spier. Vóór aanvang van het trainingsprogramma waren TIP-47 niveau's in type 2 diabeten significant lager dan in gezonde personen, maar dit herstelde naar controlewaarden onder invloed van training. Gezien de functie van TIP-47 en een bijna-significante verhoging in de vetaccumulatie, kan dit er op wijzen dat training de opslagcapaciteit van vetten in de spier in mensen met type 2 diabeten 
verbetert. In tegenstelling tot TIP-47, waren ATGL, CGI-58, ADRP en OXPAT niveau's vóór training wel gelijk in beide groepen en het is daarom weinig waarschijnlijk dat deze eiwitten een oorzakelijk rol spelen in het ontstaan van insuline resistentie. Terwijl training resulteerde in een verhoging van ADRP en OXPAT en een verlaging van TAG hydrolase activiteit in beide groepen, leidde training alleen tot een toename van ATGL bij de diabeten. De bevinding dat de verhoging in ATGL niet gepaard ging met een verhoging in TAG hydrolase activiteit is op het eerste zicht verrassend, maar is waarschijnlijk te verklaren door de stijging in ADRP. Van ADRP is bekend dat het de vetdruppel beschermt tegen de werking van lipasen, dus hierdoor hoeft een stijging in ATGL niet noodzakelijk te leiden tot een stijging van de lipolyse. Opmerkelijk nog was dat er geen correlatie wat tussen de stijging van ADRP en OXPAT niveau's en de verbetering in insuline gevoeligheid, maar wel tussen de stijgin in ADRP en OXPAT en de verbetering in metabole flexibiliteit. Concluderend kan dus gesteld worden dat een insulin gevoeligheid verbeterend trainingsprogramma leidt tot gunstige aanpassingen in vetdruppel-gerelateerde eiwitten met een verbeterde vetopslag, een verbeterde bescherming van de vetdruppel, en een verbeterde metabole flexibiliteit tot gevolg.

Zowel type 2 diabetes als te hoge cholesterol spiegels (hyperlipidemie) worden in sterke mate veroorzaakt door een teveel aan vetten. Beide aandoeningen komen dan ook vaak gelijktijdig voor en terwijl lichaamsbeweging een belangrijke plaats inneemt in de behandeling van type 2 diabetes, worden veel van deze patienten voor hun hyperlipidemie behandeld door middel van statines. Er zijn echter onderzoeken die suggereren dat statine gebruik geassocieerd is met een verslechterde functie van mitochondrien, met spierschade en met een verminderde positieve respons op inspanning. In deze studie zijn de type 2 diabeten en gezonde mannen die eerder hadden deelgenomen aan het trainingsprogramma, retrospectief onderverdeeld in statine gebruikers $(n=14)$ en een niet-statine gebruikers $(n=22)$. De bevindingen van deze analyse worden beschreven in hoofdstuk 5 en laten zien dat statine gebruik niet geassocieerd was met een verminderde mitochondriele functie of met spierschade en evenmin met een verminderde inspanningstolerantie. Mitochondriele functie en dichtheid verbeterden in beide groepen evenveel en verrassend waren de bevinding 
dat een aantal positieve effecten van inspanning (bloed-lipiden profiel, insuline gevoeligheid, niet-oxidatieve glucose opname en onderdrukking van insuline gemedieerde vetverbranding) meer uitgesproken of zelfs enkel aanwezig waren in de groep statine gebruikers. Het onderzoek suggereert daarom dan statine gebruik gecombineerd kan worden met inspanning en dat combinatie van beiden mogelijk zelfs overwogen moet worden.

Hoofdstuk 6 beschrijft de studie waarin een jonge getrainde mannen en jonge ongetrainde mannen onderworpen werden aan een hyperinsulinemische euglycemische clamp met glycerolinfusie en een hyperinsulinemische euglycemische clamp met vetinfusie. Zoals verwacht lieten de resultaten van de glycerol clamp zien dat de getrainde mannen met een betere oxidatieve capaciteit ook een betere insuline gevoeligheid hadden in vergelijking met de ongetrainde mannen, en dit verschil was enkel te verklaren door een hogere oxidatieve glucose opname. Ook in de lijn van de verwachtingen lag de observatie dat de getrainde mannen minder insuline resistent werden na lipid infusie in vergelijking met de ongetrainde mannen. Verrassend was wel dat oxidatieve glucose opname in beide groepen in gelijke mate verslechterde, terwijl de niet-oxidatieve glucose opname enkel in de ongetrainden proefpersonen daalde. Dit is analoog aan de bevinding in de type 2 diabeten en suggereert dat een defect in de niet-oxidatieve glucose opname een belangrijke rol speelt in de ontwikkeling van insuline resistentie. Terzijde is het nog interessant om op te merken dat de verlaagde oxidatieve capaciteit in ongetrainden enkel te verklaren was door een verlaagde mitochondriele dichtheid en niet door een verminderde intrinsieke mitochondriele functie en dat lipid-geinduceerde insuline resistentie in geen van beide groepen gepaard ging met een gehinderde mitochondriele functie.

De studie bediscussieerd in hoofdstuk 7 is een uitbreiding van de studie beschreven in hoofdstuk 6 en behandelt het effect van salsalaat in lipid-geinduceerde insuline resistentie. Eerdere onderzoeken suggereerden positieve effecten van salsalaat op glucose homeostase en insuline gevoeligheid. Om het onderliggende mechanisme hiervan te onderzoeken werden de ongetrainde jonge mannen onderworpen aan de $3^{\mathrm{e}}$ hyperinsulinemische euglycemische clamp, met gelijktijdige infusie van lipid, 
voorafgegaan door 4 dagen salsalaatinname. Verrassend genoeg was er geen significante verbetering in de insuline resistentie na salsalaatinname. Salsalaat verhoogde wel de insuline spiegels in de basale conditie en na insuline infusie, en leidde ook tot een toename in energieverbruik dat in de basale conditie te verklaren was door een verhoogde vetverbraning, en in de insuline gestimuleerde conditie door een verhoogde glucose verbranding. Analyses van mitochondriele functie lieten echter geen veranderingen zien in mitochondriele respiratie waardoor het onderliggend mechanisme van het verhoogde energie gebruik onbekend blijft.

Hoofdstuk 8 is het slothoofdstuk en is een geintegreerde discussie van dit proefschrift. Het geeft een kort overzicht van de effecten van de verschillende interventies op de insuline gevoeligheid en bediscussieert de rol van mogelijke parameters (IMCL, mitochondriele functie, metabole flexibiliteit and lipolyse). Gezien het multifactoriele karakter van het ziektebeeld type 2 diabetes, is geen enkele parameter op zichzelf de oorzaak van het ontstaan van insuline resistentie. Dysfunctie van bepaalde parameters kunnen een bijdrage leveren aan het ontstaan van insuline resistentie in een persoon, maar deze hoeft niet noodzakelijk defect te zijn bij een ander. Het is wel duidelijk dat regelmatige lichamelijke inspanning zoals toegepast in de trainingsstudie in dit proefschrift of zoals toegepast door de duur getrainde atleten via meerdere routes een positief effect kan hebben op de insuline gestimuleerde glucose opname, maar toekomstig onderzoek is nodig om meer inzicht in te krijgen in de precieze regulatie 


\section{Dankwoord}

'Alles wird gut'! Dat was de tekst die op mijn koffiemok prijkte gedurende mijn AIO tijd. Op zich heb ik nooit aan deze boodschap getwijfeld, maar toch...! Af en toe keek ik wat vaker naar mijn mok om me er extra van te overtuigen.

Eigenlijk vind ik mijn AIO jaren wel te vergelijken met het rijden van de Marmotte. Bij de Marmotte stel je een doel: eindigen. En natuurlijk niet zomaar eindigen, maar liefst in een zo goed mogelijke tijd. Minstens zilver halen, maar als het even kan goud. Zo ook mijn AIO periode. Ik wilde het tot een goed einde brengen, en het liefst met mooie publicaties. Maar niet alleen wat betreft het eindpunt kan de vergelijking met de Marmotte gemaakt worden; ook wat betreft de afgelegde weg zijn er tal van overeenkomsten. Ok, tijdens mijn projecten had ik dan misschien wel niet te kampen met maagpijn, hongerkloppen, kettingen die afgaan, opkomende krampen of misselijkheid, maar de weg was vaak wel erg steil. Ja, een beetje zoals een alpencol. Tijdens de zware momenten van de Marmotte bekeek ik elke pedaalslag als een meter dichter bij de finish, en zo ook was elke proefpersoon een stap dichter bij het einde van de studie, en elk gelezen artikel een stap dichter bij het einde van mijn proefschrift...

Maar ook al waren het mijn benen die moesten trappen, zonder fietsenmakers had ik nooit kunnen beginnen met fietsen, laat staan de eindmeet halen. Vandaar dus ook mijn speciale dank aan de hoofdfietsenmakers van dienst, Matthijs en Patrick. Beste Matthijs en Patrick, jullie boden mij de mogelijkheid om jullie team te vervoegen en te werken aan een superleuk onderwerp. Van meet af aan had ik daar ontzettend veel zin in en ik ben blij dat ik deze keuze gemaakt heb. Zonder twijfel was het (vooral ten tijde van de trainingsstudie) soms erg moeilijk, maar ik heb tijdens deze jaren veel geleerd en en er zijn heel mooie dingen uit voortgekomen. Matthijs, jij hebt het met al je bijkomende taken altijd razend druk, maar toch verlies je zelden je humeur daarbij. Het was soms even zoeken en goed plannen, maar we hebben toch alles tot een heel mooi einde kunnen brengen. Ik vind het super dat je in de laatste maanden van mijn proefschrift samen met mij een versnelling hoger bent geschakeld en samen 
met mij de eindsprint hebt ingezet. Je bent van tijd tot tijd ook niet vies van een flinke portie humor en onzin. Dat mag ik wel! Patrick, als 2e begeleider was je meestal wat meer op de achtergrond aanwezig, maar als ik je nodig had was je er. Jouw efficiënte en succesvolle manier van werken zijn na te streven eigenschappen! Het feit dat je mij ooit eens als een malloot bestempeld hebt omdat ik op een ijskoud winterdagje in korte broek ging fietsen, vergeef ik je. Het feit dat je me vanop een afstand nog niet meteen herkend had en het feit dat een hele hoop andere mensen hetzelfde dachten als jij, speelt daarbij licht in je voordeel. Matthijs en Patrick, niet in het minst wil ik jullie ook bedanken voor jullie steun met betrekking tot mijn sollicitatie bij Matthew Watt in Australie, en bij het aanvragen van beurzen. Nee, de meest logische carrierestap was het misschien niet, en al helemáál niet de gemakkelijkste weg, maarre... als ik eenmaal iets in mijn hoofd heb... (Nee, dat heet niet koppigheid, dat heet vasthoudendheid!)

Prof. dr. Stehouwer, Prof. dr. van Baak, Prof. dr. Glatz, dr. Kersten and Prof. dr. Zechner; I would like to thank you all very much for evaluating my thesis.

Maar om heel even terug naar de roots te gaan... Eigenlijk zijn mijn eerste meters in de wetenschap afgelegd in het wiel van Luc. Halverwege mijn studie Bewegingswetenschappen was ik op zoek naar een begeleider voor mijn jaarwerkstuk en stage, en na 1 gesprek was het voor mij al duidelijk dat ik die gevonden had. Luc, door jouw gerichte begeleiding ervaarde ik het schrijven van mijn jaarwerkstuk en scriptie als een makkie en een groot plezier. Ik waardeerde je snelheid van nakijken en je betrokkenheid enorm, en ik heb een groot respect voor de kennis die je bezit en voor de manier waarop je wetenschap bedrijft. Bedankt voor al je hulp en voor alle kansen die je mij tijdens en na mijn stage bood! En verder... tsja... Onze wegen zijn in de jaren daarna niet bepaald uit elkaar gegaan. Hier in Australie moet ik het zonder jou stellen, maar ik kijk met veel mooie herinneringen op de afgelopen jaren terug. Rest me nog je te bedanken voor de adviezen die me hebben gebracht waar ik nu sta, en voor je immer eerlijke mening over eh... alles :-). Nee, je hebt gelijk, luisteren deed ik niet altijd naar je, maar het treft dat jij qua koppigh... eh, ik bedoel vasthoudendheid, niet hoeft onder te doen voor mij. ;-) 
Esther, Essepes, Eps! Een groot deel van onze 'AIO-marmotte' hebben we samen op een tandem afgelegd en ik denk dat we wel kunnen stellen dat, zodra onze tandem gesmeerd en goed afgesteld was, $1+1=3$ was ;-). We hebben hard moeten trappen, dat wel; maar tussen de talloze clamps door hebben we ook hopen lol gehad en uitspraken zoals "waar is het DDD?", en "Zo, wat een respiratie, ik heb een chocomoussemoment!”, behoeven voor ons geen verdere uitleg. Jij wist ook als geen ander met mijn proefpersonen te communiceren ("Zooooo, en doe de broek maar uit!") en hen gerust te stellen voor het biopt (“Ontspannen, Ontspaaannen!! Ontspppaaannnennn!!!!”) En verder... tsja,... wat kan ik zeggen... fotoshoots op een autowrak, filosoferen in een vriezer, de tijd verdrijven tijdens NWO-avonden, proefpersoonbezoek in Sweikhuizen, rennen tijdens de clamp omdat er 'iemand' de glucosezak had lek geprikt, Matthijs die ons 'leerde' hoe we een glycerolinfuus moesten klaarmaken... ;-) Ik kan nog wel uren doorgaan. Super! Wat houd ik hier goede herinneringen aan over!! Ik mis je in Australie wel hoor!! Oja, nog bedankt dat je me hebt medegedeeld dat jij 1 van mijn paranimfen gaat zijn. (Ik ga er waarschijnlijk vast nog wel spijt van krijgen dat ik "nou, vooruit dan maar" heb geantwoord). ;-)

Ellen en Milou, mijn vroegere kamergenootjes, mijn mede-chicks op de werkvloer. Gek genoeg zijn we met zn drieën begonnen en met zn vieren geeindigd. (:). Ik vond het super leuk jullie als kamergenootjes te hebben gehad. Als de muren van onze kamer konden spreken zouden ze vast zeggen dat ze wel even schrokken van onze lachsalvo's nadat wij drietjes er onze intrek in hadden genomen, en ik ben bang dat de collega's van BW dat alleen maar kunnen bevestigen. Milou, veel succes met je verdere opleiding tot sportarts, en Ellen, jij veel succes met je baan in het bedrijfsleven en met al wat je in de toekomst nog gaat ondernemen. Chicks rule!!

Mijn collega's van de SHOCk groep; ik vind het fijn jullie als naaste collega's te hebben gehad. Naast Matthijs en Patrick waren dat Vera, Joris, Lauren, Sabina, Ronnie, Johan, Katarina, Esther, Miranda, Silvie, Noud, Ellen, Lena, Madeleen, Tineke, Bianca, Eline, Johanna, Gert, Eshter K, Wendy, Alie, Denis en niet te vergeten, Marco. Marco, jij bent diegene die ons heeft leren fietsen. (Eerst met zijwieltjes, later vasthoudend aan het zadel en toen we vol vertrouwen zelfstandig 
trapten, ging je naar Wageningen). Bedankt voor de kennis die je op ons hebt overgedragen.

Verder ook het vernoemen waard zijn natuurlijk de collega's van Bewegingswetenschappen -ik heb hier 4 leuke jaren doorgebracht-! Het moet vast een hele schok voor jullie geweest zijn toen in de kamer van Frans opeens 3 Chics gedropt werden, vooral voor Jos, Jons, en Desiree, onze naaste buren. (Ja, Leon, jij blijft hardnekkig volhouden dat mijn lach ook nog bij jou 8 deuren verder te horen was, maar dat is natuurlijk absoluut niet waar!)

Antoine, bedankt voor de keren dat je al je samples liet vallen om ons te helpen met prikken indien dat nodig was. Harry en Leon, bedankt om me te redden als mijn computer -en bijgevolg ik ook- error error gingen. Jos, bedankt voor de vele koffie's die je mij in al die weekenden hebt verschaft. (Je hield mijn vocht- en caffeinebalans mooi op peil!) Mijn stagiaires Ruud, Thijs, Rachel, Camiel, Erik, Samefko, Rick en Saichon; jullie namen me tijdens de trainingsstudie heel wat werk uit handen en zorgden ervoor dat mijn energiereserves niet helemaal uitgeput raakten! Thanks! En niet te vergeten natuurlijk de talloze proefpersonen die alle testen voor mij en voor de wetenschap hebben doorstaan!

De mensen die de tijd op en vooral naast het werk nog leuker makten. Miranda, Silvie, Eps, Guy, Lian, Jos, Maartje, Antoine, Thamar, Ralph, Johan, Joost, Andrea en Stevie. Met lichte weemoed denk ik terug aan onze campeerweekendjes, wandelingen, pubavonden,... Stevie, jouw slechte ideen vond ik altijd ronduit prachtig en vulden mijn slechte ideeen altijd erg goed aan. Wat heb ik geweldige avonden en weekenden doorgebracht met jou!! (Jammer wel nog dat onze inbraak op het balkon van Eps mislukte...)

Marij en Gerard, ik heb de afgelopen jaren aardig wat uurtjes bij jullie gespendeerd onder het genot van verfijnde metal-muziek. Fijn contact met jullie te houden nu ik hier in Australie zit. Lieve Marij, ik denk vaak aan je! Katja, Maud, Coretta, Roel en Marcelle; ons toneelcluppie was geweldig; ik heb jullie met spijt in het hart verlaten! Mijn BW-studievriendinnetjes Elmo, Tiny en Anda; helaas is het contact 
sporadischer geworden, maar wanneer we een weekendje afspreken is het elke keer weer als vanouds! Niki, je hebt super werk geleverd bij het maken van de kaft van mijn proefschrift; ontzettend bedankt voor je flexibiliteit en voor je inspanningen!

Liefste Connie, al 15 jaar beste vriendinnen en nu mijn paranimf! (Heb ik tenminste toch 1 van mijn paranimfen zelf kunnen kiezen ;-) ) Geen haar onder mijn fietshelm dat er aan twijfelde dat ik jou tijdens mijn promotie achter mij wil hebben staan! Jij bent geweldig en we zitten zó vaak op 1 lijn. Ik vind het zelfs bijna eng hoe vaak we dezelfde gedachten hebben of hetzelfde zeggen op hetzelfde moment! Met jou heb ik altijd hopen lol! Shoppen, filmpjes kijken, saunaatjes doen, sjeekies slurpen, karbonkelen, pottenbakken, toneel spelen... Hoeveel kilometers ons ook scheiden, ik hoop dat we elkaar nooit uit het oog zullen verliezen! (Eén positief vooruitzicht hebben we in ieder geval: veel meer kilometers dan nu zullen het in ieder geval nooit zijn! ;-) )

Matthew Watt..., dear Matt... When we met for the first time at the IBEC conference in Guelph, you didn't know me yet, and you certainly had no idea of my desire to do a postdoc in your lab. But... you were about to find out!! I don't know what convinced you to take me into your lab. Was it my charm, my lovely Dutch accent, or was it the fear that I would never stop stalking you if you didn't hire me? I'm not sure, but it must have been a combination of all three. But I'm very happy that you gave me this chance. You were very well aware of my lack of laboratory skills (or did you think I wouldn't be that bad?). You were also aware of the fact that I still had to finish my thesis (you were, weren't you?). It wasn't (isn't) an easy work switch, but you gave and still give me all the support and freedom I need! Your optimism is absolutely admirable! There is currently absolutely no place I'd rather be than in your team!!

I would also like to thank the other people of the Watt-lab; Andrew, Romana, Joanne, Maria, Vanessa, Rachael, Melissa, James, Alice, and former members Alex and Dolly. You've made me feel very welcome! Special thanks to Maria, Andrew, Joanne, Romana and James for your patience, help, and advice with respect to my experiments. Maria, I love your optimistic personality and your positive attitude! 186 
And Rach, Nessie and Mel; ('zuperzuperzuperzuperhot') it's great to work and hang out with you guys! Thanks for the nice evenings and parties, but also for your support during difficult times! I'm looking forward to all the great things that are yet to come!

Also many thanks to the people who made my move to Australia even more pleasant. Tineke, Tien, jij leeft mee met mijn werkperikelen, maar je herinnert me er ook met enige regelmaat aan dat er meer is dan werk! Onze kroegavonden, beach-middagen, weekendtripjes en uitstapjes zijn heerlijk! Ik vind het fantastisch jou hier te hebben!! Ilona, lovely Elise and Chris ("SHIMMYYYYY" and "FREE DRINKS!!"). Thanks for those wonderful hours on the dance floor; you guys kept me going! (“Awesome! In your face, cha cha!!! Eh, I mean, that's awful! Get out of here!”)

Liefste mama en papa. Wat ik hier moet zetten weet ik niet goed want de dingen die jullie voor mij gedaan en gelaten hebben zijn met geen mogelijkheid in woorden te omschrijven. Jullie hebben te stellen met een eigenzinnige (ik bedoel vasthoudende) dochter; daar ben ik me heel goed van bewust. :-) Jullie hebben me wel altijd mijn eigen zin laten doen, doch met 'raad' bijgestaan: "Ruth, doe nu eens OF OF, in plaats van altijd EN EN" en "Ruth, je pleegt roofbouw op je lichaam" en "Ruth, je ziet er uit alsof je een week niet geslapen hebt", enz enz...). Mams, paps... een hele hele dikke kus! Tot slot... broer, al van jongs af aan vond ik in jou een partner in crime wat betreft een heleboel zaken. "Ik zag eigenlijk al meteen dat het snor zat met jou toen ik in het huis kwam." ;-) Jij en Judith; jullie zijn met z'n tweetjes goed op weg!

Nou, hier houdt het wat mij betreft op. Deze Marmotte is bijna voltooid. Nog 1 laatste klim (letterlijk + figuurlijk) naar de Minderbroedersberg, en dan... pasta-feest!

Ik heb gefietst...

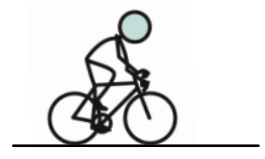




\section{Curriculum Vitae}

Ruth Meex was born on the 21st of December 1981 in Genk (Belgium). In 1999, she completed her high school study 'Science-mathematics' at the Royal Atheneum in Maasmechelen (Belgium) and in 2003 she successfully finished her study as a professional nurse at the Hoge School Zuyd, Heerlen (the Netherlands). Thereafter, she started with the study Health Sciences, specialisation Human Movement Siences at Maastricht University (the Netherlands).

Her interest for research was set during her internship with prof dr. L. van Loon at the department of Human Biology, where she investigated the effect of protein hydrolysate and amino acid ingestion on plasma glucose concentration in patients with type 2 diabetes in daily living conditions. Following her graduation in September 2005, she performed several months pro Deo research in the research group of prof. van Loon, and was awarded a student Kootstra-scholarship 'talent of the future'.

In January 2006, Ruth Meex accepted a PhD-position under supervision of prof. M. Hesselink and Prof. P. Schrauwen at the department of Human Movement Sciences (Maastricht University), aiming to identify mechanisms contributing to the insulin resistant state and to the development of clinically overt type 2 diabetes. She performed 2 extensive human studies in which hyperinsulinemic euglycemic clamps were combined with measurements of metabolic flexibility, in vivo and in vitro mitochondrial function, mitochondrial density and intramuscular lipid accumulation in six groups varying in age, BMI, training status and insulin sensitivity. In addition, she focussed on how disturbances in lipid droplet dynamics may contribute to the development of diabetes.

Following her PhD-project, Ruth Meex was awarded 'The Albert Renold Travel Fellowships for Young Scientists' (February 2010) and the PhD Kootstra-scholarship 'talent of the future' (June 2010). These grants allowed her to join the Biology of 
Lipid Metabolism Laboratory within the School of Biomedical Sciences (Monash University, Australia) from May 2010 onwards, to gain extensive expertise in a variety of cell culture-, animal- and lab techniques and to perform molecular experiments focussing on lipid droplet breakdown. Hence, under advisement of A/prof. M. Watt, she currently combines a mix of genetic manipulations and in vitro cell biology with physiological interventions in mice and humans to investigate the phospho-regulation of several proteins in lipolysis and energy metabolism.

In her free time, Ruth Meex is an enthusiastic sporter. She did judo, tennis and athletics for many years and at present she is keen on cycling, Thai boxing, jiu jitsu and ball room dancing. Apart from sports, she likes to enrol in courses and drama classes, loves to spend an evening to the movies, and enjoys dining. 


\section{Publications:}

\section{$\underline{\text { Scientific publications }}$}

1. V. Schrauwen-Hinderling, Ruth C.R. Meex, M. Hesselink, T. van de Weijer, T. Leiner, M. Schär, H. Lamb, J. Wildberger, J. Glatz, P. Schrauwen, E. Kooi. Cardiac lipid content is unresponsive to a physical activity training intervention in type 2 diabetic patients, despite improved ejection fraction. Cardiovascular Diabetology, May 2011 (Accepted for publication)

2. Ruth C.R. Meex, Phielix E, Moonen-Kornips E, Schrauwen P, Hesselink MK. Stimulation of human whole-body energy expenditure by salsalate is fueled by higher lipid oxidation under fasting conditions and by higher oxidative glucose disposal under insulin-stimulated conditions. JCEM, feb 2011 (Accepted for publication)

3. Ruth C.R. Meex, E. Phielix, V. Schrauwen-Hinderling, E. Moonen-Kornips, G. Schaart, P. Schrauwen and M. Hesselink. The use of statins potentiates the insulin sensitizing effect of exercise training in obese males with and without type 2 diabetes. Clin Sci (Lond), 2010, Jun 25;119(7):293-301.

4. E. Phielix, Ruth C.R. Meex, E. Moonen-Kornips, M. Hesselink and P. Schrauwen. Exercise training increased mitochondrial content and ex vivo mitochondrial function in male type 2 diabetic patients to similar levels as control subjects. Diabetologia, 2010, Aug; 53(8):1714-21.

5. V. Schrauwen-Hinderling, M. Hesselink, Ruth C.R. Meex, S. van der Made, M. Schär, H. Lamb, J. Wildberger, J. Glatz, G. Snoep, M. Eline Kooi, P. Schrauwen. Improved ejection fraction after exercise training in obesity is accompanied by reduced cardiac lipid content. J Clin Endocrinol Metab. 2010 Apr;95(4):1932-8 
6. Ruth C.R. Meex, V. Schrauwen-Hinderling, E. Moonen-Kornips, G. Schaart, M. Mensink, E. Phielix, T. van de Weijer; J-P Sels, P. Schrauwen and M. Hesselink. Restoration of muscle mitochondrial function and metabolic flexibility in type 2 diabetes by exercise training is paralleled by increased myocellular fat storage and improved insulin sensitivity. Diabetes, 2009, 59:572-579.

7. Ruth C.R. Meex, P. Schrauwen, and M. Hesselink. The modulation of myocellular fat stores; lipid droplet dynamics in health and disease. Am J Physiol Regul Integr Comp Physiol, 2009, 297:R913-924.

8. E. Phielix, V. Schrauwen-Hinderling, M. Mensink, E. Lenaers, Ruth. C.R. Meex, J. Hoeks, M. Kooi, E. Moonen-Kornips, J-P Sels, M. Hesselink, and P. Schrauwen. Lower intrinsic ADP-stimulated mitochondrial respiration underlies in vivo mitochondrial dysfunction in muscle of male type 2 diabetic patients. Diabetes, 2008, 57:2943-2949.

9. R. Manders, S. Praet, Ruth C.R. Meex, R. Koopman, A. de Roos, A. Wagenmakers, W. Saris, and L. van Loon. Protein hydrolysate/leucine coingestion reduces the prevalence of hyperglycemia in type 2 diabetic patients. Diabetes Care, 2006, 29: 2721-2722.

10. S. Praet, R. Manders, Ruth C.R. Meex, A. Lieverse, C. Stehouwer, H. Kuipers, H. Keizer, and L. van Loon. Glycaemic instability is an underestimated problem in Type II diabetes. Clin Sci (Lond), 2006, 111: 119-126. 


\section{$\underline{\text { Manuscripts submitted }}$}

1. Ruth C.R. Meex, P. Schrauwen, C. Moro, D. Langin, G. Schaart, E. MoonenKornips, and M. Hesselink. Improved control of basal lipolysis and increased capacity to store and mobilize fat in skeletal muscle of obese and type 2 diabetic subjects after an insulin sensitizing training program. (Submitted)

2. Ruth C. R. Meex, L. Sparks, E. Phielix, E. Moonen-Kornips, G. Schaart, M. Hesselink, P. Schrauwen. Relation of lipid metabolism to the athlete's paradox (Submitted)

3. E. Phielix, Ruth C. R. Meex, J. Hoeks, L. Sparks, G. Schaart, E. MoonenKornips, M. Hesselink and P. Schrauwen. High oxidative capacity protects against lipid-induced insulin resistance via lipid-induced mitochondrial uncoupling. (Submitted)

4. E. Phielix, V. Schrauwen-Hinderling, Ruth C.R. Meex, R. Nilwik, H. Duimel, P. Frederik, and M. Hesselink. Deficiency of subsarcolemmal mitochondria associates with compromised in vivo mitochondrial function in type 2 diabetic subjects; an electron microscopy study. (Submitted)

\section{$\underline{\text { Scientific publications in Dutch }}$}

1. Invited author for 'Nederlands Tijdschrift voor Diabetologie' a journal for specialists, general practitioners and nurses working in the field of diabetes. Ruth.C.R. Meex, V. Schrauwen-Hinderling, E. Moonen-Kornips, G. Schaart, M. Mensink, E. Phielix, T. van de Weijer; J-P Sels, P. Schrauwen and M. Hesselink. Nederlands Tijdschrift voor Diabetologie, 2010, July; 8(2): 49-50. 


\section{Popular publications in Dutch}

1. Invited interview for 'Bloedsuiker', a magazine aimed to inform persons with diabetes. 'Geef uw spieren nieuwe energie', Bloedsuiker, 2010; 25(1): 49-50.

2. Invited interview for 'Truckstar', aiming to inform truck drivers about the risks of diabetes and reporting the findings of my training study, earlier published in Journal of Diabetes. 'Ziek van suiker', Truckstar, 2010, 7: 42-44. 
Perfection is lots of little things done well.

(Fernand Point) 